\title{
PERSONAL BRANDING OF TOP MANAGERS
}

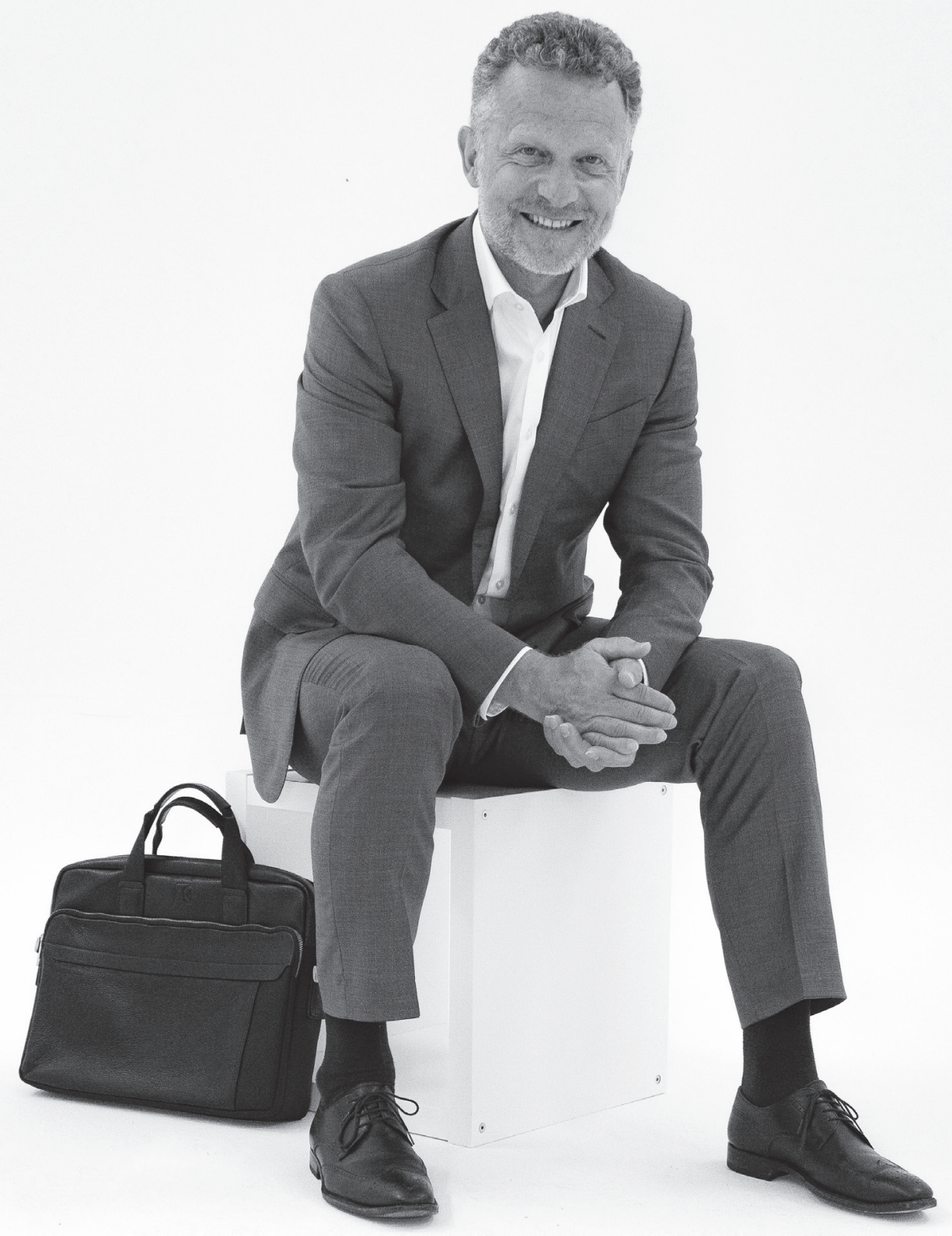

STEFAN SCHEIDT 


\section{PERSONAL BRANDING OF TOP MANAGERS}

Stefan Scheidt 


\title{
PERSONAL BRANDING OF TOP MANAGERS
}

\author{
DISSERTATION
}

\author{
to obtain \\ the degree of doctor at the University of Twente, \\ on the authority of the rector magnificus, \\ prof. dr. ir. A. Veldkamp, \\ on account of the decision of the Doctorate Board \\ to be publicly defended \\ on Friday 10 December 2021 at 16.45 hours
}

by

\section{Stefan Scheidt}

born on the 15th of April, 1968

in Berlin, Germany 
This dissertation has been approved by:

Supervisor

Prof. Dr. Ir. J. Henseler

Co-supervisor

Dr. R.P.A. Loohuis

Cover design: Gabriele Scheidt

Cover pictures: Horst Ruland

Printed by: Ipskamp Printing, Enschede

Lay-out: $\quad$ Douwe Oppewal, www.oppewal.nl

ISBN: $\quad 978-90-365-5291-2$

DOI: $\quad 10.3990 / 1.9789036552912$

(c) 2021 Stefan Scheidt, The Netherlands. All rights reserved. No parts of this thesis may be reproduced, stored in a retrieval system or transmitted in any form or by any means without permission of the author. Alle rechten voorbehouden. Niets uit deze uitgave mag worden vermenigvuldigd, in enige vorm of op enige wijze, zonder voorafgaande schriftelijke toestemming van de auteur. 


\section{Graduation Committee}

Chair:

Prof. Dr. Ir. H.F.J.M. Koopman

Prof. Dr. Ir. J. Henseler

Dr. R.P.A. Loohuis

Co-supervisor:

Committee Members:
Prof. Dr. Ir. P.C. de Weerd-Nederhof Prof. Dr. C.P.M. Wilderom

Prof. Dr. E. Fischer

Prof. Dr. S. Khapova

Prof. Dr. H. Schmidt
University of Twente

University of Twente

University of Twente

University of Twente University of Twente York University Vrije Universiteit Amsterdam University of Applied Sciences Koblenz 


\section{FORWARD}

This dissertation arose from a very practical question. In my work as a business coach of top managers, the change of perspective is one of numerous methods to support these top managers in broadening their perspectives and their range of action, but also in their positioning. 'What USPs do you ascribe to yourself?', 'What attributes are you associated with?' and 'What effect do you evoke in connection with your corporate brand from the perspective of others?' were just a few of the many questions that led to extremely helpful insights through differentiated and profound joint reflection. The overarching question 'Have you ever considered yourself as a brand?' was answered in the negative by almost all top managers, while they were absolutely aware of their own internal and external visibility. They were also very quickly aware of the importance and usefulness of the topic of 'personal branding' for themselves as top managers. How their personal brand is created, however, was something that the top managers could hardly answer right away, or only in fragmented individual aspects. As it turned out, science did not provide a comprehensive answer to this question either. The idea of researching personal branding was born and laid the founding stone for this dissertation and an exciting as well as enriching research journey.

Looking back, this research journey offered wonderful opportunities to exchange ideas with inspiring people, to work with them and also to reflect on myself. However, this journey would not have been possible without the support of some special people in particular, for which I am very grateful.

First of all, my thanks go to my supervisor and co-supervisor, Jörg and Raymond. I cannot imagine better supervisors. Our discussions far beyond the obvious and original topic as well as your inspirations in looking at my research ideas have given me extremely valuable perspectives and raised my research activities to a very high level. Thanks also to Prof. Harald Vergossen from the Niederrhein University of Applied Sciences in Mönchengladbach, who got the ball rolling for my PhD.

I would also like to thank all members of my graduation committee, Prof. Dr. Ir. P. C. de Weerd-Nederhof, Prof. Dr. C. P. M. Wilderom, Prof. Dr. E. Fischer, Prof. Dr. S. Khapova, Prof. Dr. H. Schmidt, for their precious time and efforts.

I also wish to thank all the members of the Department of Design, Production and Management at the University of Twente and some people in particular who made my life as an external PhD student noticeably easier. Annemarie, Benni, Bjorn, Carsten and Inge, thank you for the great support and the always humorous conversations. 
My thanks also go to all my fellow PhD students from the Chair of Product-Market Relations, especially to Eveline and Samuel, for great days and long evenings at the PhD Days. Also, my thanks go to all the managers and top managers who have supported my research activities from different roles, be it as sparring partners, part of the sample group or as personal confidants.

Finally, I would like to thank three people personally from the bottom of my heart. Very dear thanks to my father, who passed away much too early. During the time we spent together in my childhood and youth, it was you who gave me the attitude and values that now, many years later, are the guarantor for me to complete this research journey. Very many thanks to my wife and our son. Ele and Lenny, I will always appreciate your infinite patience in putting up with me in all my personal facets during this PhD. 


\section{CONTENTS}

$\begin{array}{lll}\text { Forward } & \text { VI }\end{array}$

Contents VIII

List of Figures $\quad X$

List of Tables $\quad$ XI

1 INTRODUCTION TO THIS DISSERTATION 1

1.1 Research Background and General Objective 2

1.2 Context: Top Manager 5

1.3 Research Questions and Objectives 6

$\begin{array}{lll}1.4 & \text { Dissertation Outline } & 10\end{array}$

$\begin{array}{ll}1.5 \text { Contribution } & 15\end{array}$

2 OLD PRACTICE, BUT YOUNG RESEARCH FIELD: A SYSTEMATIC BIBLIOGRAPHIC REVIEW OF PERSONAL BRANDING 19

$\begin{array}{lll}2.1 & \text { Introduction } & 20\end{array}$

$\begin{array}{ll}2.2 \text { Methodology } & 21\end{array}$

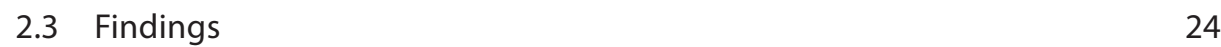

$\begin{array}{lll}2.4 & \text { Conclusions } & 47\end{array}$

3 HOW TOP MANAGERS BUILD THEIR PERSONAL BRAND: STRATEGIZING AND OVERCOMING DUALITIES ALONG THE CAREER PATH

3.1 Introduction 52

3.2 Theoretical Background 54

$\begin{array}{lll}3.3 & \text { Methods } & 60\end{array}$

3.4 Identifying three Key Personal Branding Practices 64

$\begin{array}{lll}3.5 & \text { Discussion } & 76\end{array}$

$\begin{array}{lll}3.6 & \text { Contributions } & 78\end{array}$

3.7 Limitations and Further Research 81

4 IN FOR A PENNY, IN FOR A POUND? EXPLORING MUTUAL ENDORSEMENT EFFECTS BETWEEN CELEBRITY CEOS AND CORPORATE BRANDS 85

$\begin{array}{lll}4.1 & \text { Introduction } & 86\end{array}$

4.2 Theoretical Background and Hypotheses 88

$\begin{array}{lll}4.3 & \text { Empirical Studies } & 100\end{array}$

$\begin{array}{ll}4.4 \text { General Discussion } & 104\end{array}$ 
5 THE VALUE OF TEMPORAL WORK IN THE DEVELOPMENT OF TOP MANAGERS' PERSONAL BRANDS DURING THEIR CAREER

5.1 Introduction 114

5.2 Literature Review 116

$\begin{array}{ll}5.3 \text { Theoretical Approach } & 117\end{array}$

$\begin{array}{lll}5.4 \text { Methodology } & 119\end{array}$

$\begin{array}{lll}5.5 & \text { Main Findings } & 123\end{array}$

$\begin{array}{ll}\text { 5.6 Discussion and Implications } & 129\end{array}$

5.7 Limitations and Further Research 131

6 SYNOPSIS 133

6.1 Introduction 134

6.2 Discussion 135

6.3 Theoretical Implications 146

6.4 Implications for Practice 151

6.5 A Perspective on Further Research 155

$\begin{array}{ll}\text { APPENDIX } & 159\end{array}$

$\begin{array}{ll}\text { Appendix A } & 160\end{array}$

$\begin{array}{ll}\text { Appendix B } & 165\end{array}$

$\begin{array}{ll}\text { BIBLIOGRAPHY } & 169\end{array}$ 


\section{LIST OF FIGURES}

$\begin{array}{lll}\text { Figure 1.1 This dissertation's research journey } & 11\end{array}$

$\begin{array}{lll}\text { Figure 2.1 Review methodology process } & 22\end{array}$

Figure 2.2 Publication of academic articles with relevance to 24 personal branding over time

Figure 2.3 Pyramid of different human brand classes and 39 their appearance in the history of personal branding

$\begin{array}{lll}\text { Figure 3.1 Key practices, dual activities and their interrelations } & 64\end{array}$ during top managers' personal branding process

$\begin{array}{lll}\text { Figure 4.1 Expanded conceptual framework findings } & 105\end{array}$

$\begin{array}{lll}\text { Figure 5.1 } & \text { Frame for data collection and analysis } & 122\end{array}$

$\begin{array}{lll}\text { Figure 5.2 Actions and decisions in personal brand development } & 129\end{array}$ over phases in career development 


\section{LIST OF TABLES}

$\begin{array}{lll}\text { Table } 2.1 & \text { The expert sample group } & 23\end{array}$

Table 2.2 The structure of scholarly knowledge on personal branding: 25 Research streams, concepts and contributions

Table 2.3 Number of publications focusing on three different classes 33 of human brands in eleven different categories

$\begin{array}{lll}\text { Table } 3.1 & \text { Potential key factors of personal branding and } 58\end{array}$ corresponding authors

Table 3.2 Personal and company information of the six top managers 61 investigated in this study

Table 3.3 Steps of the research strategy in this study to collect 62 and analyze process data

Table 3.4 Stakeholder sample group interviewed in this study 63 to enhance validity by triangulation

$\begin{array}{lll}\text { Table 3.5 Application and balance of the dual activities 'standing out' } & 67\end{array}$ and 'fitting in' to build a personal brand across different career stages

Table 3.6 Managing the duality between 'facilitators' and 'obstructors' $\quad 70$ during the personal branding process of top managers

Table 3.7 Visibility management enables the development of top managers' personal brands on three levels of dual activities

Table 4.1 Endorsement mechanisms and their implications to celebrity CEOs

$\begin{array}{lll}\text { Table 5.1 Top manager personal and company information } & 120\end{array}$

Table 5.2 Personal branding do's and don'ts

Appendix 1 Overview of publications concerning three different classes of personal brand in eleven different categories

Appendix 2 Protocol of the semi-structured interviews with top managers Appendix 3 Protocol of the semi-structured interviews with stakeholders 
INTRODUCTION TO THIS DISSERTATION

1 


\subsection{RESEARCH BACKGROUND AND GENERAL OBJECTIVE}

Probably everyone knows examples of personal brands. Christiano Ronaldo or Tiger Woods from a sports background, Donald Trump in politics, the Pope in religion, and Elon Musk or Jeff Bezos from the world of business to name but a few. And probably everyone also knows individuals in their personal environment about whom people say: "What a brand!". Yet, personal branding looks back at a long history. Alexander the Great is claimed as one of the first, if not the first celebrity in human history (Braudy, 1997). Erudite Goethe achieved success by using all elements of the marketing mix in order to differentiate himself from other authors of his time (Woischwill, 2003). The affair of Elizabeth Taylor and Richard Burton in 1963 has been identified as "an insightful turning point, marking a juncture whereby the public were seen to have become more interested in one particular celebrity's private life than her abilities as an actress" (Mills et al., 2015, p. 5). Key to the late David Bowie's successful brand is the constant change in his appearance and behaviour, which consists of three components: the real person (David Jones), the performance persona (David Bowie) and the characters derived from this persona, such as Ziggy Stardust (Auslander, 2006; Lindridge and Eagar, 2015). It can be traced back even to Shakespeare who stated, that "All the world is a stage, and the men and women are merely actors" (Keehn, 2013). Thus, personal brands became a vital part of society, culture, and economy over time. Today, rankings such as Forbes' (2020) "The World's Most Powerful People", "The Celebrity 100", "The World's Most Powerful Women" or even "The Highest-Paid Dead Celebrities" as well as "The CEO 100" (HBR, 2019), and the number of tweets featuring each club manager's name in British Premier League (Stanton and Jackson, 2015) are merely some of innumerable examples that underpin the rising interest for branded individuals in the public.

Personal branding as a contemporary phenomenon is not in itself an entirely new notion from an academic angle. As early as 1969, Kotler and Levy (1969, p. 10) posed the fundamental question "whether the principles of 'good' marketing in traditional product areas are transferable to the marketing of persons". Over time this question has not only been answered positively by numerous researchers (e.g., Arai et al., 2014; Carlson and Donavan, 2013; Close et al., 2011; Huang et al., 2015; Parmentier et al., 2013; Preece and Kerrigan, 2015; Thomson, 2006). Rather, personal branding has become an object of interdisciplinary interest as various academic disciplines, including sociology (e.g. Furedi, 2010; Goffman, 1956; Kurzman et al., 2007; Wee and Brooks, 2010), psychology (e.g. Li, 2007; Moulard et al., 2015), information technology (e.g. Alghawi et al., 2014; Chen, 2013; Elwell, 2014; Whitty, 2008) and educational science (e.g. Edmiston, 2014; Jillapalli and Jillapalli, 2014), have begun to converge on this subject. 
With an increasing attention to and expansion of personal branding as a field of research, considerable efforts have been devoted to identifying and examining primarily antecedents (e.g., Hearn, 2008; Lair et al., 2005), the outcomes (e.g., Gorbatov et al., 2019; Hanusch and Bruns, 2017; van Oort, 2015), and the key ingredients (e.g., Elwell, 2014; Moulard et al., 2015; Parmentier and Fischer, 2012) of personal branding. In this context, visibility is not only the most frequently mentioned key building block of what constitutes a personal brand (Brown, 2010; Chen, 2013; Clark, 2011; Gander, 2014; Philbrick and Cleveland 2015; Preece and Kerrigan, 2015; Shepherd, 2005). Rather, the idea of visibility as a key currency in life has given enormous impetus to the personal branding movement through the explosion of Web 2.0 and social media (Lair et al., 2005; Saleem and Iglesias, 2015). As a result, the branding of people is no longer limited to movie stars, singers, entertainers or sports stars. The top manager represents another category that is increasingly receiving attention in the media and significantly impacts on business and society. However, both personal branding in general and the personal branding of top managers in particular still suffer from a number of partly enormous gaps in understanding.

Top managers and, given the vast literature on them, in particular CEOs attract scholars for several decades to be studied. This covers an enormous range and is conducted primarily from the angle of boundary spanning (e.g., Markóczy et al., 2013), power and influence (e.g., Daily and Johnson, 1997), decision making (e.g., Arendt et al., 2005), attributions (e.g., Hayward and Hambrick, 1997), specific traits (Ahn et al., 2014; Fetscherin, 2015), identity (e.g., Boivie et al., 2011), reputation (e.g., Graffin et al., 2012; Zajac and Westphal, 1996), and the company's performance (Malmendier and Tate, 2009; Wade et al., 2006). Nonetheless, an empirical branding perspective on top managers is largely absent, with only some exceptions in rather fragmented aspects such as a measurement scale for CEO brands (Chen and Chung, 2016), top level executives' social media activities (Alghawi et al., 2014; Karaduman, 2013) and how to position skills, knowledge, and values during a transition from for-profit sector into second careers in the non-profit sector (Schlosser et al., 2017). Given this rare empirical evidence in the field of top managers and their personal brands, it is helpful to look outside the box for inspiration. Marie-Agnès Parmentier and Eileen Fischer (2021), for instance, investigated how individuals working in prestigious posts, i.e., high-profile jobs in established organizations, manage their professional brands. They recommend finding a balance between the benefits of being part of the company in the eyes of external stakeholders and at the same time maintaining their professional independence in order to preserve career mobility.

Endorsement is a widely accepted mechanism in personal branding with specific regard on celebrities (Arai et al., 2014; Bergkvist and Zhou, 2016; Ohanian, 
1990) based on a meaning transfer model (McCracken, 1989) and the transfer of brand knowledge (Keller, 2013) that has become well established. Outside the research field of personal branding, the mechanism of endorsement is also well studied, e.g., the transfer of associations from sponsors to events Henseler et al., 2009), and allows for further research inspirations. But while there is common consensus that celebrity CEOs serve as endorsers for their companies (Bendisch et al., 2013; Fetscherin, 2015; Graffin et al., 2012), research to date is silent about empiric evidence of mutual endorsement effects between celebrity CEOs and corporate brands, or how these endorsements may work.

Managerial work and practices are a well investigated field for many decades (e.g., Mintzberg, 1973; Kotter, 1982; Willmott, 1984) where scholars have been inspired to explore subjects such as leadership (Cho and Poister, 2014), knowledge management (Inkinen, 2016), or the implementation of Industry 4.0 technologies (Agostini and Filippini, 2019). However, personal branding as a key practice of today's top managers remains unaddressed, although proven research methods such as the integrative framework of strategy practice (Whittington, 2006) provides a coherent approach to investigate personal branding as a widely practiced tool by top managers.

Consequently, the maturity of theories in the field of personal branding has to be questioned regarding its continuous development as an academic discipline. According to Webster and Watson (2002) referring to Parsons and Shils (1962) who outline a hierarchy from "ad hoc classification systems (in which categories are used to summarize empirical observations), to taxonomies (in which the relationships between the categories can be described), to conceptual frameworks (in which propositions summarize explanations and predictions), to theoretical systems (in which laws are contained within axiomatic or formal theories)", the field of personal branding especially for top manager is still in its infancy. To date, there is no universal framework capturing the personal branding paradigm and focusing top managers as personal brands. Further insights are needed into personal branding as the process of emergence and development and into the construction and application of personal brands as the outcome of this process. The main goal of this dissertation is therefore to enhance the understanding of personal branding in general and the top managers' personal branding in particular in order to allow for a conscious and targeted development and use of top managers' personal brands. 


\subsection{CONTEXT: TOP MANAGER}

The number of widely used terms for people who belong to the upper echelons of organisations and have influence on the strategic decision-making of companies (Carpenter et al., 2004; Finkelstein and Hambrick, 1996; Hambrick, 2007; Hambrick and Mason, 1984) has grown steadily over the past decades. Beside the 'top manager' there are numerous other labels, such as top management team (TMT) members (Graffin et al., 2008) and various kinds of executives, for instance business executives (Hernandez et al., 2014), senior executives (Bendisch et al., 2013) and top executives (Bonet et al., 2020). They all encompass a variety of multiple functions ranging from Presidents and Vice Presidents to the Chief Financial Officer and the Chief Information Officer up to the Chief Executive Officer (CEO) among many others.

Media attention, unprecedented visibility and influence on the economy and society are important factors that all these different types of top managers have in common. The CEO in particular enjoys great popularity as a top manager to be studied in various disciplines and fields of research (Fetscherin, 2015; Graffin et al., 2012; Gupta et al., 2018; Wade et al., 2006). Empirically examining the CEO as a unique functional and general representative of the entire category of top managers is caused by scholars viewing the CEO "as a convenient context for testing broader theories rather than as a theoretically distinct phenomenon" (Busenbark et al., 2016, p. 235). However, the notion of CEO also obviously offers additional possibilities for differentiation, e.g., the distinction between agent or non-founder CEOs and founder CEOs (He, 2008; Randøy and Goel, 2003; Shulman, 2010) or the celebrity CEO (Lovelace et al., 2018; Sinha et al., 2012), which are being pursued from an academic point of view and further expand the field of top managers. Although personal branding is a contemporary and widely applied phenomenon in practice, and despite their increasing media attention and power of decision, top managers or even CEOs or even are hardly target figures for academic attention from a personal branding perspective, especially with an empiric approach.

In this dissertation, I define top managers in line with Pepper and Gore (2015) as those people in an organisation who fulfil a senior executive role and who are responsible for the definition and execution of a company's strategy and able to affect the company's profits, share price, reputation, and market position by force of their individual activities. This includes functions as chief executive officers (CEOs), chief operating officers (COOs), chief financial officers (CFOs), and further chief officers, divisional heads, and other heads of functions. From a gender perspective, this definition of the top manager encompasses male, female, transgender and intersex people. 


\subsection{RESEARCH QUESTIONS AND OBJECTIVES}

Given the entirely unexplored field of top managers' personal branding, it is valuable to consider personal branding and personal brands as a discipline in its own right and not, for the time being, geared to a specific target group such as top managers. A review of existing research is essential to understand where the contemporary phenomenon of personal branding originates, to identify gaps in knowledge and to suggest avenues for future research that may help formulate and answer the advancing research questions. The introductory research question therefore asks

\section{What is the nature of personal branding?}

The bibliographic examination of the academic literature reveals that a comprehensive personal branding framework, let alone a sustainable and widely accepted theory, is still lacking. Rather, personal branding is "one of several operationalizations of the broader concept of brand" (Thomson, 2006, p. 104) and represents the logical extension of more conventional forms of branding, such as product brands, service brands, corporate brands, or retail brands (Gehl, 2011; Hearn, 2008; Kotler and Levy, 1969; Lair et al., 2005; Philbrick and Cleveland, 2015). On the one hand, an application of traditional branding practices to the field of personal branding has few clear advocates (Close et al., 2011; Ternès et al., 2014) indicating that, for instance, corporate brand associations seem to work similarly for animate personal brands as they do for inanimate product brands. On the other hand, a forthright applicability of product branding theories and instruments to personal brands appears to be questionable at least, caused in branding relevant distinctions. The complete attribute and value set of a person is already formed, they are more abstract and intangible, person brands can be difficult to control and keep consistent as they can have many interactions and experiences with many different people over time, and person brands may adopt different personas for different situations that will affect the dimensionality of their brand (Keller, 2013; Zarkada, 2012). However, this transferability promises constructive approaches through a selective adaptation of best branding practices, such as the involvement of stakeholders in the personal branding process as a collective act (Bendisch et al., 2013; Preece and Kerrigan, 2015). Consequently, personal branding should be understood as an independent and interdisciplinary form of branding in itself.

In addition, a large majority of scholars do not distinguish clearly between the thing, i.e., the personal brand and the process, i.e., personal branding. These two perspectives trace back to the differing philosophies of Democritus and Heraclitus. Whereas Democritus depicted the whole of nature as consisting of stable material 
substance or things that changed only in their positioning in space and time, Heraclitus, on the contrary, considered reality not as a constellation of things but as a process involving diverse and fluctuating activities (Rescher, 1996). This differentiation indicates that a "personal brand" is used to describe the outcome of the process named "personal branding", which constitutes a fundamental aspect in my consideration of the emergence of top managers' personal brands. Therefore, it is useful to provide initial definitions for reasons of guidance.

Personal branding is defined in this research as the process of establishing, maintaining, and developing an individual's personal brand with the active and selective integration of certain personal preconditions and with due consideration for the changing nature of the field in which the personal brand is to be established.

A personal brand, in turn, is the continuously developing outcome of a collective act between stakeholders and the branded individual's entire personality by which she/he is visible within and beyond her/his professional field to stand apart from other personal brands and to fit into a defined field where these activities try to gain specific benefits.

Since this research also aims to continuously question and critically examine my own findings, the above definitions of personal branding and personal brand may only serve as an initial guidance and will be considered from more advanced perspectives as we proceed.

Based on the situation of personal branding in practice and theory as outlined in Section 1.1 as well as above, the central purpose of this dissertation is to answer two primary research questions:

\section{How do top managers' personal brands emerge?}

And, in addition:

How does the personal brand of top managers work?

From the existing research literature on personal branding, three core aspects were identified, along with numerous others, that are relevant for further answering these primary research questions.

(1) Although a general agreement exists that personal brands have to be managed over time (Gander, 2014; Grant, 2008; Lunardo et al., 2015; Philbrick and Cleveland, 2015; Thomson, 2006), the understanding of personal brands is strongly oriented towards a static proposition, with very few exceptions only. Artistic brands follow individual evolutionary paths due to different stakeholders and their relationships with these stakeholders, which leads to a career trajectory with distinct different stages drawing upon the social and cultural context, rather 
than having a definite positioning (Preece and Kerrigan, 2015). The career of late musician David Bowie, in turn, highlighted the importance of time and aging as his personal brand included multiple characters, such as Major Tom, Ziggy Stardust, or Halloween Jack, all of whom were ageless and timeless (Lindridge and Eagar, 2015). However, the temporal dimension is surprisingly missing both largely as a key building block in the creation of personal brands and completely from a methodological perspective to be applied, for instance, through process research.

(2) Considering top managers as real personal brands, a manageable amount of results reveals from empiric investigation. Scholars found that Chinese microblog users are fondest of CEOs who present themselves as experts rather than as friends (Alghawi et al., 2014). Active involvement of top level executives in social media has a significant effect for efficiently managing their personal branding efforts to both customers and non-customers (Karaduman, 2013). As a means for a CEO personal brand measurement, a measure scale may serve, containing seven dimensions (i.e., work standards, style, leadership, personality, values, character and team work) and thirty-one items serves (Chen and Chung, 2017). At each stage of transition from the for-profit sector into second careers in the non-profit sector, executives revisit their personal brands, deciding how to best position their skills, knowledge, and values within the context of their new organizations (Schlosser et al., 2017). A general understanding of what top managers' personal brands constitute, how they are created or even a comprehensive theory on the subject is not yet available.

(3) Personal brands of top managers are primarily considered from a branding perspective, which sounds logical at first glance. So far, the few researchers have limited themselves to fragmented aspects of branding-related fields such as social media (Alghawi et al., 2014; Karaduman, 2013) or brand equity (Chen and Chung, 2017). However, the far more versatile and complex positioning, activity and impact of top managers in reality is not taken into account. In this context, methodological approaches from other disciplines, which can be attributed a proximity to top managers, such as organisational development or practice research, are not applied.

These findings led to the first research sub-question:

What do top managers do to develop their own personal brand over time and how do they do it?

In the course of answering this first sub-question, a multi-method approach has evolved, building on different best practices in the empirical context. A multiple case study design (Eisenhardt and Graebner, 2007; Noor, 2008; Yin, 2003) was adopted, consisting of a within-case and a cross-case analysis based on six personal brand development case stories of top managers. An alternate template, visual mapping and temporal bracketing as commonly recommended strategies 
to analyse process data (Gehman et al., 2013; Langley, 1999; Langley et al., 2013) have been applied according to empiric research in organization studies. These two methodological approaches were embedded in an integrative framework from strategy practice, which includes the three concepts of praxis, practices and practitioners (Whittington, 2006). In this study, practitioners are the top managers who make, design and execute their personal brands. Praxis covers all the different activities of top managers that are necessary for the development and application of their personal brands. Finally, the domain of practices is the set of different key personal branding practices that top managers typically employ in their activities.

The findings demonstrate that three key practices, namely 'managing visibility', 'managing individuals' and 'managing position' and their respective set of specific activities represent the pillars of top managers' personal branding process with managing dualities as a core theme to overcome tensions at the level of these activities. The impact of each key practice for the development of a personal brand varies across four career phases over time i.e., 'beginner', 'professional', 'manager', and 'top manager'. While the 'what' and 'how' questions on the development of top managers' personal brands could already be answered in relevant content and as a mechanism of managerial practice over time, some important aspects remained open, two of which led to the further research sub-questions.

Firstly, the top managers studied indicated that during their personal branding process and in their current function, they can both benefit and be harmed by the corporate brand through spillover effects. Conversely, there was also evidence that the corporate brand can benefit from the personal brand of the top managers. The presumed meaning transfer effects between a top manager's personal brand and a company's brand are conceptually based on the notion of celebrity endorsement. In this case, it describes an agreement between a person who enjoys public recognition, i.e., a celebrity, and a company, i.e., its brand, to utilize this celebrity for the purpose of promoting the company (Bergkvist et al., 2016). Earlier work by cultural theorists supports this central idea, indicating that it is the cultural significance of the celebrity and the transmission of meaning that influence the endorsement outcomes (McCracken, 1989). However, research in this area is mostly limited to athletes and movie stars and has predominantly considered endorsement from a celebrity-to-brand-perspective (Bergkvist et al., 2016; Eisend and Langner, 2010). Consequently, the research sub-question to be applied here is:

How do meaning transfer effects between top managers' personal brands and corporate brands work?

Secondly, inspired by organizational researchers who applied process research to understand how things evolve over time and why they evolve in this way (Berends 
and Lammers, 2010; Bingham and Kahl, 2013; Gehman et al., 2013; Van de Ven and Huber, 1990; Van Oorschot et al., 2013), Chapter 3 already emphasizes the term 'personal branding', instead of 'personal brand' to stay with a verb or process, rather than a finished object or noun (Langley et al., 2013; Maguire and Hardy, 2013; Tsoukas, 2005; Van de Ven and Poole, 2005; Weick, 1979). Considering personal branding as a process, time and temporality becomes an issue because career paths do not only stretch over time but are also lived in time. The longstanding distinction between objective and subjective views of time do not sufficiently explain how people's actions shape and are shaped by structural conditions within and outside of their immediate control (Orlikowski and Yates, 2002). A practice-based perspective on time that covers both the shaping of people's action and the being shaped by such action would focus on a set of practices known as 'temporal work' that links the subject's interpretations of the past, present, and future to strategic action (Kaplan and Orlikowski, 2013; Loohuis and Ehrenhard, 2016). Originally applied to study what actors do when established strategic accounts break down, exploring the personal brand of top managers through the lens of temporal work (Emirbayer and Mische, 1998; Kaplan and Orlikowski, 2013) offers a valuable approach and resulted in the following two research sub-question:

How are interpretations of the past, present and future incorporated in the efforts of top managers to build their own brand during their career trajectories?

What are the patterns in the actions and decisions that strengthen the development of the personal brand of top managers?

\subsection{DISSERTATION OUTLINE}

The dissertation at hand comprises an overall of six chapters. Following the general introduction to the research topic and this dissertation itself in this chapter, the subsequent chapters numbered 2, 3, 4 and 5 represent the individual papers that provide answers to the primary research questions applying different research approaches. While the papers in Chapters 2 and 4 have been published in peerreviewed journals and the paper in Chapter 3 is currently in the review process of a journal, the paper in Chapter 5 was presented at an international conference. This section also explains the 'research journey' how the individual papers in the next chapters are interlinked and how they contribute to answering the primary research questions in a series of steps.

Figure 1.1 summarizes this 'research journey'. 


\begin{tabular}{|c|c|c|}
\hline \multirow{2}{*}{$\begin{array}{l}\text { CHAPTER } 2 \\
\text { Systematic } \\
\text { Bibliographic } \\
\text { Review of } \\
\text { Personal Branding }\end{array}$} & \multicolumn{2}{|c|}{ RQ: What is the nature of personal branding? } \\
\hline & $\begin{array}{l}\text { Expert discussions } \\
518 \text { articles } \\
\text { Ancestry approach } \\
\text { Citation research }\end{array}$ & $\begin{array}{l}\text { Fundamental understanding of personal branding } \\
\text { Updated terminologies and definitions } \\
\text { Structure of classes and categories }\end{array}$ \\
\hline
\end{tabular}

\begin{tabular}{|c|c|c|c|c|c|}
\hline & \multicolumn{3}{|c|}{$\begin{array}{l}\text { RQ } 1 \text { : How do top managers' } \\
\text { personal brands emerge? }\end{array}$} & \multicolumn{2}{|c|}{$\begin{array}{l}\text { RQ 2: How does the personal brand } \\
\text { of top managers work? }\end{array}$} \\
\hline \multirow{2}{*}{$\begin{array}{l}\text { CHAPTER } 3 \\
\text { How top managers } \\
\text { build their personal } \\
\text { brands }\end{array}$} & \multicolumn{5}{|c|}{$\begin{array}{l}\text { RQ: What do top managers do to develop their own personal brand } \\
\text { over time and how do they do it? }\end{array}$} \\
\hline & \multicolumn{2}{|c|}{$\begin{array}{l}\text { Six top managers } \\
\text { Retrospective interviews } \\
\text { Within-/Cross-case study } \\
\text { Practice/Process research }\end{array}$} & \multicolumn{3}{|c|}{$\begin{array}{l}\text { Three distinct key practices across four career } \\
\text { phases } \\
\text { Managing dualities at activities level to overcome } \\
\text { tensions }\end{array}$} \\
\hline \multirow{5}{*}{$\begin{array}{l}\text { CHAPTER } 4 \\
\text { Endorsement } \\
\text { effects between } \\
\text { celebrity CEOs and } \\
\text { corporate brands }\end{array}$} & \multicolumn{4}{|c|}{$\begin{array}{l}\text { RQ: How do meaning transfer effects between top } \\
\text { managers' personal brands and corporate brands work? }\end{array}$} & \\
\hline & \multicolumn{2}{|c|}{$\begin{array}{l}\text { Experimental design } \\
\text { Mock newspaper article } \\
\text { Succession scenario } \\
268 \text { participants }\end{array}$} & \multicolumn{2}{|c|}{$\begin{array}{l}\text { Meaning transfer effects in } \\
\text { both directions for specific } \\
\text { brand attributes }\end{array}$} & \\
\hline & \multirow{3}{*}{$\begin{array}{l}\text { CHAPTER } 5 \\
\text { Temporal work in } \\
\text { the development of } \\
\text { top managers' } \\
\text { personal brands }\end{array}$} & \multicolumn{4}{|c|}{$\begin{array}{l}\text { RQ 1: How are interpretations of the past, present and future } \\
\text { incorporated in the efforts of top managers to build their } \\
\text { own brand during their career trajectories? }\end{array}$} \\
\hline & & \multicolumn{4}{|c|}{$\begin{array}{l}\text { RQ 2: What are the patterns in the actions and decisions that } \\
\text { strengthen the development of the personal brand of top } \\
\text { managers? }\end{array}$} \\
\hline & & \multicolumn{2}{|c|}{$\begin{array}{l}\text { Six top managers } \\
\text { Retrospective interviews } \\
\text { Process research } \\
\text { Lens of temporal work }\end{array}$} & $\begin{array}{l}\text { Mod } \\
\text { the } p \\
\text { man } \\
\text { Inter } \\
\text { past, }\end{array}$ & $\begin{array}{l}\text { Model of temporal work in } \\
\text { the personal branding of top } \\
\text { managers } \\
\text { Interpretative links between } \\
\text { past, present and future }\end{array}$ \\
\hline
\end{tabular}

Figure 1.1: This dissertation's research journey 


\subsubsection{Chapter 2: Old Practice, but Young Research Field: A Systematic Bibliographic Review of Personal Branding}

At the beginning of the research journey into how top managers' personal brands emerge and how they work, a fundamental understanding of the contemporary phenomenon of personal branding is necessary. A steadily increasing number of scholars have devoted themselves to the topic of personal branding, especially in the past 15 years, and have produced numerous conceptual mechanisms as well as empirical findings. However, the body of knowledge in personal branding appears fragmented and lacks a comprehensive personal branding framework, let alone a sustainable theory. Therefore, Chapter 2 provides the application of a framework that covers six key research streams by which the growing body of literature on personal branding acquires a transparent structure in its essential content. In order to do so, 518 articles were included in a bibliographic analysis that resulted in proposing updated terminologies and definitions as well as a structure of classes and categories in which personal branding is applied. The identified antecedents of personal branding demonstrate the reasons for which it has been spreading and indicate that visibility is a central factor. The further identification of key ingredients and applications also shows, however, that personal brands are mainly viewed statically and their emergence over time has hardly been studied, and for top managers not at all. On the one hand, the analytical findings from this chapter call for countless further investigations to make the fragmented field of personal branding more tangible. On the other hand, this initial exploration of personal branding facilitated the necessary guidance in terms of content and methodology for the further research journey.

All in all, Chapter 2 promotes the recommendation to understand personal branding as a distinct and interdisciplinary expression of branding and not just as a simple variation thereof, which places this dissertation in a broad research environment.

\subsubsection{Chapter 3: How top managers build their personal brands: Strategizing and overcoming dualities along careers}

In view of the findings from the previous chapter that in particular the actual emergence of personal brands is under-researched, a clear distinction between the process of personal branding and the personal brand as a result of it hardly exists and top managers as a very visible and impactful category of personal brands are scarcely investigated, Chapter 3 aims at an empirical deepening of these research aspects. In doing so, the purpose of this chapter is twofold.

First, and in line with the two primary research questions, to identify key practices and activities that constitute the emergence of top managers' personal brands. Understanding a personal brand not as a static phenomenon made up of 
simple variables, but as something practical that continuously evolves over time, allows for indications of what practices and factors critical to success exist, which in turn need to be explored in more depth further down this research journey.

Second, and derived from the findings in Chapter 2 on the research approaches applied so far in the field of personal branding, Chapter 3 aims to specifically expand the methodological scope and perspective on this research subject. The multi-method approach employed involves the combination of process research strategies with cross-case and within-case analyses and an integrative framework from strategy-as-practice research. Only this enabled the construction of an extended, differentiated and profound complexity of the management practice 'personal branding' for top managers.

This chapter is based on a sample group of six top managers with different industry backgrounds and experiences whose insights into the development and events in the creation of their own personal brand resulted in individual narratives that were iteratively analysed.

The findings show that personal branding is a managerial practice for top managers in itself. The development of a top manager's personal brand is a complex process involving interdependent and sometimes overlapping key practices. Each key practice comprises a set of specific activities that are carried out by the top managers in different ways over time, creating both supporting and hindering effects for the development of the personal brand. Here, a central theme of personal brand development is managing dualities in all phases of career development and overcoming the tensions accompanied by these dualities. Apart from the additional result that top managers benefit from their personal brand as a tool for strategy development in corporations, this chapter suggests avenues for future research to purposefully shed more light on the field of personal branding. This allows for more differentiated investigation later on how top managers' personal brands interact with the corporate brand and what value temporal work may have in a personal branding process.

\subsubsection{Chapter 4: In for a penny, in for a pound? Exploring mutual endorsement effects between celebrity CEOs and corporate brands}

On the one hand, this chapter takes into account the celebritization of CEOs, which already receives its basis in Chapter 2 through the distinction between icons, celebrities and personal brands of ordinary people. On the other hand, it became clear in Chapter 3 that the personal brand of the top manager is not developed, works and has an effect in isolation. Rather, the personal brand is the result of a collective branding process in which different stakeholders are involved as endorsers. The brand meaning transfer effect in the context of endorsements, however, does not only arise from other personal brands, but in the specific case 
of top managers also from the corporate brand of the company where they are working. The top managers of the sample group in Chapter 3 pointed this out in concrete terms. In addition, it can be assumed that the personal brand of a top manager can also have an impact on the corporate brand. Two hypotheses thus emerge for this chapter. First, 'Celebrity CEO attributes transfer to corporate brand attributes'. And second, 'Corporate brand attributes transfer to celebrity CEO attributes'.

For the two empirical studies with a total of 268 participants, a between-subjects true-experimental design was chosen in each case, using fictitious newspaper articles about a succession scenario at the CEO level of different companies.

The results demonstrate that meaning transfer effects at the brand attribute level in both the celebrity-CEO-to-corporate-brand and corporate-brand-tocelebrity-CEO direction exist, which confirms the applicability of the concept of brand endorsement to celebrity CEOs and the mutuality in co-branding models. In addition, Chapter 4 reveals which exact brand attributes actually have an effect in each direction of the meaning transfer effect between the celebrity CEO brand and the corporate brand.

\subsubsection{Chapter 5: The value of temporal work in the development of top managers' personal brands during their career}

For answering the primary research questions, the process view proved to be an essential methodology in Chapter 3, in order to do justice to the time factor in the creation of personal brands. However, in addition to the approach of developing personal brands over time already applied in Chapter 3, this process view also offers the further perspective that top managers' personal brands must also be built in particular time contexts equally to their career.

This chapter therefore looks at the development of a personal brand over time through the lens of temporal work, which implies reflections on the past, present and future on behalf of the careerist and considers that decision-making is contextually dependent. The sample group from Chapter 3 and the data collected there form the basis for the research in Chapter 5. The top managers are analysed on how each of them dealt with threats and opportunities throughout their career which led them to reflect on past experiences in the face of a current situation and essentially revise their future as necessary to maintain or improve their personal brand.

The findings result in a model of temporal work in the personal branding of top managers with different mechanisms in terms of decisions and actions that are linked within a phase and between phases of the career. Furthermore, the application of temporal work in this analysis of top managers' personal branding processes opens the door towards a re-examination of the way in which time is addressed in personnel branding research, and thus in theory-building. This 
approach indicates that personal branding is not a conscious, predictable and future-oriented process, but requires frequent interpretative links between past, present and future in the different career phases.

In the context of this dissertation, this Chapter 5 is not intended to consolidate or even conclude the research findings gained in this and the previous chapters. Rather, it points to additional factors and activities that contribute to the emergence of top managers' personal brands and to the fact that methodological avenues from disciplines beyond personal branding are indispensable for a sound investigation, which may encourage other researchers in this research field to adopt a similar approach.

\subsubsection{Chapter 6: Synopsis}

Finally, Chapter 6 summarizes the findings of the previous chapters focusing on the central research questions of this dissertation. An overview and a discussion of the implications of the findings for personal branding researchers and practitioners is presented before pointing out certain limitations and suggestions for further research.

\subsection{CONTRIBUTION}

By addressing the overarching main research questions as well as the subordinate research questions in the individual chapters, this dissertation contributes to several literature and research streams and to practice in different ways. This section briefly describes these contributions.

\subsubsection{Theoretical contributions}

Given that the contemporary phenomenon of personal branding has proven to be an interdisciplinary field of research in the course of this research project, I attempt to make several contributions to various streams of literature.

First, and certainly most obvious, contributions will be made to the literature devoted to personal branding as a distinct expression of branding (Gorbatov et al., 2018; Shepherd, 2005), and related to this stream, to scholarship interested in personal branding as a process over time (Lindridge and Eagar, 2015; Preece and Kerrigan, 2015) as well as a sound structure of classes and categories and their appearance in the history of personal branding (Epstein, 2005; Khamis et al., 2017; Lunardo et al., 2015; Parmentier and Fischer, 2012).

Likewise, drawing naturally from the research field, this dissertation contributes to the literature that deals with top managers, such as CEOs (Busenbark et al., 2016; Gupta et al., 2018; Lovelace et al., 2018), and in particular their impact on corporates (Black, 1997; Hsu et al., 2013; Kedia and Mukherji, 1999; Sambharya, 1996). 
I also aim to contribute to celebrity endorsement research (Bergkvist et al., 2016; Eisend and Langner, 2010; Keller, 2013; Miller and Allen, 2012) and cobranding research (Close et al., 2011; Fournier, 2010; Keller, 2003). Here, my focus is particularly on the call by scholars to also take brand-to-celebrity transfer more seriously in research (Arsena et al., 2014; Bergkvist and Zhou, 2016). Chapter 3 looks at these approaches in particular.

Another contribution can be made to the stream of management literature, especially on managerial work and practices (Korica et al., 2017; Kurke and Aldrich, 1983, Tsoukas, 1994, Chia and Holt, 2006). The literature on managerial work efforts to answer the decades-old fundamental question 'What do managers do?' (Mintzberg, 1973) by identifying numerous managerial practices in various areas of management. This study contributes by adding a new facet caused in the identification of personal branding as a managerial practice in itself. Moreover, I contribute to practice-oriented literature (Bourdieu, 1990; Giddens, 1984, 1991; Reckwitz, 2002), which in particular considers strategy practice (Jarzabkowski, 2004; Whittington, 2006). In addition, this study contributes to the literature stream that addresses dualism and duality (Abbott, 2001; Elias, 1991; Farjoun, 2010; Giddens, 1984; Orlikowski, 1992). Chapter 4 provides the focus on these literature streams.

Time is a key dimension in the process research literature (Berends and Lammers, 2010; Bingham and Kahl, 2013; Jaques, 1982; Orlikowski and Yates, 2002; Van de Ven and Huber, 1990; Van de Ven and Poole, 2005) that I contribute to because, while scholars agree that personal brands need to be managed in and over time (Gander, 2014; Lunardo et al., 2015), they have been previously portrayed as static constructs rather than something that emerges over time. I extend the very few empiric studies that consider how personal brands are built over time (Lindridge and Eagar, 2015; Preece and Kerrigan, 2015) by applying process research strategies (Gehman et al., 2013; Langley, 1999; Langley et al., 2013). Furthermore, this research enriches the career literature and especially the scholarship interested in the role of time in career development (Arthur et al., 1989; Bateson, 1989, 2011; Gunz and Mayrhofer, 2018; Lawrence 1984) by providing clear practices and activities over the duration of the career. These approaches are the ones I contribute to with studies in Chapters 4 and 5.

Finally, the literature stream on temporal work implies a practice-based perspective on time that encompasses both the shaping of people's action and the being shaped by structural conditions within and outside of their immediate control (Emirbayer and Mische, 1998; Kaplan and Orlikowski, 2013). I contribute to this concept of temporal work in grasping how managers make reflexive links to the past, present and future in the development of their personal brand. Chapter 5 is particularly concerned with these approaches. 


\subsubsection{Contributions to practice}

A key argument for conducting the research project in this dissertation relates to the fact that the contemporary phenomenon of personal branding of top managers has created a dilemma for practitioners. On the one hand, visibility in the offline and online public sphere and the media attention of top managers as well as the competition for attractive jobs are all higher now than they have ever been. Also, the added value of personal branding has been recognized by numerous consultants, resulting in a now almost unmanageable plethora of services offered in this field. On the other hand, most of these services declared as personal branding are limited to pure communication services, mostly further reduced to a mere visibility of the top manager in the social media. A comprehensive understanding of personal branding or even a differentiated and profound concept derived therefrom is rarely offered or even applied by practitioners. Furthermore, my experience over many years as a coach of managers and top managers reveals that while most of them do not consider themselves to be a branded individual, they are very interested in such a perspective and quickly realize its benefits for themselves.

Therefore, I claim to provide valuable contributions for practice that do not stoop to the qualitative level of the countless guidebooks from railway station and airport bookshops and are not intended to be simple instruction manuals. Rather, this dissertation's quality of contributions for practice results from well-founded empirical research on the reflected needs orientation of different target groups. Here, I am essentially targeting three groups. Firstly, it concerns professionals and managers who are in different career phases on the path to becoming a top manager. Secondly, it is about top managers themselves. And finally, my contributions also focus on those people who support the aforementioned two target groups in their personal branding.

Through these contributions, all three target groups equally gain a differentiated access to the topic of personal branding, where it comes from, how it is to be understood, what it entails, what it can serve for and what challenges it faces. This enables an individual and self-critical transfer from know-what and know-how of personal branding to the development and application of one's own personal brand.

In particular, the first target group of professionals and managers can benefit in the development of their personal brand by expanding their scope of action for goal-oriented activities with the help of the key practices I have identified. They may also be made aware of the dualities inherent in these key practices and receive inspiration to overcome them on their way to the next career stage. Finally, young careerists are encouraged to critically reflect on their own personal branding process at every stage of their career and to align it for the future by temporal work. 
Top managers, in turn, are sensitized that personal branding is an indispensable part of their managerial work and they receive advice on the required key activities to build up their personal brand or to stabilize and further develop it. In addition, I show this target group how they interact as a personal brand with the corporate brand of the company they work for, but also what they should keep in mind regarding brand attributes when considering a potential change to another company.

The third target group, those who support professionals, managers and top managers in their personal branding, benefit from the advice for professionals and managers as well as from that for top managers. Brand managers, human resource managers, and advisory boards within companies are encouraged to think outside the box of their traditional professions and perspectives to gain a more comprehensive understanding of brands, people, and management. Coaches and consultants outside companies will be inspired to broaden their approach to building personal brands and to coaching managerial personalities.

Through this research work, I not only build the bridge between theory and practice in the field of personal branding. Rather, I make theoretical findings applicable to practice. 


\section{OLD PRACTICE, BUT YOUNG RESEARCH FIELD: A SYSTEMATIC BIBLIOGRAPHIC REVIEW OF PERSONAL BRANDING}

An essential first step in exploring the field of top managers' personal branding is to understand the body of knowledge about personal branding in general. The aim of this chapter is therefore to shed light on where the contemporary phenomenon of personal branding originates and what its key characteristics are. Furthermore, the analytical findings from this chapter provide the necessary content and methodological guidance for the subsequent empirical chapters.

\section{Publication history}

A previous version of this chapter, written with Prof. Dr. Jörg Henseler, was submitted as a full paper and presented at DerMarkentag in Koblenz, Germany, from September 27-28, 2018, an international branding conference addressing academics and practitioners. The paper was awarded as the best paper of this conference. An updated and extended version was published in Frontiers in Psychology in 2020 and is presented in this chapter.

\section{References to previous publications}

Scheidt, S., \& Henseler, J. (2018). Personal branding: A review on a contemporary phenomenon. 7th DERMARKENTAG (September 27-28, 2018, Koblenz, Germany), 2, 2.

Scheidt, S., Gelhard, C., \& Henseler, J. (2020). Old Practice, but Young Research Field: A Systematic Bibliographic Review of Personal Branding. Frontiers in Psychology, 11, 1809.

\section{Keywords}

Personal branding, Personal brand, Human brand, Literature review, Bibliographical analysis 


\section{ABSTRACT}

Before engaging with the already intensive and still increasing personal branding activities in many fields of practice, a scholarly approach would call for a more specific definition of the concept of personal branding processes and the resulting human brands. A multi-step analysis of the growing body of literature on personal branding is employed, integrating a framework that covers six key research streams of personal branding, (1) terminology and definition, (2) underlying theories, (3) classes and categories, (4) benefits, (5) antecedents, and (6) key ingredients and applications, complemented by challenges the domain of personal branding has to cope with. The analysis shows that personal branding is an interdisciplinary concern, which is still in its infancy and in which universally valid personal branding frameworks or even theories cannot be identified yet. Personal branding appears as a source for new academic impulses, as it may sensitize scholars to opportunities for intensifying collaboration with practitioners and with other academic domains to enrich and disseminate knowledge in their fields.

\subsection{INTRODUCTION}

While "personal branding" and "human brands" as terms are a modern invention, the branding of individuals is as old as human interaction and society itself. Alexander the Great has been claimed as the first celebrity in human history (Braudy, 1997), the archetypal erudite Goethe achieved success by using all elements of the marketing mix in order to differentiate himself from other authors of his time (Bendisch et al., 2013), and Andy Warhol's "idea that 'everyone will be famous for 15 min' comments on a world where image reigns supreme" (Schroeder, 2005, p. 1294). Personal branding has become a vital part of individuals, society, culture, and economy. Research has responded accordingly, with different academic disciplines converging on this subject over time, each focusing on many different aspects. Goffman (1956) described self-presentation as the intentional and tangible component of identity, human brands have been a defining characteristic of the broadening of the traditional concept of marketing (Kotler and Levy, 1969), and, from a social psychology perspective, rarity and stability affect celebrity authenticity (Moulard et al., 2015) to name just a few developments in the field.

Whereas personal branding as a term is a relatively recent invention, the reality behind it is not. The significant increase of scientific attention to personal branding, especially in the last 10 years, has given this contemporary phenomenon widespread, albeit fragmentary academic presence. Schau and Gilly (2003), investigating selfpresentation in the Web 1.0 environment, and Thomson (2006), exploring why 
consumers form strong attachments to human brands, published the first scientific articles to empirically examine human brands. More and more empirical studies have been conducted in the field in the last few years (e.g., Parmentier et al., 2013; Hofmann et al., in press), but they remain few and far between. Several personal branding frameworks have also been put forward, some based on these empirical studies (e.g., Khedher, 2019) and some on more conceptual work (e.g., Bendisch et al., 2013), but a comprehensive personal branding framework, let alone a sustainable theory, is yet sorely missing for academic purposes. Moreover, the key question as to whether science can "reclaim self-marketing and personal branding from the enthusiasts" (Shepherd, 2005, p. 12) is still waiting for an academically valid answer.

As research is continually developing both in terms of breadth, going into new directions, e.g., studying bloggers and influencers in social media, and depth, with more studies covering well-known topics, such as brand attributes, it seems an opportune moment for an updated review of current literature. To address the mentioned lacuna, the objective of this paper tries to present an analysis of the growing body of literature on personal branding, covering its terminology and definitions, underlying theories, classes and categories, benefits, antecedents, key ingredients and applications as well as its challenges. In doing so, this review contributes significantly to the positioning of personal branding in the applied psychology, branding, and business research context by bundling fragmented ideas and structuring single key aspects. Such an approach complements to the interdisciplinary review on personal branding by Gorbatov et al. (2018), systematically links the underlying and existing body of knowledge and opens avenues for future novel research (Palmatier et al., 2018).

\subsection{METHODOLOGY}

The fragmented and not clearly arranged field of knowledge in personal branding does not benefit from providing merely a more comprehensive overview on existing literature. Rather, we aim to identify trends and key research streams in personal branding resulting in constructive criticism of existing work and avenues for future research. Therefore, a structured approach that implies a bibliographic analysis in its core is suited for the method of choice (Paul and Singh, 2017; Ferreira, 2018).

The current body of literature on the subject to be studied has been surveyed systematically (works published before 31 December 2019), complementing this bibliographical data with substance-centered research in a loop of crossfertilization that enriched both perspectives (Figure 2.1). 


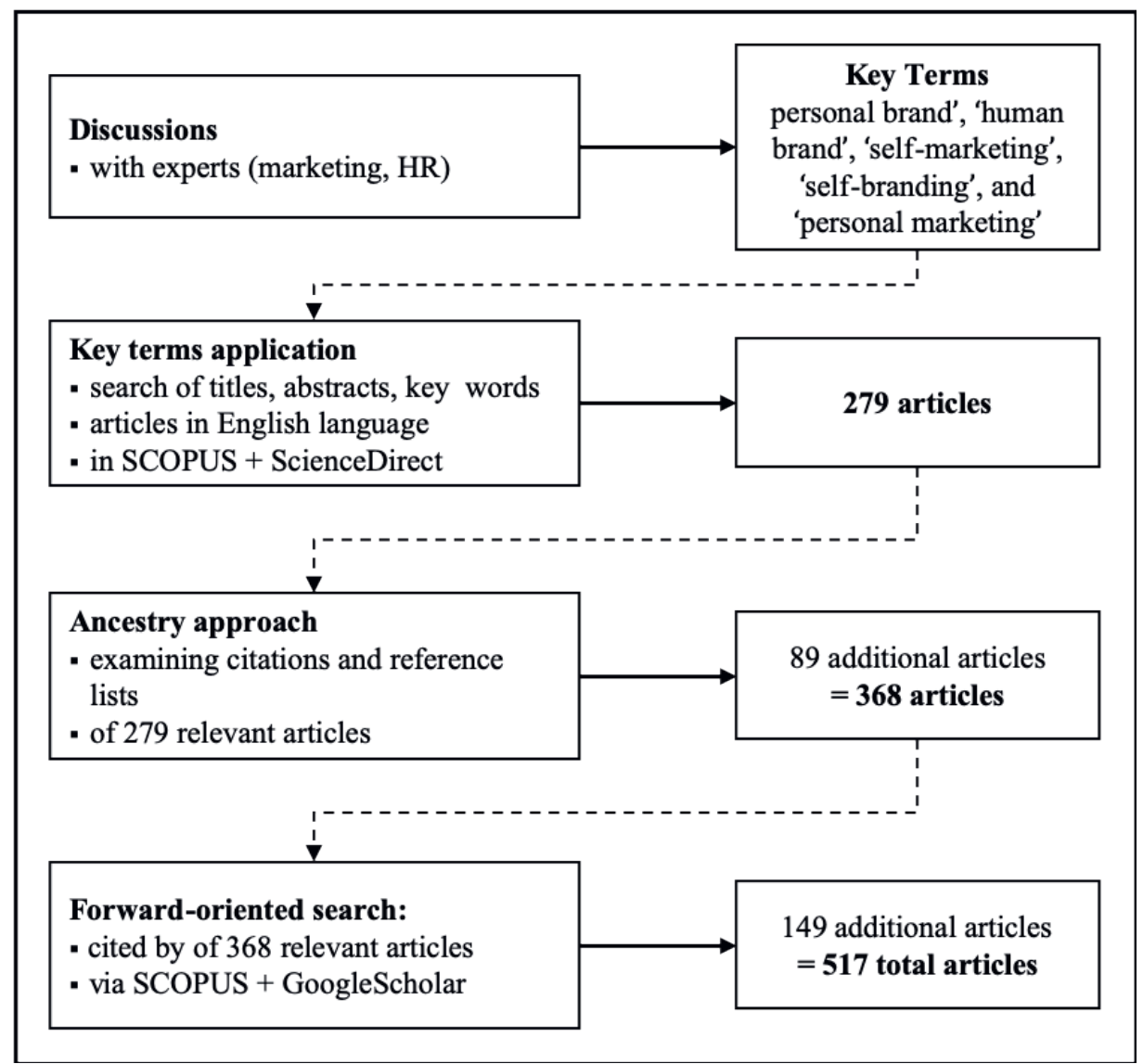

Figure 2.1: Review methodology process

During pre-analysis a pilot study was conducted in which chosen experts, such as top managers responsible for corporate HR, HR managers doing recruitment and development at managerial level, and professionals who deliver communication services for CEOs and other branded individuals were invited to join several discussions (see Table 2.1). This first step was used initially to improve awareness of previous research into the branding of individuals. It revealed the following set of key terms for further enquiry: "personal brand," "human brand," "self-marketing," "self-branding," and "personal marketing."

For the purposes of the main analysis, the chosen terms were applied in a search of the titles, abstracts, and keywords of articles in the English language. This analysis required good coverage of branding- and business-related research in multiple disciplines, for which SCOPUS and ScienceDirect are suitable and popular databases. 
Table 2.1: The expert sample group

\begin{tabular}{|l|l|l|l|l|l|l|}
\hline Interviewees & Age & Gender & Nationality & Function & $\begin{array}{l}\text { Educational } \\
\text { background }\end{array}$ & Industry \\
\hline Expert 1 & 51 & Female & German & CEO & $\begin{array}{l}\text { Business } \\
\text { marketing, } \\
\text { architecture }\end{array}$ & $\begin{array}{l}\text { Real estate/ } \\
\text { Construction }\end{array}$ \\
\hline Expert 2 & 57 & Male & Austrian & $\begin{array}{l}\text { SVP Corporate } \\
\text { Communications, } \\
\text { Corporate Marketing }\end{array}$ & $\begin{array}{l}\text { Philosophy, } \\
\text { literature }\end{array}$ & Utilities \\
\hline Expert 3 & 48 & Female & German & HR Manager & $\begin{array}{l}\text { Business } \\
\text { economics } \\
\text { (industrial } \\
\text { psychology) }\end{array}$ & Utilities \\
\hline Expert 4 & 43 & Male & German & Managing Director & $\begin{array}{l}\text { English literature, } \\
\text { political science, } \\
\text { Anglo-American } \\
\text { history }\end{array}$ & Advertising \\
\hline Expert 5 & 50 & Male & German & CEO & $\begin{array}{l}\text { Banker, business } \\
\text { economics } \\
\text { (marketing) }\end{array}$ & Advertising \\
\hline Expert 6 & 39 & Female & German & HR Director & $\begin{array}{l}\text { Business } \\
\text { economics } \\
\text { (marketing and } \\
\text { labour) }\end{array}$ & Mobility \\
\hline Expert 7 & 46 & Male & Spain & HR Manager & $\begin{array}{l}\text { Business } \\
\text { economics }\end{array}$ & Automobile \\
\hline
\end{tabular}

Following this first search and to ensure the most exhaustive literature review possible, the ancestry approach (Cooper, 1989, 2010; Atkinson et al., 2015) was applied to identify additional articles. This backward search uncovers new articles of interest that meet the criteria by examining the citations and the reference list of the articles already available to the researchers (e.g., Cornwell and Maignan, 1998; Xyrichis and Lowton, 2008; Filo et al., 2015). To compensate for the main limitation of the ancestry approach, i.e., its one-sided retrospective direction, citation research (cited by) via SCOPUS and GoogleScholar was conducted as a forward search on all academic articles to cover relevant later citations. In addition, articles published after 2019, but before the manuscript was finalized were added to the review. In total, 518 articles were included in this review whose publication started in 1969 and increased significantly after the mid-2000s (Figure 2.2).

The following subject matter research analysed and matched the articles with each other via a fine-grained and critical reading to support both an immediate check of the thematic relevance of the articles and identification of the key topics in personal branding. 


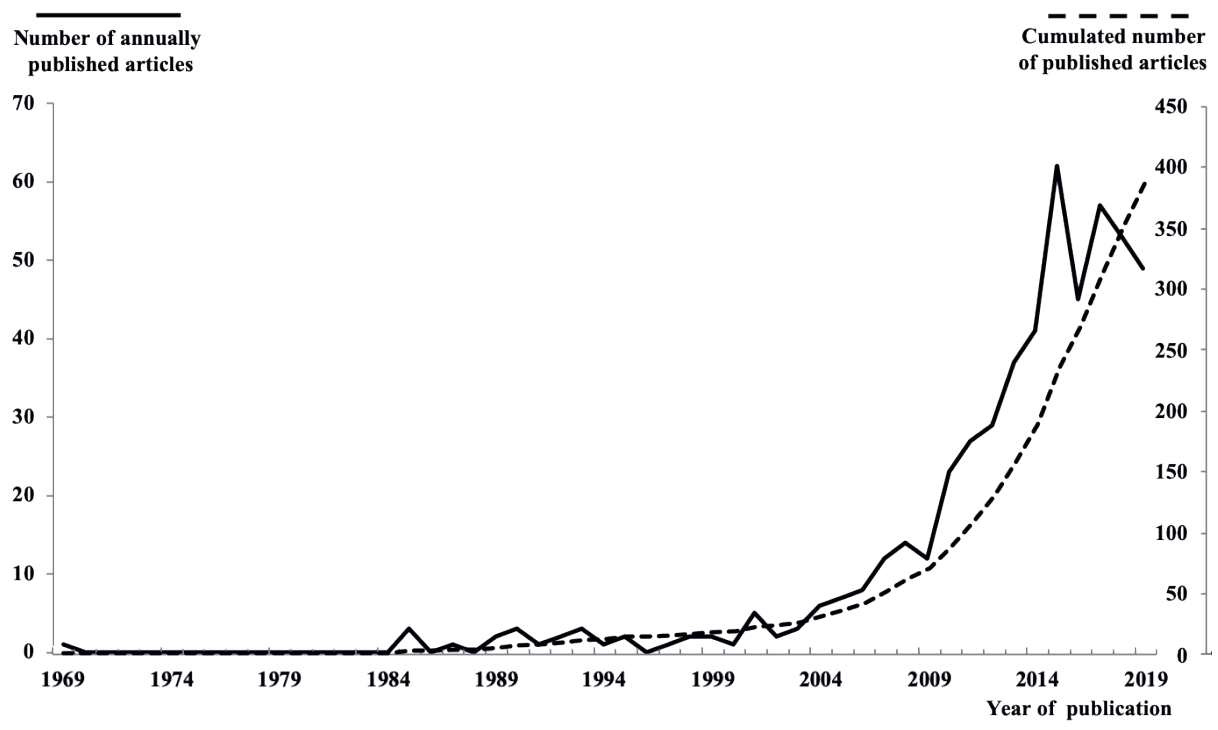

Figure 2.2: Publication of academic articles with relevance to personal branding over time

\subsection{FINDINGS}

Six key research streams were identified and served as a framework to investigate the chosen articles with a view to relevant key topics (Table 2.2). (1) It opens by reviewing what a human brand and personal branding respectively are, proposing updated terminologies and definitions; (2) This leads to a consideration of the main psychological theories in their application to personal branding; (3) Followed by an examination of the classes and categories in which personal branding is applied by highlighting the difference between celebrities, icons, and branded ordinary people; (4) The benefits of personal branding reveal its importance for the branded individual as well as for stakeholders; (5) It then focuses on the antecedents of the contemporary phenomenon of personal branding, answering the question of the reasons for which it has been spreading; (6) Key ingredients and applications indicate how human brands emerge and how it is applied in a branding context and beyond. Subsequently, the challenges that appear with personal branding have been elaborated, as a critical view on personal branding is needed to support a responsible and conceptually meaningful development of future concepts and theories. 
Table 2.2: The structure of scholarly knowledge on personal branding:Research streams, concepts and contributions

\begin{tabular}{|c|c|c|}
\hline \begin{tabular}{|l|} 
Research \\
Streams
\end{tabular} & Concepts & Contributions \\
\hline \multirow[t]{5}{*}{ Terminology } & Personal branding & $\begin{array}{l}\text { Dumont and Ots, 2020; Harris and Rae, 2011; Lair et al., } \\
\text { 2005; Labrecque et al., 2011; Manai and Holmlund, 2015; } \\
\text { Shepherd, } 2005\end{array}$ \\
\hline & Human branding & $\begin{array}{l}\text { Carlson and Donavan, 2013; Close et al., 2011; Thomson, } \\
2006\end{array}$ \\
\hline & Self-branding & Duffy and Pooley, 2019; Gandini, 2016; Hearn, 2008 \\
\hline & Self-marketing & Shepherd, 2005; Shuker, 2014 \\
\hline & Corporate personhood & Gershon, 2014 \\
\hline \multirow[t]{5}{*}{ Definition } & Individual contribution & $\begin{array}{l}\text { Clark, 2011; Gander, 2014; McNally and Speak, 2002; } \\
\text { Morton, } 2012\end{array}$ \\
\hline & Focus on the audience & $\begin{array}{l}\text { Parmentier et al., 2013; Philbrick and Cleveland, 2015; } \\
\text { Preece and Kerrigan, } 2015\end{array}$ \\
\hline & Differentiation & Gander, 2014; Parmentier et al., 2013; Lunardo et al., 2015 \\
\hline & Focus on career & $\begin{array}{l}\text { Gershon, 2014; Gorbatov et al., 2019; Lair et al., 2005; } \\
\text { Morton, 2012; Shepherd, } 2005\end{array}$ \\
\hline & Commercialization & Fillis, 2015; Preece and Kerrigan, 2015 \\
\hline \multirow[t]{6}{*}{ Theories } & Attachment theory & $\begin{array}{l}\text { Huang et al, 2015; Loroz and Braig, 2015; Saboo et al., } \\
\text { 2015; Thomson, } 2006\end{array}$ \\
\hline & Self-determination theory & $\begin{array}{l}\text { Huang and Phau, 2015; Ryan and Deci 2000; Moulard et } \\
\text { al., } 2015\end{array}$ \\
\hline & Attribution theory & Moulard et al., 2015 \\
\hline & Social identity theory & Carlson et al., 2009; Carlson and Donavan, 2013 \\
\hline & Cue utilization theory & $\begin{array}{l}\text { Close et al., 2011; Moulard et al., 2014; Zamudio et al., } \\
2013\end{array}$ \\
\hline & Structuration theory & Lindridge and Eagar, 2015; Turner, 2004 \\
\hline \multirow[t]{8}{*}{ Benefits } & Career & $\begin{array}{l}\text { Close et al, 2011; Gorbatov et al., 2019; Harris and Rae, } \\
\text { 2011; Moulard et al. 2015; Parmentier and Fischer, 2012; } \\
\text { Philbrick and Cleveland, 2015; Zamudio et al, } 2013\end{array}$ \\
\hline & Differentiation & Chen, 2013; Shepherd, 2005 \\
\hline & Improvement of the self & $\begin{array}{l}\text { Gall, 2010; Gander, 2014; Hearn, 2008; Philbrick and } \\
\text { Cleveland, 2015; Preece and Kerrigan, } 2015\end{array}$ \\
\hline & Visibility and attention & $\begin{array}{l}\text { Fillis, 2015; Harris and Rae, 2011; Hearn, 2008; Philbrick } \\
\text { and Cleveland, 2015; Thomson, } 2006\end{array}$ \\
\hline & Sales/risk reduction & $\begin{array}{l}\text { Carlson and Donavan, 2013; Huang et al, 2015; Mills et } \\
\text { al, 2015; Moulard et al, 2014; Preece and Kerrigan, 2015; } \\
\text { Schroeder, } 2005\end{array}$ \\
\hline & Identity construction & $\begin{array}{l}\text { Cocker et al., 2015; Huang et al., 2015; Lunardo et al., } \\
\text { 2015; Thomson, } 2006\end{array}$ \\
\hline & Co-branding effects & $\begin{array}{l}\text { Bendisch et al, 2013; Close et al, 2011; Moulard et al, 2014; } \\
\text { Scheidt et al., 2018; Zinko and Rubin, } 2015\end{array}$ \\
\hline & Impact on society & Fillis 2015; Lindridge and Eagar 2015; Schroeder 2005 \\
\hline
\end{tabular}




\begin{tabular}{|c|c|c|}
\hline $\begin{array}{l}\text { Research } \\
\text { Streams }\end{array}$ & Concepts & Contributions \\
\hline \multirow[t]{4}{*}{ Antecedents } & New world of work & $\begin{array}{l}\text { Gandini, 2016; Gershon, 2014; Hearn, 2008; Lair et al, } \\
\text { 2005; Philbrick and Cleveland, 2015; Vallas and Cummins, } \\
\text { 2015; van Oort, } 2015\end{array}$ \\
\hline & Development of media & $\begin{array}{l}\text { Chen, 2013; Dutta, 2010; Elwell, 2014; Fillis, 2015; Gandini, } \\
\text { 2016; Gehl, 2011; Hearn, 2008; Labrecque et al., 2011; Lair } \\
\text { et al, 2005; Mills et al, 2015; Schau and Gilly (2003) }\end{array}$ \\
\hline & New individualism & $\begin{array}{l}\text { Gershon, 2014; Hearn, 2008; Lair et al, 2005; Lindridge } \\
\text { and Eager, } 2015\end{array}$ \\
\hline & Existential angst & $\begin{array}{l}\text { Harris and Rae, 2011; Labrecque et al, 2011; Lair et al, } \\
\text { 2005; Shepherd, 2005 }\end{array}$ \\
\hline \multirow{9}{*}{$\begin{array}{l}\text { Key } \\
\text { ingredients } \\
\text { and } \\
\text { applications }\end{array}$} & Personality & $\begin{array}{l}\text { Arai et al., 2014; Chen, 2013; Fillis, 2015; Philbrick and } \\
\text { Cleveland, 2015 }\end{array}$ \\
\hline & Authenticity & $\begin{array}{l}\text { Gander, 2014; Kowalczyk and Pounders, 2016; Lunardo } \\
\text { et al, 2015; Mills et al, 2015; Morton, 2012; Moulard et al., } \\
\text { 2014; Moulard et al, 2015; Philbrick and Cleveland, 2015; } \\
\text { Thomson, } 2006\end{array}$ \\
\hline & Differentiation & $\begin{array}{l}\text { Carlson and Donavan, 2013; Chen, 2013; Cocker et al, } \\
\text { 2015; Gander, 2014; Labrecque et al., 2011; Mills et al, } \\
\text { 2015; Parmentier and Fischer, } 2012\end{array}$ \\
\hline & Visibility & $\begin{array}{l}\text { Elwell, 2014; Gander, 2014; Harris and Rae, 2011; } \\
\text { Labrecque et al., 2011; Morton, 2012; Parmentier and } \\
\text { Fischer, 2012; Philbrick and Cleveland, } 2015 \\
\end{array}$ \\
\hline & Social media & $\begin{array}{l}\text { Chen, 2013; Elwell, 2014; Gandini, 2016; Gehl, 2011; Hearn, } \\
\text { 2008; Labrecque et al, 2011; Lindridge and Eagar, } 2015\end{array}$ \\
\hline & Narrative identity & Belk, 2013; Elwell, 2014; McAdams, 2011 \\
\hline & Attachments & $\begin{array}{l}\text { Carlson and Donavan 2013; Chen, 2013; Loroz and Braig, } \\
\text { 2015; Thomson, } 2006\end{array}$ \\
\hline & $\begin{array}{l}\text { Co-brands and } \\
\text { stakeholders }\end{array}$ & $\begin{array}{l}\text { Bendisch et al., 2013; Close et al., 2011; Dumont and Ots, } \\
\text { 2020; Parmentier and Fischer 2012; Parmentier et al., } \\
\text { 2013; Preece and Kerrigan, 2015; Speed et al., } 2015\end{array}$ \\
\hline & Brand equity & $\begin{array}{l}\text { Chen and Chung, 2016; Cottan-Nir, 2019; Hearn, 2008; } \\
\text { Moulard et al., 2014; Parmentier and Fischer, } 2012\end{array}$ \\
\hline
\end{tabular}

\subsubsection{What is a human brand? What is personal branding?}

\subsubsection{Terminology}

The branding of individuals has introduced a diverse set of new terms into the jargon of professionals and academics alike. Brand You (Peters, 1999), Brand Yourself (Andrusia and Haskins, 2000), and me Inc (Peters, 1999) are neologisms introduced by marketers and professionals who focus primarily on a personcentered approach "constructing a product based on themselves that can then be marketed as effectively as possible" (Shepherd, 2005, p. 6). At the same time, academic efforts in this field suffer from a lack of consistent terminology, with terms such as self-branding, self-marketing, or corporate personhood. However, personal branding and, to a limited extent, human branding remain the most frequently used and accepted terms. "Personal branding" was coined in 1997 by Tom Peters 
in the Fast Company Magazine. Although Peters did not give an explanation or definition, "the phrase 'personal branding' is now fairly well established, and more consistently used" (Shepherd, 2005, p. 2), which can be confirmed by the research produced for this literature review.

\subsubsection{Definitions}

Personal branding and its various synonyms are frequently used without any explicit or even consistent definitions of the term, giving rise to a certain degree of terminological fuzziness. A deeper investigation of the definitions identifies, nonetheless, some common ground and suggests a conceptual approach based on three pillars: First, what the branded individual brings in. This implies personal qualifications, such as skills, competencies, experience, or expertise. Second, a focus on the audience or specific target groups and their perceptions of the branded person and relevant associations. This aspect ranges from few specific definitions, such as "the employee trying to impress his boss" (Kotler and Levy, 1969, p. 12) and psychologists' "clients" (Cederberg, 2017) to mostly very abstract circumscriptions like "who you are to the world around you" (Philbrick and Cleveland, 2015, p. 183) or "to a target audience" (Parmentier et al., 2013, p. 382). Third, differentiation appears as the end product, and the process of personal branding aims to produce a distinction from peers by leveraging one's points of difference and defining individual unique selling proposition. Beside this conceptual triangle, a strong focus on career and employment as well as the commercialization of the branded individual can be identified as other particularly key aspects.

A distinction between the process, i.e., personal branding, and the thing, i.e., the human brand, is obvious and can traced back to the differing philosophies of Heraclitus and Democritus (Rescher, 1996). However, a large majority of the reviewed articles do not distinguish clearly between these two perspectives. In this vein, confusion arises as "personal branding" serves as a term for the entire phenomenon of the branding of individuals, whereas "personal brand" is used to describe the outcome of personal branding in general as well as the class of ordinary people and field-specific individuals who do not own a celebrity status.

On the whole, updated definitions for the contemporary phenomenon of personal branding and its statement as a resulting brand need to be determined. Therefore, the following definitions can be proposed: "Personal branding" could remain as a term from a process perspective and, thus, is the entire process of establishing, maintaining, and developing an individual's human brand. It includes the active and selective integration of certain personal preconditions with due consideration for the changing nature of the field in which the human brand is to be established. In order to resolve terminological confusion, "human brand" could serve as a general term for the brand that results from a personal branding process, 
independent of class. In this sense, a human brand is an intangible asset linked to a person, which generates economic and social value through its visibility as a result of a personal branding process. Whereas the personal branding process is a collective act between stakeholders and the branded individual's entire personality, visibility is expected to arise within and beyond her/his professional field to stand apart from other human brands and to fit into a defined target market. All aspects of the definitions proposed before will be considered during the course of this literature review.

\subsubsection{Underlying theories}

Not surprisingly, scholars refer to theories and concepts from the discipline of branding in their understanding of personal branding, such as Keller's (1993) customer-based brand equity model that serves as a basis for the concept of athletes' brand images (Arai et al., 2014) and the idea of human brand equity for football players (Parmentier and Fischer, 2012) or the model of establishing points of differentiation and points of parity (Keller et al., 2002). However, the interdisciplinary domain of personal branding does not only call for a broader approach in underlying theories and concepts. Rather, theories specifically from psychology are used to do justice to the components "personal" or "human" in personal branding and human brand.

\subsubsection{Attachment theory}

This psychological, evolutionary and ethological theory (Bowlby, 1969) serves as a foundation for a detailed investigation into personal branding, as "understanding how to create or intensify attachments could offer both an effective and an economical means of achieving stronger marketing relationships that may prevent consumer defections, increase consumers' forgiveness in the face of negative information, and can predict brand loyalty and willingness to pay" (Thomson, 2006, p. 105). Whereas autonomy, relatedness, and competence serve as antecedents of the strength of people's attachment to human brands, Loroz and Braig (2015) create an empirically more comprehensive and sophisticated picture of consumer attachments to human brands. Thus, the importance of the competence dimension to develop strong human brand attachment depends on the extent to which the human brand maintains competence. In addition, brand appeal, consistent focus, and longevity are effective moderators of human brand attachment strength and dimensions such as favorability, originality, and clarity should be included for a broader understanding of human brands.

\subsubsection{Self-Determination theory}

Regarding the perception of a celebrity's authenticity (Moulard et al., 2015), self- 
determination theory in its focus on human motivation and personality proposes that intrinsically motivated behavior is "authentic in the fullest sense of those terms" (Ryan and Deci, 2000, p. 74). Intrinsic motivation in turn is characterized by participation in an activity for its inherent satisfaction of three innate psychological needs that are essential for optimal functioning: autonomy (i.e., need to perceive origin of source of one's own behavior), relatedness (i.e., need to feel connected with others), and competence (i.e., need to have an effect on one's outcomes and surroundings). Autonomy, relatedness, and competence are therefore assumed to be prerequisites for the authenticity of celebrities.

\subsubsection{Attribution theory}

Derived from attribution theory, rarity and stability are suggested as the main components of human brands (Moulard et al., 2015) as they are expected to contribute to authenticity. The augmentation principle within the attribution theory is used to derive rarity, since it states that that actions that involve costs, risks, or sacrifices (i.e., nonconforming behaviors) are more likely to be attributed to the person than to external causes. This hypothesis is grounded in the idea that it is often difficult to express one's true self, with social pressure causing most people to adapt to the norm. Therefore, it is difficult to "go against the grain" because social acceptance is less likely to be achieved. People who do so are more likely to be perceived as intrinsically motivated. This idea is in line with previous research (Anton, 2001; Vannini and Franzese, 2008) indicating that social conformity and impression management are the antithesis of authenticity. Stability, in turn, is justified on the grounds that similar behavior in various situations and similar behavior in response to distinct stimuli/units may collapse to similar behavior over time. Thus, consumers' perceptions of a celebrity's authenticity are driven by the fact that that the behavior is unique to that person and is stable over time. Concerning the age of the celebrities' target group, younger people are more likely to rely on rarity than older people when judging the authenticity of celebrities, while older people rely primarily on stability when assessing the authenticity of a celebrity. Consequently, a celebrity's authenticity is influenced by the rarity and stability antecedents, yet the relative weights of these antecedents evolve with age.

\subsubsection{Social identity theory}

According to this theory originally formulated by social psychologists, consumers demonstrate membership in a particular social category by associating themselves with a personal brand, thus creating a social identity. Carlson and Donavan (2013) investigated the extent to which brand personality attributes of professional athletes influence consumer-brand relationships with a professional sports 
team. They used social identity theory as a framework for a model that predicts consumer connections with athletes and the team, retail spending and number of games watched. According to social identity theory, self-categorization into a group serves a self-definitional role that helps individuals make sense of the world (Tajfel and Turner, 1985; Hogg et al., 1995). Social identification serves as a source of self-esteem that should be enhanced by membership in a valued group. Here, strong identification with the group should go hand in hand with positive evaluation of the ingroup (Leary and Tangney, 2012). Consequently, consumers are drawn to sports teams that have a strong "similarity" to their own actual or ideal self (Madrigal and Chen, 2008; Carlson et al., 2009; Fink et al., 2009). Carlson and Donavan (2013) suggest that likewise, consumers should be drawn to individual athletes perceived to be similar to their own actual or ideal self. They identify with famous athletes because they are perceived to be symbolic of desirable reference groups and being associated with the athlete's brand personality attributes may enhance their own self-image. Additionally, consumers are more likely to identify with a player who is perceived to be both prestigious and distinctive. These findings are in line with social identity theory, which suggests people seek to differentiate themselves from others in social contexts and are thus likely to affiliate with entities that enhance their self-esteem (Tajfel and Turner, 1985; Leary and Tangney, 2012). In contrast to more traditional brands, human brands have the unique opportunity to successfully differentiate themselves from the consumer's perspective and to offer social identification even through negative characteristics. The image of being rebellious is often perceived as being highly desirable since, for instance, many celebrities and athletes are very popular among consumers because of their negative "bad boy" or "bad girl" images (Burton et al., 2001).

\subsubsection{Cue utilization theory}

An application of cue utilization theory enables to differ between intrinsic and extrinsic cues of human brands which is comparable to Keller's (1993) distinction between product-related, i.e., a product's physical composition, and non-product related brand attributes, e.g., price and packaging. Investigating artist brands from the point of view of cue utilization theory (Moulard et al., 2014) the appearance and the quality of the artwork itself can be conceptualized as an intrinsic cue whereas the attitude toward the artist, or the artist's brand equity, can be conceptualized as an extrinsic cue. Doctoral candidates' brand attributes are categorized into intrinsic and extrinsic cues, each with a positive impact on certain aspects of the candidates' job search process (Close et al., 2011). Whereas the candidates' research productivity and dissertation progress are attributed to the intrinsic cues, the extrinsic cues are represented by granting faculty research productivity, advisor research productivity, and doctoral consortium attendance. Additionally, doctoral 
candidates' publications in top ranked journals strengthen the confidence that a candidate's publication in a particular journal meets a certain quality standard and thus served as important predictors of the candidate's placement success. This is consistent with the cue utilization theory, suggesting that some cues have higher predictive and confidence values than other cues (Olson, 1977; Richardson et al., 1994), and that cues with such high values are given the greatest weight in assessing quality. The predictive value of a cue is directly connected to the degree to which the evaluators associate the cue with quality.

\subsubsection{Structuration theory}

This theory explains how social systems are created and reproduced through the engagement of structure and individual's, group's or organization's behavior (Giddens, 1984) and is utilized to explore the extent that celebrities' human brand can emancipate themselves from a character they are associated with (Lindridge and Eagar, 2015). Exemplarily applied to the late singer, songwriter and actor David Bowie, the structure of his human brand can be understood through the interactions and knowledge between so-called "agents," i.e., producers, managers, agents, publicists and the entire machinery of the music industry, who work with and sometimes even force the artists to construct and perform their persona. Consequently, agents' behaviors are not only determined by the structure that they exist within but are also constantly recreated and adapted through differing time periods. Emphasizing the question about the ownership of a human brand and its characters leads to the recognition of celebrities as image-creators and -prisoners depending on which agents hold the power to influence image associations. In this respect, structuring theory is expected to enable scholars to deal with this conflict by considering how agents within the structure can influence the agency of a human brand, leading to an "ongoing negotiation between the different agents within the celebrity structure" (Turner, 2004).

\subsubsection{Classes and Categories}

Regarding the fact that scholars primarily use the term "personal brand" when considering or investigating ordinary people as brands, three different classes of human brands are proposed: the celebrity, the personal brand, and the icon.

\subsubsection{Classes}

Celebrities, defined as "part of the social elite who engage in the public relations machine of television and movie roles, special event appearances and talk show and gossip magazine placements" (Lunardo et al., 2015, p. 687), enjoy great popularity in personal branding among both practitioners and scholars. While the very first empirical studies of personal branding targeted celebrities (Thomson, 2006), 
recent investigations have evolved to form a separate interdisciplinary research area beyond a personal branding perspective, particularly in the last few years, as expressed in its publication platform in the Celebrity Studies journal. Nonetheless, the search through key terms in this review resulted in 83 articles that focus on celebrities confirming the manifest interest of scholars in investigating them.

The chronological aspect of the demographics of celebrity culture comes into play when turning to the branding of ordinary people. Because of the contradictory forces affecting media visibility, namely the need for constant renewal and the competition for that scarce resource that is public attention, there is a rapid turnover of celebrities in the media. Whereas, traditional media, such as television, radio, and newspapers, had been the exclusive domain of corporate entities and celebrities, social media allows all individuals to create their own unique virtual spaces and to reach broader audiences irrespective of time or place. How much room is there for celebrities to not fall out from the celebrity zone and step into the zone of ordinary human brands, i.e., personal brands? In turn, micro-celebrities appear as an intermediate stage during the transition from a personal brand to celebrity status (Khamis et al., 2017) enabled by social media.

Finally, the icon is a legitimate cultural symbol of personal achievement and societal values. While celebrities, for a period of time, own the symbolic meanings associated with their private and public selves, icons experience a convergence and transformation of meanings across time, reflecting wider cultural concerns. Celebrities transition into icons when their fame endures through the transformation of their cultural meaning and values that mirror changes in society (Lindridge and Eagar, 2015). Even if terms such as "superstar" and "idol" (Epstein, 2005) may confirm that a consistent separation does not exist, an icon stands out from the crowd of an increasing number of celebrities.

Scholars tend to prioritize some areas in their research, while others still lack scholarly attention (Table 2.3) regarding the assignment of three human brand classes to 11 different categories (see Appendix 1).

\subsubsection{Categories}

By reason of the increasing presence in the public and in the media, celebrities are no longer limited to actors and musicians. It covers athletes, business persons, technology entrepreneurs, politicians, scientists, and others as well (Moulard et al., 2015). Celebrities are primarily studied in the sports category, such as Andy Murray, and in politics, for example Kevin Rudd and Donald Trump. However, performing artists, such as Oprah Winfrey, represent the largest category of celebrities being investigated. Whereas these three categories mirror the high level of attention they have in the media, royals or the family members of higher or lower aristocracy have rarely yet been targeted by scholarly interest. In a similar vein, visual artists, 
Table 2.3: Number of publications focusing on three different classes of human brands in eleven different categories

\begin{tabular}{|c|c|c|c|c|}
\hline \multirow[t]{2}{*}{ Categories } & \multirow[t]{2}{*}{ Sub-categories } & \multicolumn{3}{|c|}{ Classes of Human Brands } \\
\hline & & Icon & Celebrity & Personal brand \\
\hline \multirow[t]{3}{*}{ Sports } & Athletes & 0 & 4 & 30 \\
\hline & Athletic trainers & 0 & 0 & 2 \\
\hline & $\begin{array}{l}\text { Athletes from specific } \\
\text { disciplines }\end{array}$ & 2 & 7 & 6 \\
\hline \multirow[t]{3}{*}{ Academics } & General & 0 & 0 & 9 \\
\hline & Professors & 0 & 0 & 4 \\
\hline & Students & 0 & 0 & 22 \\
\hline \multirow[t]{5}{*}{ Politicians } & General & 0 & 2 & 8 \\
\hline & Prime ministers & 0 & 4 & 0 \\
\hline & \begin{tabular}{|l|} 
Presidents \\
\end{tabular} & 0 & 4 & 0 \\
\hline & Election candidates & 0 & 1 & 4 \\
\hline & Ordinary politicians & 0 & 0 & 1 \\
\hline \multirow[t]{4}{*}{ Visual artists } & General & 0 & 0 & 7 \\
\hline & Painters & 0 & 4 & 0 \\
\hline & Sculptors & 0 & 1 & 0 \\
\hline & Video/film producers & 0 & 1 & 0 \\
\hline \multirow[t]{5}{*}{ Performing artists } & Actors & 0 & 6 & 1 \\
\hline & Musicians & 2 & 4 & 6 \\
\hline & Comedians & 0 & 1 & 0 \\
\hline & Models & 0 & 4 & 2 \\
\hline & TV Anchor & 0 & 2 & 1 \\
\hline Aristocracy & Royals & 1 & 0 & 1 \\
\hline $\begin{array}{l}\text { Producers of hedonic } \\
\text { products }\end{array}$ & Chefs & 0 & 3 & 0 \\
\hline \multirow[t]{8}{*}{ Professional services } & General & 0 & 0 & 6 \\
\hline & Medical staff & 0 & 0 & 10 \\
\hline & Consultants & 0 & 0 & 1 \\
\hline & IT professionals & 0 & 0 & 1 \\
\hline & \begin{tabular}{|l|} 
Engineers \\
\end{tabular} & 0 & 0 & 2 \\
\hline & Salespeople & 0 & 0 & 2 \\
\hline & Teachers & 0 & 0 & 1 \\
\hline & Librarians & 0 & 0 & 6 \\
\hline \multirow[t]{3}{*}{ Self-employed } & General & 0 & 0 & 1 \\
\hline & Creative industry & 0 & 0 & 3 \\
\hline & \begin{tabular}{|l|} 
Spiritual \\
\end{tabular} & 0 & 0 & 1 \\
\hline \multirow[t]{5}{*}{ Business managers } & CEOs & 0 & 0 & 15 \\
\hline & Executives & 0 & 0 & 2 \\
\hline & Leaders & 0 & 0 & 3 \\
\hline & Entrepreneurs & 0 & 2 & 5 \\
\hline & Owner-manager & 0 & 0 & 1 \\
\hline \multirow[t]{6}{*}{ Content creators } & Journalists & 0 & 0 & 22 \\
\hline & Authors & 0 & 1 & 3 \\
\hline & Influencers & 0 & 1 & 1 \\
\hline & \begin{tabular}{|l|} 
Bloggers \\
\end{tabular} & 0 & 0 & 16 \\
\hline & YouTubers & 0 & 1 & 5 \\
\hline & Vloggers & 0 & 2 & 2 \\
\hline
\end{tabular}


business managers, and content creators have been the subject of only few studies of celebrities, despite their intense visibility in different kinds of media.

Personal brands in the category of content creators have been facing increasing scholarly interest in the last few years, especially journalists, bloggers, and YouTubers. Similarly, professors and students face intense academic attention, which might simply be caused by the ready availability of the sample group. Whereas personal brands in the sports category emphasize the athlete in general, numerous different jobs have been studied in the professional services, such as doctors and nurses in the medical field, psychologists, librarians, and engineers. Business managers, for example CEOs, represent another category studied more frequently. However, the personal brands in the categories of the producers of hedonic products and the aristocracy suffer from a lack of scholarly interest.

The number of branded individuals being labelled and studied as icons is very low so far, which mirrors their hardly existing availability for research efforts. British royals as human brands, for example, serve as "iconic British symbols" (Otnes and Maclaran, 2018, p. 9). Ziggy Stardust, a character derived from the performance persona of David Bowie, represents "a powerful icon of a time, place, ethos and subculture that would never age and is infinitely replicable and symbolically malleable, in ways that the celebrity cannot reproduce" (Lindridge and Eagar, 2015, p. 24). David Beckham, who embraces multiple masculinities, including the romantic and compassionate husband, the hands-on father, the football legend, and the fashionable style icon (Cocker et al., 2015), mirrors a societal shift in positioning himself as a metrosexual human (Parmentier and Fischer, 2012).

Nonetheless, the category of aristocracy in general is still an under-investigated area that calls for deeper investigation, similar to some others. Although Kotler and Levy $(1969$, p.10) already stated that "political contests remind us that candidates are marketed as well as soap," and despite the fact that political marketing is big business, particularly in the United States, and that it attracts sophisticated investigation from scholars (e.g., Butler and Harris, 2009; Hughes and Dann, 2009; Algara, 2019), the personal branding of politicians still lacks empiric consideration (Harris and Rae, 2011; Gershon, 2014). In same vein, the art market offers numerous well-known brands of visual artists, like Dali, Picasso, van Gogh, Rembrandt, or Warhol, all of whom are imbued with celebrity status (Schroeder, 2005; Fillis, 2015).

\subsubsection{Benefits of personal branding}

First and foremost, the branded individual benefits generally from personal branding when competing for work, seeking advancement in specific occupations or professions, or pursuing a career path that leads to higher financial earnings. This fundamental advantage includes other specific aspects, such as lucrative endorsement opportunities for athletes, the self-branded business ventures 
of celebrities, or entry-level placement as well as entry salary premiums in the marketing job market. While these benefits are closely linked to differentiation as a consequence of personal branding and can be traced back to the idea of a new world of work, personal branding is thought to offer some impact to the individual personality as well. Continuous self-reflection throughout the personal branding process may lead to continuous learning and thus enable the branded individuals to improve their abilities and achieve much greater self-awareness, self-esteem, self-confidentiality, and self-worth. Visibility acts as a beneficial consequence of personal branding too, enhancing social capital for the branded individual.

Turning to the target groups of personal branding, human brands as endorsers are a major force driving retail sales when products are associated with them. In the art market in particular, personal branding serves as a means for reducing risks and increasing the willingness to pay a premium price. Beside commercial considerations, psychological aspects are of interest, such as consumer-human brand attachment that may advance identity construction. Celebrities complement or even replace the family system for identity construction of young people. The family system and the family subsystem are interconnected to satisfy the basic human needs of belonging, autonomy and distinctiveness, all of which are essential for identity development (Scabini and Manzi, 2011). The fulfilment of psychological needs, such as autonomy, relatedness, or competence as well as appearance attractiveness seems to be of great importance in the transition from parental attachment to idol attachment for young people especially. Identity includes, but is not limited to gender, race, ethnicity, spirituality, sexuality, and social class (Dillon et al., 2011). The latter has not been at the forefront of the marketing literature on celebrity but is an important part of the appeal of many celebrity brands and, thus, a crucial factor for identity construction at consumer side. For instance, several working-class celebrities based in Britain, such as Kerry Katona, Jade Goody and Wayne Rooney, have labelled themselves 'chav' and have become figures of national misery or disgust. The term 'chav' has been described as the "ubiquitous term of abuse against the white poor" (Tyler, 2008, p. 17), which has been used to mock and deride the appearance, accent, clothing, lifestyle, and culture of working class men and women in Britain (Tyler, 2008). The example of the "celebrity chav" indicates that the social class cannot be understood only from the point of view of economic capital and therefore offers a broad approach for consumer identity construction.

Many scholars suggest the presence of co-branding following from personal branding activities, for example between ordinary employees or CEOs and companies. Furthermore, due to spill-over and meaning transfer, deliberate and unintentional effects may arise between human brands, corporate brands, and product brands. For example, the entire artistic brand, from which consumers 
derive their judgements about the uncertain product quality of the artwork, results from spill-over effects between an artist's human brand and the artist's artwork (Moulard et al., 2014). Some first indications that personal branding impacts society can be found, as e.g., David Bowie's societal and cultural relevance is also obvious "by sanctioning his homosexuality as an important socio-cultural statement and response to Britain's post-industrial decline" (Lindridge and Eagar, 2015, p. 23).

\subsubsection{Antecedents of personal branding}

From today's point of view, the branding of individuals is an old practice that has produced numerous examples in human memory, such as Alexander the Great (Braudy, 1997) and savant Goethe (Bendisch et al., 2013). An analysis of $18^{\text {th }}$ century auction records serves as an additional example and revealed that artists have always been branded as the prices for their artworks was determined by their reputation and status in society (Preece and Kerrigan, 2015). It is obvious that there has been a long history during which celebrity was attained through family relationships or achieved through talent (Rojek, 2012). However, the affair of Elizabeth Taylor and Richard Burton in 1963 has been identified as "an insightful turning point, marking a juncture whereby the public were seen to have become more interested in one particular celebrity's private life than her abilities as an actress" (Mills et al., 2015, p. 5). As such, contemporary personal branding has not just become more mediadriven, complex, and multilayered. However, it finds its most effective antecedents only in the recent past. The joint impact of societal, economic, and technological developments provides three key areas that have given rise to the emergence of ubiquitous personal branding.

First, the development of the new world of work means a transformation from an industrial to an information-based economy, with the spread of neoliberal capitalism and increasing complexity. Massive changes and turbulences were caused by the mass layoffs of the 1970s, followed in the late 20th and early $21^{\text {st }}$ century by"economic globalization, new arenas of competition, and rapidly evolving information technologies" (Lair et al., 2005, p. 311). As a result, powerful social norms and pressures that promised stability in uncertain environments have become unstable. Individuals could no longer depend on employers to be "guarantors of life-long employment and personal economic stability" (Philbrick and Cleveland, 2015 , p. 182). Competition for jobs increased, as careers became unpredictable, not limited to a single job description, and as traditional job applications based on a curriculum vitae became insufficient. "Hiring, as a consequence of these changes, has become a matter of choosing potential employees who signal that they are managing themselves correctly, replete with expandable skills, useful alliances, and appropriate branding strategies" (Gershon, 2014, p. 288). People offering their abilities, skills, and performance are in competition with each other, not dissimilar 
to the competition between products or services for attention in saturated markets. This need for personal responsibility and individual differentiation seems accompanied or exemplified by the emergence of the figure of the entrepreneur. Hearn (2008, p. 201) states that "the overt practices of self-branding [...] have their root in the rise of the networked organization and the entrepreneurial workplace" which is supported by other scholars (e.g., Gandini, 2016). Workers are encouraged to become enterprises in their own right in corporate employment or in a job application process. Thus, personal branding serves as a supportive tool in employment in times of neoliberal precariousness and as a "communicative response to economic uncertainty" (Lair et al., 2005, p. 309).

Second, various forms of media have developed alongside the rise of the idea of visibility as a key currency in life. The explosion of the Web 2.0 and social media offers continuously evolving platforms for an emerging attention economy that self-branding is directly related to. Multiple media outlets enable personal branding for everyone, e.g., by searching on Google, sharing via Facebook, networking on Linkedln, broadcasting on YouTube, or linking via Twitter to access and contribute to the story of the individual self. A key academic contribution that is frequently cited is the investigation of self-presentation in personal web space by Schau and Gilly (2003). They see the link between sociologist Erving Goffman's "presentation of self in everyday life" (Goffman, 1956) with the computer-mediated environment in that "personal Web sites allow consumers to self-present 24/7 beyond a regional setting to the virtual world" (Schau and Gilly, 2003, p. 387), as building a digital self can be taken as par for the course. David Bowie became "the first artist in 1999 to release an album ('The Hours') through the Internet signifying Bowie's human brand innovation" (Lindridge and Eagar, 2015, p. 21). With the development from Web 1.0 to Web 2.0, online personal branding has mutated into an interactive and meaningful presence through the use of chat rooms, blogs, and other kinds of third-party sites. Ubiquity and user-friendliness, free and open access, crumbling technological barriers, and space for individuals are factors inviting self-expression and self-presentation-not least for purposes of personal branding. Broader audiences can be reached, irrespective of time or place, while branding in social media is migrating from being an exclusive business pursuit to allowing individuals to create their own unique virtual spaces. Consequently, cultural values change, with fame and attention gaining significant importance and people mutating into "gossip-hungry consumers" (Mills et al., 2015, p. 1). Thus, "personal branding reflects one logical reaction to the cultural and political economics of Web 2.0" (Gehl, 2011, p. 2).

Third, a new understanding of individualism developed as a countermovement to traditional collectivistic systems. Scholars claim that the symptoms and forms of individualism represent a reflection of the concept of humankind in its respective 
era. Under earlier forms of capitalism, for instance, workers provided their physical and mental capacities to the employer for a limited period of time each day. By contrast, in the era of neoliberalism, the individual now owns and treats herself/ himself as a corporate business aiming to maintain her/his human capital, i.e., her/ his collection of skills, assets, and alliances. The responsibility for self-fulfilment, self-reliance, self-sufficiency, self-actualization, and self-realization as fundamental psychological needs lies exclusively with the individual today, reinforced by the American myth. Realizing the American dream implies accepting a world of change and opportunities in which "you can create and recreate yourself so as to be the master of your own destiny" (Lair et al., 2005, p. 314). This understanding of individualism is located as a difference that began to exist historically only within a broader system from the 1860 s to the $1880 \mathrm{~s}$, in the wake of the Civil War in the US. At that time, people began to understand themselves as individuals individualized by their place within the system (Michaels, 1989). To the same degree of development, trust is eroding in any all-embracing system of determined norms and values, as the quest for identity fails when applying traditional collectivistic interpretations. Therefore, practitioners postulate the process of self-managed self-improvement as the means of choice, and the self-help movement appears as a precursor of personal branding.

Additionally, scholars (e.g., Shepherd, 2005) have identified existential angst as a driver and a major selling proposition for personal branding by consultants and counsellors. The individual has to cope with the inevitability of building her/his human brand, as the otherwise inescapable consequence is "being marginalized or left behind" (Harris and Rae, 2011, p. 14) and going "through a brand divorce" (Lair et al., 2005, p. 329). Fear of losing one's livelihood is attended by the fear of losing human brand ownership, since someone else will manage the human brand if the individual does not do so himself or herself.

Nonetheless, the antecedents of personal branding have to be determined in more detail for different cultures and societies, e.g., comparing the US and Europe or considering traditional collectivistic societies such as Japan.

Derived from the review of the classes of human brands and antecedents of the personal branding movement, celebrities appear as the cradle from which human brands for ordinary people have sprung, due to the opportunities and needs produced by societal, economic, and technological developments. Icons, in turn, represent a select group containing long-lasting and outstanding branded individuals who stand out from the growing number of commoditized celebrities (Figure 2.3). 


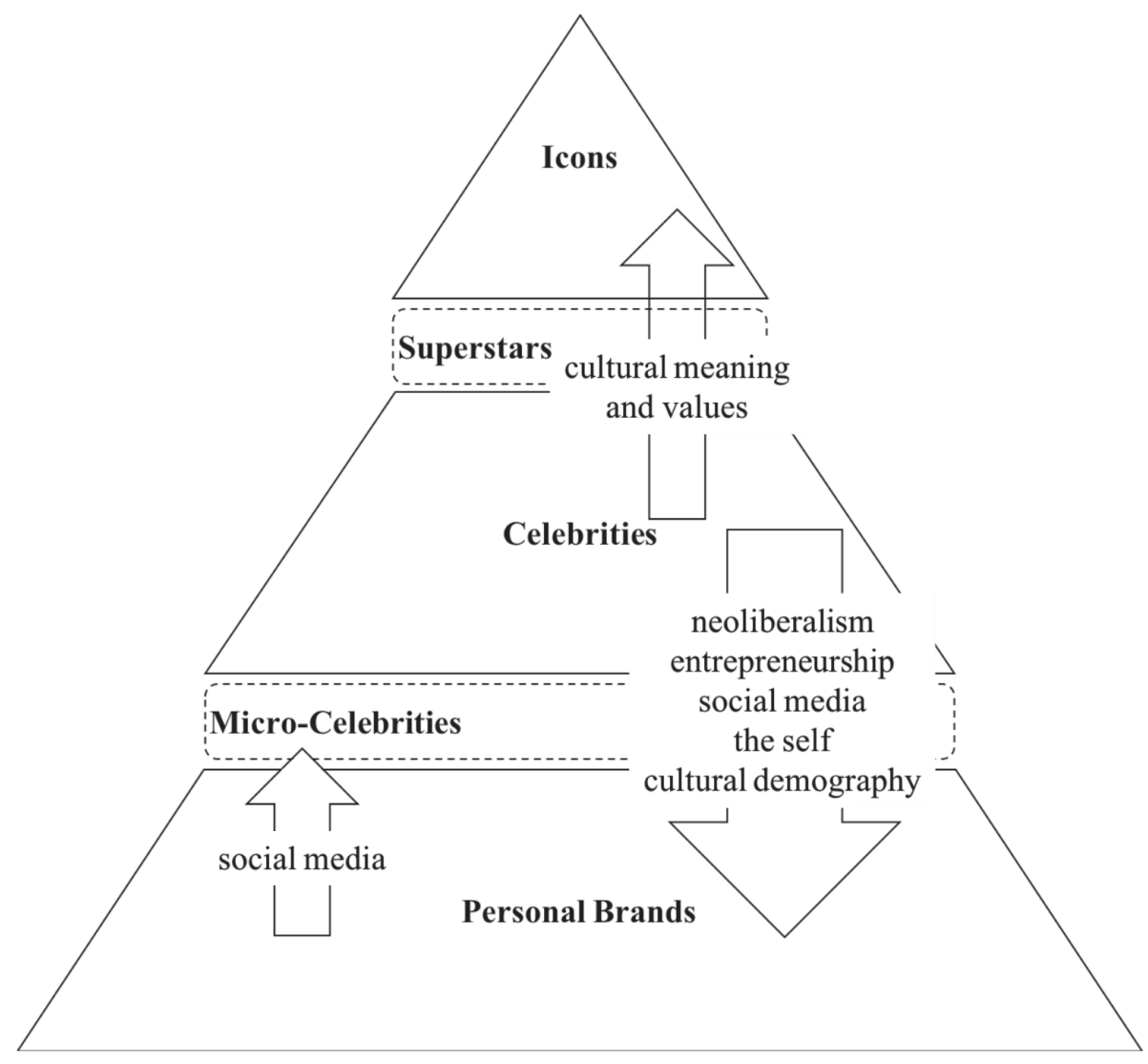

Figure 2.3: Pyramid of different human brand classes and their appearance in the history of personal branding

\subsubsection{Key ingredients and applications}

Beside numerous fragmented findings and concepts and some more general conceptual approaches, many scholars have come to agree on a small number of elements of what human brands may consist of and which fields of application they can be encountered in, partly based on empirical investigation.

\subsubsection{Personality and authenticity}

At a very early stage of the personal branding process, one's personality, i.e., individual strengths and weaknesses, values, skills, expertise, and attributes, needs to be reflected in order to transform it into the human brand personality. Credibility and, in particular, authenticity are two attributes that are understood to represent the crucial ingredients for human brands. Authenticity affects attitudes toward the branded individual positively, which in turn is a critical component used in consumer judgments and decision-making. Consumers demonstrate an increased 
demand for authentic brands. An authentic human brand claims to represents the true self of the branded person and thus delivers a constant promise of value. Clarity as well as rarity, with its subdimensions of talent, discretion, and originality, contribute to authenticity and are closely linked to differentiation as a further key element of personal branding.

\subsubsection{Differentiation}

Most scholars tend to one-sidedly emphasize that the branded individual should differ from everybody else and, as such, neglect the points of parity (e.g., Chen, 2013). In contrast, Parmentier et al. (2013), who explored fashion models, identified points of differentiation to stand out from other competitors in terms of the amount and the quality of their field-specific cultural and social capital as well as points of parity that are visibly fitting in with the expectations of the field in which the human brand is competing. This is confirmed for first faculty positions in marketing as well (Close et al., 2011). Distinction does not necessarily have to have positive connotations. Even negative "bad boy" or "bad girl" images (Carlson and Donavan, 2013), the refusal to comply with societal conventions, or even scandals may lead to differentiation (Mills et al., 2015) and attention.

\subsubsection{Visibility}

Above all, visibility is named as indispensable, following the key expectation "You need to get noticed" (Gander, 2014, p. 101). On the one hand, a physical footprint is expected in the form of writing articles, speaking in public, extending one's network, giving presentations, or producing publications to create an offline self. On the other hand, a digital footprint leads to an online self by way of social media platforms, which obviously now plays a far more prominent role in personal branding. From another perspective, visibility is to be attained in two areas: First, on-field in the original field of practice and profession of the branded individual, aiming for instance for awards and honours conferred by peers in the field, and second, off-field outside of the professional field in the sense of building a mainstream media persona (Parmentier and Fischer, 2012). The interrelations of these different areas as well as constant connectivity with an increasing number of online opportunities suggests a need to bundle individual visibility activities in a transmedia model of storytelling and story-world construction. Stories that build brand meaning have transitioned from being developed by the original brand owner, i.e., storytelling, to being developed by the stakeholders, i.e., storygiving. The integration of different story elements that are dispersed across multiple media platforms in an episodic format and co-creative audience interaction are key characteristics (Elwell, 2014). 


\subsubsection{Narrative Identity}

Contemporary ways of visibility and the digital world in particular call for a new paradigm to conceptualize the dialectic of the digital-analog self-identity. The self is much more actively managed, jointly constructed, interactive, openly disinhibited, confessional, multiply manifest, and influenced by what the branded individual and his or her avatars do online (Belk, 2013). Much of the influence on contemporary self-concepts and people's activities in creating them, is absent when only the self is studied offline in an extended way. It is not an either-or between offline and online identities, but an "as well" because "it becomes impossible to tell where one begins and the other ends as the two are seamlessly integrated. Online and off-line identities are not functionally equivalent to one another such that one is interchangeable for the other. Rather, together they cocreate the experience of identity in the space between the digital and the analog" (Elwell, 2014, p. 235). The transmedia model (Elwell, 2014) serves as a helpful paradigm for understanding the nature of self-identity and self-formation in this new liminal space by offering the conceptual architecture necessary for exploring and articulating its integrated, dispersed, episodic, and interactive narrative character as a key element of the contemporary human brand. Integrated narrative elements, such literal series of episodes in the form of sequential films, books, and games create a continuous and evolving story of the self. In this respect, the psychological perspective contributes valuably to a deeper understanding of personal branding by defining the story a selective reconstruction of the autobiographical past and a narrative anticipation of the imagined future that serves to explain, for the self and others, how the person came to be and where his or her life may be going (McAdams, 2011). Developing one's own human brand implies that the I becomes an author, seeking to fashion the Me into a self-defining story. Consequently, narrative identity is not just an internalized and evolving story of the self that provides a person's life with some semblance of unity, purpose, and meaning. Rather, narrative identity, then, is that feature of human selfhood that begins to emerge when the adolescent or youngadult I assumes the guise of a storyteller.

\subsubsection{Social media}

Social media in particular are assumed to allow human brands to develop stronger bonds with consumers, resulting in "a formation of a social relations exchange" (Chen, 2013, p. 335) and a network of relationships in a general sense, as increased attention is a conditional element for brand attachment. In current digital knowledge industries, self-branding directly contributes to socialized value production through the social construction of a branded persona-a process called "digital work" (Gandini, 2016). In addition, specific consumer-brand relationships are built, for example in sports, where the athlete brand "has a positive influence on the 
extent to which consumers feel an emotional attachment to the athlete" (Carlson and Donavan, 2013, p. 204). Human brands to which people are attached offer potential as endorsers, which has been the primary focus when exploring athletes and celebrities as human brands. While autonomy, relatedness, and competence have been seen to serve as antecedents of the strength of people's attachment to human brands (Thomson, 2006), Loroz and Braig (2015) create an empirically more comprehensive and sophisticated picture of consumer attachments to human brands that emphasizes the dimension of competence.

\subsubsection{Co-brands and stakeholders}

As human brands do not function in isolation, the collaborative process at work in building the human brand is obvious. Brand meaning transfer effects and cocreation are inevitable elements that are generally considered, be it between businesspeople or politicians and their organizations, athletes "fraternizing with figures from the entertainment world" (Parmentier and Fischer, 2012, p. 116), photographers and agencies and fashion models, or between employees and companies. Based on Freeman's (1984) stakeholder theory and the multistakeholder approach (Keller, 2003), stakeholder models of human brand equity are being developed for the art market, for CEO branding, and for professional rock climbers. First studies indicate beneficial as well as damaging co-branding activities in personal branding (e.g., Parmentier and Fischer, 2012) and a potential risk of broken links between human brands and organizational brands (e.g., Speed et al., 2015).

\subsubsection{Brand equity}

After all efforts and investment into creating a human brand, it is crucial to measure whether personal branding activities are successful at all and, if so, to what extent they are. Certainly, the price of artworks, record sales or online downloads of a musician's work, career earnings, or the number of endorsement contracts as well as rankings in the annual Forbes's list of celebrities are measurable quantities, but they do not offer reliable information about the comparative human brand equity of different individuals. Professional equity that is built in the original field of practice and celebrity equity that is earned outside the original field are two main elements of human brand equity for football players (Parmentier and Fischer, 2012). A measurement scale for CEO human brands should contain work standards, style, leadership, personality, values, character, and teamwork (Chen and Chung, 2016) and CEO brand's characteristics and action parameters influence stakeholder's perceptions and behavior and may lead to the creation of added perceived value at reputational and financial level that reflects the actual essence of CEO brand equity (Cottan-Nir, 2019). Nonetheless, a real brand equity measurement in 
practice, considering all human brands as multidimensional constructs and taking into account the multi-stakeholder approach to cocreate the human brands in a collective act, is still sorely lacking.

\subsubsection{Challenges for personal branding}

By contrast to the rational or even enthusiastic contemplation of the consequences of personal branding, scholars (e.g., Lair et al., 2005; Gershon, 2014) are increasingly sensitive toward its dark side as well and have revealed its essential challenges.

"The more personal branding, the better the impact" does not necessarily work as expected either, as too successful a human brand may appear as a threat to colleagues or superiors in a corporate setting, resulting in suspicion and scepticism (Harris and Rae, 2011). Based on the optimal stimulation level (OSL) theory, consumers may switch quickly to other human brands due to their desire for variety. Too frequent encounters with a human brand may also cost stimulatory potential and may result in a perception of boredom (Huang et al., 2015). In same vein, a higher level of visibility increases the probability of getting involved in affairs compared to ordinary people and, especially with regard to online personal branding, professional and career advantages cannot be taken for granted. Inappropriate photos or information posted on a candidate's page, poor communication skills, "bad-mouthing" from former employers or fellow employees, implied links to criminal behavior, or confidential information about past employers are top areas of concern when seeking for job opportunities (Harris and Rae, 2011).

Scholars only sporadically point out the fundamental, gender-specific differences in the context of work and career in their investigations of personal branding. In this respect, the contemporary phenomenon of personal branding and all its advocates face the challenge of developing strategies to address two key issues. First, the common task in personal branding of combining one's own authenticity with the need to take on multiple roles shows significant differences between women and men in the way they cope with it. Women are expected to reach for the top, but also to look feminine, pay attention to their appearance, be there for their children and husbands and routinely take on the role of caretaker at work. Consequently, working women with families run the risk of experiencing even greater tension between work and family if they commit to becoming a human brand (Lair et al., 2005). In the sense of "true-to-self " strategies, women can maintain their authenticity as individuals yet still achieve the desired rewards if they are good enough (Fletcher, 1999; Singh et al., 2002). Really successful, however, are chameleons (usually males) who pick strategies out of a number of role models by trying different approaches, with a greater chance of understanding what worked for them (Singh et al., 2002). Additionally, it is not acceptable and is risky for future career progression to promote a "whole" identity in some 
organizations (Sheppard, 1989). Only a work-focused person receives the ticket for the next round. This limitation raises the question for women with children that energy must be spent on positioning themselves to fit into a model that they still consider "different." Second, women are less likely to self-promote than men (Dobbins et al., 1990; Oakley, 2000; Singh et al., 2002). This gender gap in selfpromotion is reflective of the gender gap in self-evaluations and, in addition, the gender gap in self-evaluations is specific to evaluations of own performance (Exley and Kessler, 2019). Women evaluate their performance less favourably than men, which then is likely to have a continuing impact on their careers. In contrast, men are actively reading the promotion systems in their organization and working to fit the career success model using impression management. Most of the managerial and professional males seem to understand and comply with the rules of the game of acknowledgment, recognition and promotion in a more straightforward and less emotional way compared to their female colleagues. Although many women are aware of the potential of impression management, self-expression and networking, they decide not to use it (Singh et al., 2002).

Authenticity represents a crucial ingredient for human brands as it affects attitudes toward branded individuals positively, which in turn is a critical component used in consumer judgments and decision-making (Mills et al., 2015). The understanding of what authenticity of a human brand means exactly is predominantly twofold. On the one hand, it is understood as the "fit between persona and underlying personality" (Speed et al., 2015) and to act "according to his/ her true self" (Moulard et al., 2015). In this way, authenticity is thought to be derived from intrinsic motivation as opposed to extrinsic motivation, with commercially driven interests which implies that commercialization must not be part of intrinsic motivation. Against this background, Paris Hilton, for example, is perceived as hardly authentic, but she is without doubt a celebrity brand (Moulard et al., 2015). Is authenticity then indeed indispensable in personal branding? On the other hand, the focus lies on being "unconventional and [...] seen to be going against the mainstream" (Lunardo et al., 2015). Here, clarity as well as rarity contribute to authenticity and are closely linked to differentiation as a further key element of personal branding. However, distinction does not necessarily have to have positive connotations. Even negative "bad boy" or "bad girl" images (Carlson and Donavan, 2013), the refusal to comply with society's conventions, or even scandals may lead to differentiation. How to separate then between "good authenticity" and "bad authenticity," and how far does a human brand benefit from it?

Obviously, a dilemma for personal branding arises from its tendency to demand both maintaining the true self, i.e., authenticity, and responding to different target groups, even more when it comes to creating a digital footprint that implies multiple online identities. In branding the self, people often have trouble 
crafting their individual web presence across various platforms when fashioning a coherent branded self (Gershon, 2014). Social psychologist Gergen (1991) and other postmodernists have argued that multiple selves are an adaptive response to a world of multiple demands. The multiplicity of roles is ascribed to represent a major psychological challenge today as people are expected to enact different identities to fit in different contexts (Leary and Tangney, 2012), which is in line with scholars' perspective on personal branding, especially considering human brands' presence on social media:"They struggle to seem like a coherent self across multiple platforms, despite the complexities of audiences for the different interfaces they use" (Gershon, 2014, p. 29). In fact, scholars indicate successful examples of human brands consisting of different roles offline as well as online, such as David Beckham and David Bowie. Beckham's human brand, for example, encompasses several masculinities, including the romantic and compassionate husband, the hands-on father, the football legend and the fashion icon. He has become what his fans wish to see in him, which suggests that an important component of his popularity and success derives from these multiple identities (Cashmore and Parker, 2003; Vincent et al., 2009; Cocker et al., 2015). The human brand of late celebrity David Bowie consisted of three components, i.e., the real person (David Jones), the performance persona (David Bowie) and the characters derived from this persona, such as Ziggy Stardust (Lindridge and Eagar, 2015). Despite a few successful examples in the celebrity sector, there remains the question of the effects when having multiple discrepant identities for the infinite number of human brands. Psychologists found that, despite their buffering effects in stressful events (Linville, 1987), a greater variability across identities was associated with lower well-being (Donahue et al., 1993), a lack of coherence and integrity (Ryan et al., 2005), and inauthenticity (Sheldon et al., 1997). Self-determination theory could serve as a helpful framework as "under conditions in which the identities offered individuals are both supported by significant others and allow fulfilment of the psychological needs for relatedness, competence, and autonomy, a healthy integration of the individual is possible" (Leary and Tangney, 2012, p. 242).

Despite the creation of few personal branding frameworks, partly based on empirical studies (e.g., Preece and Kerrigan, 2015) and partly as a result of conceptual work (e.g., Bendisch et al., 2013), a comprehensive personal branding framework or even theory has not yet been developed in the academic field. Even in a well-defined field such as commercial sports, a general model for personal branding is not effective, as "wrestlers or boxers might be seen as rude athletes, while golfers might be seen as sophisticated ones" (Lunardo et al., 2015, p. 706). Nonetheless, the empirically based artistic brand model constructed as a diffusion process over time (Preece and Kerrigan, 2015) may serve as an inspiring example. Broken down to the individual level, an infinite number of different human brands 
is possible, with each having its own human complexity. In addition, the more people have acquired a status symbol as a human brand, the less distinctive it is and the less status it confers on its holders. Simply said, "even if it were possible that we could all be famous, if everyone were famous, then no one would be famous" (Holmes and Redmond, 2006, p. 14).

As personal branding represents the logical extension of previous forms of branding, such as product brands, service brands, corporate brands, or retail brands, it would seem natural to call for an application of traditional branding practices in equal measure to the younger field of personal branding. As a matter of fact, this transfer has few clear advocates (e.g., Close et al., 2011; Ternès et al., 2014) or critics (e.g., Russell and Schau, 2010; Preece and Kerrigan, 2015), but it promises constructive approaches (e.g., Parmentier and Fischer, 2012; Preece and Kerrigan, 2015) that very selectively adapt proven branding practices. So far, no one attribute from traditional branding can be identified that has explicitly been rejected from personal branding. Others, such as the brand personality (Aaker, 1997), competition which implies points of differentiation as well as points of parity (Keller et al., 2002), brand visibility (Keller, 2013), brand relationships (Fournier, 1998), or brand meaning transfer (McCracken, 1989) as well as brand co-creation (Prahalad and Ramaswamy, 2000) have already been adapted to the context of personal branding as discussed earlier, defining them as single key ingredients. Nonetheless, personal branding is not investigated as an entire process to clarify how it emerges and even though a "great brand is not built by accident" (Keller, 2013, p. 125), it remains unclear how aware people really are about their own human brand and their brand building process. Furthermore, target groups and categories represent two indispensable dimensions in traditional branding (Keller, 2013). However, abstract terms such as "customer" (Gehl, 2011), "consumer" (Carlson and Donavan, 2013), and "audience" (Mills et al., 2015) are widely applied in personal branding but it remains nebulous as to who is meant by this. Similarly, the term "target market" serves as an undefined focus for numerous activities in human brand positioning (Shepherd, 2005), except for the art market (Schroeder, 2005), the music market (Lindridge and Eagar, 2015) and the job market (Zamudio et al., 2013). Finally, the dimension of time suggests that "if there is one rule for modern branding, however, it is that brands can never stand still" (Keller, 2013, p. 479). One should understand that "achieving and maintaining your personal brand is a journey, not a destination" (Trepanier and Gooch, 2014, p. 57). Human brands are not static and face continuous change during their lifetimes. Athletes may experience unexpected injuries or performance slumps (Arai et al., 2014), models have biological limits affecting their ability to keep their physical appearance (Parmentier et al., 2013), transgressions can damage human brands (Moulard et al., 2015) and, finally, every branded individual will pass away (Fillis, 2015). There 
are first insights into viable means to extend the life expectancy of a human brand, as can be seen in David Beckham maintaining human brand equity even after his active career in football had ended (Parmentier and Fischer, 2012). Similarly, the artistic brand model has been considered in terms of a diffusion process over time (Preece and Kerrigan, 2015). However, the research domains of traditional branding (Kapferer, 2012; Keller, 2013) as well as personal branding (Philbrick and Cleveland, 2015) show clear agreement about brands having to be managed over time. But, in contrast to traditional branding again, the issue of longevity faces a lack of clarity too in the sense of how to handle it in personal branding.

\subsection{CONCLUSIONS}

Fundamentally, personal branding has long outgrown its original academic role as another instance of "broadening the concept of marketing" (Kotler and Levy, 1969). Instead, it is worth appreciating personal branding as a distinct and interdisciplinary expression of branding and not just as a simple variation thereof. However, before giving a positive answer to the key question of whether science can "reclaim selfmarketing and personal branding from the enthusiasts" (Shepherd, 2005, p. 12), further academic efforts are needed. Beside empirical studies, different formats such as review papers (Gorbatov et al., 2018) not only offer valuable contributions in this regard, but they also serve as a means to incite the required sophisticated debate on the contemporary phenomenon of human brands and their emergence.

Universally valid personal branding frameworks or even theories cannot be identified yet, and those that have been put forward do not show great promise due to their fragmented nature. Therefore, this review suggests updated definitions to better structure the fragmented approaches toward the process of personal branding and to the human brand as a thing, as proposed above. Celebrities serve as the cradle of the personal branding movement as well as for all kind of human brands (Figure 2.3). Apart from the "celebrity," two additional classes of human brands, i.e., the "icon" and the "personal brand," as well as two intermediate classes, i.e., the "superstar" between celebrities and icons and the "micro-celebrity" between celebrities and personal brands, complement the aspect of classes.

Nonetheless, personal branding happens in many and diverse shapes and forms and takes place in a distinctly complex setting, so a precise and readily transferable recipe for personal branding that is applicable to every walk of life has to remain wishful thinking. Any search for the one universal personal branding theory would seem doomed from the outset. In addition, since proposing a model implies pragmatism, structure, and universality, personal branding faces a paradox in that a generalizable branding model has to be applied to something that is completely 
unique, namely human beings. Therefore, more empirical evidence, exploration, and conceptual development are sorely needed, as they may result in class and category-specific definitions as well as models. In particular, the icon as a human brand class, celebrity academics, or the aristocracy call for deeper investigation, while social media influencers, e.g., Bhad Bhabie, as the new type of endorsers and "celefictions" (Nayar, 2009; Kerrigan et al., 2011), such as Harry Potter, Lara Croft or Dr Z, must not be neglected.

Gender differences in personal branding, whether in the branded individual itself or on the consumer side, have so far only been examined sporadically and rather one-sidedly with regard to the effect of human brands' gendering in social media (e.g., Duffy and Pruchniewska, 2017; Draper and McDonnell, 2018). But the open questions are far more fundamental and very diverse, for example with regard to the world of work. What explains the existence of the gender gap in selfevaluations which affects the gender gap in self-promotion? How can the gender gap in self-evaluations be mitigated? how does the potential for gender-specific backlash influence self-evaluations and how employers view self-evaluations? (Exley and Kessler, 2019). Future research should also consider the gender-oriented role of personal branding in private life. Sexual selection theory, for instance, can help to understand how people act in an effort to attract another person (Schmitt and Buss, 1996) and psychological mechanisms, to suggest further possibilities, appear to underlie between-sex differences in what people prefer in mates (Buss, 1989) and how they attract mates (Buss, 1988).

Especially since, looking beyond the snapshot, the sustainability of human brands still suffers from a lack of attention, research questions such as "How do top managers' human brands emerge over time?" demand an answer based on empirical studies. From an academic vantage point, this more comprehensive understanding of personal branding also needs to expand from the synchronic to the diachronic level, that is, the human brand's fate over time in the sense of developing a lifecycle approach and identifying ways to ensure the longevity of a brand. The same applies as well to further branding attributes promising useful applicability to personal branding such as target groups, competition, visibility, or human brand authenticity or, finally, human brand equity measurement.

As human brands cannot function in isolation, brand leveraging processes between human brands and their organizational environment and stakeholders need to be investigated further. How do human brands develop an interactive, individualized, yet communal brand experience at all brand touch points for all stakeholders, considering that not all stakeholders are actively involved?

All in all, it is obvious that personal branding is an interdisciplinary domain where research into branding-oriented explanatory and development approaches is given considerable, if not too much, emphasis. Although some scholars already 
refer to psychological models and theories in their research, we advocate for much more attention to be paid to the components "personal" and "human" in personal branding and human brand. The concept of narrative identity, for instance, plays a major role today in the multi-layer personality theory developed by McAdams and Pals (2006) which corresponds to today's "flexible personality" the modalities of selfhood have shifted to from a preoccupation with "character" in the19th century to "personality" in the 20th (Hearn, 2008). Additionally, the concept of narrative identity serves as a framework to understand how human beings make narrative sense out of their own lives, how they develop the stories that come to comprise their very identities, how those stories change over time, and how those stories function-psychologically, socially, morally, culturally-as the storyteller journeys across the long course of adult life (McAdams, 2011). In turn, personal brands have so far been presented primarily as a static construct, which must be overcome in the future through a life-span approach. The method of process research, which has proven itself in organizational research, is just as obvious in its application as models and concepts from psychology. Erikson's (1980) model of identity development, for instance, provides different life stages each with its own central identity tasks that can contribute to the emergence of a human brand over time. Especially for the further challenges that personal branding faces, applied psychology offers numerous options for a deeper exploration of this contemporary phenomenon. A review from a psychological perspective, for instance, examining the literature on the context in which the concept of self-branding developed, the experience of presenting self-brands to a public audience, and the psychological construction of authenticity within the self-branding discourse, would certainly contribute significantly to the state of knowledge on personal branding.

This review provides an overview of the contemporary phenomenon of personal branding from the angle of academic publications. As it certainly cannot avoid certain shortcomings, a deeper and even more systematic literature research is recommended, which, for example, implies specific inclusion as well as exclusion criteria (Ramírez et al., 2017), such as the classification of journals or a more recent timeslot for the articles' publication.

In the end, personal branding remains a field deserving to be scholarly explored and an academic impulse for rethinking branding, as it may sensitize scholars in applied psychology to the concept of more collaboration with practitioners and with other academic domains, e.g., culture theory, management education, organizational studies, or vocational behavior, in the interest of knowledge dissemination and mutual enrichment. 


\section{HOW TOP MANAGERS BUILD THEIR PERSONAL BRAND: STRATEGIZING AND OVERCOMING DUALITIES ALONG THE CAREER PATH}

In order to investigate what top managers do to develop their own personal brand over time and how they do it, a multi-method approach has been developed, building on various best practices in an empirical context. Using process research and the narratives of six top managers, three key practices are identified, each involving a set of specific and dual activities. This chapter further highlights how these key practices change in their application and impact across different career stages, but also how dualities in personal branding activities require strategic choices in order to overcome the tensions arising from these dualities.

\section{Publication history}

This chapter, written with Prof. Dr. Jörg Henseler and Dr. Raymond Loohuis, has been submitted initially to Organization Science but has been removed during the review process following the reviewers' suggestions. In consideration of the reviewers' feedback, this chapter will be revised to make it suitable for submission to a journal with an even stronger focus on management, probably the Journal of Management Studies, or on work and career, probably the Journal of Professions and Organizations.

\section{References to previous publications}

None

\section{Keywords}

Managerial practice, Managerial work, Top manager, Career, Dualities, Personal branding, Process research 


\section{ABSTRACT}

While top managers are becoming increasingly visible, their managerial work and practices are now attributed to numerous themes. Personal branding is one of them and considered an indispensable catalyst for careers. Despite the importance of personal branding, there is still very little empirical evidence in the academic literature on how top managers' personal brands actually emerge and what they themselves do to shape these brands. This paper opens the black box of personal brand development by deploying a process and practice perspective and argues that personal branding is a distinct key practice underlying managerial work for managers at all levels, from beginner to top manager. Evidence was collected by studying the cases of six German top managers' career trajectories - two women and four men. Using multiple strategies to analyse process data within and across cases, we identified three distinct key practices describing how these top managers managed the development of their personal brands across the four phases of their careers. A central theme of personal brand development is managing dualities in all phases of career development and overcoming the tensions accompanying these dualities. We highlight the practical implications for today's managers as well as add to the literature on personal branding by posing personal branding as a practice in itself.

\subsection{INTRODUCTION}

Understanding what managers actually do has inspired practitioners, experts, researchers, and academics alike for several decades (Kurke and Aldrich, 1983; Willmott, 1987; Tsoukas, 1994; Chia and Holt, 2006). For today's managers, developing their personal brand is inevitably part of their scope of work. A glance at celebrity CEOs suffices to show that these individuals embody a brand that likely creates value beyond their individual traits. This may apply to founder CEOs such as Oprah Winfrey (Loroz and Braig, 2015), Martha Stewart (Murphy, 2010), and Bill Gates as well as to agent CEOs exemplified by Carly Fiorina at Hewlett-Packard (Johnson, 2008) and the late Jack Welch at General Electric (Abetti, 2006). But what about the ordinary top manager, especially as careers have changed over the last two decades (Crossland et al., 2014)? Radical changes in the economic environment such as globalization and corporate restructuring, combined with changing personal aspirations as in the work-life balance, have had a major impact on how people experience and shape their career (Koch et al., 2017). Given its impact and ability to advance careers, personal branding has gained increasing attention in the corporate and public world. It appears worthwhile to explore how top managers' 
personal brands develop during their careers. So far, research on personal branding has been concentrated on the antecedents (e.g., Hearn, 2008), the key variables (e.g., Moulard et al., 2015), and the positive outcomes of personal brands in terms of career opportunities for managers (e.g., van Oort, 2015). These contributions show that personal branding has emerged as a branch in management sciences that deserves to be researched.

In this paper we take up the perspective by examining what top managers actually do to develop a personal brand across career phases. Similar to the idea of practitioners doing 'strategy' (Whittington, 2006) and by bringing contemporary notions of practice to the study of managerial work (Korica et al., 2017), we examine what exactly managers do in terms of activities to develop their personal brand over time through managerial work. From this perspective, we perceive a personal brand not as a static phenomenon made up of variables, but as something that "can never stand still" (Keller, 2013, p. 479) as it continuously evolves over time (Lindridge and Eagar, 2015; Preece and Kerrigan, 2015). Consequently, our research question is:

What do top managers do to develop their own personal brand over time and how do they do it?

In our study, we emphasize top managers as 'actors' and their actual activity 'in practice' (De Certeau, 1984) as a central part of our study. This practice-oriented approach is complemented by existing knowledge on personal brands to make sense of the managerial work underlying personal brand development given that a general theory simply does not exist. Empirically, we draw on a cross-case analysis of six successful, highly experienced, German top managers working in various industries ranging from the field of advertising to utilities. We extensively interviewed them between May 2018 and May 2019 followed by a systematic analysis of the activities conducted by these top managers to develop their own personal brand over time across defined career stages. We particularly looked at the challenges they faced in the development of their personal brand, usually in the form of controversies or dualities which pose a paradox (Smith and Lewis, 2011; Farjoun, 2010). To make sense of the data emerging from the interviews, we used an alternate template, visual mapping, and temporal bracketing as commonly recommended strategies to analyse process data (Langley, 1999; Gehman et al., 2013; Langley et al., 2013).

This paper is one of the first to deliver an integrated understanding of personal branding posed as a distinctive managerial practice. In cross-case examinations, we found that top managers' personal brand development is a complex process that contains three interdependent and sometimes overlapping key practices, 
i.e., 'managing position,' 'managing individuals,' and 'managing visibility.' Although these practices are consistent in themselves, the impact of each one for the development of a personal brand varies across four career phases, i.e., 'beginner,' 'professional,''manager,' and 'top manager.'The activities within these key practices, in turn, invariably pose dualities that present different challenges and outcomes shaping the course of the personal branding process.

With these findings, we contribute to the literature on personal branding by opening the black box of personal branding as a process that requires deliberate efforts by top managers, rather than a static concept useful for career development. We demonstrate how top managers and aspiring top managers can advance their careers by carefully building their personal brand over time. Finally, we contribute to the strategy as practice community by pointing out that actors, such as top managers, benefit from their personal brand as a tool for strategy development in corporations.

The paper continues as follows. We first give an overview of the relevant literature on managerial work and practices on the one hand and the key factors of personal brands on the other. We also expand the traditional view of personal brands to include a practice-theoretical position using strategy-as-practice (SAP) as an inspirational guide. In the next section, we highlight the methodology used in the research, and briefly present data collection as well as data analysis containing cross-case analysis and cross-practice analysis. The findings section summarizes the results of our research, emphasizing the key practices along different career phases and their interrelations. Finally, we discuss the theoretical and practical implications of our study and use the conclusions and limitations to derive avenues for further research in the field of personal branding as a managerial practice.

\subsection{THEORETICAL BACKGROUND}

\subsubsection{Managerial work and managerial practices}

Research into management and managerial work is increasingly concerned with managerial practices, in areas such as leadership (Cho and Poister, 2014), technology (Dougherty, 2004), knowledge management (Inkinen, 2016), accounting (Ahrens and Chapman, 2007), and marketing (Allen, 2002). For decades, the managerial practices underlying strategy-making have probably received the most attention. Starting with Mintzberg (1978) and Mintzberg and Waters (1985), it has been made clear that strategies can emerge as a result of spontaneous managerial actions as "a pattern in a stream of actions" rather than planned in a vacuum. This was certainly addressed in the seminal work of Henry Mintzberg's The Nature of Managerial Work (1973). He contributed to a broader understanding of managerial work by developing 
ten roles of managers, which he divided into three categories, i.e., interpersonal roles, informational roles, and decisional roles. Although these roles are intended to provide a descriptive theory of what managers do, critical examination reveals limitations concerning the 'how' and 'why' of managerial work. Closer examination of the inner workings of strategy processes from a practice-based approach led to research questions that seem to fundamentally guide the study of managerial work and practices, such as "Where and how is the work of strategizing and organizing actually done?" and "Who does this strategizing and organizing work, and with what skills and tools?" (Samra-Fredericks, 2003; Whittington, 2003; Jarzabkowski, 2004). According to Whittington, who describes 'strategy-as-practice' as being concerned with how managers actually "do strategy" (Whittington, 1996, p.732), we suggest that any managerial work - like personal brand development - must be understood from a practice point of view. The integrative framework of strategy practice, with its three concepts of praxis, practices, and practitioners (Whittington, 2006), provides a coherent approach to practice-oriented studies. While 'praxis' is concerned with actual activity, with what people do in practice, 'practices' refer to shared routines of behavior, including traditions, norms, and procedures for thinking and acting (Reckwitz, 2002). Practitioners, in turn, are the actors who both carry out this activity and bear its practices. They depend on their practical skills in what they do and may become creative agents: they are potentially reflexive enough and their social systems open and plural enough to liberate their activity from the thoughtless reproduction of initial conditions (Giddens, 1984, 1991; Whittington, 2006). From an interest in situational actors, the focus lies on the actual activity of people "in practice," and the challenge is to capture the "practical sense" with which life is actually lived in the moment (Bourdieu, 1990). In their practice, actors can both change and replicate an existing body of practices to which they have recourse.

Building on this practice, praxis, practitioner scheme, the analysis of management practices for personal branding is more of a necessity than ever before as managers today act in an era of high visibility and are expected to take unprecedented personal responsibility for their own professional destiny in a corporate world. Empirical consideration of managerial practices focuses on their impact on organizations and people, e.g., organizational effectiveness, employee improvement, and organizational performance, thereby providing valuable insights. However, little attention is paid to managers' development of their own brand as a managerial work practice in itself by considering management practices, i.e., what managers do, how they do it, and why. What we do know is that the literature on personal branding has highlighted its key factors. Before we conceptualize the how's and why's of personal brand development as a part of everyday managerial work, we first discuss the key factors to get acquainted with the scope of personal branding. 


\subsubsection{Key factors of personal brands}

The topic of personal branding has received increased academic attention over the past decade (Gorbatov et al., 2018; Scheidt et al., 2020), which has resulted in scholars increasingly contributing to our understanding of the personal branding of individuals. In doing so, they have focused primarily on antecedents (Lair et al., 2005; Hearn, 2008), key ingredients (Parmentier and Fischer, 2012; Elwell, 2014), and benefits (Harris and Rae, 2011). While forming the basis for this ambition by identifying key factors of what constitutes a personal brand, it is important to understand how personal brands come into existence over time and what appears to be critical in this endeavour, even more so with regard to the personal branding of managers and the emerging personal brand of top managers.

A widely recognized motivation to position oneself as a personal brand lies in gathering advantages in business (Rampersad, 2008; Moulard et al., 2015) or in specific occupations or professions (Gall, 2010; Close et al., 2011). Benefits from personal branding activities in careers in general (Labrecque et al., 2011; Gorbatov et al., 2019) are expected to apply to managers as well, as they are on a career path that they can further shape and continue through their own managerial practices. In turn, the risk of being marginalized or left behind should people fail to brand themselves (Shepherd, 2005; Harris and Rae, 2011) can pose an existential threat to the continuation of the manager's career or the top manager's raison d'être.

The target group (Parmentier et al., 2013; Philbrick and Cleveland, 2015) represents a frequently mentioned factor, such as auction houses and artwork buyers as well as museums and their visitors as members of the audience of an artist's brand (Preece and Kerrigan, 2015). While employers as well as colleagues are targeted in the case of personal branding efforts in the labour market in general (Schau and Gilly, 2003; Parmentier and Fischer, 2012), a multi-stakeholder approach to CEO brands (Bendisch et al., 2013) provides an extended list that includes media, agencies, customers, employees, analysts, investors, and advisory boards, to name just a few.

These different stakeholders, not merely consumers, need to be addressed by a personal brand in order to have real and comprehensive value (Keller, 2003; Roper and Davies, 2007). Different stakeholders have different points of contact with the personal brand as well as different expectations, needs, and interests (Freeman, 1984; Wolfe and Putler, 2002). This calls for a selective managerial practice that is consciously geared to the individual stakeholder in order to build up the personal brand towards the position of top manager. An investigation of artists' brands (Preece and Kerrigan, 2015) provides valuable insights into stakeholder management, considering key figures for starting to build the brand, external influences on the brand narrative, the changing of stakeholders over time, and the collective act of brand building, with producers, consumers, and other stakeholders collectively developing, maintaining, and changing the brand identity. 
Considering endorsement effects between stakeholders and personal brands in general (Halonen-Knight and Hurmerinta, 2010; Bergkvist and Zhou, 2016; Bergkvist et al., 2016) and CEO brands in particular (Bendisch et al., 2013; Scheidt et al., 2018) is necessary to enable collective branding and distributed ownership of a personal brand and goes beyond simple producer-consumer relationships (De Chernatony, 1999; Preece and Kerrigan, 2015).

Similar to the question of target groups and stakeholders, there is a definite gap in our understanding of the specific target market as the category in which a personal brand competes. The art market (Schroeder, 2005; Fillis, 2015; Preece and Kerrigan, 2015), the music market (Lindridge and Eagar, 2015), and the job market (Close et al., 2011; Parmentier and Fischer, 2012; Zamudio et al., 2013) seem to appear clearer, but also rather abstract in the end. The category in which the personal brand of managers acts and competes also remains undefined. Is it the internal company field, the industry in which one's company is located, the yellow press that gives publicly known people a stage, a completely different category, or is it even several at the same time?

In order to set a personal brand apart from competitors in the respective target market, differentiation is an entirely accepted factor (Shepherd, 2005; Labrecque et al., 2011; Gander, 2014), for example through skills, values, or competencies. This is all the more true for managers as they progress up the career ladder while, at the same time, the number of highly sought-after jobs continually decreases. Parmentier et al. (2013) explored the job category of fashion models and identified points of differentiation to "stand out from other competitors in terms of the amount and the quality of their field-specific cultural and social capital" (Parmentier et al., 2013, p. 375) as well as points of parity that are "visibly fitting in with the expectations of the field" (Parmentier et al., 2013, p. 375) in which the personal brand is competing. Accordingly, the balancing of differentiation and conformance is supposed to be a managerial practice.

Probably the most frequently mentioned key factor of personal brands is visibility (Shepherd, 2005; Gander, 2014; Philbrick and Cleveland, 2015; Preece and Kerrigan, 2015), caused by the advent of mass communication (Kotler and Levy, 1969), cable television (Lair et al., 2005), and the explosion of the Web 2.0 and social media (Gehl, 2011; Fillis, 2015). In a society where fame and attention have significant cultural value and entrepreneurs such as Richard Branson, Jeff Bezos, or Elon Musk mutate into pop stars, media coverage turns into a key currency that can enhance or destroy personal brands (Hearn, 2008; Bendisch et al., 2013). Visibility is to be attained in two areas: First, on-field in the original field of practice and profession of the branded manager aiming for instance at awards and honours conferred by those in the field; and, second, off-field outside the professional field in the sense of building a mainstream media persona (Parmentier and Fischer, 2012). What 
managerial practices are required to enable this visibility of the personal brand has so far remained underexamined.

Table 3.1: Potential key factors of personal branding and corresponding authors

\begin{tabular}{|c|c|c|}
\hline Factors & Key content & Sources in personal branding literature \\
\hline Motivation & $\begin{array}{l}\text { The reasons and purposes for } \\
\text { building the personal brand; } \\
\text { level of intentionality in brand } \\
\text { building }\end{array}$ & $\begin{array}{l}\text { Harris and Rae, 2011; Hearn, 2008; Labrecque } \\
\text { et al., 2011; Lair et al., 2005; Moulard et al., 2015; } \\
\text { Rampersad, 2008; Shepherd, 2005; Thomas, } 2011\end{array}$ \\
\hline Target group & $\begin{array}{l}\text { People the personal branding } \\
\text { activities are designed to reach } \\
\text { in a positive way }\end{array}$ & $\begin{array}{l}\text { Gall, 2010; Gershon, 2014; Huang and Phau, 2015; } \\
\text { Lair et al., 2005; Philbrick and Cleveland, 2015; } \\
\text { Schau and Gilly, } 2003\end{array}$ \\
\hline Category & $\begin{array}{l}\text { The market or industry in } \\
\text { which the personal brand is } \\
\text { competing }\end{array}$ & $\begin{array}{l}\text { Close et al., 2011; Fillis, 2015; Lair et al., 2005; } \\
\text { Lindridge and Eagar, 2015; Parmentier and } \\
\text { Fischer, 2012; Preece and Kerrigan, 2015; } \\
\text { Schroeder, 2005; Zamudio et al., } 2013 \\
\end{array}$ \\
\hline Competition & $\begin{array}{l}\text { Points of differentiation } \\
\text { to stand out from other } \\
\text { competitors }\end{array}$ & $\begin{array}{l}\text { Fillis, 2015; Parmentier et al., 2013; Preece and } \\
\text { Kerrigan 2015; Schroeder, } 2005\end{array}$ \\
\hline Visibility & $\begin{array}{l}\text { Observable attention in the } \\
\text { professional field and beyond, } \\
\text { supported by the narrative of } \\
\text { the personal brand }\end{array}$ & $\begin{array}{l}\text { Fillis, 2015; Gehl, 2011; Lair et al., 2005; Lindridge } \\
\text { and Eagar, 2015; Parmentier and Fischer, 2012; } \\
\text { Preece and Kerrigan, } 2015\end{array}$ \\
\hline Stakeholder & \begin{tabular}{|l|} 
Incorporation of different \\
entities and individuals into the \\
personal branding process
\end{tabular} & $\begin{array}{l}\text { Bendisch et al., 2013; Gurrieri, 2012; Labrecque et } \\
\text { al., 2011; Preece and Kerrigan, 2015; Thomas, } 2011\end{array}$ \\
\hline Endorsement & $\begin{array}{l}\text { A synergistic brand alliance } \\
\text { between a personal brand and } \\
\text { another brand for promotion } \\
\text { purposes }\end{array}$ & $\begin{array}{l}\text { Bergkvist et al., 2016; Bergkvist and Zhou, 2016; } \\
\text { Halonen-Knight and Hurmerinta, 2010; Scheidt } \\
\text { et al., } 2018\end{array}$ \\
\hline Longevity & $\begin{array}{l}\text { Managing the personal brand } \\
\text { over time }\end{array}$ & $\begin{array}{l}\text { Arai et al., 2014; Lindridge and Eagar, 2015; } \\
\text { Lunardo et al., 2015; Moulard et al., 2015; } \\
\text { Parmentier et al., 2013; Philbrick and Cleveland, } \\
\text { 2015; Preece and Kerrigan, 2015; Trepanier and } \\
\text { Gooch, } 2014\end{array}$ \\
\hline
\end{tabular}

Beyond the potential key factors discussed above (Table 3.1), scholars are in clear agreement about the fact that personal brands have to be managed over time (Gander, 2014; Lunardo et al., 2015; Philbrick and Cleveland, 2015) for specific reasons. Branded athletes, for instance, face the potential risk of unexpected injuries or performance slumps (Arai et al., 2014) or the deterioration of their physical ability with age (Hoeymans et al., 1997). Thus, their appeal decreases steadily over time (Lunardo et al., 2015). Similarly, fashion models have physical limits for adapting their appearance as time passes (Parmentier et al., 2013), and managers change jobs, employers, or even industries during their career. Brand extension has been named as a constructive response to this, indicating a possible managerial practice. David Beckham's move into new categories, for instance, ranges from the field of sports, as club owner in US American Major League soccer, to other realms, becoming a mainstream media person and developing his own line of fashion apparel (Vincent 
et al., 2009; Parmentier and Fischer, 2012). Obviously, the issue of longevity is of great importance for personal brands to "maintain momentum" (Dutta, 2010, p. 5) as they mature and adapt to changing circumstances (Parmentier, 2010), but still needs to be explored in more detail (Preece and Kerrigan, 2015).

In general, it becomes obvious that, on the one hand, personal brands do not just happen, their emergence is based on practices. On the other hand, despite the knowledge about the key factors of personal brands (see Table 3.1), the literature has not addressed how these factors are incorporated into the day-today managerial work of top managers.

\subsubsection{Personal branding as a practice in itself}

Personal branding represents something that managers and top managers definitely are supposed to apply to themselves (Bendisch et al., 2013; Schlosser et al., 2017). However, it is not yet seen as a managerial practice in itself. To achieve this, we need to introduce a radical shift in the current way of thinking about how personal brands are constructed in general and the path that personal branding takes in this process. In line with Whittington's (2006) integrative framework for strategy practice, we apply its three core elements, i.e., practitioners, praxis, practices, to personal branding as a managerial practice. In our study, practitioners are the top managers who do the work of making, shaping, and executing their personal brands. Praxis encompasses all the various activities on the part of top managers that are necessary for the development of personal brands and their application. Finally, the domain of practices is the set of different key personal branding practices that top managers typically draw on in their activities. This recognition of personal branding as a managerial practice from the angle of practice theory opens up perspectives in three distinct but ultimately interrelated directions that are pursued in our study. First, we are asked to identify the single activities that the individual manager engages in against the background, content, and impact of those activities. Personal branding here represents a type of work that the individual manager undertakes from a specific and situational context. Second, we are confronted with the fact that activities that influence, enable, or even inhibit the personal brand development may be repeated, changed, or have ceased to occur over the course of a career. In this case, personal branding is a process over time and the personal brand merely the result of managerial activities at a particular point in time. Third, we expect that managerial activities in the creation of top managers' personal brands do not act independently, but rather exhibit various causalities, ranging from reinforcements and mitigations to interdependencies. Personal branding development may appear as a complex construct of key practices, their interrelationships and crossovers, which contributes to the fact that personal branding is an entire contemporary phenomenon that influences business and society. 
To make such claims, this paper explores personal branding as composed of managerial practices and activities across various career phases. We explore how top managers attribute the key factors discussed here in the development of their personal brand. In fact, we consider that these attributes pose potential dualities for managers in the development of their personal brand. Therefore, we start with these factors but conceive of them dynamically in the process of developing a personal brand. We are still open to include the emergence of other factors in the empirical study. We also explore the characteristics of the personal branding key practices and how they interrelate or influence each other over the course of different career phases. We assume that while these key practices last for a long time, if not throughout a person's entire career, the activities underlying them may vary over the course of that career. The 'what' and the 'how' of personal branding as a managerial practice form the black box we are trying to open with this paper. How we proceed will be explained in the next section.

\subsection{METHODS}

\subsubsection{Study design}

In this paper, we adopted a multiple case study design (Yin, 2003; Eisenhardt and Graebner, 2007; Noor, 2008) consisting of a within-case and a cross-case analysis based on six personal brand development case stories. In the spring of 2018, we selected six top managers - two female and four male - with different industry backgrounds and experiences (Table 3.2). Since the aim of our study was theory development, we based the selection on theoretical sampling (Eisenhardt and Graebner, 2007), in this case six knowledgeable top managers with insights into the development and events in the production of their own individual brand. The top managers' job responsibilities and variety of positions represented additional criteria for selection (Noor, 2008). In our case, we picked top managers who fulfil a senior executive role and are responsible for the definition and execution of a company's strategy and able to affect the company's profits, share price, reputation, and market position by the force of their individual activities. This includes functions like chief executive officer (CEO), chief operating officer (COO), chief financial officer (CFO), divisional head, and other heads of functions (Carpenter et al., 2004; Pepper, 2006; Pepper and Gore, 2015). 
Table 3.2: Personal and company information of the six top managers investigated in this study

\begin{tabular}{|l|l|l|l|l|l|l|l|}
\hline \multicolumn{3}{|c|}{ Personal Information } & \multicolumn{3}{c|}{ Company Information } \\
\hline Name & Age & Gender & Current function & Nationality & Industry & $\begin{array}{l}\text { No. of } \\
\text { employees } \\
\mathbf{( 2 0 1 8 )}\end{array}$ & $\begin{array}{l}\text { Financials } \\
\text { in 2018 (€) }\end{array}$ \\
\hline $\begin{array}{l}\text { Ann } \\
\text { (pilot) }\end{array}$ & 54 & Female & CEO & German & $\begin{array}{l}\text { Real estate/ } \\
\text { Construction }\end{array}$ & 2,153 & $\begin{array}{l}10.2 \mathrm{bn} \\
\text { total assets }\end{array}$ \\
\hline Brad & 60 & Male & $\begin{array}{l}\text { SVP Corporate } \\
\text { Communications }\end{array}$ & Austrian & Utilities & 21,775 & $\begin{array}{l}20.6 \mathrm{bn} \\
\text { turnover }\end{array}$ \\
\hline Clare & 50 & Female & General Partner & German & Banking & 612 & $\begin{array}{l}2.9 \mathrm{bn} \text { total } \\
\text { assets }\end{array}$ \\
\hline Dean & 51 & Male & $\begin{array}{l}\text { Global Portfolio } \\
\text { Director }\end{array}$ & German & $\begin{array}{l}\text { Trade fairs \& } \\
\text { events }\end{array}$ & 831 & $\begin{array}{l}294 \mathrm{~m} \\
\text { turnover }\end{array}$ \\
\hline Edwin & 44 & Male & $\begin{array}{l}\text { Global Medical } \\
\text { Director }\end{array}$ & Swiss & Pharmaceutical & 38,478 & $\begin{array}{l}16.8 \text { bn } \\
\text { turnover }\end{array}$ \\
\hline Frank & 46 & Male & $\begin{array}{l}\text { Managing } \\
\text { Director }\end{array}$ & German & Advertising & 813 & $\begin{array}{l}85 \mathrm{~m} \mathrm{gross} \\
\text { income }\end{array}$ \\
\hline
\end{tabular}

It was important to have access to these top managers as well as to get them to trust us enough to share their personal stories. To this end, it was beneficial that the first author maintained a trusting relationship with these top managers as their personal coach. In fact, close collaboration between the researcher and the interviewee is a key advantage, particularly when the research is rooted in a constructivist research paradigm (Stake, 1995; Yin, 2003). The professional occupation of the first author as executive coach, in combination with his substantive experience in international business environments, was not only helpful to get access but was also appreciated by the participants. Familiarity and appreciation are important to create a trusting atmosphere for the collection of in-depth data (Collins, 2004; Jay, 2013; Langley et al., 2013). The number of six cases is based on Eisenhardt's (1989) suggestion to have a sufficient quantity of cases, with fewer than four making it more difficult to generate theory, while more than ten would make it too complex and unwieldy given the amount of data generated. We maintain that six cases were sufficient to generate the transparent emergence of theoretical insights (Pettigrew, 1990).

\subsubsection{Strategies for collecting and analysing process data}

Complementary combinations of process research strategies were applied sequentially (see Table 3.3) to our interest in top managers' lived experiences of creating their personal brands. 
Table 3.3: Steps of the research strategy in this study to collect and analyse process data

\begin{tabular}{|c|c|c|c|}
\hline Step & Added value & Output & \begin{tabular}{|l|} 
References \\
\end{tabular} \\
\hline $\begin{array}{l}\text { Alternate } \\
\text { template }\end{array}$ & $\begin{array}{l}\text { Combining richness and theoretical } \\
\text { parsimony by decomposing the } \\
\text { problem; } \\
\text { marking certain boundaries of the } \\
\text { study object and research feasibility }\end{array}$ & $\begin{array}{l}\text { Interview content and } \\
\text { structure }\end{array}$ & $\begin{array}{l}\text { Collis, 1991; Langley, } \\
\text { 1999; }\end{array}$ \\
\hline $\begin{array}{l}\text { Top manager } \\
\text { interviews }\end{array}$ & $\begin{array}{l}\text { Authentic view of the top managers } \\
\text { on their own story and activities; } \\
\text { matching top managers' activities } \\
\text { and events with personal brand } \\
\text { factors from literature }\end{array}$ & $\begin{array}{l}\text { Purposeful information } \\
\text { about relevant events, } \\
\text { ideas and main } \\
\text { activities; } \\
\text { identification of } \\
\text { significant stakeholders }\end{array}$ & $\begin{array}{l}\text { Baxter \& Jack, 2008; } \\
\text { Goulding et al., 2004; } \\
\text { Noor, } 2008\end{array}$ \\
\hline Visual map & $\begin{array}{l}\text { Intermediate step between the } \\
\text { raw data and a more abstract } \\
\text { conceptualization; transform } \\
\text { subjective data into constructive } \\
\text { stories }\end{array}$ & \begin{tabular}{|l|} 
Story timeline of each \\
top manager; \\
individual and authentic \\
narratives containing \\
complex personal \\
branding trajectories \\
\end{tabular} & $\begin{array}{l}\text { Langley, 1999; } \\
\text { Langley \& Truax 1994; } \\
\text { Langley et al., 2013; } \\
\text { Quinn 1980; Van de } \\
\text { Ven \& Grazman, } 1999\end{array}$ \\
\hline $\begin{array}{l}\text { Stakeholder } \\
\text { interviews }\end{array}$ & $\begin{array}{l}\text { Applying a variety of lenses which } \\
\text { allows for multiple facets of the } \\
\text { phenomenon to be revealed and } \\
\text { understood; } \\
\text { triangulation of data }\end{array}$ & $\begin{array}{l}\text { Final verification and } \\
\text { refinement of each } \\
\text { timeline and story; } \\
\text { increasing validity }\end{array}$ & $\begin{array}{l}\text { Baxter \& Jack, } \\
\text { 2008; Eisenhardt, } \\
\text { 1989; Eisenhardt \& } \\
\text { Graebner, } 2007\end{array}$ \\
\hline $\begin{array}{l}\text { Temporal } \\
\text { bracketing }\end{array}$ & $\begin{array}{l}\text { Mass of process data is transformed } \\
\text { into a series of connected blocks; } \\
\text { identification of specific theoretical } \\
\text { mechanisms that reappear over } \\
\text { time; } \\
\text { identifying continuity in the } \\
\text { activities within each phase and } \\
\text { discontinuities at its frontiers; } \\
\text { revealing how activities in the key } \\
\text { practices over one period resulted } \\
\text { in changes in the context that } \\
\text { impacted activities in subsequent } \\
\text { periods }\end{array}$ & $\begin{array}{l}\text { One table for each key } \\
\text { practice containing } \\
\text { a clear structure of } \\
\text { the 'what' and the } \\
\text { 'how' during the top } \\
\text { managers' careers } \\
\text { and corresponding } \\
\text { illustrative quotes }\end{array}$ & $\begin{array}{l}\text { Giddens, 1984a; } \\
\text { Langley, 1999; } \\
\text { Langley et al., } 2013\end{array}$ \\
\hline
\end{tabular}

The interviews with the six top managers were conducted between June 2018 and December 2018 and were semi-structured (Appendix 2). To structure the interview questions, we used an alternate template that was built on specific factors of personal branding (see Table 3.1) as discussed in the previous section. We then mapped out the stories chronologically as revealed from archival data and the interviews and constructed a visual map for each top manager. Dividing the ordinate of the graph into horizontal bands, one for each proposition of the alternate template (e.g., visibility, relationships, brand personality), we then plotted the events, activities, and recollections from our database onto the grid. Between April 2019 and May 2019, we conducted interviews with ten stakeholders (see Table 3.4) as they were identified as knowledgeable attesters referred to by the top managers. These interviews (see Appendix 3) were based upon the narratives constructed in the top managers' visual maps and aimed to verify and refine each top manager's story. 
Table 3.4: Stakeholder sample group interviewed in this study to enhance validity by triangulation

\begin{tabular}{|c|c|c|c|c|c|c|}
\hline \multicolumn{4}{|c|}{ Stakeholders' Personal Information } & \multicolumn{3}{|c|}{ Stakeholder/Top Manager Relation } \\
\hline Name & $\begin{array}{l}\text { Age } \\
\text { Gender }\end{array}$ & Nationality & $\begin{array}{l}\text { Function / } \\
\text { Industry }\end{array}$ & $\begin{array}{l}\text { Professional } \\
\text { Relationship } \\
\text { with the Top } \\
\text { Manager }\end{array}$ & $\begin{array}{l}\text { Top } \\
\text { Manager }\end{array}$ & $\begin{array}{l}\text { Duration } \\
\text { of the } \\
\text { Relationship } \\
\text { in General }\end{array}$ \\
\hline George & $\begin{array}{l}51 \\
\text { Male }\end{array}$ & Swiss & $\begin{array}{l}\text { Country Head/ } \\
\text { Pharmaceutical }\end{array}$ & $\begin{array}{l}\text { Former } \\
\text { superior }\end{array}$ & Edwin & 11 years \\
\hline Howard & $\begin{array}{l}53 \\
\text { Male }\end{array}$ & German & $\begin{array}{l}\text { Head of HR / } \\
\text { Real estate \& } \\
\text { Construction } \\
\end{array}$ & $\begin{array}{l}\text { Former } \\
\text { colleague }\end{array}$ & Ann & 18 years \\
\hline Irvin & \begin{tabular}{|l}
64 \\
Male \\
\end{tabular} & German & $\begin{array}{l}\text { CEO / } \\
\text { Trade fairs \& events }\end{array}$ & $\begin{array}{l}\text { Current } \\
\text { superior }\end{array}$ & Dean & 32 years \\
\hline Joyce & $\begin{array}{l}32 \\
\text { Female } \\
\end{array}$ & German & $\begin{array}{l}\text { PR Manager / } \\
\text { Banking } \\
\end{array}$ & $\begin{array}{l}\text { Current } \\
\text { subordinate }\end{array}$ & Clare & 5 years \\
\hline Kylie & $\begin{array}{l}53 \\
\text { Female } \\
\end{array}$ & German & $\begin{array}{l}\text { MD / } \\
\text { Advertising }\end{array}$ & $\begin{array}{l}\text { Former } \\
\text { consultant }\end{array}$ & Ann & 21 years \\
\hline Lenny & \begin{tabular}{|l}
53 \\
Male \\
\end{tabular} & German & $\begin{array}{l}\text { CEO / } \\
\text { Advertising }\end{array}$ & $\begin{array}{l}\text { Former } \\
\text { superior }\end{array}$ & Frank & 16 years \\
\hline Melinda & $\begin{array}{l}42 \\
\text { Female } \\
\end{array}$ & German & $\begin{array}{l}\text { HR Director/ } \\
\text { Mobility }\end{array}$ & $\begin{array}{l}\text { Former } \\
\text { subordinate }\end{array}$ & Brad & 10 years \\
\hline Nancy & \begin{tabular}{|l}
58 \\
Female
\end{tabular} & German & $\begin{array}{l}\text { Chair \& Full Professor / } \\
\text { Academic }\end{array}$ & $\begin{array}{l}\text { Former } \\
\text { professor }\end{array}$ & Ann & 30 years \\
\hline Oliver & \begin{tabular}{|l|}
62 \\
Male \\
\end{tabular} & German & $\begin{array}{l}\text { Entrepreneur / } \\
\text { Consultancy } \\
\end{array}$ & $\begin{array}{l}\text { Former } \\
\text { superior }\end{array}$ & Brad & 15 years \\
\hline Phil & $\begin{array}{l}65 \\
\text { Male }\end{array}$ & German & $\begin{array}{l}\text { Partner / } \\
\text { Consultancy }\end{array}$ & $\begin{array}{l}\text { Former } \\
\text { consultant }\end{array}$ & Brad & 19 years \\
\hline
\end{tabular}

We conducted a within-case analysis that took place iteratively and parallel to a cross-case analysis after the first case. By this means, we generated different areas of equal, similar, and interrelated activities on the visual maps which we aggregated to 'key practices', i.e., 'managing position,' 'managing individuals,' and 'managing visibility'. In order to better understand the linkages between the key practices used by the top managers and the kinds of activities they involved during the personal branding process, we adopted the temporal bracketing strategy. In doing so, we decomposed the time scale of the career of the top managers into four successive phases, i.e., 'beginner,' 'professional,' 'manager,' and 'top manager.' This data analysis step resulted in one table for each key practice containing a clear structure of the 'what' and the 'how' in the top managers' careers and corresponding illustrative quotes. For verification reasons, we went back to the transcribed top managers' interviews and matched them with the provisional tables resulting from our previous step. In order to understand the temporal emergence, interrelations, and interdependencies of the specific events and activities in each top manager's narrative, we transformed each table into a process scheme. Afterwards, we concentrated all six tables per key practice from the six top managers into one 
processual master table per key practice containing the temporal career phases, the 'what' and the 'how,' and illustrative quotes. With this coding process, we clustered and re-clustered iteratively the activities in the key practices of personal branding. The resulting master tables of each key practice together with the process figures were transformed into a single cross-over figure of the process in the top managers' personal branding (Figure 3.1). Using these overviews, we were ultimately able to identify both the key practices and their activities for the development of the top managers' personal brands, as well as their interrelationships.

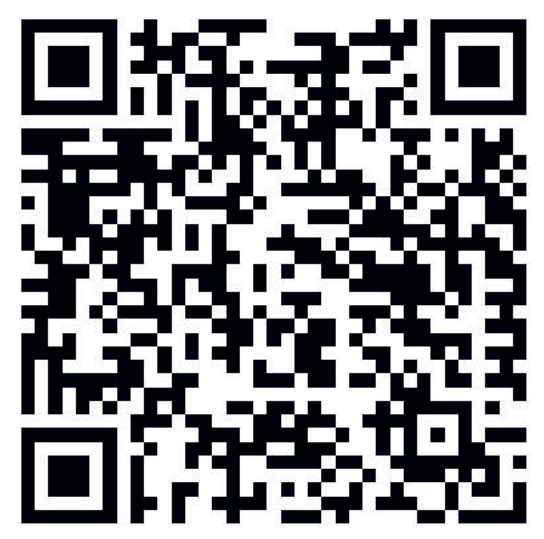

Figure 3.1: Key practices, dual activities and their interrelations during top managers' personal branding process

\subsection{IDENTIFYING THREE KEY PERSONAL BRANDING PRACTICES}

\subsubsection{Key practices}

We found that personal brand development is a complex process in which top managers resort to various key practices, i.e., 'managing position,' 'managing individuals,' and 'managing visibility,' in each career stage, i.e., 'beginner,' 'professional,' 'manager,' and 'top manager.' These key practices were interdependent, sometimes overlapping and shifting in focus over the course of a career, a fact that Ann mentioned in the way she manages individuals. "I knew when I was in that organization that it would work [moving powerful people to personal facilitators]. You learn this by chance and tell yourself: What can I do with this? So that it stops being a happy accident and becomes a conscious decision." Collectively, the key practices enabled the top managers to broaden their personal experience and awareness over time, as Frank reflected. "I'm surprised myself how much impact it [Frank's personal brand] has, or maybe I just notice it more consciously now than in the past." 
We present them as distinct practices in themselves, all of which inherently exhibit dualities at the level of activities. We start by describing each key practice separately along with its manifestations in each career phase, and then we continue to examine how top managers were challenged by dualities and how they were resolved.

\subsubsection{Key practice: 'managing position'}

An awareness to position their own personal brand through their own activities could be ascribed to the top managers in our study and resulted in 'managing position' as one of three key practices. Frank recalled the importance of position building in the development of a personal brand. "I do believe that it is part of being a leader that you establish yourself so strongly in some form - well, brands are, in a sense, figureheads that set a direction and stake a certain claim. But it has to be authentic and believable. You cannot fake it."

We identified positioning activities during the personal branding process of top managers that were highly compatible with the concept of points of differentiation and points of parity (Keller et al., 2002). With 'standing out' and 'fitting in,' our study revealed an important duality encountered by managers, which we labelled collectively as the key practice 'managing position.'

The activities of top managers focusing on 'standing out' answered questions such as 'How does your personal brand differ from competitors?' and 'Have you established a certain uniqueness with your personal brand and, if so, why?' In general, the top managers offered a broad and profound awareness of their individual differentiation. In this regard, Edwin argued, "This uniqueness came from me doing certain things much better than others." Dean, in turn, stood out because "I'm this contrary guy. I love it, I ask for it, doing things differently, even if everybody tells me: You cannot do that, you must not do that."

In contrast, top managers' activities aimed at 'fitting in' enabled them to adapt to people and the environment, which represented an important component in their own positioning. Ann and Edwin clearly pointed this aspect out. "You get older, your horizons get wider. And some things might not fit anymore, which means you need to adjust your brand, or its character. (...) And when the requirements or the demand changes, you need to think: Does my brand, my brand's character fit it, or do I need to adjust it to survive in this world?" (Ann) "Let's say, when you move up the ladder, people's expectations change. It goes from delivering performance, to leading a team, forming a team, vision, strategy, and, in the end, about being able to adapt in a way to your colleagues." (Edwin)

The top managers' activities of 'standing out' and 'fitting in' along the four career phases are presented below (Table 3.5).

In the earliest career phase 'beginner,' individual differentiation from others 
arose through the application of exceptionally well-developed skills and expertise, such as soft skills or the ability to serve customers particularly well, and through extraordinary achievements based on this. To stand out in these ways resulted in further responsibility, such as projects, tasks, and jobs. This early awareness and activities were not counterbalanced by any views or approaches to fit in, which changed during the next career phase, 'professional,' due to competition with other people but also new entrepreneurial conditions after a job change. Initial activities to fit in contained an adapted working style and conforming to the background and expectations of new colleagues and led to changing career paths within the company. For individual differentiation from others, in turn, the exceptionally welldeveloped skills, whether professional or personal, were further sharpened and led to a more distinctive positioning with influential individuals within the company. Eye-catching but meaningful contributions in meetings, the questioning of existing things, and the successful completion of difficult tasks constituted the activities to stand out.

The insecurity of an organization and its size as well as competition with other people for further career opportunities, promotions, and filling interesting vacancies were the main reasons to stand out in the'manager' career phase. In order to attract the attention of internal decision-makers and convince them of being the right person for the next step, extraordinary single skills and expertise were no longer sufficient. Rather, the emphasis was on unique combinations of skills and expertise that not only exceeded those of the others but were also the best in absolute terms. Successful delivery as a standing out activity was conducted now under very difficult or even unique conditions or even from a role as a successful first mover. As individual differentiation can also entail risks and disadvantages if pursued unilaterally, complementary activities were carried out to fit in by adapting one's own way of working to the lower level of skills of others in a given situation, meeting the expectations of influential people in the company, and adapting to the changing conditions around the company and in the markets. Ultimately, the 'manager' career phase saw an active balance of positioning activities between 'standing out' and 'fitting in.'

In their current career phase, the activities of top managers to stand out were justified in the competition for the few places on influential committees and the equally small number of vacancies to be filled. Preserving one's own authenticity and consistent positioning that differs from any unsteadiness as well as constant rethinking and questioning of success and the tendency for continuous improvement, as opposed to complacency, were part of a prominent attitude that results in being positioned as a benchmark within the company. Besides a unique combination of outstanding and extraordinarily strong non-technical skills and expertise, which no one or hardly anyone else at the same level in the company has, and the meaning 


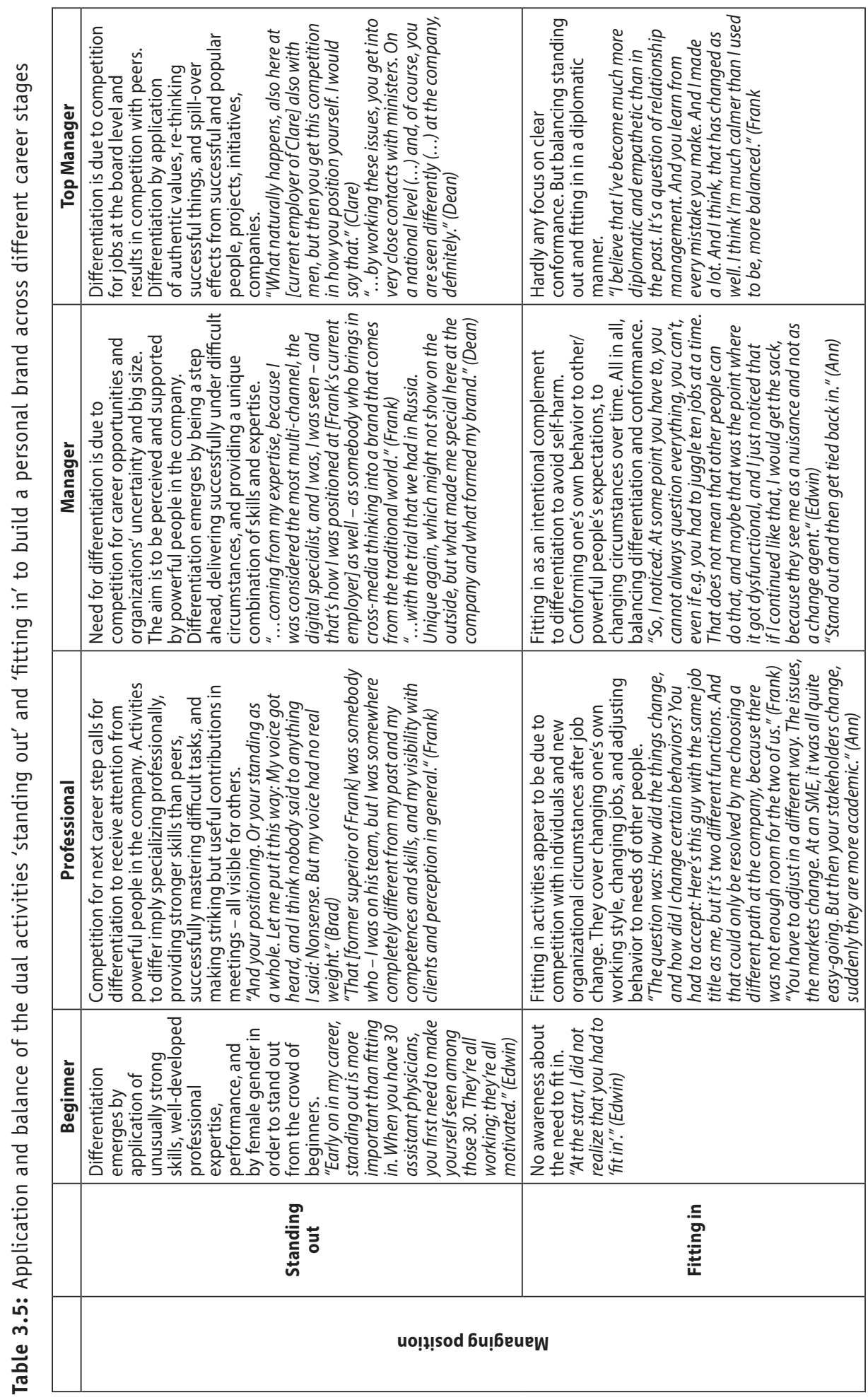


transfer effects of successful and well-known personalities, functions, initiatives, and corporate brands also differentiated oneself from others. Therefore, the top managers worked primarily on deepening and expanding their network and on their relationship management. They did not mention any specific other activities to fit in during their current career phase. However, the top managers were obviously very aware that a balance between 'standing out' and 'fitting in' was necessary and had been developed by them during their career.

\subsubsection{Key practice: 'managing individuals'}

Although the number and the nature of these individuals seemed at first sight to be quite unmanageable, the question of their concrete influence on the development of the top managers' personal brands provided two clearly distinguishable groups.

First, the top managers in our study pointed to numerous, diverse individuals who affected their personal branding process positively. We labelled those persons as facilitators, defined as individuals who helped today's top managers to achieve an effective personal brand more easily by suggesting ways of doing things and enabling next steps in their careers. Representing the sample group, Edwin expressed the relevance of these facilitators as "Careers don't happen by themselves. Careers always happen with somebody acting as your facilitator in the end."

Second, and in contrast to those who support top managers in their endeavour to become branded, the top managers in our study were also confronted with people who negatively influenced the development of their personal brands. We termed these people obstructors and defined them as individuals who prevented or hindered actions that today's top managers wanted to take during their careers, thereby impeding progress in their personal branding. It seems to be the case that top managers were aware that these obstructors are a fact of life. In this regard, Clare stated, "Of course, there are people, in the background I think, who speak bad about you." To Ann's point of view, it is "competition that does not allow strong personal brands. Not competition between industries, but a competition - let me put it negative - in the company. If you have certain superiors at the company, or if stakeholders are a certain way (...) That can be an obstructing factor."

The key practice'managing individuals' is thus also based on a duality whose two elements appear as opposing activities. In addition to the role and function in which these facilitators and obstructors acted, we were also interested in gaining further and deeper insights into these people and their perceptions by top managers. How did facilitators and obstructors emerge? How did the top managers create them? How did facilitators and obstructors affect the top managers' personal branding process? Why were facilitators and obstructors important during the top managers' personal branding process? In the following, we answer these and further relevant why and how questions and thus describe the key practice 'managing individuals' 
and its two activities 'facilitators' and 'obstructors' for the respective career phases (Table 3.6).

During the first career phase, 'beginner,' superiors and top managers within the respective company appeared as facilitators at first, while obstructors did not have a significant influence on the personal branding of the later top managers. People around the beginners became facilitators during this career phase because the beginner had previously successfully delivered what represented added value for the company from the perspective of the facilitators. The type of support provided by the facilitators was primarily a matter of handing over new tasks and jobs with greater responsibility.

A significant increase in activities characterized the second career phase. The professionals were personally visible in their deliveries that provided added value for the company and people at higher hierarchical levels and in powerful positions, who therefore turned into facilitators. The facilitators' support took place along three lines. First, the professionals received appreciation, respect, and trust in their skills and work on a personal level. Second, some facilitators provided reflection and coaching for the facilitated individual. Finally, the facilitation resulted in next career steps covering new and more responsibility, more leeway, a new job, or a new project in the organization.

Obstructors appeared for the first time at the 'professional' career level and were limited to direct superiors and colleagues within the company. They primarily arose from personal comparison and tried to protect and defend their own field, also by deliberately damaging the personal brand of the professional and his/her reputation with direct superiors, who prevented him or her from further career steps.

While supportive relationships to individuals at higher hierarchical levels were still based on give-and-take in the 'manager' phase, the conditions and situations for the activities now contained considerably more critical facets affecting the facilitators and the company. The manager was clearly at the forefront and was expected to meet the facilitators' expectations, which included tactical and reputational aspects. Trust, support in difficult situations, and the possibility to tackle new, even visionary things on a higher level formed part of the support provided by facilitators. The managers also received greater transparency on internal company aspects, which gave them a better awareness of how to act in the corporation. External facilitators, such as journalists and coaches, now also joined in. Colleagues and superiors emerged as obstructors due to the lack of experience and skills of the later top managers in political and tactical procedures. Scepticism, envy, loss of reputation, obstacles in day-to-day business, and empty promises were experienced by the top managers in this career phase from those who obstructed them. 


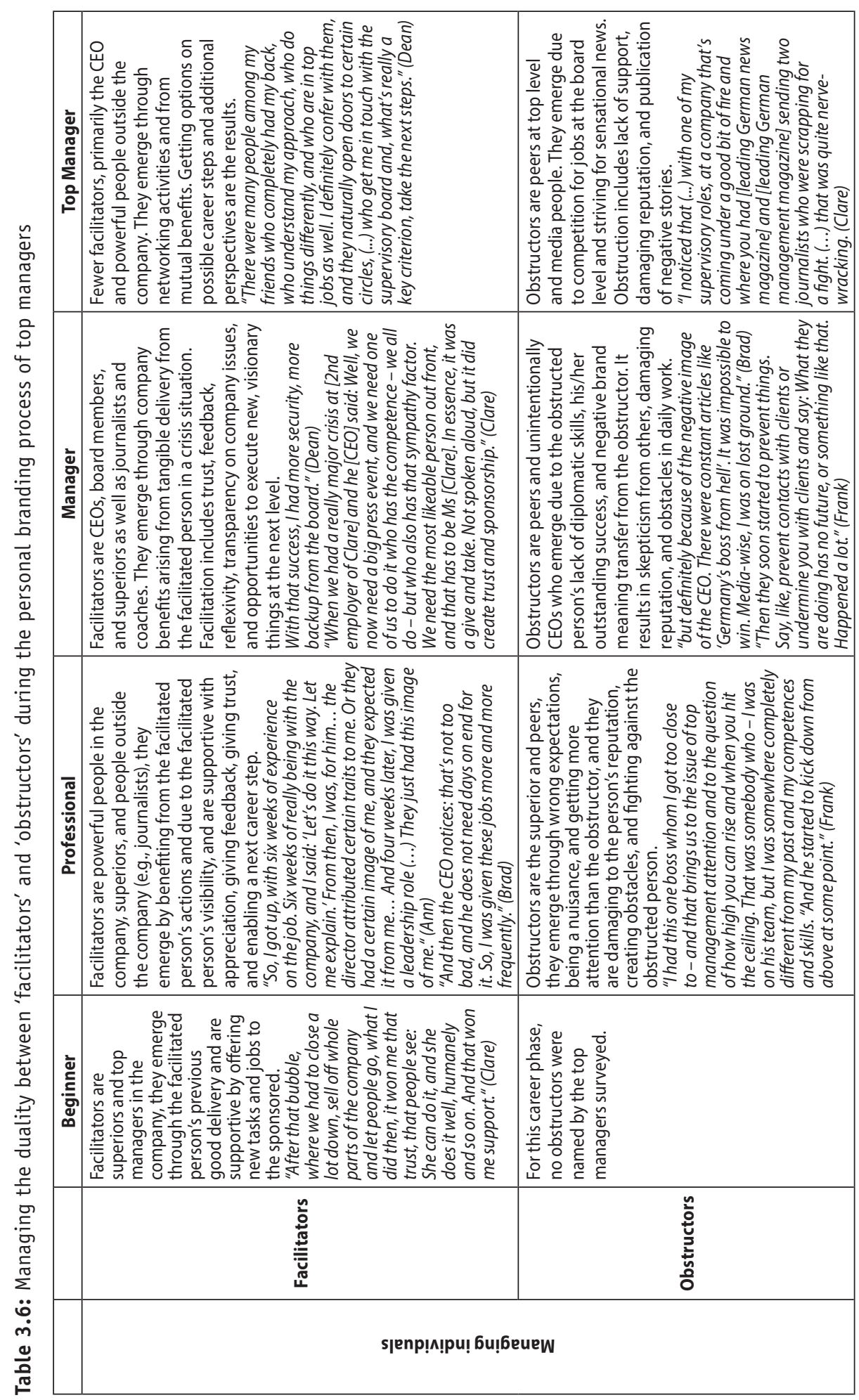


At their current career level, the top managers only knew of the company or group CEO as the exclusive facilitator within the company, mainly as a result of the proximity to that person and the function. Outside the company, facilitators were found exclusively in very powerful positions, such as politicians, supervisory boards, and boards of directors of other companies. Similarities, such as a comparable function and responsibility or interest in the same topics, were as much the basis for the relationship between a top manager and facilitator as mutual benefit at eye level. Supporting activities of the facilitators resulted in a broadening of the top managers' views through personal exchange, but also in access to other people and groups of people, which could provide next career steps and in turn might be of interest or benefit to the facilitators themselves. Peers at the top manager level were explicitly named as obstructors. Their behavior was justified by their active resistance to changes in the company and the competition for free CEO jobs. In addition, journalists could become obstructors by sniffing out the challenges, problems, and difficulties around the top manager and creating a story that causes a stir when published.

\subsubsection{Key practice: 'managing visibility'}

In line with our findings from the literature review on the key factors of personal branding which resulted in visibility as a proposition for the alternate template and the interviews, personal visibility was a prominent, if not the most present topic for the interviewed top managers. Edwin exemplified for all top managers in our study the awareness of the importance of visibility in personal branding and that it has to be managed as a key practice. He stated that "I didn't know it at the time, but I slowly realized that visibility matters if you want to get ahead."

Visibility appeared as a very abstract and flexible term in general and with fragmented content in the research field of personal branding. Since we were interested in filling this term with precise content and a clear structure, we cascaded the application of 'what' and 'how' questions from the research field of this study, i.e., personal branding of top managers, down to this key practice 'managing visibility' during our iterative process of interviewing top managers and during our data analysis: What kind of visibility did the top managers aim for or face? What activities did the top managers conduct to get visible? How were the top managers visible during their career? As a result, our data analysis revealed three activities for the key practice 'managing visibility,' each of which contains two opposing aspects, thus also indicating that dualities need to be managed during the personal branding process (Table 3.7).

First, managing on-field and off-field visibility can be traced back to an investigation of athletes' personal brands (Parmentier and Fischer, 2012) that examined how athletes manage their visibility in their original field of practice and 
profession (on-field visibility) and outside to build a mainstream media persona (off-field visibility). Second, managing internal and external visibility, which refers to the visibility of the individual within the company and outside the company by which he/she is employed. Third, managing online and offline visibility. While a digital footprint forms an online self, e.g., on social media platforms, a physical footprint occurs by means of articles, public speeches, the expansion of one's own network, presentations, or other publications to create an offline self (Philbrick and Cleveland, 2015). Below we describe the 'managing visibility' key practice and its three activities along the four career stages we have identified.

The focus during the 'beginner' phase was on one's own professional performance, technical expertise, and professional function, which created a distinct onfield visibility, while an off-field visibility was not relevant at all in this career phase. While this did not change in the subsequent career phase 'professional,' aspects such as strategy, business development, change management, and leadership were mentioned for the first time as providing off-field visibility in the 'manager' phase. For the 'top manager,' on-field visibility based on professional expertise was still relevant, but off-field visibility came very much to the fore as the top manager became visible through activities that were related to his or her function and hierarchical level, but also had an impact in a cross-company and societal context.

As 'beginners,' the future top managers actively worked on internal visibility through professional performance, aiming to stand out from the many other beginners. Internal company visibility became more targeted on influential people during the 'professional' phase, such as one's own supervisor and members of the top management. This progressed to a central role for internal visibility in the 'manager' phase, whether through personal conversations or one's own contributions in management meetings.

While the external visibility was mainly ascribed to technical publications and interaction with clients in the 'beginner' and the 'professional' phases, interviews, portraits, articles in professional journals, magazines, and daily newspapers as well as press releases were the channels of activity through which the person was presented to the external public beyond professional topics during the 'manager' phase. In their current career phase, top managers face a significant increase in external visibility rooted in their externally representative role and in meaning transfer effects from the corporate brand. They used the outwardly effective and visible media channels in a variety of ways, e.g., interviews, lectures, press conferences, and acted by means of personal mandates and in cooperation with associations.

Given the age of the top managers interviewed for this study, the Internet and social media did not yet exist or only existed to a limited extent during their 'beginner' and 'professional' phases. Consequently, they left behind a physical 


\begin{tabular}{|c|c|c|c|}
\hline & 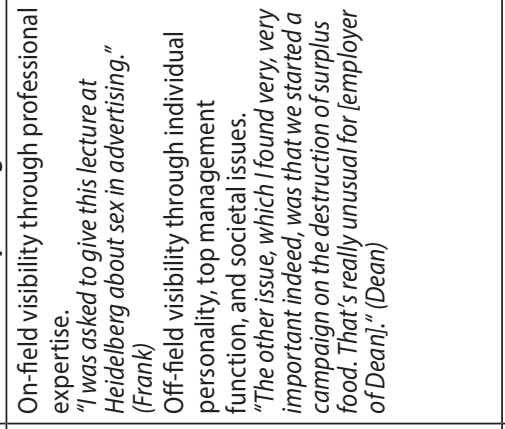 & 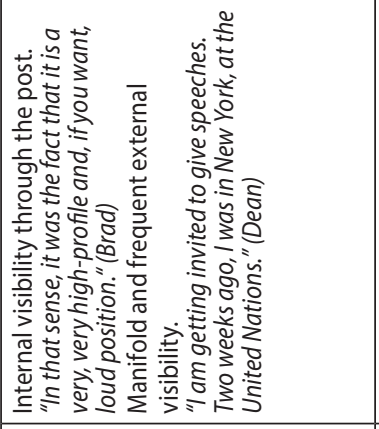 & 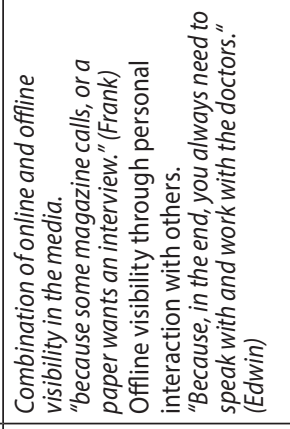 \\
\hline & 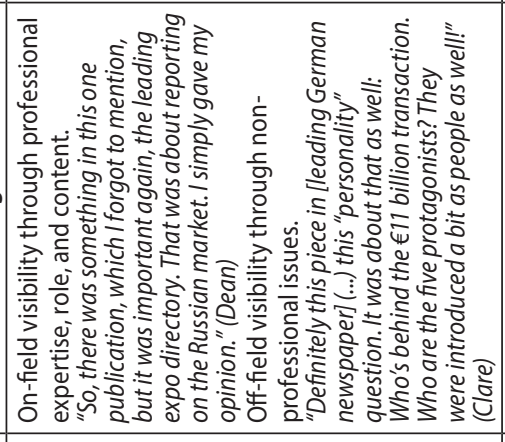 & 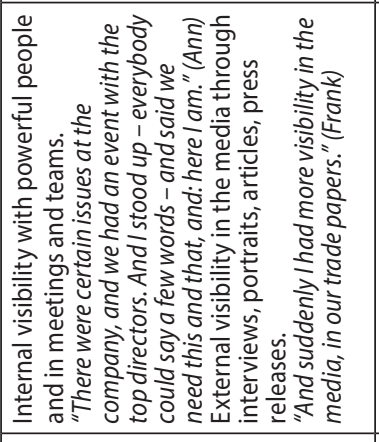 & 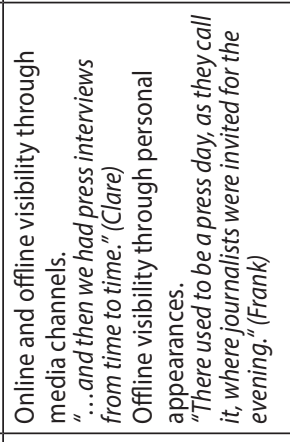 \\
\hline 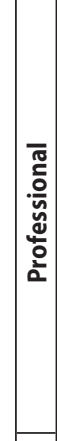 & 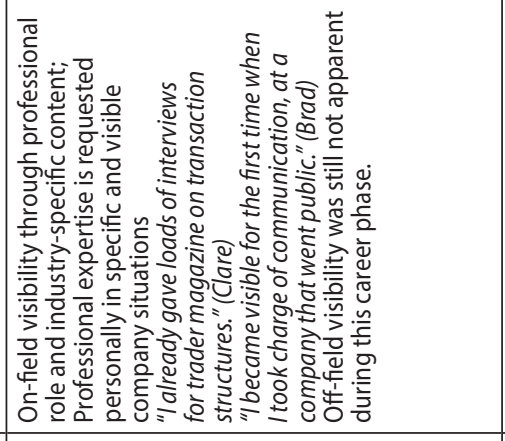 & 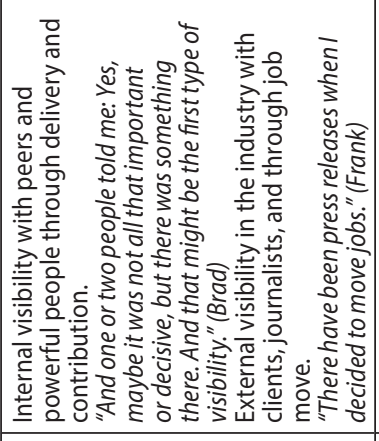 & 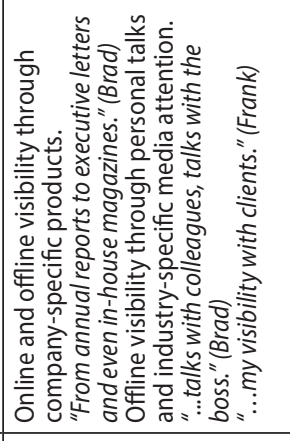 \\
\hline 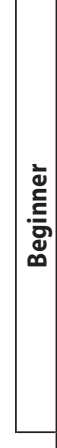 & 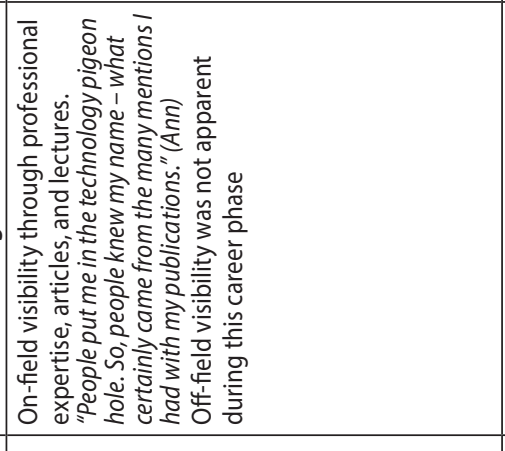 & 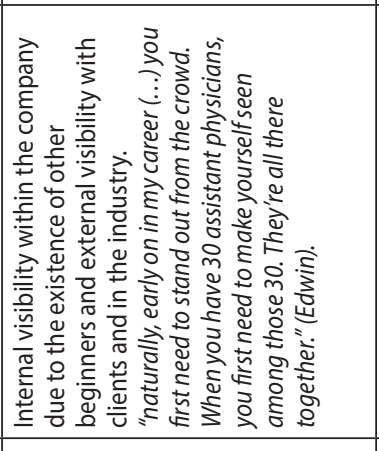 & 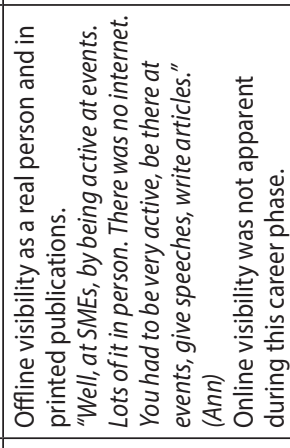 \\
\hline & 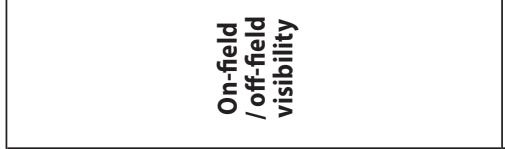 & $=$ & \\
\hline & \multicolumn{3}{|c|}{ 4!!!!s!̣ бu!бeuew } \\
\hline
\end{tabular}


rather than a digital footprint. External visibility in the media during the 'manager' phase resulted in overlapping and interlocking online and offline visibility as the technology improved. However, offline visibility as a real person continued to gain importance through press conferences, press trips, personal appearances at events, and direct collaboration and interaction with colleagues, clients, and journalists. The development of an individual digital self directly linked to the physical self represented a conscious practice for current top managers to build up their own visibility. Offline visibility at press conferences, for example, also meant an online presence on the Internet, and interviews or portraits about the top managers appeared simultaneously in newspapers, magazines, and journals and in their online channels.

\subsubsection{Managing dualities}

In the previous section, we showed that each key practice is a category in itself. However, we recognized that these key practices as well as their underlying activities do not operate independently of each other during the emergence of the top managers' personal brands (Figure 3.1). Rather, these activities constitute dualities that are inherent to each key practice.

The duality between 'standing out' and 'fitting in' within the key practice 'managing position' only arose in the second career phase, 'professional,' and initially represented a paradox in which the two activities proved to be opposites. In the further course of personal branding, however, these two activities must have been balanced against each other to avoid turning the previous advantage of differentiation through 'standing out' into a disadvantage. Or, considered from an alternate perspective, this balance between deliberately 'standing out' and 'fitting in' created an additional differentiating factor to stand out in turn. "You can be seen as an innovator or a nuisance, but you have to make sure that you are seen as the right one at that" (Edwin).

Similarly, 'facilitators' and 'obstructors' within the key practice 'managing individual' only appeared as a duality in the 'professional' career phase. It is evident that the facilitators of personal brands were superiors or people higher up in the organizational hierarchy. The obstructors were colleagues from the peer group or one's own supervisor. There was no fundamental personal connection between facilitators and obstructors, which was neither actively evoked nor consciously capitalized on by top managers. Therefore, it was a given circumstance and not a personal branding activity that facilitators and obstructors were incompatible and mutually exclusive in their duality. They maintained this status in relation to each other as the personal branding process continued. However, an indication was given of a possible resolution of this consistently opposing duality: "I know, back then, at [former employer of Clare] my supervisor told me, when I resigned, that he was 
sad, which was true, because we got along well, but then he came out with: I will never recruit anybody who shines like you again, because they'd outshine me. That was really interesting, to put it like that, but he never hurt me." (Clare).

In the 'managing visibility' key practice, the activities also represented dualities without exception, although they differed from each other in their design and development during the personal branding process. The duality of on-field and off-field visibility became apparent only at an advanced career stage (during the 'manager' stage), since before that only on-field visibility influenced the development of personal brands as an activity. After complementing on-field visibility with off-field visibility, i.e., by the role as manager as well as the individual personality, the balance of this duality shifted even further towards off-field visibility in the 'top manager' career phase.

From another perspective, this shift in balance also offered the approach that on-field visibility increasingly took over some content of off-field visibility, as aspects such as management function, mandates, strategic actions, and nonprofessional personality could be attributed to the profession as a manager and especially as a top manager. This connotes that the original sharp distinction in the duality between on-field and off-field visibility mutated into a duality with one activity enabling the other.

The duality between internal and external visibility showed an asymmetrical dependence on each other. As far as the personal brand was visible outside the company, for example in the media through interviews, portraits, articles, and press releases, this also resulted in internal visibility. Conversely, visibility within the company did not necessarily lead to visibility outside the company. Here, too, one activity supported the effect of another to which it seemed at first glance to be contrary in the sense of a dual relationship. The interplay of the two dualities of on-field and off-field visibility on the one hand and internal and external visibility on the other indicated that at an advanced career stage, i.e., from the career stage 'manager' onwards, the personal brand was mainly developed outside the company and in public through non-technical issues.

The duality between online and offline visibility and its development during the personal branding processes of the top managers studied was primarily caused by technological progress. At the beginning of the careers of today's top managers, the Internet or even social media simply did not exist. It was not until the 'professional' career phase that a veritable duality between the two activities of online and offline visibility began to evolve. But then these two activities went hand in hand and produced a digital and a physical footprint in equal measure, both in terms of the content that was communicated and the formats, such as interviews, portraits, or press releases.

The management of dualities thus extends both to strategizing with these dualities and to overcoming the tensions arising from the dualities. 


\subsection{DISCUSSION}

Our study took the form of a journey through the careers of six top managers, on the one hand, and through the analyses of their personal branding processes, on the other. At the beginning of this journey, we were motivated by our academic and practical ambition to understand how top managers' personal brands develop over time. Basically, studying the emergence of personal brands implies a fundamental appreciation of "explanations that tell a narrative or story about how a sequence of events unfolds to produce a given outcome" (Van de Ven and Poole, 2005, p. 1381), that is, mainly the lived experience of events that form a unique narrative for each top manager, resulting in his or her personal brand. Thus, personal brands correspond to what Tsoukas and Chia (2002) refer to as temporary instantiations of ongoing processes, continually in a state of becoming. This sequence of events over a temporal process does not entirely explain what top managers really do to develop their personal brand and how they do it, however.

Personal branding as an essential part of today's managerial work needs to be understood from a practice perspective. Top managers as actors with their practical skills and activities understood how it is done, and the social environment that drives and facilitates their actions requires close anthropological attention for a constant stream of tricks, stratagems, and manoeuvres (De Certeau, 1984). Examining these activities and processes in real time is of course as equally impossible as our intervening to produce optional effects. We could only describe and analyse the past experiences of the top managers as actors, which activities they implemented themselves or experienced through others, how they operated, which interrelations resulted from this, and what impacts this entailed.

On this basis, we demonstrated that what top managers do 'in practice' over the course of their careers from a personal branding perspective can be categorized into three key practices that we labelled as 'managing position,'managing individuals,' and 'managing visibility.' At this level of analysis, the question inevitably arises as to how exactly the top managers and other actors engaged in these key practices from a micro-behavioral point of view. Our differentiated, in-depth approach to the key practices allowed us to identify different activities at the next level of granularity. The activities clearly aggregate what the numerous single actions aim at, what they contribute to, or even what they are rooted in, thus giving the actors concrete guidance for the development of their personal brand.

In their juxtaposition within a key practice, the activities themselves exhibited aspects that are of a dual character, both in their positioning as an activity and in their effects. These activities, which emerged as dualities in the course of the study, show completely different as well as independent characteristics in comparison to each other over the duration of a career. The duality between online and offline 
visibility, for instance, depended on the fact that our study is a retrospective analysis of the careers of today's top managers. The share and type of online visibility and its role in the duality were obviously dependent on how the required technology developed over the years. From our research, we can only speculate what activities underlie the 'online/offline visibility' duality and how it works for managers who are still on their way to becoming future top managers.

Dualism typically demonstrates a clear and definite contradiction, a welldefined boundary, and an absence of overlap. This often turns into a synonym for opposition and potential conflict (Farjoun, 2010). In contrast, the recognized dualities in the top managers' personal branding processes confirmed the approach of social theorists who claim that conceptual distinctions can be maintained in dualities without being committed to a rigid antagonism or separation (e.g., Elias, 1991; Giddens, 1984a). Rather, the two imperatives a duality consists of are no longer separate but interdependent, potentially compatible, and even mutually enabling and a constituent of one another, while remaining conceptually distinct.

Without a systematic process analysis, it would not have been possible to obtain transparency in crucial aspects of personal branding. Only by doing so did it become clear how important on-field visibility is at the beginning of a career, how it is created, and what changes (in terms of activities) it undergoes over time in subsequent career phases. Our practice-theoretical-processual methodology also revealed that the on-field visibility is extended by activities in the field of management and leadership from the 'manager' career phase onwards. From a different interpretative perspective, on-field visibility is supplemented here by off-field visibility, i.e., with activities in the area of management, leadership, and personality beyond the original professional competences. We want to emphasize that the personal branding process of top managers is not a unidirectional process of positive and supportive activities. Obviously, building up and dealing with supporters is an indispensable part of the managerial practice in personal branding. It is also important to identify obstructive activities, e.g., by colleagues or superiors, and to develop a way to deal with them. Our findings counteract the one-sidedness of merely wanting to differentiate oneself as a personal brand. We were able to demonstrate that conformity in approaches and behavior matter as well and complement differentiation activities in that way. We witnessed that top managers are able to maintain a good balance between fitting in and standing out, depending on the situation.

Our study did not end in a superficial list of key practices and individual activities. In fact, we believe that our study adds value to the field of personal branding by identifying and distinguishing key practices as well as activities and examining them with their interrelations across different career phases. This enabled us to answer the 'what' and 'how' questions in the comprehensive and 
highly condensed complexity of personal branding. We also commented on the origins of the activities and thus of the aggregated key practices. The question of 'why' could only be answered to a limited extent from our analyses. It is equally relevant to answer the 'why' question with a view to the individual imprint of the respective personality and his or her personal background.

\subsection{CONTRIBUTIONS}

\subsubsection{Theoretical contributions}

Specific contributions are made to three distinct streams of literature.

First, we contribute to the management literature, and in particular managerial work and managerial practices, by adding a new facet when answering the decadesold fundamental question 'What do managers do?' (e.g., Mintzberg, 1973) with the key practices of personal branding and through bringing contemporary notions of practice into the study of managerial work (Korica et al., 2017). We provide answers to both the 'what' and 'how' questions with a view to managerial practices and use them to unravel the black box of 'personal branding as practice'. Given the high visibility of top managers as individuals and as representatives of companies, the managerial practice of 'personal branding' may be counted among the most crucial contemporary managerial practices of current and future top managers. Given that top managers are the multipliers of corporate strategy through their visibility and brand power, both internally and externally, we also contribute to the SAP literature by calling for more research into the relationship between personal brands of actors in strategy-making. In other words, personal branding has a direct influence on strategy practice, "both as an activity within organizations that is central to managerial work and as a phenomenon that extends outside organizations with potential influence upon whole societies" (Whittington, 2006, p. 614), and thus contributes to an expanded and innovative understanding of 'strategy-as-practice' (Whittington, 1996). In this light, personal branding is a practice that can co-exist with strategy-related issues such as strategic decision-making, corporate strategies, and strategy implementation, to name a few.

Second, this work contributes to advancing the career literature on the role of time and of personal branding in career development and how personal brands are actually developed by careerists over time. We support and extend the understanding of careers as "the evolving sequence of a person's work experiences over time" (Arthur et al., 1989, p. 8) and the suggestion of considering careers as patterns of positions and conditions of a career actor within a bounded social and geographical space over a lifetime (Gunz and Mayrhofer, 2018) by substantiating them through clear practices and activities over the duration of careers. In addition, we can enrich the knowledge 
of how different career stages can be characterized in terms of certain continuities in activities within each stage and certain discontinuities at their boundaries. This certainly contributes to two distinct traditions in career research in which time has played a particularly prominent role, namely classic career studies in the form of models of the developmental and career stages through which actors pass during their lives (e.g., Bateson, 1989, 2011) and studies that focus on timetables as playing an important role in describing and understanding careers (e.g., Lawrence, 1984). By better integrating the temporal perspective into career studies, we decisively improve the understanding of the career phenomenon: instead of a static, momentary view of people's job-related positions and experiences, the concept of career now captures how these positions and experiences develop or, conversely, remain stable over time. Here we enrich the view of career with the important facet of the contemporary phenomenon of personal branding as a career catalyst, which has not yet played a role in the career literature.

Third, we extend the understanding of personal brands, which is strongly oriented towards a static proposition, to the processual view of personal branding over time. We thus empirically respond to the scholarly call (Keller, 2013; Gander, 2014; Lunardo et al., 2015) to highlight time as an indispensable factor in the creation of personal brands and have added to the few existing examples of viewing personal brands as true narratives (Lindridge and Eagar, 2015; Preece and Kerrigan, 2015). The application of an alternative template, visual mapping, and temporal bracketing as commonly recommended strategies to make sense of process research strategies (Langley, 1999; Langley et al., 2013; Gehman et al., 2013) was successful in our study. It significantly broadened the consideration of the personal branding process, especially as we have taken into account the fact that top managers' personal brands also "need to evolve with career changes and trends in the field" (Philbrick and Cleveland, 2015, p. 188). We have significantly expanded the previously limited understanding of the 'what' and 'how' in the emergence of top managers' personal brands by identifying and structuring relevant key practices and activities. The integrative framework consisting of practice, praxis, and practitioners from strategy-as-practice research (Whittington, 2006) was helpful in exploring the managerial work underlying personal brand development. We would like to pay special attention to the key practice of 'managing visibility, with the activities in 'on-field/off-field visibility' being exemplary for an aspect of personal branding. We have significantly developed and substantiated this aspect from its previous beginnings (Parmentier and Fischer, 2012) by considering its change during the course of the personal branding process.

In addition, we have followed up on the findings of earlier studies on the emergence of personal brands and can specifically confirm them. Our selection of the sample group is in line with the distinction between the concept of 
person brands who are celebrities (Thomson, 2006) and person brands who are professionals (Parmentier and Fischer, 2012) and are not famous beyond a restricted field of endeavor.

On-field visibility through professional publications early in one's career, as well as off-field visibility through personal engagement in societal issues as a top manager, leads to being known as a personal brand in one's field of practice (Close et al., 2011; Parmentier et al., 2013; Zamudio et al., 2013), but also to a fieldspecific capital that increases personal brand equity (McQuarrie et al., 2013; Rein et al., 2006). Our study can confirm that the activities of professional brands in the two relevant fields from a field theory perspective, i.e., in the field of the specific organization the professional brand is currently working for and in the broader field of which this organization is a member (Parmentier and Fischer, 2021), are also relevant for the emergence of top managers' personal brands. Smith and Fischer's (2020) summarizing statement that "person brands are built by accumulating field specific capital forged through forming high status social connections, achieving institutionally well-recognized accomplishments, and/or receiving prestigious awards regarded as valuable by others in the field" (ibid., p. 259) also applies to our results. Thus, relationships with influential people are forged at the upper levels of the hierarchy in the field of the organization and in the field of industry. Commercial project successes meet the expectations of the business organization and being named as a special manager in a leading manager magazine is highly recognized in the field of top managers.

A final contribution can be made to the usefulness of a multi-method approach in empirical studies. The combination of process research strategies with cross-case and within-case analysis and an integrative framework from strategy-as-practice research resulted in the construction of an expanded, differentiated, and profound complexity of the managerial practice of 'personal branding' for top managers. This may also encourage other researchers to adopt a similar approach.

\subsubsection{Practical contributions}

How can the findings from this study support managers and top managers in developing or sustaining their personal brand? We established distinct key practices across career phases, each of them posing dualities and overcoming the challenges accompanied by these dualities. Although we are not able to outline an instruction manual at this point, we still can draft implications for three distinct target groups, i.e., professionals and managers, top managers, and those people who support them in their personal branding.

Depending on the stage of their career that professionals and managers have entered on their path to becoming top managers, the key practices presented provide support for raising awareness of their own activities as well as for their 
implementation. It depends very much on how effectively one recognizes the dualities involved and how one overcomes them in order to move on to the next career phase. Here, we particularly point out the importance of keeping a balance between 'standing out' and 'fitting in,' which changes over the course of a career. In order to maintain this balance and overcome this duality, we advise a continuous and reflective change of perspective. From an external perspective or from a metalevel, it is possible to assess how strongly pronounced 'standing out' and 'fitting in' should be in a given situation in order to make personal progress. The development of skills on the company political level and in the tactical area helps to expand one's scope of action for goal-oriented activities.

Top managers who are already working on their own personal brand but are now faced with expanding their brand exposure are advised to actively manage off-field visibility in its duality with on-field visibility, which changes over the course of a career. We recommend that top managers do not rely on their initial professional qualifications or their own professional expertise from the early stages of their career. The off-field visibility that contributes to the necessary external company visibility requires a conscious expansion of skills and experience in the areas of management, strategy, leadership, and communication. Only then can the top management function be filled and social activities successfully implemented, which adds to the top managers' personal brand.

People who support the first two target groups, such as coaches and staff from human resources management and communication units, may perceive our findings as practice-oriented inspirations. They may use them for aligning with the individual activities of the branded individuals they are responsible for but also for building comprehensive programs, for instance in leadership development.

\subsection{LIMITATIONS AND FURTHER RESEARCH}

In spite of contributing to a more comprehensive, nuanced, and profound knowledge of managerial practices, personal branding, and career development as well as their intertwined and complex construct, we need to discuss some limitations of our study and inspirations for future research that emerged during our empirical work.

From a methodological point of view, we limited our sample to six German top managers from different industries. On the one hand, the application of our empirical approach to a numerically larger study group of top managers is obvious. On the other, the comparison between different companies and industries seems to be necessary to consider contextual characteristics that influence the brand building process over the course of careers. Sociological field theories offer a lens 
that has already been applied to understand how professional brands are managed simultaneously in the field of the specific organization the top manager is currently working for and in the broader field of which this organization is a member (Parmentier and Fischer, 2021). These insights may be transferred to other sectors in order to identify to what extent, for instance, regulatory framework conditions of industries such as the financial sector and the energy and telecommunication industries have an impact on personal branding in comparison to non-regulated industries such as the event industry. While the prevailing management theory developed in the US and applied worldwide (House, 1998; Triandis, 2004) suggests that modern management practices are largely cross-cultural, this should also be explored for the managerial practice of 'personal branding.' Finally, with the gender heterogeneous composition of our research group, we were not able to identify gender-specific differences for the personal branding of top managers, which should be covered by future research.

We have clarified the 'what' and 'how' in the management practice of 'personal branding' and have recognized that the development of a top manager brand is based on overcoming dualities through strategizing. On the one hand, we suggest that these dualities be investigated more deeply and enriched by additional empirical studies in the field of top manager brands. On the other, the top managers surveyed in our study provided even further guidance concerning the 'what' and 'how'. Frank, for instance, was aware that "With [employer of Frank] I have exceptional visibility." This indicated an endorsement effect from the corporate brand to the personal brand of the top manager, which was confirmed by Dean who stated, "That I keep making the [leading trade fair of Dean's current employer] better and stronger, great, that gives me my brand. But it will lose some of its shine if I stop being with this company." Therefore, it seems worthwhile to investigate empirically how the personal brand of top managers interacts with the corporate brand of the company in which they work.

Beside the 'what' and 'how', the'why' still needs deeper investigation. We suggest examining the antecedents of the individual personal brand and considering their impact on the individual personal branding process. This could include the family background and other factors that imprint and form the personal brand personality. We positioned the managerial work underlying personal branding from a methodological individualist perspective, taking into account the agency bias inherent in this social theory. The construction of the personal brand personality is a part of personal branding practices that cannot be entirely controlled by the top manager and therefore may add a structuralist position to the perspective on this managerial practice. In addition, it can be assumed that decision-making in the course of the personal branding process is context-dependent and to some extent involves reflections on the past, present, and future on behalf of the top manager. 
Thus, the study over time of personal brands in general, and the personal brand of top managers in particular, through the lens of temporal work (Emirbayer and Mische, 1998; Kaplan and Orlikowski, 2013) offers a valuable approach to an even better understanding of personal branding. 


\section{IN FOR A PENNY, IN FOR A POUND? EXPLORING MUTUAL ENDORSEMENT EFFECTS BETWEEN CELEBRITY CEOS AND CORPORATE BRANDS}

In this chapter, different indications from the previous two chapters converge to explore one particular aspect that contributes to understanding how top managers' personal brands work. The celebritization of CEOs derived from the distinction between icons, celebrities and personal brands of ordinary people (Chapter 2), as well as the fact that the top managers' personal brand is the result of a collective branding process in which different stakeholders are involved as endorsers (Chapter 3 ) result in the quantitative investigation of brand meaning transfer effects between top managers' personal brand and corporate brand. This step shows that the concept of brand endorsement is applicable to celebrity CEOs and indicates a mutual brand meaning transfer effect between the personal brand of top managers and the corporate brand.

\section{Publication history}

The earliest version of this chapter was written together with Dr. Carsten Gelhard and Prof. Dr. Jörg Henseler as a conference paper and subsequently presented at the $11^{\text {th }}$ Global Brand Conference in Bradford, United Kingdom, from April 27-29, 2016. A full paper has been submitted to the Journal of Product and Brand Management for publication in 2018. This full paper is presented in this chapter.

\section{References to previous publications}

Scheidt, S., Gelhard, C. V., \& Henseler, J. (2016). Boon or bane: how top manager brands spill over into company brands. In 11th Global Brand Conference 2016, Bradford, United Kingdom.

Scheidt, S., Gelhard, C., Strotzer, J., \& Henseler, J. (2018). In for a penny, in for a pound? Exploring mutual endorsement effects between celebrity CEOs and corporate brands. Journal of Product \& Brand Management, $27(2), 203-220$.

\section{Keywords}

Corporate brand, Experiment, Meaning transfer, Personal branding, Celebrity endorsement, Celebrity CEO 


\section{ABSTRACT}

While the branding of individuals has attracted increasing attention from practitioners in recent decades, understanding of personal branding still remains limited, especially with regard to the branding of celebrity CEOs. To contribute to this debate, this paper aims to explore the cobranding of celebrity CEOs and corporate brands, integrating endorsement theory and the concept of meaning transfer at a level of brand attributes. A between-subjects true experimental design was chosen for each of the two empirical studies with a total of 268 participants, using mock newspaper articles about a succession scenario at the CEO level of different companies. The study is designed to analyse the meaning transfer from celebrity CEO to corporate brand and vice versa using 16 personality attributes. This study gives empirical support for meaning transfer effects at the brand attribute level in both the celebrity-CEO-to-corporate-brand and corporatebrand-to-celebrity-CEO direction, which confirms the applicability of the concept of brand endorsement to celebrity CEOs and the mutuality in co-branding models. Furthermore, a more detailed and expansive perspective on the definition of endorsement is provided as well as managerial guidance for building celebrity CEOs and corporate brands in consideration of meaning transfer effects. This study is one of only few analysing the phenomenon of meaning transfer between brands that focus on non-evaluative associations (i.e., personality attributes). It is unique in its scope, insofar as the partnering relationship between celebrity CEOs and corporate brands have not been analysed empirically from this perspective yet. It bridges the gap between application in practice and the academic foundations, and it contributes to a broader understanding and definition of celebrity endorsement.

\subsection{INTRODUCTION}

The branding of individuals is increasingly attracting attention from professional practitioners (Peters, 1999; Montoya, 2004; Rampersad, 2009). In particular, celebrities have become a staple feature of mainstream media, as evidenced by recent reports that the former Mayor of London, Boris Johnson, "battles to turn brand Boris from "comedy act" to leading man" (Rigby and Parker, 2015, p. 3). They have also become an object of interdisciplinary interest, covering various academic disciplines, such as sociology (Furedi, 2010; Kurzman et al., 2007), psychology (Li, 2007; Moulard et al., 2015), information technology (Alghawi et al., 2014; Elwell, 2014) and educational science (Edmiston, 2014).

Celebrities appear as a phenomenon of post-modernism in which "we are witnessing the alteration of human roles due to the multiplying spaces or to 
deconstructing structures" (Rotaru et al., 2010, p. 330). Consequently, there is no single consistent definition of what a celebrity is, and, in addition, there remains considerable room for enriching this definition, which this study will contribute to. Contemporary celebrity status is not limited to actors and actresses (e.g., Jennifer Aniston and Johnny Depp) or singers (e.g., Bono and Alicia Keys). It has come to cover a variety of other celebrity types (Moulard et al., 2015) that also include artists (Fillis, 2015; Preece and Kerrigan, 2015), politicians (Speed et al., 2015) and business personalities such as Carly Fiorina (Johnson, 2008) or Richard Branson (Rein et al., 2006). In particular, celebrity CEOs are gaining increasing attention in management and marketing research. While prior research has consistently shown that certain certifications impact celebrity CEOs' compensation positively (Malmendier and Tate, 2009; Wade et al., 2006) or that a CEO's reputation serves as a proxy for managerial ability (Graffin et al., 2012; Milbourn, 2003), previous research on the impact of celebrity CEO's on company-related outcomes, such as stock returns, was inconclusive. Whereas some researchers have found a positive relationship between CEO reputation (Agarwal et al., 2011; Milbourn, 2003) or award-winning CEOs (Wade et al., 2006) and stock-based pay sensitivities, others allude to negative corporate performance evaluation due to CEO's reputation (Fombrun, 1996; Rajgopal et al., 2006) and awards (Malmendier and Tate, 2009). To contribute to this debate, the study at hand examines the effects of a CEO's personal brand on the corporate's brand, and vice versa.

Proposed meaning transfer effects between a CEO's personal brand and a corporate's brand is conceptually grounded in the concept of celebrity endorsement, defined as "an agreement between an individual who enjoys public recognition (a celebrity) and an entity (e.g., a brand) to use the celebrity for the purpose of promoting the entity" (Bergkvist et al., 2016, p. 644). While research in this area is mostly limited to athletes and movie stars, a more precise understanding of the endorsement roles of celebrity CEOs is crucial to explore the nature and effects of a CEO's personal brand. The major mechanisms forming the basis of celebrity CEO endorsement are the source credibility model (Ohanian, 1990; Silvera and Austad, 2004), congruence theory (Friedman and Friedman, 1979; Mittelstaedt et al., 2000), co-branding (Fournier, 2010; Parmentier and Fischer, 2012; Preece and Kerrigan, 2015) with spill-over effects (Swaminathan et al., 2012) and the brand personality (Aaker, 1997; Eisend and Stokburger-Sauer, 2013; Lee, 2014). They coherently accentuate that the interaction between brands can be characterized by a meaning transfer (Bergkvist and Zhou, 2016). This central notion is further supported by previous work of cultural theorists, such as McCracken (1989), who proposed that it is the celebrity's cultural meaning and transfer of meaning that drives endorsement outcomes.

While previous research has shown that meaning transfer might indeed occur between celebrity CEOs and corporate brands, empirical evidence is still scarce, and comparatively little is known about how this process operates. Drawing on 
existing literature on the humanization of brands (Aaker, 1997; Aggarwal and McGill, 2012), we refer to the concept of brand personality as a theoretical lens for exploring the mechanism of celebrity CEO endorsement. Brand personality "grasps the set of human personality traits ascribed to a brand" (Eisend and StokburgerSauer, 2013, p. 951) resulting when consumers attribute human characteristics to nonhuman forms, such as brands.

To empirically examine how a celebrity CEO transfers meaning to a corporate brand and vice versa, the study at hand uses a between-subjects true experiment using a set of 16 human personality attributes. The results provide new theoretical insights into what specific attributes possess the potential to turn CEOs into successful celebrity CEO endorsers and, thus, into the meaning transfer process from celebrity CEOs to corporate brands. Moreover, this study generates the first empirical evidence that a corporate brand can serve as a source for an endorsement to a CEO through personality attributes. It additionally contributes to the literature on cobranding insofar as the partnering relationship between celebrity CEOs and corporate brands is two-sided and, thus, calls for an analysis and development of co-branding models that must not be restricted to one direction between the partner brands. Apart from providing insights into a more detailed and expansive perspective on the definition of endorsement, the study derives valuable managerial implications for building celebrity CEOs and corporate brands in consideration of meaning transfer effects.

\subsection{THEORETICAL BACKGROUND AND HYPOTHESES}

\subsubsection{Celebritization of CEOS}

The contemporary phenomenon of celebrity has seen countless definitions from merely "being famous" (Epstein, 2005; Furedi, 2010), "well-known for his wellknownness" (Boorstin, 2012; Epstein, 2005), "the few, known by the many" (Banister and Cocker, 2014), "result of great good luck" (Milner, 2010), "celebrated not for doing, but for being" (Banister and Cocker, 2014) to "not born, but made" (Epstein, 2005). Similarly, the notion of celebrity has been substituted by various other abstract terms, including "heroes", "stars", "superstars", "television personalities", "idols" or "icons" (Epstein, 2005; Holmes and Redmond, 2006). A more integrated understanding of celebrities implies the distinction between an ascribed status based on bloodline or family relationships, an achieved celebrity status that originates from talent or accomplishments and the attributed celebrity (Rojek, 2012). The latter seems most in line with the contemporary type of celebrity, manufactured and made famous by media publicity alone (Furedi, 2010; Kerrigan et al., 2011; Lindridge and Eagar, 2015; Milner, 2010; Rojek, 2014; Turner, 2004). 
The vast and complex celebrity industry contains celebrity-creating institutions, from paparazzi to public relations experts to reality television. In most cases, celebrities are exploited in the promotion of some special interest, such as selling commodities or influencing political decisions (Cashmore and Parker, 2003; Milner, 2010). While they may benefit from their status, celebrities may also suffer from a temporary loss of ownership of celebrity images and their shift from celebrity producer to industry reproducer to the audience, and they might become a virtual hostage to the brand recognized and expected by the public (Lindridge and Eagar, 2015). This also applies to ordinary people, as new media, and the Internet in particular, supports them in shaping their own personal brand (Khedher, 2014). Correspondingly, the phenomenon of celebrities and the cultural personal branding movement are closely linked together. Personal branding faces numerous interpretations and definitions (Zarkada, 2012), emptying into a triangular view of:

- what the branded individual brings in, such as values, competencies, skills, abilities, personality (Gander, 2014; Philbrick and Cleveland, 2015);

- audience and target group orientation and the public (Bendisch et al., 2013; Preece and Kerrigan, 2015);

- $\quad$ and the differentiation from others (Harris and Rae, 2011; Shepherd, 2005).

While some discussions of celebrity assume that the state of celebrity entails being famous beyond a restricted endeavour (McCracken, 1989; Turner, 2004), others emphasize that celebrities are usually nothing more than a more publicized version of ordinary people (Boorstin, 2012; Kerrigan et al., 2011). If celebrities are people the public is interested in, it can be argued that "some, but not all, person brands are celebrities" (Parmentier and Fischer, 2012, p. 109). This lack of an accurate distinction between individuals who enjoy public recognition and those who are not known or who are buried in oblivion characterizes the contemporary view of celebrities in the era of post-modernism (Hearn, 2008; Lair et al., 2005; Vallas and Cummins, 2015). The inevitability of building a personal brand is additionally justified by the fear that individuals who do not use the concept of brands as a metasemiotic ideology to regiment their selves into legible employable personas risk are marginalized or left behind (Harris and Rae, 2011; Lair et al., 2005; Shepherd, 2005). "If you don't brand yourself, someone else will" (Kaputa, 2016) appears as a slogan of post-industrial socioeconomic transformation, in which the traditional bases of solidarity erode significantly with a decay of trust in any overarching system of values. Instead, cultural changes encourage a dominant ethos of radical individualism (Arnould and Thompson, 2005; Zarkada, 2012) with fame and attention gaining significant importance and people mutating into "gossip-hungry consumers" (Mills et al., 2015, p. 1). This supports the rise of a culture of promotionalism, with the postmodern celebrity brand as a life-defining resource (Hearn, 2008). Celebrity has become far 
more attainable than traditional movie stardom. Being within reach of ordinary people (Hearn, 2008; McQuarrie et al., 2013), it confirms a central feature of postmodernism: "the collapse of the hierarchic distinction between high culture and mass culture" (Rotaru et al., 2010, p. 328). Accordingly, there is growing concern over the fact that there are innumerable individuals vying for the coveted topdog status in the marketplace (Shepherd, 2005). The more people have acquired a status symbol, the less distinctive it is and the less status it confers on its holders (Milner, 2010; Rotaru et al., 2010). Simply said, "even if it were possible that we could all be famous, if everyone were famous, then no one would be famous" (Holmes and Redmond, 2006, p. 14). Thus, how much room is there for celebrities to not step out from the celebrity zone and step into the zone of ordinary personal brands? "Celebrity", Kurzman et al. $(2007,363)$ said, "is status on speed", resulting in "instant celebrities" (Furedi, 2010, 493) and star favourability eroding substantially over time (Luo et al., 2010). Because of the contradictory forces affecting media visibility, namely, the need for constant renewal and the competition for that scarce resource that is public attention, there is a rapid turnover of celebrities in the media.

New forms of media (e.g., searches on Google, sharing via Facebook, networking on Linkedln and broadcasting on YouTube) are becoming central elements that shape the postmodern paradigm (Rotaru et al., 2010) and making it difficult to precisely determine where the analogue, embodied self of a celebrity ends and the digital, virtual self begins (Elwell, 2014; Gershon, 2014). While identity fragmentation due to multiple identities on the internet may be taken as a risk (Brivio and Ibarra, 2009), the fragmented self may also serve as a means to achieve freedom. As with other aspects of the digital extended self, the challenge is to adapt to as well as control all of the new possibilities for self-presentation (Belk, 2013; Gershon, 2014). Celebrity examples show that many of these identities can be connected to one another, resulting in a networked ecosystem of digital selves (Elwell, 2014), and characterized by the rise of what Holmes (2002) has called "the flexible personality": perpetually active and willing to innovate and to change personal affiliations at a moment's notice. Former football player David Beckham, for instance, embraces multiple masculinities, including the romantic and compassionate husband, the hands-on father, the football legend and the fashionable style icon (Cashmore and Parker, 2003; Cocker et al., 2015; Vincent et al., 2009).

Recognizing the importance of celebrities in contemporary society, their relationships with customers must not be disregarded. Customers borrow from celebrities in the construction of their own identities (Cocker et al., 2015; Cohen, 2001; Lunardo et al., 2015; Maltby et al., 2002; Zarkada, 2012). To this end, Twitter, Instagram and others offer celebrity platforms in the virtual world of social media, while charities (e.g., charity portals such as Omaze, IfOnly or CharityStars) connect celebrities and ordinary people in real life. The latter covers the experiential 
perspective, beside the traditional information processing perspective, where value is considered to reside not in a sense-making, cognitive process, but in the experience of consumption (Arnould and Thompson, 2005; Payne et al., 2008; Payne et al., 2009). Neotribalism, which is characterized by fluid and temporary assemblies of individuals, may foster collective identifications. Celebrity Cruises, for example, offer opportunities for "collaborative customisation [that] has the potential to generate experiences that are truly tailored to the requirements of consumers and thus satisfy diverse groupings within a highly fragmented market" (Weaver, 2011, p. 57).

Taken together, celebrities appear as a fluid phenomenon if we accept that there is "no Unitarian postmodernist theory, but more likely a set of perspectives, of post-modern theories that sometimes coexist with each other, including the modern perspective" (Rotaru et al., 2010, p. 330). The fraying of the categorical terminology mirrors both the loss of accurate distinctions between human roles in post-modernism and the economic law that the demand for and manufacturing of new celebrities lead to new celebrity categories beyond movie stars, singers, entertainers or sports stars (Fillis, 2015; Furedi, 2010; Kerrigan et al., 2011; Lunardo et al., 2015; Moulard et al., 2015). Celebrity CEOs constitute an additional celebrity category that gains increasing attention in media and substantially impacts on business and society. Outstanding corporate performance associated with idiosyncratic behaviour or management practices have made individuals such as Richard Branson, Warren Buffett or Elon Musk more noteworthy and ready to be singled out by the media (Hayward et al., 2004). Very often, they appear more like rock stars than traditional business executives (Johnson, 2008). However, the burden of celebrity lies in ever-increasing expectations that push celebrity CEOs into pursuing high-risk, high-reward strategies (Fombrun, 1996; Graffin et al., 2012). Furthermore, holders of responsibility and power are regularly exposed for abusing their authority caused in a culturally ingrained suspicion of the exercise of authority (Furedi, 2010). In this context, negative media coverage has the potential to damage both the image of the corporate enterprise and its CEO (Jin and Yeo, 2011). Celebrity CEOs are also viewed as corporate spokespersons, representing their company's values with a "master's voice" the public is eager to listen to (Ferns et al., 2008). Additionally, numerous examples indicate the impact of celebrity CEOs particularly on a company's performance. The announcement of Kasper Rorsted's move from the helm at cosmetics and adhesives maker Henkel to become the CEO of sportswear company Adidas resulted in Henkel's shares falling by 4.8 per cent, offset by Adidas's share price increasing 8 per cent, representing $£ 2.2 \mathrm{bn}$ in market capitalization (Jervell, 2016).

It can reasonably be argued that celebrity CEOs might serve as a management instrument for endorsement. Celebrity endorsement, defined as "an agreement 
between an individual who enjoys public recognition (a celebrity) and an entity (e.g., a brand) to use the celebrity for the purpose of promoting the entity" (Bergkvist and Zhou, 2016, p. 644), is one of most popular means to enhance marketing communications. Brand endorsement effects, such as brand attitudes and behaviour towards the brand (Amos et al., 2008; Choi and Rifon, 2007), negative brand evaluation effects caused by the perceived lack of a fit between the celebrity and the brand (Lafferty, 2009), as well as financial effects on sales (Elberse and Verleun, 2012; Garthwaite, 2014) or share prices (Nicolau and Santa-María, 2013), represent a central piece of a brand's advertising strategy.

Previous research on celebrity CEOs indicates that there is general agreement in the public about a corporate's reputation and performance being attributed to the image of its CEO (Alghawi et al., 2014; Bendisch et al., 2013; Fetscherin, 2015). In particular, some evidence for the impact of employing award-winning CEOs on stock returns has been found by scholars, both in positive (Koh, 2011; Wade et al., 2006) and in negative terms (Malmendier and Tate, 2009). Media coverage may lead celebrity CEOs to become overconfident in their own managerial ability, which may, in turn, lead to lower levels of performance, as they underestimate the impact of external factors and are forced to pay higher premiums for acquisitions (Hayward and Hambrick, 1997).

\subsubsection{Celebrity CE0 endorsement mechanisms}

The humanization of brands provides some unmistakeable prospects for a deeper understanding of the underlying mechanisms concerning celebrity endorsements. Consumers tend to ascribe uniquely human characteristics and features to non-human beings, natural phenomena, material objects and brands (Aaker, 1997; Aggarwal and McGill, 2007; Fournier, 1998). This phenomenon of anthropomorphizing results in the creation of brand personalities which encompass the set of human personality traits, also known as personality attributes, that are both applicable to and relevant for brands (Aaker, 1997; Eisend and StokburgerSauer, 2013), such as product and corporate brands or, indeed, celebrities (McCutcheon and Maltby, 2002).

While there is general agreement about effects transferred from presenter to product through celebrity endorsement, e.g., as a neural mechanism (Stallen et al., 2010), and about the fact that celebrity CEOs serve as endorsers for their corporate (Bendisch et al., 2013; Fetscherin, 2015; Graffin et al., 2012), prior research is silent about mutual endorsement effects between celebrity CEO and corporate brand or about how these endorsements may work. The literature on source credibility and on congruence represents a starting point for a more holistic understanding of the phenomenon of celebrity CEO endorsement. When explaining celebrity endorsements, numerous source credibility studies emphasize the celebrity 
Table 4.1: Endorsement mechanisms and their implications to celebrity CEOs

\begin{tabular}{|c|c|c|c|}
\hline Mechanism & Key Content & Sources & Implications \\
\hline $\begin{array}{l}\text { Source } \\
\text { Credibility } \\
\text { Model }\end{array}$ & $\begin{array}{l}\text { The celebrity being } \\
\text { the source of a } \\
\text { communication } \\
\text { and the consumer } \\
\text { being the receiver; } \\
\text { three dimensions } \\
\text { of source credibility } \\
\text { (trustworthiness, } \\
\text { expertise, attractiveness). }\end{array}$ & $\begin{array}{l}\text { Arai et al., 2014; Ohanian, } \\
\text { 1990; Silvera and Austad, } \\
2004\end{array}$ & $\begin{array}{l}\text { Celebrity CEOs credibility } \\
\text { as an endorser is based on } \\
\text { that he/she is trustworthy, } \\
\text { attractive, and provides } \\
\text { expertise in his field which } \\
\text { refers to be professional. }\end{array}$ \\
\hline $\begin{array}{l}\text { Congruence } \\
\text { Theory }\end{array}$ & $\begin{array}{l}\text { Congruence of the } \\
\text { product with the } \\
\text { celebrity creates a more } \\
\text { favorable impact on } \\
\text { consumer attitudes than } \\
\text { that of an incongruent } \\
\text { celebrity-product } \\
\text { combination. } \\
\end{array}$ & $\begin{array}{l}\text { Bergkvist et al., 2016; } \\
\text { Lafferty 2009; Simonin } \\
\text { and Ruth 1998; Amos et } \\
\text { al., 2008; Choi and Rifon, } \\
2007\end{array}$ & $\begin{array}{l}\text { Congruence and fit } \\
\text { respectively, in the } \\
\text { combination of celebrity } \\
\text { CEO and corporate leads to } \\
\text { a more positive perception } \\
\text { of this combination by } \\
\text { consumers compared to } \\
\text { incongruence. }\end{array}$ \\
\hline $\begin{array}{l}\text { Meaning } \\
\text { Transfer Model }\end{array}$ & $\begin{array}{l}\text { The celebrity personifies } \\
\text { a set of meanings to } \\
\text { the consumer; these } \\
\text { meanings get transferred } \\
\text { to the brand from the } \\
\text { celebrity through an } \\
\text { endorsement. }\end{array}$ & $\begin{array}{l}\text { McCracken, 1989; } \\
\text { Bergkvist and Zhou, } 2016\end{array}$ & $\begin{array}{l}\text { Celebrity CEOs transfer } \\
\text { evaluative and non- } \\
\text { evaluative associations to } \\
\text { a brand (e.g., a corporate } \\
\text { brand); customers then } \\
\text { consume this set of } \\
\text { meanings. } \\
\end{array}$ \\
\hline Co-Branding & $\begin{array}{l}\text { Two or more individual } \\
\text { brands, products, } \\
\text { or other distinct } \\
\text { proprietary assets are in } \\
\text { combination; } \\
\text { a co-brand may } \\
\text { positively influence } \\
\text { quality perceptions of } \\
\text { unobservable product } \\
\text { attributes of a partner } \\
\text { brand. }\end{array}$ & $\begin{array}{l}\text { Close et al., 2011; Fillis, } \\
\text { 2015; Fournier, 2010; } \\
\text { Parmentier and Fischer, } \\
\text { 2012; Preece and } \\
\text { Kerrigan, 2015; Speed et } \\
\text { al., 2015; Swaminathan et } \\
\text { al., 2012 }\end{array}$ & $\begin{array}{l}\text { The partnering between } \\
\text { a celebrity CEO and a } \\
\text { corporate brand implies } \\
\text { that specific attributes spill } \\
\text { over from each brand to } \\
\text { the other and thus have } \\
\text { an impact on perception } \\
\text { of the celebrity CEO and } \\
\text { the corporate brand } \\
\text { respectively. }\end{array}$ \\
\hline Brand Alliance & $\begin{array}{l}\text { A brand is presented in } \\
\text { the context of another } \\
\text { brand and vice versa } \\
\text { to form a synergistic } \\
\text { alliance. }\end{array}$ & $\begin{array}{l}\text { Erevelles et al., 2008; } \\
\text { Gammoh and Voss, 2011; } \\
\text { Park et al., 1996; Rao and } \\
\text { Ruekert, 1994; Rodrigue } \\
\text { and Biswas, 2004; } \\
\text { Simonin and Ruth, } 1998 \\
\end{array}$ & $\begin{array}{l}\text { A celebrity CEO-corporate } \\
\text { brand combination will } \\
\text { create an impact on each } \\
\text { party's brand and will } \\
\text { shape attitudes toward the } \\
\text { alliance. }\end{array}$ \\
\hline $\begin{array}{l}\text { Brand } \\
\text { Personality }\end{array}$ & $\begin{array}{l}\text { The set of human } \\
\text { characteristics } \\
\text { associated with a } \\
\text { brand used through } \\
\text { anthropomorphism. }\end{array}$ & $\begin{array}{l}\text { Aaker, 1997; Aggarwal } \\
\text { and McGill, 2012; Eisend } \\
\text { and Stokburger-Sauer, } \\
\text { 2013; Lee, } 2014\end{array}$ & $\begin{array}{l}\text { Celebrity CEOs as natural } \\
\text { human beings and other } \\
\text { brands (e.g., corporate } \\
\text { brands) are ascribed to be } \\
\text { associated with human- } \\
\text { like characteristics (e.g., } \\
\text { age, skills, attitudes, traits/ } \\
\text { attributes), which facilitates } \\
\text { the consumer-brand- } \\
\text { relationship building. }\end{array}$ \\
\hline
\end{tabular}


as the source of communication and the consumer as the receiver (Arai et al., 2014; Ohanian, 1990). Source credibility comprises three dimensions, namely, trustworthiness, expertise and attractiveness (Ohanian, 1990) that have an impact on consumer attitudes.

The theoretical argument for the importance of congruence is that perceived lack of celebrity-brand congruence leads to negative attributions which, in turn, lead to negative brand evaluation effects (Bergkvist et al., 2016; Lafferty, 2009). On the other hand, researchers found that congruence of the product with the celebrity creates a more favourable impact on the consumer attitudes compared to an incongruent celebrity product combination (Amos et al., 2008; Choi and Rifon, 2007).

However, evidence about the impact of these credibility dimensions and of celebrity-brand-congruence on consumer attitudes is inconsistent. The situation asks for a more expansive view of endorsements (Roy, 2012). Therefore, McCracken (1989) indicates that celebrity endorsement models also need to take into account the various meanings with which celebrities are imbued. His meaning transfer model (McCracken, 1989) has become well established in celebrity endorsement, suggesting that celebrities transfer a wide range of associations to the brand (Bergkvist and Zhou, 2016). Those associations can be evaluative, i.e., measured directly and thus dependent on judgement (e.g., price or age), or non-evaluative, i.e., measured by a means or instrument and thus immediately comparable (e.g., positive or negative character and personality traits). As customers consume the set of meanings associated with the product rather than the actual product or service, the objective of celebrity endorsement should be to transfer a set of meanings (Miller and Allen, 2012). Prior literature has mostly limited the concept of meaning transfer to conventional advertising (McCracken, 1989). This, however, appears to be outdated in the fragmented contemporary world, where social media and mass media afford the consumer more control over the distinction between celebrities and meanings (O'Reilly, 2005). Advertising has experienced a revolution to a twoway conversation, in which listening, involving, engaging and staying in continuous communication with the customer are now essential elements of delivering a message to potential customers (Arnould and Thompson, 2005; Wetsch, 2012). Customers assume a more active role in the meaning transfer process, deriving considerable meaning from advertisements without necessarily consuming the goods that they advertise (Ritson and Elliott, 1999). They experience celebrities as socially and not just managerially constructed cultural brands (Banister and Cocker, 2014; O'Reilly, 2005). Moreover, the required multistage model, incorporating all contacts of celebrities with customers (Swain, 2004), has resulted in the rise of integrated marketing communications as a strategic concept, rather than a tactically oriented tool to build brand equity (Kitchen et al., 2004). 
Customers taking over a more active role in the meaning transfer process resonate with the concept of co-branding. Two essential effects characterize cobranding: First, the alliance's aggregated brand value is greater than the value of each partner's individual brand value. This synergy effect (Lee, 2014) can be explained by applying the maximum rule (Murphy, 1988), instead of the additive rule (i.e., the sum is greater than the individual parts; Rao and Ruekert, 1994). Second, the spill-over effect implies that the value of the brand alliance is greater for each partner than without the alliance in cases of a positive spill-over effect (Lee, 2014; Swaminathan et al., 2012). The main success factor contributing to this effect is identified in the perceived fit between the two allying brands (Radighieri et al., 2014; Swaminathan et al., 2012), which results from a high level of consistency between the two brand images (Baumgarth, 2004). Considering the continued lack of clear selectivity between co-branding and brand alliances (Erevelles et al., 2008) and the fact that co-branding has even been taken as the ultimate form of brand alliance strategies (Helmig et al., 2008; Kippenberger, 2000), the mutual endorsement of celebrity CEOs and corporate brands can be regarded as an active brand alliance. Both co-branding and brand alliances affect the same processes (i.e., meaning transfer and associative learning), and both produce associative networks (Halonen-Knight and Hurmerinta, 2010). Complementarity between partnering brands is also a motivational factor for building a brand alliance (Choi and Jeon, 2007) and has been identified as an important variable influencing consumers' evaluations of brand alliances (Park et al., 1996) beside other factors, such as prior attitudes towards each brand (Rodrigue and Biswas, 2004; Simonin and Ruth, 1998). In general, spill-over effects and meaning transfer are closely connected to the concept of brand alliances, where a brand is presented in the context of another brand and vice versa to form a synergistic alliance, resulting in how consumers react to the brand alliance and in an impact on each party's brand (Dickinson and Barker, 2007; Erevelles et al., 2008; Rao and Ruekert, 1994; Simonin and Ruth, 1998; Gammoh and Voss, 2011). This impact can be beneficial, for instance, through securing competitive advantages in the marketplace (Park et al., 1996; McCarthy and Norris, 1999), but it might negatively influence partnering brands as well (Rao and Ruekert, 1994; Simonin and Ruth, 1998; Helmig et al., 2008).

With regard to celebrities, the concepts of brand alliance and of co-branding elucidate that celebrities can gain end consumer awareness by fraternising with figures from the entertainment world (Parmentier and Fischer, 2012). Moreover, the transfer process from highly accepted institutions to celebrities and co-branding strategies around celebrities leading ideological campaigns and moral crusades confirm the suitability of celebrities for co-branding strategies. Co-branding is assumed to work too for the partnering relationship between celebrity CEOs and corporates, but research appears reluctant here from a branding perspective (Table 4.1). 
Derived from this theoretical discussion, it can be hypothesized that celebrity CEO attributes transfer to corporate brand attributes and, vice versa, that corporate brand attributes transfer to celebrity CEO attributes:

H1. Celebrity CEO attributes transfer to corporate brand attributes.

H2. Corporate brand attributes transfer to celebrity CEO attributes.

\subsubsection{Celebrity CEO attributes}

To investigate meaning transfer with personality attributes, defined as "relatively enduring styles of thinking, feeling, and acting" (McCrae and Costa, 1997, p. 509), a hybrid approach was chosen for select relevant attributes. First, bibliographic research of academic literature was conducted to reveal the personality attributes that are ascribed to CEOs and celebrity CEOs respectively and the models as well as theories applied to them. This revealed that prior literature has primarily considered age, education, organizational or position tenure and functional background of the CEO as human characteristics that have an impact on their corporates, e.g., in the form of corporate performance (Herrmann and Datta, 2006; Hsu et al., 2013). Considering that a general factor of brand personality embraces numerous characteristics, such as gender, age or others (Eisend and Stokburger-Sauer, 2013; Rushton, 2012), and thus induces a construct validity problem, this study had to focus on a more narrowly determined approach and refer to specifically nominated personality attributes. Therefore, as a second step in this hybrid approach, a pretest was conducted to define 16 relevant brand attributes for both celebrity CEOs (Study 1 ) and corporates (Study 2) as the dependent variables. The available brand attributes were identified through a review of academic and business literature and were confirmed by individual semi-structured interviews $(n=12)$ with a sample group that matches the sample group in the experiments in terms of its composition. Emphasis was placed on the clarity of the attributes. In doing so, the attributes were verified in terms of whether they are readily understandable, have a single meaning that is known to the respondents and do not imply any irony. Moreover, ordinary terms that match the vocabulary level of the sample group were used, while redundancies and synonyms were eliminated (Couper, 2000).

In the following, we outline the attributes that resulted from the hybrid nomination approach and were tested in the study at hand with regard to meaning transfer between celebrity CEO and corporate brand. The nominated attributes are "successful", "innovative", "tolerant", "trustworthy", "transparent", "stable", "creative", "progressive", "likeable", "credible", "agile", "professional", "international", "responsible", "famous" and "authentic". Nonetheless, it needs to be acknowledged that this list of attributes cannot claim to be exhaustive. 
"Successful" managers or organizations are always expected to produce high performance (Boynton and Zmud, 1984). As CEOs are already at the peak of their careers and the organizational hierarchy, they are already successful, which confirms the self-reliance-equals-success myth (Lair et al., 2005). While celebrity status is commonly associated with being "successful" (Furedi, 2010, p. 493), the attribute "successful" is named as an important attribute for an endorser brand (Arai et al., 2014), and it is suggested for a transfer from CEO to the corporate brand (Bendisch et al., 2013).

"Innovative" organizations "transform ideas into new/improved products, service or processes, in order to advance, compete and differentiate themselves successfully in their marketplace" (Baregheh et al., 2009, p. 1334). CEOs may adopt company values, such as being innovative, if they work for an innovative company (Bendisch et al., 2013). In turn, innovative CEOs identify fast-changing market needs, deal with their weak internal R\&D capacities and may use customers' knowledge to obtain fresh ideas and respond quickly to market changes (Ahn et al., 2014), which is something the corporate organization can then benefit from.

From a social sciences perspective, tolerance refers to the belief that all cultures ought to be given equal respect. The notion of tolerance and the related ideas of human dignity and self-determination have always been at the basis of the strong appeal enjoyed by the construct of culture (Wainryb, 2006). Celebrity CEOs as part of contemporary culture may be perceived or even expected to be "tolerant" as well.

Trust refers to situations that are characterized by one party (i.e., the trustor) who has a general propensity to be willing to depend on others (i.e., the trustees), resulting in the trustee being perceived as "trustworthy". This is expected to be applicable for both interpersonal trust, where the direct object is the other specific individual (i.e., the celebrity CEO), and institution-based trust, implying that the trustor trusts the structure (i.e., the corporate) or situation (McKnight and Chervany, 2001). For building successful brands, there is an urgent need for first building trust, especially as trust seems to be a shrinking commodity in post-modern societies (Ternès et al., 2014). Following past literature, "trustworthiness" is named as an important attribute for an endorser (Arai et al., 2014; Braunstein and Zhang, 2005; Erdem and Swait, 2004; Ohanian, 1990).

"Transparency" can be defined as "an individual's subjective perception of being informed about the relevant actions and properties of the other party in the interaction" (Eggert and Helm, 2003, p. 103). Furthermore, transparency in relationships has been argued to involve the sharing of information and knowledge about important characteristics of the other person (Eggert and Helm, 2003). As celebrity CEOs are also viewed as corporate spokespersons representing their company's values (Ferns et al., 2008), this may also hold for customer-brand relationships with regard to celebrity CEOs and corporate brands. 
Stability is defined as:

The degree to which the celebrity is perceived as unwavering. Celebrities that exhibit stability are those who are firm and steadfast in their words, actions, principles, and their mental and physical characteristics (Moulard et al., 2015).

While CEOs appear to be "stable" by building reputation (Bendisch et al., 2013), work as a primary source of individual identity became much less stable as companies began to lay off large numbers of workers (Lair et al., 2005).

While most theories describe creativity as a process by which an individual produces creative ideas that includes both skill and motivational elements, the definition of creativity primarily appears as a combination of novelty and appropriateness (Amabile, 2012). Although the attribute "creative" has not yet been ascribed to CEOs from the scholars' side, the definition above suggests the applicability of this attribute to CEOs.

Being "progressive" means to provide constantly expanding and deepening insights as well as a sense of change (Carr et al., 2001). The antonym "traditional" is used in organizational research, being associated with a concern for morality, high standards, appropriate social behaviour and a lifestyle guided by specific, established principles and respect for authority figures (Giberson et al., 2009). Numerous examples, such as conventional car manufacturers, show that companies aim to balance the progressive and the traditional approach, and that they try to employ a suitable CEO who represents both attributes.

Brodsky et al. (2009) identified a list of verbal and nonverbal components associated with high likeability, such as a pleasant facial expressions and smiles, the use of "we" or "us" when referring to groups, demonstration of a less controlling attitude, physical attractiveness, a low degree of arrogance exhibited in verbal responses and the use of informal speech. There exists evidence that less likability is expected for large firms' CEOs compared to small firms' CEOs and for CEOs compared to non-CEOs (Graham et al., 2010). Additionally, more mature-looking CEOs are less likable (Graham et al., 2010), and "likeable" personalities have been identified as a factor for an athlete's ability to act as an endorser (Braunstein and Zhang, 2005).

Erdem and Swait (2004, p. 193) defined brand credibility as "the believability of the product information contained in a brand, which requires that consumers perceive that the brand continuously deliver what has been promised". As credibility is considered as an essential element for celebrities to be endorsers (Arai et al., 2014; Ohanian, 1990), the CEO's attribute "credible" is assumed to be transferred to the company (Bendisch et al., 2013).

Conboy and Fitzgerald (2004, p. 40) define agility as "the continual readiness of an entity to rapidly or inherently, proactively or reactively, embrace change, 
through high quality, simplistic, economical components and relationships with its environment". Although scholars have not yet used "agile" as an attribute of CEOs, the definition above suggests its applicability to CEOs.

Professionalism is described as a "set of attitudes and behaviors believed to be appropriate to a particular occupation and represents the active demonstration of the traits of a professional" (Hammer, 2000). Celebrity researchers distinguish between professional or on-field skills and marketing or off-field skills, stating that both are needed in general for self-branding (Fillis, 2015). Additionally, professionals are subject to strict codes of conduct, enshrining rigorous ethical and moral obligations, which apply to both the celebrity CEO and the corporate. Numerous examples, such as the Volkswagen's Dieselgate affair, indicate that there is a meaning transfer here.

CEOs' "international" experience is associated with a firm's level of international diversification, reduced levels of uncertainty in international operations, increased awareness of international opportunities and superior ability to manage operations in different countries (Black, 1997; Sambharya, 1996) and, thus, has a significant positive relationship with corporate performance (Hsu et al., 2013). Additionally, CEOs' international experience further contributes to the development of a "global mindset" throughout the organization (Kedia and Mukherji, 1999), which may reciprocally have an impact on the people working in such an organization.

What matters most for being "responsible" in a business context is the morality and accountability of managers (Windsor, 2001). Whereas responsibility as an organizational characteristic is assigned to management boards in the AngloSaxon hemisphere (Balmer, 2001), global business managers in general have the over-riding responsibility to further their companies' global-scale efficiency and competitiveness (Bartlett and Ghoshal, 2003). The idea of meaning transfer concerning responsibility suggests itself.

People and organizations that are widely known and respected for their achievements are considered to be "famous". The fame of a CEO is assumed to be inextricably linked with the reputation of the company, and a CEO's name and fame is important to identify and distinguish the company from others (Bendisch et al., 2013). Moreover, consumers identify with famous athletes (Carlson and Donavan, 2013) and products as well as corporate brands because they are perceived to be symbolic of desirable reference groups. Thus, meaning transfer might happen between celebrity CEOs and corporate brands for the attribute "famous".

Authenticity is defined as "the perception that a celebrity behaves according to his or her true self" (Moulard et al., 2015, p. 175). While consumers exhibit an increased focus on authenticity and have begun to look for authentic brands (Lunardo et al., 2015) in general, being "authentic" appears as a key success factor in the branding of celebrities (Moulard et al., 2015; Speed et al., 2015) and hence potentially for celebrity CEOs. 


\subsection{EMPIRICAL STUDIES}

\subsubsection{Research design and pre-test}

A between-subjects true experimental design that includes a posttest-only control group (Bakker et al., 2007; Hartmann and Apaolaza-lbàñez, 2012; Henseler et al., 2009) was chosen for each of the two empirical studies examining meaning transfer. This experimental design promises to a high degree of control and a randomisation in the selection of test units and their assignment to experimental groups (Malhotra and Birks, 2007) as used in this study.

A mock newspaper article (Elving, 2013; Morwitz and Fitzsimons, 2004; Raska, 2011) of about 300 words was used as a stimulus during the experiment, followed by a questionnaire to assess given brand attributes.

The choice of a student sample group (i.e., business students from a German university), qualifies as research subjects, as fundamental research is conducted in this study (Bello et al., 2009; Pernice et al., 2008). Furthermore, students may also be potential consumers (Megehee, 2009) or even future business leaders and can be expected to have broader knowledge of the business world in general in view of their higher level of education. It can therefore be reasonably argued that their views on celebrity CEOs and corporates are well-founded and would promise reliable and meaningful results. Moreover, students tend to be homogeneous on demographic, psychographic and educational dimensions. Such apparent homogeneity makes student samples easier to compare than other groups of people (Peterson and Merunka, 2014) and, thus, helps ensure internal validity. While the majority of the sample group, i.e., 83.3 per cent in Study 1 and 90.4 per cent in Study 2, are German native speakers, non-native speakers among the participants successfully completed a German language test to be accepted for their study. It can be expected that all subjects understood the mock newspaper articles, the survey questions and especially the attributes. However, an effect caused in the culture of individual respondents cannot be excluded completely.

During the pre-test, unprompted questions as well as aided questions which the subjects were asked led to the nomination of two celebrity CEOs and two corporate brands, reflecting the highest numbers of mentions by the sample group. This refers to brand awareness that is related to the identification of a brand under different conditions and the ability to retrieve the brand from memory when given a relevant category (Keller, 2013), i.e., the CEO and industry in this pre-test.

The two individual celebrity CEOs, i.e., Mark Zuckerberg and Dieter Zetsche, were nominated based on the level of public awareness, their strong profile and the expected divergence in terms of the elicited meaning transfer effects. It might seem worthwhile investigating celebrity CEOs with different genders in such an empiric study, but female celebrity CEOs are completely unrepresented in Germany, 
which is where the study was conducted. With that in mind, no such figures were used here. The perceived brand images of Mark Zuckerberg and Dieter Zetsche were used as independent variables in Study 1[1].

The pre-test served to determine the independent variables for Study 2 as well, i.e., the brand images of two nominated suitable companies. Again, the level of awareness and the distinct perceptions were important nomination criteria. Moreover, we decided to conduct Study 2 with companies from the same industry to increase the reliability of the experiment. With this in mind, BMW and Opel were nominated as two representatives of the car manufacturing industry. Whereas Opel operates under a different name in some regions, for instance as Vauxhall in the UK, as Chevrolet in Argentina and Brazil, and as Buick in North America and China, Opel is very well known in Germany, since it was founded there in 1862, took the German market's leadership in the 1960s and 1970s, and gained increasing media attention as a result of massive redundancies as well as financial difficulties in the past few years. Studies conducted in Germany, confirm Opel's high brand awareness of 75 per cent and of almost 90 per cent for BMW (Goebel, 2011).

Our emphasis on the celebrity CEOs' names and corporates' names follows the finding of De Chernatony (2001) that a brand's name receives most consumer attention and is a key influencer on perceptions of quality compared to all other marketing variables.

\subsubsection{Experiment procedure and data collection}

\subsubsection{Empirical study 1}

The first study aimed to test the hypothesis that celebrity CEOs brand attributes transfer to corporate brand attributes $(H 1)$.

The participants were randomly assigned to one of two experimental groups in a controlled environment, i.e., during a lecture in a lecture hall, supervised by two lecturers, with no incentive for participating in the study. After excluding incomplete questionnaires, our final response sample was 132 subjects. Their ages ranged from 19 to 36 years, with a mean of 23.76 years. In total, 59 female and 73 male respondents participated, and each of the two experimental groups had 66 participants.

In a paper-based document, the participants were asked to answer questions concerning their demographic data, including age, gender, native language and degree course. The results showed the homogeneity within the sample group, which supported a higher validity of the experiment.

Second, they were presented with a mock newspaper article, in which a fictitious corporate was described in unbiased terms to reduce the risk of intervening variables. The text stated that one of the two celebrity CEOs being nominated in the pre-test, has been announced to become the next CEO of that fictitious 
company. Two versions of the newspaper article were developed in response to the pre-test, differing only in the choice of the celebrity CEO, Mark Zuckerberg or Dieter Zetsche, mentioned as the new CEO. This manipulated the perceived celebrity CEO brand images enacted in each case at the brand attribute level. Furthermore, this procedural method and the fact that no measurement of the dependent variable was conducted before the presentation of the mock newspaper article, i.e., a pretest-post-test control group design was not applied, ensured high internal validity by avoiding testing effects (Malhotra and Birks, 2007). As the respondents were not informed about the purpose of the study, it is to be expected that demand artefacts did not arise; thus, neutrality was supported significantly (Malhotra and Birks, 2007).

Finally, all respondents completed a survey composed of two sections. First, the questions asked about the respondents' perception of how the fictitious corporate might develop in future, referring to the facts presented in the mock newspaper article. In these questions, the 16 brand attributes revealed in the pre-test were applied on a semantic differential scale, i.e., a rating scale whose end points are opposite labels. Specifically, the respondents rated the brand attributes on sevenpoint rating scales (Coelho and Esteves, 2006) that were defined at each end with two opposite expressions, such as "successful" and "unsuccessful" (Morwitz and Fitzsimons, 2004). In addition, the positive rating was sometimes put at the right and sometimes at the left side of the scale to prevent the respondents marking the right or left column of the scale without properly reading the brand attributes (Naresh and Birks, 2007). Moreover, filler tasks, represented by questions about the company beyond brand attributes, were used to disguise the purpose of the experiment (Raska, 2011). The respondents were then asked to rate their perceptions of the celebrity CEO in question. Depending on which questionnaire they were randomly assigned, the respondents either had to rate the brand attributes of Mark Zuckerberg or Dieter Zetsche. Again, the 16 brand attributes were successively presented on a semantic differential scale, but without any interjacent filler tasks.

\subsubsection{Empirical study 2}

The second study aimed to test the hypothesis that corporate brand attributes transfer to celebrity CEO attributes $(\mathrm{H} 2)$.

The design of this second experiment was similar to the first experiment with no incentive for participating the study. Neither the sample group of the first empirical study nor the sample group of the second empirical study had been informed about the other study to keep them unbiased. However, it needs to be acknowledged that subjects of a student sample group may be dependent on their lecturer or feel to be forced to participate and, thus, respond differently compared to an independent group. The participants were randomly assigned to one of two 
experimental groups. They were given a link to an online version of the experiment. In total, 136 respondents delivered complete questionnaires. Their ages ranged from 19 to 51 years, with a mean of 26.3 years. A total of 82 female and 54 male subjects participated, and 66 answered the questionnaire on BMW and 70 the questionnaire about Opel.

The initial questions concerning demographic data (i.e., age, gender, native language and degree course) were followed by a mock newspaper article that introduced a fictitious CEO in unbiased and neutral terms. He was announced as the next CEO of either BMW or Opel, depending on the version of the newspaper article. This manipulated the perceived corporate brand images in question at a brand attribute level. Subsequently, the respondents completed a questionnaire that asked them about their perceptions of how the fictitious CEO might develop in future referring to the mock newspaper article. The 16 brand attributes revealed in the pre-test were applied to a scale of a design similar to the first experiment. Depending on which questionnaire they were randomly assigned, the respondents had to rate the brand attributes of either BMW or Opel. The procedural method to avoid testing effects and to ensure neutrality (Malhotra and Birks, 2007) was similar to the first experiment.

\subsubsection{Findings}

\subsubsection{Empirical study 1}

First, a manipulation check was conducted on the perceived celebrity CEO brand images to ensure the experimental validity of the research design. A set of independent sample $t$-tests revealed significant differences $(p<0.05)$, which showed that the manipulation was successful for 12 brand attributes: "progressive" (0.000), "famous" (0.000), "creative" (0.000), "international" (0.000), "successful" (0.000), "innovative" (0.000), "agile" (0.000), "transparent" (0.000), "professional" (0.000), "responsible" (0.000), "trustworthy" (0.016) and "credible" (0.037). Therefore, we met the requirements given by Perdue and Summers (1986) "to establish that the manipulation produced a large enough variance in the indented independent variable to provide for a meaningful test of the hypotheses of interest" (Perdue and Summers, 1986, p. 321).

Second, $H 1$ was tested by a statistical analysis that used a multivariate analysis of variance (MANOVA). This showed a significant meaning transfer effect from celebrity CEO to corporate brand, $F(12,119)=6.306, p=0.000$. Therefore, $H 1$ is supported by this experiment. At the level of brand attributes as key dimensions of brand knowledge, the MANOVA showed significance for "famous" $(F(1,130)=$ $25.884, p=0.000)$, "creative" $(F(1,130)=17.420, p=0.000)$, "international" $(F(1,130)=$ $12.031, p=0.001)$, "transparent" $(F(1,130)=8.601, p=0.004)$, "progressive" $(F(1,130)$ 
$=7.203, p=0.008)$, "credible" $(F(1,130)=5.416, p=0.022)$ and "professional" $(F(1,130)$ $=4.030, p=0.047)$. These brand attributes differ depending on which celebrity CEO, Mark Zuckerberg or Dieter Zetsche, was announced as the new CEO of the fictitious corporate. However, tests of between-subject effects indicated that not all brand attributes provide a transfer effect from celebrity CEO into corporate brand, namely, "successful", "innovative", "agile", "responsible" and "trustworthy".

\subsubsection{Empirical study 2}

First and in a similar process as was used in the first experiment, a manipulation check was conducted to ensure the experimental validity of the research design concerning the perceived corporate brand images as independent variables. A set of independent sample $t$-tests showed that the manipulation was successful for 15 brand attributes, with significant differences $(p<0.05)$ : "successful" $(0.000)$, "stable" (0.000), "innovative" (0.000), "agile" (0.000), "professional" (0.000), "creative" (0.000), "trustworthy" (0.000), "international" (0.000), "authentic" (0.000), "responsible" (0.000), "famous" (0.000), "likeable" (0.000), "credible" (0.004), "progressive" (0.004) and "tolerant" (0.004). As in the manipulation check for the first main hypothesis, we can state that the requirements for a meaningful test of the hypothesis were met (Perdue and Summers, 1986).

Second and again as in the first experiment, $\mathrm{H} 2$ was tested by a statistical analysis that used a MANOVA. The MANOVA with $F(15,120)=2.60, p=0.002$ showed that $\mathrm{H} 2$ is supported by this second experiment, indicating that there is a significant meaning transfer effect from corporate brand to celebrity CEO. At the level of brand attributes, a test of between-subjects effects showed significance for "successful" $(F(1,134)=16.423, p=0.000)$, "international" $(F(1,134)=10.744, p=$ $0.001)$ and "professional" $(F(1,134)=5.601, p=0.022)$. These three brand attributes differ depending on which company, BMW or Opel, announced the fictitious CEO as their new CEO (Figure 4.1).

\subsection{GENERAL DISCUSSION}

\subsubsection{Theoretical implications}

While current literature suggest that celebrity CEOs can act as brand endorsers, i.e., that meaning transfer occurs between celebrity CEOs and corporate brands, empirical evidence is still scarce, and relatively little is known about how this process operates. Making use of an experimental setting, the study at hand answers the call for more rigorous research. Its contribution is at least fourfold.

First, this study provides new theoretical insights into what specific attributes possess the potential to turn CEOs into successful celebrity CEO endorsers. 


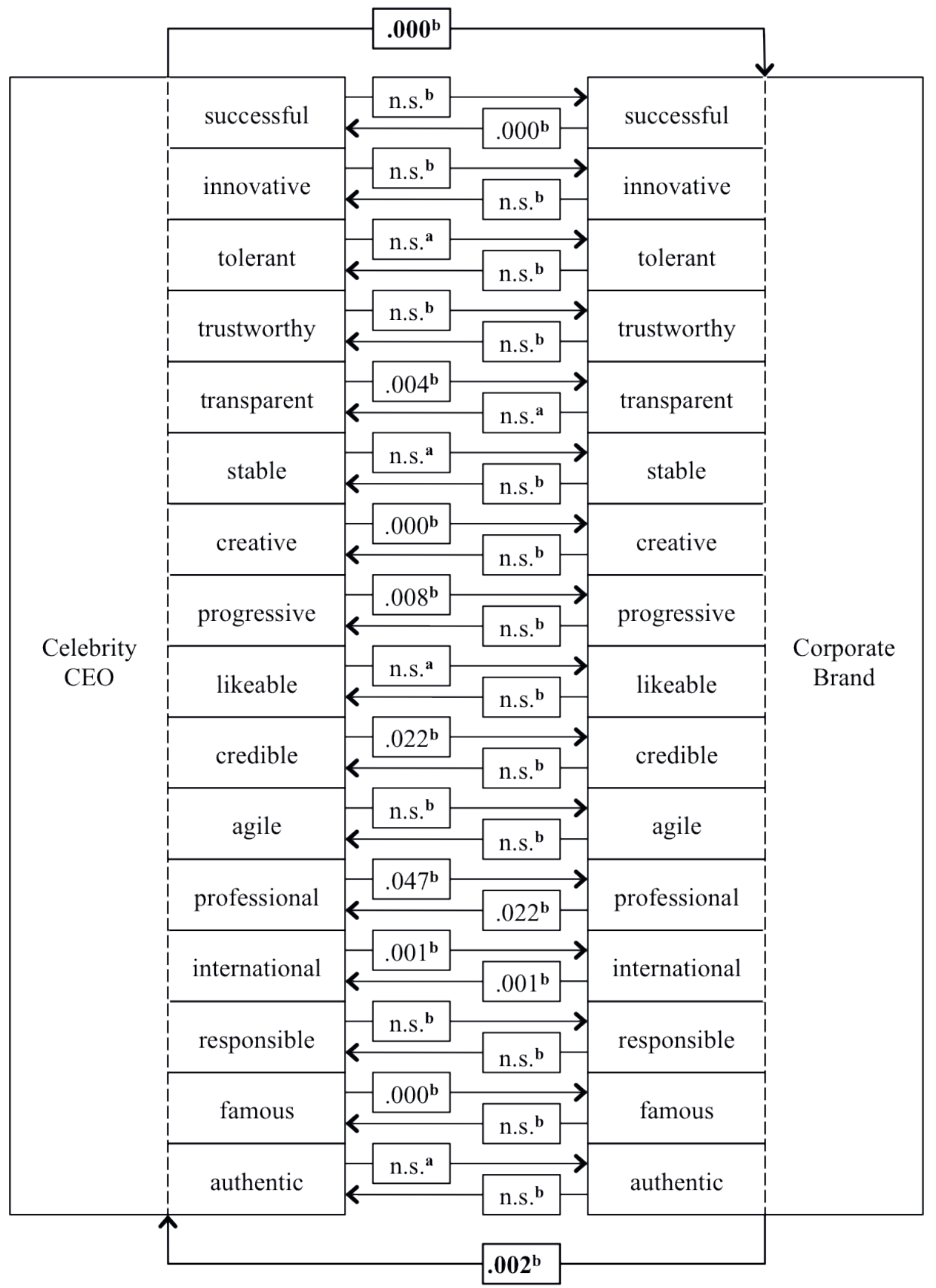

Note: n.s. $=$ non-significant; ${ }^{a} t$-test $(p<0.05) ;{ }^{\text {bMANOVA }}(p<0.05)$

Figure 4.1: Expanded conceptual framework findings 
Whereas prior literature has predominantly considered demographic and functional associations (e.g., age, tenure and educational background), the study at hand applies a more anthropomorphised and thus distinctive view by identifying non evaluative associations as underlying carriers of meaning between celebrity CEOs and corporate brands. In particular, our results show that "famous", "creative", "international", "transparent", "progressive", "credible" and "professional" as attributes can contribute to the establishment of celebrity CEO endorsers and, thus, to the meaning transfer process from celebrity CEOs to corporate brands.

Considering prior literature (Black, 1997; Hsu et al., 2013; Kedia and Mukherji, 1999; Sambharya, 1996), this study extended the impact of an international CEO on corporates in the form of a meaning transfer of the attribute "international" from celebrity CEO to corporate brand. The suggestion of professional skills that are needed in general for self-branding (Fillis, 2015) is also extended in that the celebrity CEO perceived as professional indeed reveals a meaning transfer effect with the corporate brand. Furthermore, the study at hand provides evidence to support the assumption that the fame of a CEO is inextricably linked with the corporate (Bendisch et al., 2013). Finally, this empirical research confirms that credibility is an essential element for celebrities to be endorsers (Arai et al., 2014; Ohanian, 1990) and especially for celebrity CEOs in their meaning transfer to a corporate brand, which confirms the assumption of Bendisch et al. (2013).

In contrast to several scholars, several suggestions and empirical findings are not supported by this study with specific regard to celebrity CEOs. This concerns especially the attributes "likeable" (Braunstein and Zhang, 2005), "trustworthy" (Arai et al., 2014; Braunstein and Zhang, 2005; Erdem and Swait, 2004; Ohanian, 1990) and "successful" (Arai et al., 2014) that are named as important attributes for endorsers. Moreover, the suggestion of transferring the attribute "successful" from CEO to corporate brand and the attribute "innovative" from corporate brand to CEO (Bendisch et al., 2013) is disproved. Being "authentic" may remain a key success factor for the branding of celebrities (Moulard et al., 2015; Speed et al., 2015), but it does not work in meaning transfer from celebrity CEO to corporate brand.

Second, this study contributes to the under-researched area of "brand-to celebrity transfer" (Bergkvist and Zhou, 2016). Existing literature on associations transferring between brands has predominantly considered endorsement from a celebrity-to-brand-perspective (Bergkvist et al., 2016; Eisend and Langner, 2010), which underpins the celebrity CEO taking the role as the endorser. Arsena et al. (2014), however, show that brand traits may also transfer to people who are associated with the brand. The present research extends these findings and supports a broader view of endorsements by demonstrating which personality attributes can be transferred from an organizational brand to a person brand as meaning transfer between these two brands. As such, the findings eventually 
provide the first empirical evidence that a corporate brand can serve as a source for an endorsement to a CEO. In particular, "successful", "international" and "professional" are revealed as personality attributes that make a corporate brand an endorser for the CEO. With regard to the predominant manufacturing of celebrity CEOs by media publicity (Furedi, 2010; Kerrigan et al., 2011; Lindridge and Eagar, 2015; Milner, 2010; Rojek, 2014; Turner, 2004), a more expansive approach of taking the corporate brand and its meaning transfer into account for celebritization of CEOs needs to be suggested.

Third, by showing that a meaning transfer occurs from the CEO celebrity brand to the corporate brand as well as from the corporate brand to CEO celebrity brand, the endorsement between celebrity CEO and corporate brand can be characterized as two-sided. This is particularly supported for the attributes "international" and "professional". For the other attributes, the present research does not find evidence for mutual meaning transfer between celebrity CEO and corporate brand concerning any of the personality attributes used in this study. By this, we contribute especially to the literature on cobranding, which has generally traced a one-sided approach that produces outcomes for just one of the two partnering brands (Close et al., 2011; Fournier, 2010; Keller, 2003). The extension of this limited view on co-branding has wide-ranging implications. For instance, the mutual meaning transfer demonstrated in the study at hand calls for an analysis and development of co-branding models that must not be restricted to one direction between the partner brands. Moreover, reciprocal effects in co-branding models are to be considered, as this has significant impact on theory building as well as on applicability. Nonetheless, it has to be acknowledged that cobranding between celebrity CEO and corporate brand works for different brand attributes depending on the direction of the spill-over effect. Given the presence of reciprocal meaning transfer, it has to be confirmed that celebrity endorsement in general and particularly the celebrity CEO-corporate brand combination should be considered brand alliances, in which meanings and values can transfer from either partner to the other (Halonen-Knight and Hurmerinta, 2010).

Fourth, the results of the study provide an insight into a more detailed and expansive perspective on the definition of endorsement. Following prior literature, the definition of endorsement has been restricted to a general endorsement of products through celebrities in advertising. Here, the celebrity endorser has been primarily defined as "any individual who enjoys public recognition and who uses this recognition on behalf of a consumer good by appearing with it in an advertisement" (McCracken, 1989, p. 310). Considering the results of this study, this definition seems limited and dated. Borrowing from prior literature on celebrity endorsements (Bergkvist and Zhou, 2016; Keller, 2013; Miller and Allen, 2012) and drawing on the findings of the study at hand, a more differentiated view on 
endorsement needs to be suggested. A CEO endorsement, as one category of celebrity endorsement, may be defined as a celebrity CEO endorser is a CEO who receives public recognition and effects meaning transfer at the level of nonevaluative associations (i.e., personality attributes) to his or her corporate organization. Likewise, there exists evidence through this study that the corporate entity can act as an endorser. Precisely, it is suggested to define that a corporate endorser is a corporate brand that effects meaning transfer at the level of non-evaluative associations (i.e., personality attributes) to its CEO.

Taken together, extending and specifying the definition of endorsement resonates with the empirical setting and findings of this study and provides valuable guidance for exploring celebrity CEOs and their role as endorsers in its entity. Following up on this specification, future scholars should consider an endorsement between a celebrity CEO and a corporate brand as one-sided or mutual meaning transfer between the celebrity CEO and the corporate brand, depending on non-evaluative associations (i.e., personality attributes).

\subsubsection{Practical implications}

This study has several useful implications for different target groups, including marketers, brand manager, HR manager, advisory boards and, not least, CEOs.

Marketers should be encouraged to make use of the meaning transfer process from celebrity CEO to corporate brand. This calls for thinking outside the box of traditional marketing and for a more expansive understanding of the humanization of brands, of meaning transfer at the level of non-evaluative associations, and of cobranding between celebrity CEOs and corporate brands. Celebrity CEOs should play an active part in a company's brand advertising strategy to make the celebrity CEO more relatable. The brand-customer relationship needs to exist in the virtual world as much as in the real world to make full use of the reach in social media and of experiential effects. To reduce confusion or dilution, the celebrity CEO is ideally not linked to a number of other brands or otherwise overexposed (Keller, 2013). This, for instance, implies that the members or chairpersons of advisory boards should not be considered as preferred co-branding partners, as they typically hold several mandates.

HR professionals and advisory boards should be made more aware of meaning transfer effects during the recruitment processes for a new CEO. Specific attributes of the celebrity CEOs, i.e., "famous", "creative", "international", "transparent", "progressive", "credible" and "professional", should be given attention, as they provide meaning transfer to the corporate brand. The situation of the company may call for a celebrity CEO with specific image, skills or attributes, in the hope that these will be infused back into the organization, comparable to sports teams employing coaches depending on the team's situation. It is thus not always a matter of celebrity CEOs adapting to the corporate brand, but of corporate brands trying 
to acquire some of the non-evaluative associations of their CEOs. Moreover, the mutual transfer effects by the brand attributes "professional" and "international" ties in with brand managers who should strive to manage congruency between celebrity CEO and corporate brand. A good fit was illustrated, for instance, by Juergen Hubbert, the former boss of the Mercedes Car Group, who was called "Mister Mercedes" during his 45 years working for the Daimler group (Rother, 2005).

Furthermore, celebrity CEOs should be aware of their presence as a personal brand as well as brand attributes and the meaning transfer between their own brand and the corporate brand. Specifically, the brand attributes "international", "professional" and "successful" of the corporate brand should be analysed prior to a move, as they have a significant meaning transfer effect on celebrity CEOs.

Finally, practitioners such as coaches and consultants should be expected to understand celebrity endorsements as well as the meaning transfer processes between their CEOs and corporate clients, as they do not happen in isolation. Brand building is a collective development process, for CEOs and for corporate organizations alike, which goes beyond simple producer-consumer relationships (De Chernatony, 1999; Preece and Kerrigan, 2015). This area of responsibility can be expected to gain significant prominence for practitioners, supported by further research from the academic angle. This also applies to the idea that celebrity CEOs are brand assets for corporates, such as Richard Branson, who sustains his own celebrity brand and the Virgin brand (Bendisch et al., 2013). Whereas brand personality is accepted to be a dimension of brand assets (Kapferer, 2012), it still is questionable how exactly celebrity CEOs may serve as a brand asset.

Overall, we would suggest that the figure of the celebrity CEO is not simply the embodiment of the person of the CEO, but rather the result of meaning transfer as perceived by others (e.g., customers). Rather than focusing on how celebrity CEOs (sub)consciously develop their brands, managers, marketers and consultants should therefore see branding from a more holistic perspective, according to which they can establish a celebrity CEO through meaning transfer processes.

\subsubsection{Limitations and further research}

Celebrities have attracted the attention of marketing practitioners, but little academic attention has been given to celebrity CEOs or their endorsement. The findings of this study contribute to celebrity CEO research by deepening our knowledge of meaning transfer processes at a brand attribute level. However, as with almost any study, the research is also subject to certain limitations.

Although our findings can be deemed comparatively well-suited for generalization due to their sound theoretical grounding, the external validity of the study could be increased through replication. Even though the purpose of this study is fundamental research and "in spite of the belief that student samples 
are very homogeneous [...] only replications can assess the reliability, validity, and generalizability of research findings pragmatically" (Peterson and Merunka, 2014, p. 1040), Lindsay and Ehrenberg (1993, p. 236) remind us that, "If a study is worth doing at all, it's worth doing twice". Future research should expand this study to other kinds of sample groups, where the perception and understanding of celebrity CEOs and corporates may be quite different compared to students. Advisory boards, for instance, are expected to accept substantial responsibility for companies when deciding which celebrity CEO to appoint.

Mock newspaper articles about a fictitious corporate and CEO were used in this study to show meaning transfer processes at work. However, in the brand building process of both celebrity CEOs and corporate brands, primary associations also have to be considered on top of the secondary associations investigated in this study. Research into how different channels and means of communication, such as blogging, television news or a speech, or specific contents, for instance resignations or other announcements by a celebrity CEO, influence the branding of CEOs or their endorsement would seem useful. Although different types of communication are practised by celebrity CEOs, there still exists plenty of room for research compared to product branding.

Moreover, our research was conducted in Europe and focused on two specific large corporations from the car manufacturing industry and two specific male celebrity CEOs. Future studies could replicate this study in other regions as well as in different industries, focusing on mid-size companies, to develop a cross-cultural comparison of personal branding in global business and to compare different types of managers in terms of their age, cultural backgrounds, and gender. Gender differences in the mechanisms and, in particular, interactions between the CEO's gender and the respondent's gender remain an interesting question for future research. In addition, future research is encouraged to consider different chief officers, such as CFO, COO or CTO, as well as distinct types of CEOs, be it with regard to celebrity CEOs in general or concerning CEOs as endorsers. For instance, the distinction between "agent or non-founder CEOs" and "founder CEOs" is explored in terms of their relation with a firm's performance (He, 2008; Randøy and Goel, 2003; Shulman, 2010) or their influence on the firm (Nelson, 2010), but it is sorely missing for CEOs in their role as celebrities. Before all such differentiation, the need for generalization among leaders, executives or top managers has to be kept in mind, as they are given greater visibility in their fields and beyond, largely due to the platform afforded to them by social media.

Beside further research to address the limitations of this study, some additional areas for investigation immediately come to mind. Recognizing the importance of celebrities in brand-customer identification, a promising avenue for future research is to further investigate whether and how celebrity CEOs, not unlike parents, nations, singers or athletes, affect identity construction processes in consumers. 
Furthermore, the "brand-to-celebrity-CEO transfer" alone was covered this study, which calls for a deeper investigation.

Finally, studies should extend their examination of the partnering between personal brand and corporate brand in general and particularly the celebrity CEOcorporate brand combination to the concept of brand alliance (Simonin and Ruth, 1998), by expanding the scope of the relevant variables. While this study focused on meaning transfer and spill-over effects between celebrity CEOs and corporate brands, the questions remain as to which effects of this brand alliance may arise concerning the attitudes towards each party's brand and which impact each brand may have on the brand alliance. Furthermore, and by contrast to, for example, the alliance of two different product brands, there is still a lack of a clear description of the brand alliance or measurement of the resulting brand equity between partnering celebrity CEOs and corporate brands. With this in mind, the concept of brand alliances represents a valuable research phenomenon for further examination of celebrity-corporate brand combinations, for which this study may act as an initial empirical door-opener.

\subsubsection{Conclusions}

This study examined the phenomenon of meaning transfer between celebrity CEOs and corporate brands. It appears unique in its nature, as the mechanism of meaning transfer at the level of non-evaluative associations (i.e., personality attributes) has not yet been analysed empirically in terms of the partnering of celebrity CEO and corporate brand. We concluded that celebrity CEOs and corporate brands could be used as mutual endorsers, depending on specific personality attributes, and that co-branding between celebrity CEOs and corporate brands works reciprocally for the brand attributes "professional" and "international". Celebrity CEO endorsement as well as corporate brand endorsement receive a more expansive perspective but need to be explored in more detail in future.

Despite all of these new insights, this study again drew our attention to the striking gap between academics and practitioners in the field. From our point of view, it is not enough to just mind the gap; rather, it is an obligation for us to bridge this gap. Establishing the celebrity CEO as a rewarding object for further investigation may help do so, as it may be used even more for the dissemination of marketing ideas, knowledge and theories through the collaboration of practitioners and other academic disciplines.

\section{Note}

1 It is recognized that the background (e.g., gender, age, life story, track record, type of CEO such as agent CEO or founder (EO) of an individual celebrity CEO can be an antecedent to his/her brand attributes. While this study is meant to analyse meaning transfer from celebrity CEO to corporate brand and vice versa using 16 personality attributes, it does not investigate how each attribute has been created. 


\section{THE VALUE OF TEMPORAL WORK IN THE DEVELOPMENT OF TOP MANAGERS' PERSONAL BRANDS DURING THEIR CAREER}

This chapter advances the idea that careers and personal brands of top managers are developed over time and adds the approach that they need to be built in particular time contexts. given the idea that careers and personal brands are not only developed over time but must also be built in particular time contexts. By exploring the issue of time in the personal branding of top managers from the perspective of temporal work, this step shows how their personal brands emerged over time through making reflexive connections between their past, present and future at each stage of their careers.

\section{Publication history}

A section of this chapter, written together with Dr. Raymond Loohuis and Prof. Dr. Jörg Henseler, was submitted as a short paper and presented at $14^{\text {th }}$ Global Brand Conference in Berlin, Germany, from May 8-10, 2019. The previous version of this chapter was submitted as a full paper and presented at $36^{\text {th }}$ EGOS Colloquium, held virtually from July 2-4, 2020. Following the reviewers' suggestions and the conference participants' feedback, the full version of this chapter will be revised for submission to a journal, probably the Journal of Management Communication or the Journal of Management Studies.

\section{References to previous publications}

Scheidt, S., Loohuis, R., \& Henseler, J. (2019). See and be seen: How visibility affects the personal branding of top managers. In 14th Global Brand Conference 2019, Berlin, Germany.

Scheidt, S., Loohuis, R., \& Henseler, J. (2020, February). The value of temporal work and timing in the development of top managers' personal brands during their career. In 36th EGOS Colloquium 2020: Organizing for a Sustainable Future: Responsibility, Renewal \& Resistance.

\section{Keywords}

Personal branding, Top manager, Temporal work, Reflexivity, Process research 


\section{ABSTRACT}

Top managers know that time and timing are important aspects of building a personal brand as their careers develop. Although career research acknowledges the importance of time as a construct, so far it has been less explored empirically, particularly given the idea that careers and personal brands are not only developed over time but must also be built in particular time contexts. Therefore, this paper explores the issue of time from the perspective of temporal work on behalf of careerists as a fundamental mechanism to develop a personal brand. In doing so, we studied in depth the career-building trajectories of six top managers and how their personal brands developed over time through making reflexive links across their past, present and future. For each phase in career development, we explored and identified the key mechanisms in terms of actions and decision making to arrive at a generalized model of personal brand development. Theoretical contributions to the career and personal brand literature are made as well as the provision of guidance to practice.

\subsection{INTRODUCTION}

The issue of personal brand has increasingly attracted scholarly attention. Personal brands, defined as "a strategic process of creating, positioning, and maintaining a positive impression of oneself, based in a unique combination of individual characteristics, which signal a certain promise to the target audience through a differentiated narrative and imagery" (Gorbatov et al., 2018, p. 6), increasingly boost careers and provide benefits not only for the person who "owns" the brand in terms of career opportunity but also for employers.

So far, research has primarily focused on the antecedents (e.g., Hearn, 2008; Lair et al., 2005), the key ingredients (e.g., Arai et al., 2014; Moulard et al., 2015) and the outcomes of personal brands in terms of material profit (e.g., Carlson and Donavan, 2013) and social capital (e.g., Hanusch and Bruns, 2017), and has portrayed personal brands as a static construct. Yet, little is known about how personal brands are actually developed by careerists over time. More specifically, we do not know how time is involved in switching jobs, embarking on new opportunities, dealing with competition of peers, managing visibility, decision-making processes and background of careers, which constrain or enable the development of a personal brand over time.

This paper is devoted to examining how personal brands are developed over time and identifies the key actions underlying the development of a personal 
brand in successive stages of career development. Such an endeavour can be examined from multiple points of view. Rational choice theory, for instance, would suggest that a personal brand is the outcome of decision-making processes by an individual over time. In general, careerists are certainly determined to shape their own future and personal brand. However, we suggest that building a personal brand is not a mere future-oriented process that relies on rational decision-making, but a contextual- and temporal-dependent one. Therefore, in this paper we examine the development of a personal brand over time through the lens of temporal work (Emirbayer and Mische, 1998; Kaplan and Orlikowski, 2013), which suggests that decision-making is contextually dependent and somehow involves reflections on the past, present and future on behalf of the careerist.

Consequently, we posed two research questions. We first wanted to understand how interpretations of the past, present and future are incorporated in the efforts of top managers to build their own brand during their career trajectories. Second, we continued with discovering patterns in the actions and decisions that strengthen the development of a personal brand across all cases of the top managers that we studied.

Our sample is based on an in-depth study of the career trajectories of six successful, German top managers who managed to successfully develop their own personal brand. We analysed how each of them dealt with threats and opportunities during their careers which made them reflect on past experiences in the face of a present situation and essentially revise their future as necessary to sustain or improve their personal brand. Through cross-case analysis, we identified key mechanisms that helped these managers develop their personal brand, starting from the beginner phase, becoming a professional, promotion to manager and, finally, reaching the top manager level.

This paper contributes to further advancement of the literature on the role of personal branding in career development. First, we demonstrate how past experiences and present situations shape actions and decision-making in the development of a personal brand. Second, we show how these actions and decision-making are linked together from phase to phase.

The remainder of this paper is structured as follows. In the next section, we first review the literature on personal branding, particularly the antecedents, key ingredients and outcomes. Then we introduce the theoretical foundations of temporal work, followed by theorizing the concept for the study of personal brands developed from the perspective of contextually situated managers. In the following section, we describe the methods and analytical approach followed by results, discussion and conclusions in the subsequent sections. 


\subsection{LITERATURE REVIEW}

The contemporary phenomenon of personal branding is traced back to three key antecedents from the recent past and their joint impact in societal, economic and technological fields: the development of the new world of work with powerful social norms and pressures that promised stability in uncertain environments but has now become unstable; a new understanding of individualism developed as a countermovement to traditional collectivistic systems and resulting in a selfhelp movement; and the explosion of the Web 2.0 and social media that offer continuously evolving platforms for an emerging attention economy that selfbranding is directly related to (Fillis, 2015; Hearn, 2008; Lair et al., 2005).

Many scholars agree on a small number of elements that personal brands may consist of besides conceptual fragmentation, such as the branded individual's personality (Moulard et al., 2015), stakeholders who contribute to personal brand co-creation (Bendisch et al., 2013), and differentiation to set a personal brand apart from competitors in saturated job markets (Parmentier et al., 2013). Visibility is probably the most frequently mentioned element of personal brands, with the digital footprint that is expected increasingly to be created on social media platforms (Chen, 2013; Gander 2014). Further importance is ascribed to on-field visibility, i.e., visibility in the original field of practice or profession of the branded individual, as distinguished from off-field visibility outside this field to build a mainstream media persona (Parmentier \& Fischer, 2012). A transmedia model of storytelling and story-world construction may bundle the different individual visibility activities (Elwell, 2014).

Despite top managers' visibility in public, their consideration as personal brands from an empirical angle reveals a manageable amount of results to date. The endorsement, for instance, between celebrity CEO and corporate brand can be characterized as two-sided, which is particularly supported for the attributes 'international' and 'professional' (Scheidt et al., 2018). A measure scale containing seven dimensions, i.e., work standards, style, leadership, personality, values, character and teamwork, serves as a means for a CEO personal brand measurement (Chen and Chung, 2017). Career background, change leadership, relationship management, and firm brand are found to be the determinants of CEOs' personal brand construction (Erdoğmuş and Esen, 2018). Finally, career transitions of executives from the for-profit sector to the non-profit sector require frequent personal rebranding activities at each transitional stage, such as creating new networks of contacts and re-positioning their skills, knowledge and values within the context of their new organizations (Schlosser et al., 2017).

Top managers in particular and personal brands in general have been portrayed so far as static constructs, although scholars acknowledge that personal brands 
have to be managed in context and over time (Gander, 2014; Lunardo et al., 2015) to adapt to changing circumstances (Parmentier, 2010) or for timing in career changes (Philbrick and Cleveland, 2015; Labrecque et al., 2011). Branded athletes, for instance, face the deterioration of their physical ability with age (Hoeymans et al., 1997), resulting in a decrease of their appeal (Lunardo et al., 2015). After all, there are empiric insights first into viable means to extend the life expectancy of a personal brand, as can be seen in artistic careers and the artists' brand building as a series of statuses over time, following individual evolutionary paths which lead to a career trajectory with distinct, different stages, drawing upon the social and cultural context, rather than having a definite positioning (Preece and Kerrigan, 2015).

Despite general agreement that personal branding serves as a support for career development and that longevity has to be considered in personal brand development, and although progressing with the identification of key elements and an examination of top managers, research has been largely cross-sectional and static and disregards the time perspective of the human being when developing a personal brand over time. Therefore, we are not yet able to indicate, explain or even recommend how personal branding processes really work in a career framework in certain stages and over time. Consequently, there is a need to advance our knowledge in order to understand how top managers actually build their personal brand as an "evolving sequence of a person's work experiences over time" (Arthur et al., 1989, p. 8), resulting in a "pattern of a career actor's positions and condition within a bounded social and geographic space over their life to date" (Gunz and Mayrhofer, 2018, p. 71).

\subsection{THEORETICAL APPROACH}

Organizational and management researchers are interested in process theory and dynamic phenomena, such as organizational learning (Cohen and Sproull, 1991), competitive interaction (IIInitch et al., 1996), innovation and change (Van de Ven and Huber, 1990) and strategic evolution (Barnett and Burgelman, 1996), and they have applied process research to understand how things evolve over time and why they evolve in that way (Berends and Lammers, 2010; Bingham and Kahl, 2013; Gehman et al., 2013; Van de Ven and Huber, 1990; Van Oorschot et al., 2013). Nonetheless, process studies have historically been underrepresented, dramatically so in the case of retrospective process studies (Langley et al., 2013), and particularly in the nascent field of personal branding. Furthermore, process research may deal with the evolution of relationships between people or with the cognitions and emotions of individuals as they interpret and react to events (Isabella, 1990; Langley, 1999; 
Peterson, 1998). Consequently, we share the conviction of Langley et al. (2013, p. 10) that "there are important opportunities to address management and organizational concerns at the individual level of analysis and would encourage such research that might deal with such temporally evolving issues as careers, work-family balance, identity, work practices, and socialization from a process perspective".

From an epistemological perspective, process narratives provide different approaches for studying organizational change (Tsoukas, 2005; Van de Ven and Poole, 2005). The 'weak' process approach conceptualizes change as a succession of events, stages, cycles or states in the development or growth of an organization. Thus, substance has priority over process. In contrast, the 'strong' process approach supposes the world is composed of processes and claims that only research that adopts the processual perspective is suited for their study. Time may be so intimately connected with change and innovation here that it is useful to consider how it might be constructed during the process. Creating a vocabulary and grammar for expressing things in processual terms is expected to produce useful insights, too. Therefore, we deliberately use the term 'personal branding' instead of 'personal brand' to stay with a verb or process rather than a finished object or noun (Langley et al., 2013; Maguire and Hardy, 2013; Tsoukas, 2005; Weick, 1979) which, according to Van de Ven and Poole (2005), poses a threat to the identity of personal branding studies, the validity of studies in personal brands, and the coherence of studies of personal brands. An additional fundamental dichotomy in how to view realities lies in the objective versus the subjective perspective on time (Adam, 1994; Blyton et al., 1989; Jacques, 1982). The objective view treats time as linear, mechanical and quantitative, aligning this view with a Newtonian assumption of time. The clock has emerged as a primary metaphor in this conceptualization of time that provides a strong limitation as it neglects the active role of people in creating and shaping the temporal conditions of their lives (Orlikowski and Yates, 2002). In contrast, the subjective view determines time as a socially constructed conceptualization "defined by organizational members" (Clark, 1985, p. 36) and the result of the norms, beliefs and customs of individuals and groups.

A practice-based perspective on time that covers both the shaping of people's actions and their being shaped by structural conditions within and outside of their immediate control would focus on a set of practices known as 'temporal work' that links the subject's interpretations of the past, present and future to strategic action (Kaplan and Orlikowski, 2013). From this perspective the future is not a simple accumulation of outcomes that appear accidentally or that can be forecasted more or less accurately. Rather, it is shaped by the reflective practices of actors anticipating what might be possible. The role of the past is that actors reconstruct histories out of their different prior experiences, and the present directs attention through their multiple assessments of current concerns (Emirbayer and Mische, 1998). 
Originally applied to study how situated actors make sense of a breakdown of current strategic accounts (Kaplan and Orlikowski, 2013), we argue that using the concept of temporal work can be fruitful in grasping how managers make reflexive links to the past, present and future in the development of their personal brand. Temporal work happens when top managers are confronted with threats or opportunities during their careers that break down their current perception of their personal brand and force them to re-think the past, present and future, possibly leading to certain actions and decisions. Using this lens potentially reveals the temporal-reflexive dynamics of personal branding also present in Schön's (1983) notion of 'reflection-in-action' (Yanow and Tsoukas, 2009). It sheds light on how temporal work guides activities and affects visibility and social relations when top managers face changing circumstances that challenge their current situation. Finally, a temporal perspective on top managers' personal branding and their career building may advance the knowledge of how different career stages can be characterized in terms of tools to develop a personal brand for a careerist.

In the next section, we describe our empirical approach to the study of temporal work of six successful top managers.

\subsection{METHODOLOGY}

\subsubsection{Setting and research strategy}

The setting for our study covers two female and four male top managers (Table 5.1), selected by theoretical sampling, as the purpose of this research is to contribute to the theory's development (Eisenhardt and Graebner, 2007). In Table 5.1, we summarize the personal background and information of the companies at which the top managers were employed. We anonymized their names for privacy reasons.

The top managers' job responsibilities and positions represented initial criteria for selection (Noor, 2008). For this, we defined 'top managers' as those very senior executives who are responsible for the definition and execution of a company's strategy and who are capable of affecting the company's profits, share price, reputation and market position by their individual activities. This includes chief executive officers (CEOs) and other heads of function (Pepper and Gore, 2015). We selected the top managers on the grounds of their knowledgeable insights and experiences into their own individual branding development process over an appropriate length of time. This makes its emergence transparently observable (Pettigrew, 1990). The participating top managers were additionally selected on the basis of the researcher's individual judgement, in the sense of having appropriate access to them, and on the grounds that they would provide the necessary information because of their trust in the researcher, who is otherwise involved as 
their personal business coach. This led to in-depth personal and reflective insights shared in a trusting atmosphere (Noor, 2008).

Table 5.1: Top manager personal and company information

\begin{tabular}{|l|l|l|l|l|l|l|l|}
\hline \multicolumn{3}{|c|}{ Personal Information } & \multicolumn{3}{c|}{ Company Information } \\
\hline Name & Age & Gender & $\begin{array}{l}\text { Current } \\
\text { function }\end{array}$ & Nationality & Industry & $\begin{array}{l}\text { No. of } \\
\text { employees } \\
\mathbf{( 2 0 1 8 )}\end{array}$ & $\begin{array}{l}\text { Financials } \\
\text { in 2018 (€) }\end{array}$ \\
\hline $\begin{array}{l}\text { Ann } \\
\text { (pilot) }\end{array}$ & 54 & Female & CEO & German & $\begin{array}{l}\text { Real estate/ } \\
\text { Construction }\end{array}$ & 2,153 & $\begin{array}{l}10.2 \text { bn } \\
\text { total assets }\end{array}$ \\
\hline Brad & 60 & Male & $\begin{array}{l}\text { SVP Corporate } \\
\text { Communications }\end{array}$ & Austrian & Utilities & 21,775 & $\begin{array}{l}20.6 \mathrm{bn} \\
\text { turnover }\end{array}$ \\
\hline Clare & 50 & Female & CEO & German & Banking & 612 & $\begin{array}{l}2.9 \text { bn total } \\
\text { assets }\end{array}$ \\
\hline Dean & 51 & Male & $\begin{array}{l}\text { Global Portfolio } \\
\text { Director }\end{array}$ & German & $\begin{array}{l}\text { Trade fairs \& } \\
\text { events }\end{array}$ & 831 & $\begin{array}{l}294 \mathrm{~m} \\
\text { turnover }\end{array}$ \\
\hline Edwin & 44 & Male & $\begin{array}{l}\text { Global Medical } \\
\text { Director }\end{array}$ & Swiss & $\begin{array}{l}\text { Pharmaceu- } \\
\text { tical }\end{array}$ & 38,478 & $\begin{array}{l}16.8 \text { bn } \\
\text { turnover }\end{array}$ \\
\hline Frank & 46 & Male & $\begin{array}{l}\text { Managing } \\
\text { Director }\end{array}$ & German & Advertising & 813 & $\begin{array}{l}85 \mathrm{~m} \mathrm{gross} \\
\text { income }\end{array}$ \\
\hline
\end{tabular}

We chose an exploratory and explanatory multiple case study design (Eisenhardt and Graebner, 2007; Yin, 2003) implying a within-case and a cross-case analysis. Complementary combinations of process research strategies, i.e., alternate template, narrative strategy and visual mapping, were applied to reflect the temporal sequence of actions and experiences unfolding over time (Gehman et al., 2013; Langley, 1999; Langley et al., 2013).

\subsubsection{Data collection}

Following Pettigrew (1990), we first collected archival data from different public and private sources about the six top managers and put all the pieces into a chronological sequence. This first outline was important to map the key events in their career lives. Between May 2018 and November 2018, we conducted individual semi-structured interviews with the selected top managers. We used the narrative strategy (Van de Ven and Poole, 2005) to enable them to tell us their own individual stories of personal branding, deeply rooted in their real-life activities and career path. In addition, we ensured that the relevant concepts and ideas assembled from the literature on personal branding were included through an 'alternate template' that contained specific propositions (Langley, 1999). In particular, the proposition 'longevity' is echoed in the methodology of our study as it involves the factor of time in process research. The first interview with a top manager served as a pilot, a format which is being increasingly adopted in qualitative case study research (Yin, 2003). This allowed us to become familiar with the topic as well as test the 
interview protocol and verify the specific instruments (alternate template, visual map). In doing so, we became aware that the top manager in the pilot case rarely consciously engaged in a complete personal branding process during her career, an observation that was also confirmed by the other top managers. In focussing on personal branding during the interviews, we deliberately attempted to flesh out certain critical moments in their careers, which somehow affected the development of their personal brand. In other words, we wanted the top managers to reflect on what they were thinking at such moments and how the past, present and future played a role in moving ahead to maintain or develop their personal brand.

Procedurally, we started each interview by asking them to openly describe their individual personal branding process and what a personal brand means for them, including their intent and motivation for pursuing a personal brand. This setting was important to maintain a focus during the interview. Then, equipped with our alternate template in mind, we tried to obtain purposeful information about relevant critical events and triggers during their careers that made them reflect on the past, their current situation and their intended actions for the future in light of their personal brands. Additionally, we verified their stories against the available data from different public and private sources for triangulation purposes. All interviews were audio-recorded with the interviewees' consent and transcribed verbatim. Our data analysis phase extended between December 2018 and March 2019.

\subsubsection{Data analysis}

In a first step, we mapped out chronologically the stories revealed from archival data and the interviews and fleshed out those parts that could be related to the aspects of the alternate template without discarding peripheral data. This led to the construction of a visual map (Langley, 1999) for each top manager. Dividing the ordinate of the graph into horizontal bands, one for each proposition of the alternate template (e.g., visibility, relationships, brand personality), we then plotted the events and key activities from our database onto the grid, resulting in individual narratives. Each narrative is far more than just a sequence of events and activities. It is a great part of an individual top manager's life (Van de Ven and Poole, 2005) as it conveys a high degree of authenticity that cannot be achieved economically with large samples (Golden-Biddle and Locke, 1993; Langley, 1999).

Next, the content of the visual maps was transferred into one table for each top manager, providing a clear structure of the career phases and containing key events and triggers, reflexivity processes, key activities, and corresponding illustrative quotes.

We looked for commonalities and differences between the maps and tables to arrive at patterns in a broader picture. Since the visual mapping of our analysis is 
"not a 'theory' but an intermediary step between the raw data and a more abstract conceptualization" (Langley, 1999, p. 702), we conducted a within-case analysis that took place iteratively and in parallel to a cross-case analysis after the pilot case. This resulted in one key table for each of the four career phases of the top managers' personal branding processes. By this means, we generated converging and diverging patterns that uncovered how the past, present and future are reconstructed along the career trajectories.

Finally, the resulting master tables of each career phase were transformed into an entire model of temporal work in the personal branding of top managers (Figure 5.2). An investigator triangulation (Eisenhardt, 1989; Thurmond, 2001) that involved the use of multiple observers, interviewers, and data analysts was part of our study for confirmation purposes.

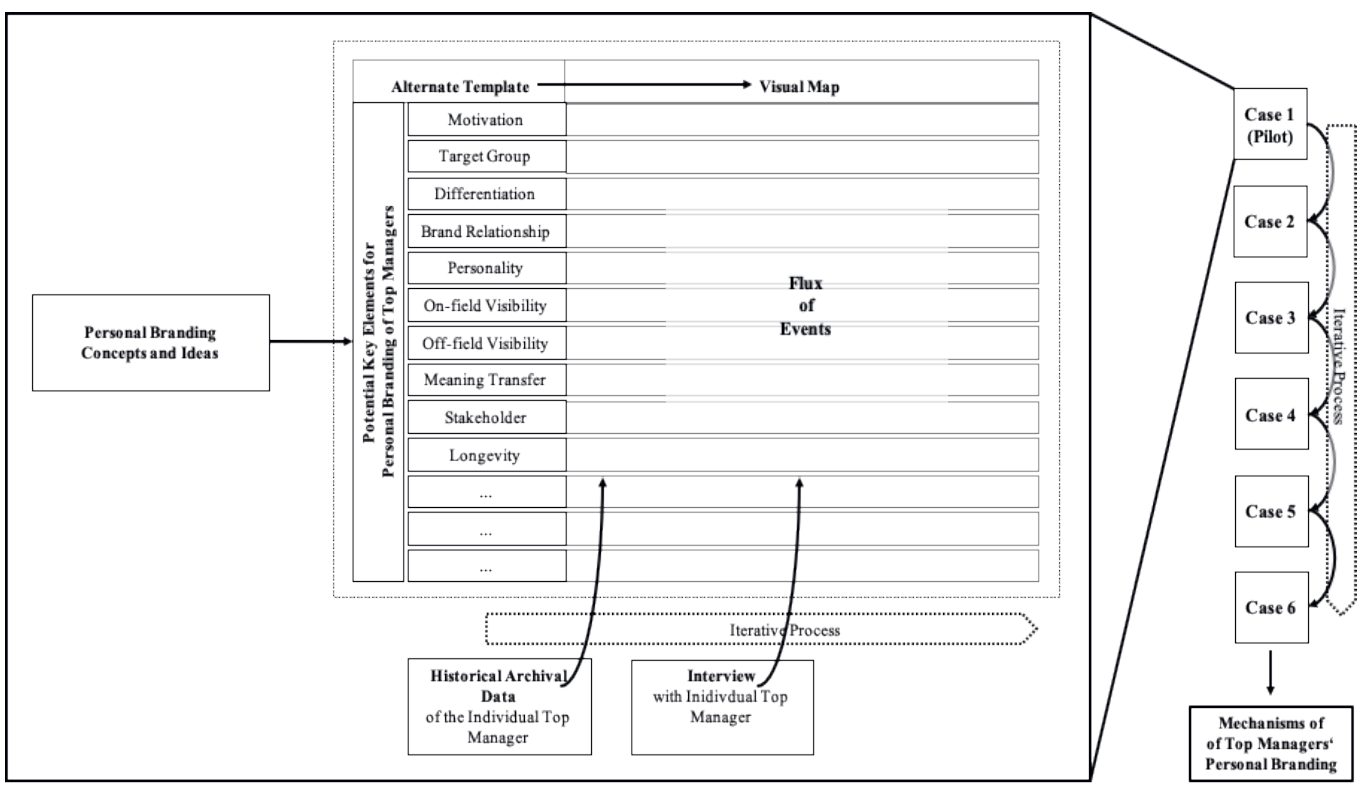

Figure 5.1: Frame for data collection and analysis

These extensive and continuous steps of iteration (Figure 5.1) challenged our emerging understanding of the processes involved. Our intention to replicate findings from earlier cases in this multiple case study, eliminate alternative explanations, and elaborate the emergent theory via an iterative process gave more theoretical support for the choice to use a constant group of top managers as participants in this study (Eisenhardt and Graebner, 2007). On the whole, our iterative, mixed inductive-deductive, and interactional process of data collection, simultaneous analysis, and emergent interpretation resulted in a synthesis that 
enhanced the robustness of our findings (Creswell, 2007; Eisenhardt, 1989; Goulding, 2005; Strauss and Corbin, 1998), as our longitudinal data built an increasingly rich and detailed picture of patterns.

\subsection{MAIN FINDINGS}

From our study of temporal work in the development of a personal brand, we uncovered the following general dominant patterns based on the six top managers. For the sake of clarity, we discuss these patterns according to their career phases starting from beginner, moving to professional stage, promotion to manager and, finally, reaching the top manager level.

\subsubsection{Beginner}

In analysing temporal work in this phase, we found that top managers were confronted at some point in time with the fact that they conceived of themselves as similar to their peers and, as such, did not stand out. For instance, Edwin, who started his career as an assistant physician in a hospital, remarked, "When you have 30 assistant physicians, you first need to make yourself seen among those 30. They're all there together; they're all working; they're all motivated. It's the same: When you have 20 people employed for the same job: Why pick A1 and not A19?"

The top managers reflected on the past by considering the many professional tasks they had to perform in order to launch their career but found themselves ending up like everybody else with having gained first visibility at best. For instance, Dean reflected on some positive feedback he received from an external consultant that "I still remember thinking: What? My boss? The lord on high? He came from [leading company in German Mittelstand] and was the model of corporate communication mastery for me. My boss can be happy to have me? I always saw it the other way around." Ann referred to numerous activities in the past based on her professional expertise that supported her first visibility, "Well, at SMEs, by being active at events. Lots of it in person. There was no internet. You had to be very active, be there at events, give speeches, write articles."

To remedy their situation, they started to think of differentiating themselves more in the future by selecting tasks and positions in which they could perform better and stand out from their peers. For instance, Dean remembered a project from the past "that we simply couldn't shift in Poland, to get that moving. (...) I took a trolley, I can still see it, went to this DIY place in Munich, with our prospectus in the trolley and went from place to place to sell this expo." Dean made the impossible possible, which no one before him had ever achieved in this trade fair project and brought him to the attention of top management, helpful for his next career steps. 
He continued for the future, "With that going so very well, even though the expo did not draw that many visitors, then it happened that the top management came to me right away and said: Listen, [Dean], we have other projects for you."

But personal traits from the past, which led to differentiating oneself from others, also have an effect in the present at the career stage of 'beginner'. Ann, for instance, considered her role as a woman in a male-dominated industry, "there aren't that many women in my industry. And at an SME, in the insulation business, you had two women. So, people always said: That's the fierce one, and you're the nice one (...) In the industry, people were speaking about these two women and that's why I had this reputation." In this regard, Ann does not disagree that gendered traits contribute to her personal branding as she noted, "But you can use that quite well for yourself."

All in all, personal branding at the first career level is characterised by the fact that employing professional competences creates an initial visibility as a person, but this does not differentiate the person from the many other job entrants. In order to stand out from colleagues, it is necessary to deliver an exceptional performance or to make use of other, almost unique, personal qualifications and qualities.

\subsubsection{Professional}

In order to steer their personal brand in the 'professional' career phase in various ways, the top managers in our study relied on their technical competencies developed in the past. For instance, Ann (in charge of the banking industry) remembered that she "was invited to lots of interviews back in the market magazines to speak about transactions", and Brad, in his capacity as communicator in this career stage, stated that, "Letter writing is a skilled art. It's a curse and a blessing. I started quite early to write letters for a CEO. Not just any letter, but maybe the ones to ministers, and the CEO noticed: That's not bad, and he does not need days on end for it. So, they trusted me with that job more and more frequently."

In addition, the application of professional skills was complemented by social skills acquired in the past, such as an exceptionally good working method, as Edwin compared himself to colleagues. "Work speed, that is one thing. I always knew that I need a third of the time other people need, and that was relatively clear for me." Edwin generalised this example for himself and is aware of the consequence of this, which is to distinguish himself from his colleagues. "This uniqueness came from me doing certain things much better than others or believing that I could do many things much better. That's where the unique thing comes through."

Similarly, Ann brought a specific mindset from her childhood, "And it's one of these formative events, I would say, from my primary school. Simply to say that you are always a step ahead." This led her to opt for an approach that set her apart from others, even though she had only recently moved to this company. "I was with the 
company for six weeks, and my boss said, 'Here comes the new director.' He was from another country where they had more centralized structures. 'We need to speak about what we do here.' He then asked these specific questions, and we were all sat on that table, and nobody was getting to the point, and it annoyed me so. So, I got up, with six weeks of experience on the job. Six weeks of really being with the company, and I said, 'Let's do it this way. Let me explain."' In this regard, Ann considered her mindset as a vehicle to create a personal brand for future career development as she noted, "From then on, I was, for him... the director attributed certain traits to me. Or they had a certain image of me, and they expected it from me. So, four weeks later, I had a leadership role."

The personal preconditions that the top managers already had in the past and therefore naturally brought with them also influenced their personal branding. Clare, for instance, remembered how she unintentionally became aware of her visibility as a woman when she noted, "I was always pushed into the limelight by my superiors and top managers, because I had a certain image, as a woman, as a mother, as a successful woman, and they liked to use that."

Given these reflections by the top managers, we concluded that in addition to professional skills, the application of social skills resulted in internal visibility and an extended differentiation. Internal visibility means being personally visible to powerful people in the company, such as CEOs and directors. This is closely related to differentiating oneself from colleagues through exceptional skills or in special situations through unique and eye-catching activities and results in career support from these powerful people, which Ann sums up in a nutshell, "To get visible and to be recognizable. When I have 40,000 employees and I, as a director, am looking for a manager, then I only see a sea of faces. But if I have somebody that gets recognized, that I see certain traits in, some that I might want or need, then I react differently."

However, distinguishing oneself from others becomes a threat in the present of the professional career stage as it results in competing with other people. Frank exemplified having a conflict with his superior due to his application of skills from the past. "I had this boss that I came too close to in a sense - so here we are with the issue of top management attention. How far can you rise without hitting the ceiling? So, he was as well - in a way, I was part of the team, but what I was doing and with my skills and my competences, my visibility with clients and how I was perceived in general, I was somewhere else. And he essentially started picking on me." By applying his skills in the past and the resulting personal visibility with customers and in the company, top management also became attentive to Frank - more attentive than to Frank's boss, which caused the latter to behave in a personally damaging way towards Frank. Looking for a way out, Frank decided to conform in the future. "And that could only be resolved by me picking a different route at the company, because there was not enough space for the two of us at that place." He was aware that the 
conflict with his boss would continue or even intensify if he continued displaying his internal visibility and the associated differentiation. Therefore, Frank adapted to the given situation and to his boss and chose a different career path.

At the career level of professional, three key activities are important to enable personal branding. First, to differentiate oneself from others in an extended way beyond professional skills by applying non-technical skills. Second, to become visible within the company as an individual personality, which is closely related to the extended differentiation. Finally, conforming to other people and situations as a key activity that complements differentiating oneself from others.

\subsubsection{Manager}

When considering the career stage of 'manager', the top managers in our study explained that they overwhelmingly relied on their ability to adjust to people and situations, especially when general conditions had changed massively or gotten difficult and when powerful people in the company expressed demanding requirements. Ann, for instance, compared one of her employers from the past, "at an SME, it was all quite easy-going", to one in the present, "The challenges change when you are in a larger company (...) Think globalization... market development. Eastern Europe. South Africa (...) But then your stakeholders change, suddenly they are more academic." She attributes challenging changes to a much larger organisation on the one hand and to a higher level of stakeholder education on the other. Consequently, she anticipates for the future that relying on the value of one's own brand from the past will not be enough. Rather, she poses herself the core questions in order to decide for herself what and how she will adapt to continue developing under changed conditions in the future: "You won't get far with the original: Nice German brand, German engineering. Unless you like German mechanical engineering. But even they have to go with the times (...) You have to adjust in a different way. (...) then you have to see: Does it still fit? Those were the issues I mean. (...) And with all these changes, how do I adjust to them? What do I need to do with my brand for it to work in this context? Or for me to position myself somehow."

Clare, in turn, reflected on a crisis situation for the company and derived from it how her CEO expected a specific role from her as a female manager in front of the male colleagues. "Yes, there was this statement from [name of former CEO at 2nd employer of Clare], (...) when we had a really major crisis at [2nd employer of Clare] and the press relations were really tough, and he said, Well, we now need a big press event, and we need one of us to do it who has the competence - we all do - but who also has that sympathy factor. We need the most likeable person out front, and that has to be Ms [name of Clare]. (...) It was evident: he was under fire, and two of my colleagues, who are also very good at what they are doing, were too rough around the edges." Clare pointed out how her family background and how she was raised caused her 
to act in certain ways today which had less to do with her gender when she noted, "maybe that comes from my roots, also from my strict father, because I never wanted any privilege, no privilege because of my gender, my family, my children, my husband. Instead, I am extremely hard working, and I did it consciously, I think, by delivering results." Despite her very clear attitude, Clare conformed to her CEO's demands and the needs in this difficult situation, resulting in "a give and take", which "did create trust and sponsorship" in her relation to the CEO in the future, which justified her decision to conform rather than look for something new.

On the other hand, the top managers became aware in the career stage of 'manager' that they were running the risk of creating too much differentiation. This occurs primarily as a result of very strong self-interested thinking and acting, too many activities that stand out, and questioning everything from the past. In this case, the top manager will move too far away from everyone else and will no longer be perceived as useful to the organisation. Edwin gave an example from a situation in the past when he was a manager, "you cannot always question everything", resulting in "the point where it got dysfunctional" in the present. He referred to the future that "if I continued like that, I would get the sack, because they see me as a nuisance and not as a change agent. And then I noticed that there is a point when you have to hold back and see: It is what it is, and I need to fit in and understand: Where do I consciously want to stand apart, where do I want to be different. Because people then see you as added value, not as a nuisance. The problem for a change agent is: You can be seen as an innovator or as nuisance. You always have to be careful that you're seen as the right choice." Obviously, Edwin realized that he would cross the Rubicon from change agent useful to the people in the company to troublemaker in the organization if he continued working unilaterally to be considered unique in the organization. Balancing activities for personal differentiation with activities through which he aligns or even adapts to people and conditions is a logical guideline for Edwin's future actions to avoid the threat of being fired and to make further progress in his career.

The three essential activities for personal branding at the 'manager' career level are the extended conforming required due to fundamental changes, building trusting sponsors especially among powerful people in the company, and a situationally conscious balance between the personal differentiation from other people and conforming to them.

\subsubsection{Top manager}

Regarding their current career stage, the top managers reflected that job activities, promotion, and the coverage by the media from the past led to shining (becoming prominent) in the present.

Dean reflected that in the past he had experienced much opposition to his new ideas. "People were completely critical at first: Oh, [Dean] and his silly ideas, what is 
that about: [founding of a global initiative by Dean]?" However, the implementation of his ideas led to Dean shining in public today. "That is now the most important image campaign for [employer of Dean]. It's the most important image campaign in the packaging industry, for all associations in it. (...) It is the fastest growing initiative globally on this type of thing. The federal government is on board. We are now getting invited, that's where my brand comes in. I am getting invited to give speeches. Two weeks ago, I was in New York, at the United Nations."

Brad in his role as SVP corporate communication remarked, "I can say honestly: I spent a long, long time on one thing: My job in the business. Full stop. And not whether I am writing an essay or attending a conference or giving a speech." Frank took the same line, "I, on the other hand, always cared about the objects of my work." However, Brad knows that his current reputation is built on his job. "In communication, you are always very exposed. In the end, you are the guy on the front line, dealing with the full force of society and speaking on behalf of the company." From his public visibility as a representative of the company in the front line, Brad realizes for the present "that it is a very, very exposed and, if you want, very loud position." Clare, in turn, considered her media coverage in the past, "... and suddenly I'm in the Bunte [leading German yellow press journal]. More and more people called me then, which really doesn't work for me." Although she had not actively contributed to this, Clare has made a surprising appearance in the yellow press.

Given the visibility activities of colleagues but also triggered by their own shining in public, the top managers concluded for the future that they have to take specific actions concerning their visibility. Both Brad and Frank have plans for actions aiming at a purposeful visibility of their own person. "I would, for instance, keep up a much more intensive dialogue and more contacts in my community" (Brad) - "You do realize that this issue of self-branding on social media is a thing. There are colleagues, if I think of [name of a colleague]. (...), he is extremely active. I'm not, I admit. I would have to change that (...) I think: I should. But I do too little in reality. Maybe more in 2019. It is definitely an issue" (Frank). Clare intends to be equally focused, but much more selective, "I'm not the person who likes to be exposed to the public mainstream. I cherish my privacy, my personality for myself, and I am ready to go public with my professional side. And I'm ready to be a model for other women, to some point also about things like: women, emancipation, professional success, also family, because I think, I'm an important example, but that's where it stops. I don't care about seeing my name in there and having other women read about my life at the hairdresser's." Clare assigns great importance to appearing in the public eye through her professional appearance and strives to leave her private life out of public visibility. Furthermore, it seems to be important to select the right media channels. In her dealings with media representatives, she claims, "and then we have a first talk that still gives me the opportunity to say: Maybe not this time." 
In contrast to previous career phases, shining appears to be one of the core activities for the personal branding of top managers. This is supplemented by a conscious, targeted and selective visibility in the future, which we labelled as 'controlled shining'.

Different mechanisms in terms of decisions and actions were identified in the development of a personal brand for top managers at each stage of their career. In Figure 5.2, we graphically display these mechanisms and how they are linked within a phase and between phases. The vertical axis represents the progress of a personal brand over time over four different and consecutive career stages plotted on the x-axis.

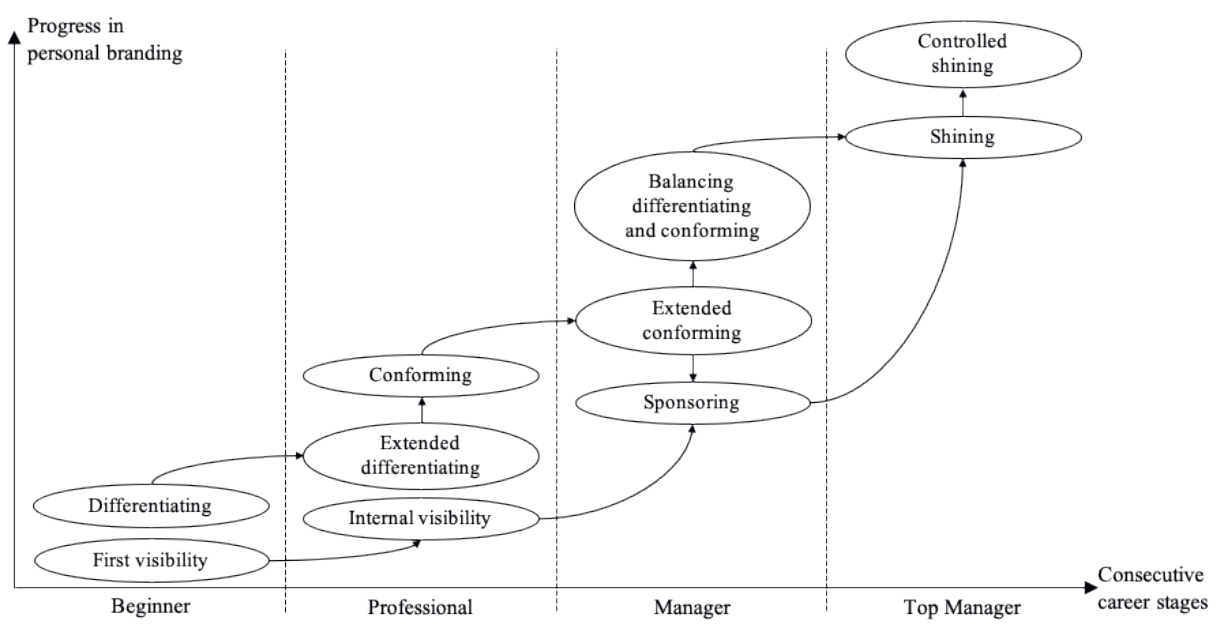

Figure 5.2: Actions and decisions in personal brand development over phases in career development

\subsection{DISCUSSION AND IMPLICATIONS}

This study of six top managers' career trajectories demonstrates how interpretations of the past, present and future are incorporated in their pursuit of building their own brand during their career trajectories. Our analysis of temporal work supplements the few existing empirical studies on longevity in personal brand development (Lindridge and Eagar 2015; Preece and Kerrigan, 2015). To our knowledge, this research is unique in nature as we discovered patterns in the actions and decisions that strengthened the development of a personal brand over time and while reflecting on the past and future in different career phases. We found that a personal brand viewed as a thing with fixed properties cannot be understood as the product of more or less intentional actions without considering the multiple interpretations of present concerns and historical trajectories as well 
as anticipations of prospective options that help to constitute those personal brands. Thus, temporal work in personal branding corresponds to the practicebased perspective on time that covers both the shaping of people's actions and their being shaped by structural conditions within and outside of their immediate control (Kaplan and Orlikowski, 2013).

In emphasizing temporal work, we appreciate more than just the call for process research in organizational concerns at the individual level (Langley et al., 2013). The importance of temporal work highlighted by our analysis of top managers' personal branding processes also provokes a general consideration of how time is treated in personal branding research and, therefore, in theory advancement. The future in an individual's personal branding process, for instance, will likely not turn out the way it was derived from the simple application of tools, decided due to given general conditions or projected from the one experience. Rather, it depends on the individual's temporal work processes generated by critical events and triggers experienced by the careerist. This approach indicates that personal branding is not a deliberate, predictable and future-oriented process but requires frequent interpretive links across the past, present and future in the various career phases. Also, a personal brand is not fully determined by background or luck for it requires a thoughtful, reflexive process by the careerist, which appears to be consistent in our cross-case study on the basis of six top managers. This amounts to a strong personal brand built on distinct actions and decision-making moments in each phase of career development. In this vein, personal branding serves as a framework within which careerists create a personal brand through temporal work. We emphasise the importance of temporal work in career research when we want to understand why certain actions are taken and decisions made to develop a personal brand during career trajectories.

Our model of temporal work in the personal branding of top managers may help practitioners deal with the challenges of creating careers when confronted with a contemporary world of work that implies the need for continuous development and constant change. In this respect, the group of practitioners is certainly manifold because it covers young careerists as they climb their way to top management, coaches of top managers, and the top managers themselves. We advise young careerists, in particular, who are still in the process of building their personal brand, not to pick out a single core activity of our model that intuitively suits them best in order to set their personal branding in motion. Temporal work is a subjective process and highly dependent on opportunities and threats posed in the successive stages of a career. Each phase offers numerous possible actions and decisions from which young careerists can choose. Therefore, our model offers a well-founded framework with do's and don'ts (Table 5.2), which enables them to critically question their own personal branding process and align it for the future. 
Table 5.2: Personal branding do's and don'ts

\begin{tabular}{|c|c|c|}
\hline Do's & \multirow{2}{*}{$\begin{array}{c}\text { Personal Branding } \\
\text { Beginner }\end{array}$} & Don'ts \\
\hline $\begin{array}{l}\text { - Apply your professional skills to gain } \\
\text { first general visibility } \\
\text { - Choose challenging tasks and deliver } \\
\text { outstanding performance }\end{array}$ & & $\begin{array}{l}\text { - Accept that you are ending up } \\
\text { like all your colleagues } \\
\text { - Feel complacent that you got } \\
\text { the job }\end{array}$ \\
\hline $\begin{array}{l}\text { - Go beyond your technical skills and } \\
\text { find out what you are exceptionally } \\
\text { good in } \\
\text { - Do things you are much better at } \\
\text { than others } \\
\text { - Be courageous when confronting top } \\
\text { management team members } \\
\text { - Recognize when you should adapt to } \\
\text { people or situations }\end{array}$ & Professional & $\begin{array}{l}\text { - Rely on what you learned at } \\
\text { school and college } \\
\text { - You can count on being } \\
\text { discovered somehow } \\
\text { - Stay humble and get in line } \\
\text { behind those who have been } \\
\text { with the company much longer } \\
\text { - Carry out your behaviour at all } \\
\text { costs }\end{array}$ \\
\hline $\begin{array}{l}\text { - Accept changing conditions and } \\
\text { adjust to them } \\
\text { - Deal constructively with unexpected } \\
\text { expectations from powerful people } \\
\text { in the company } \\
\text { - Apply a wide range of actions flexibly } \\
\text { depending on the situation }\end{array}$ & Manager & $\begin{array}{l}\text { - Accept changing conditions as } \\
\text { fate and submit to them } \\
\text { - As a matter of principle, be } \\
\text { against those positioned } \\
\text { higher up in the company } \\
\text { - Rely on recipes that have been } \\
\text { successful so far }\end{array}$ \\
\hline $\begin{array}{l}\text { - Accept your shining in public as the } \\
\text { result of your long-lasting efforts and } \\
\text { developments } \\
\text { - Control your shining and the people } \\
\text { who make it happen }\end{array}$ & Top Manager & $\begin{array}{l}\text { - Let other people see into your } \\
\text { private life, because you are a } \\
\text { public figure } \\
\text { - Rely on the fact that you will } \\
\text { always shine as a top manager }\end{array}$ \\
\hline
\end{tabular}

\subsection{LIMITATIONS AND FURTHER RESEARCH}

Although we are contributing to a more comprehensive and finer grained knowledge on career building over time, we also need to discuss a few limitations of our study and inspirations that arose during our explorative work which open avenues for future research.

Our process data is based on retrospectively collected live stories from interviews with current top managers. We suggest that even stronger patterns can be developed from temporal work by real-life longitudinal research, for instance through auto-ethnographic accounts from managers who are encountering opportunities to become top managers in the mid-term. Furthermore, frequent and issue-centric sessions in which top managers are supported and challenged by the researcher during longitudinal studies may improve the data triangulation by additional real-life temporal work. Longitudinal studies may also offer opportunities to investigate how unforeseen events that affect an entire industry, such as the 
nuclear power plant accident at Fukushima in 2011 and its impact on utilities, are reflected in the present and lead to anticipation for the future in an individual's career.

The sample group in our study provides cultural homogeneity and gender and industry heterogeneity. Future research is recommended to explore possible distinctions of temporal work in personal branding processes between female and male top managers. Also, specific industry-related aspects, for instance the impact of powerful people and their sponsoring in regulated versus non-regulated industries, cannot be neglected. 
SYNOPSIS

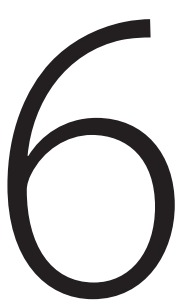




\subsection{INTRODUCTION}

This dissertation was driven by the desire to understand how personal brands in general and top managers' personal brands in particular emerge, how they work and what impact they create. Personal branding looks back on a long history, attracts innumerable practitioners as a contemporary phenomenon and has become an object of interdisciplinary interest as various scholarly disciplines have begun to approach this topic. Antecedents (Hearn, 2008; Lair et al., 2005), the outcomes (Gorbatov et al., 2019; Hanusch and Bruns, 2017), and the key ingredients (Elwell, 2014; Parmentier and Fischer, 2012) of personal branding are well investigated. Mechanisms such as endorsement are also well studied and widely accepted (Bergkvist and Zhou, 2016; McCracken, 1989) and theoretical frameworks, such as a conceptual model of CEO brands (Bendisch et al., 2013), have even considered an application of personal branding to top managers. To advance these insights with regard to personal branding and its specific mechanisms in context with top managers, this dissertation addresses two central research questions:

How do top managers' personal brands emerge?

How does the personal brand of top managers work?

In addressing these research questions, I adopted multiple theoretical perspectives that enabled me to evaluate and compare the findings from various angles. Each perspective provides its own conceptional background, ontological foundation, compositional features, and approach to human individuals or even to managers. In this dissertation, I applied a bibliographic perspective, a practice-based perspective, a career perspective, a time perspective, a meaning transfer perspective, and a reflexive perspective. The reason for utilizing these perspectives, partly in this particular order and partly in contemporaneous combination with each other, is due to the insights that have emerged from the empirical chapters in the course of this dissertation.

Similarly, the application of the methodological approaches has deliberately avoided one-dimensionality. Rather, I used a multi-method approach that contained quantitative and qualitative methods, interviews and different process research strategies, cross-case and within-case analysis, continuous steps of iteration and an integrative framework from strategy as practice research - always following the simple but truthful guiding principle that "variety contributes to richness" (Langley, 1999, p. 707).

This concluding chapter builds on the individual Chapters 2 to 5 of this dissertation and brings together their findings from the various steps of this 
comprehensive doctoral research project. Not only will the two central research questions be answered, but the individual, investigated areas will be bundled and brought into relation with each other in order to finally create a synopsis. With this in mind, the remainder of this chapter is structured as follows. The discussion in Section 6.2 consolidates the results from the separate studies of this dissertation into central research domains and scrutinizes them in order to answer the two central research questions. While Section 6.3 summarizes the theoretical contributions of this dissertation with regard to different literature streams, the implications for the practice of personal branding and especially the personal branding of top managers are explained for selected target groups in Section 6.4. The limitations of the studies have been addressed in each individual chapter. This leads to Section 6.5 indicating the limitations of this research project as a whole, in order to open up avenues for further research in the field of personal branding, also with a specific focus on top managers.

\subsection{DISCUSSION}

\subsubsection{The nature of personal branding}

The question about the fundamental 'what' with regard to personal branding, namely 'What is personal branding?', not only serves as an opening perspective on this contemporary phenomenon, but at the same time implies the need for a differentiated and profound understanding of it. However, when dealing with personal branding, scholars can be tempted to focus on specific individual aspects or sub-fields, which can be understandably justified by personal expertise or formal affiliation to a singular, academic discipline. However, despite the need for a comprehensive overview of the research field of personal branding, this also carries the risk of not embedding these individual aspects and sub-fields in an overarching context, limiting oneself to them and thereby contributing to a fragmented overall understanding. Indeed, it was exactly this circumstance that I was confronted with at the beginning of this research project through the existing literature reviews on personal branding (Alipour et al., 2015; Whitmer, 2019). My expectation of a structured and thematically coherent as well as interdisciplinary overview of personal branding therefore had to be met by independently preparing a literature review (see Chapter 2), especially since the only comprehensive overview (Gorbatov et al., 2018) was published at a time when the majority of my research had already been completed.

A key finding of the iterative multi-step analysis of the growing body of literature on personal branding is, at a methodological level, an integrating framework that, with its six key research streams, also appears applicable to other, 
fragmented research fields in order to obtain a comprehensive overview through a literature review. Webster and Watson (2002) point out that literature reviews are concept-centric and suggest the use of a concept matrix to avoid an authorcentric approach that would result in a simple enumeration of publications. The six key research streams I developed are comparable to these concepts. However, while the concept matrix is filled sequentially with each additional publication, the resulting framework was created in an iterative way by also using publications that had already been analysed for key research streams that emerged later. This gives the resulting overall picture an even greater richness of content.

In order to overcome the confusion around the terminology and definitions of an individual's branding, I propose to use the term 'personal branding' instead of the numerous neologisms and synonyms. The decisive factor here was not that Tom Peters (1997), considered by many practitioners and academics to be the founder of the personal branding movement, used this term for the first time, especially since he provided neither an explanation nor a definition. Rather, my analysis of the body of literature on personal branding confirms that "the phrase 'personal branding' is now fairly well established, and more consistently used" (Shepherd, 2005, p. 2) and, moreover, in contrast to terms such as self-marketing or self-branding, refers to personality as crucial to the branding of the individual.

Substantively, this dissertation benefited from distinguishing between the process, i.e., personal branding, and the thing or product, i.e., the personal brand, both in the early stage of drafting the literature review and throughout the entire empirical research, following Tsoukas and Chia (2002) and their view of organisations. In contrast to a large majority of scholarship in the field of personal branding who do not distinguish clearly between the process and the thing, I argue that this distinction is a fundamental issue to understand the phenomenon of personal branding. In doing so, I followed the differing philosophies of Democritus and Heraclitus in antiquity (Rescher, 1996). On the one hand, Democritus pictured all of nature as composed of stable material substance or things that changed only in their positioning in space and time. Whereas the identity or substance of things does not change, and substances exist independently of other substances, their development and adaptation in relation to other dimensions and properties and their qualities may change. This substance-cum-quality view of reality is closely associated with the subject predicate structure of language (Mesle, 2008) and applies to the notion of 'personal brand'. On the other hand, I adopted Heraclitus' view, who perceived reality not as a constellation of things but of processes. He argued that substantializing nature into enduring things (substances) is a fallacy because these are constituted by varied and fluctuating activities: "Process is fundamental: The river is not an object but an ever-changing flow; the sun is not a thing, but a flaming fire. Everything in nature is a matter of process, of activity, 
of change" (Rescher, 1996, p. 10), which I confirm from this research for personal branding as a part of today's nature. A "great brand is not built by accident but is the product of [...] a series of logically linked steps" (Keller, 2013, 125), which reveals branding as a process in general. Nonetheless, process studies have historically been underrepresented and retrospective process studies, in particular, are completely underrepresented (Langley et al., 2013), which especially applies to the research field of personal branding. The empirical studies in Chapter 3 and 5 followed the call for process research, especially since they also deal with the evolution of relationships between people or with the cognitions and emotions of individuals as they interpret and react to events (Isabella, 1990; Langley, 1999; Peterson, 1998). Therefore, I share the conviction of Langley (2013) that "there are important opportunities to address management and organizational concerns at the individual level of analysis and would encourage such research that might deal with such temporally evolving issues as careers, work-family balance, identity, work practices, and socialization from a process perspective" (Langley et al., 2013, p. 10).

However, personal branding is much more than a process that is clearly distinguishable from its outcome, the personal brand. It is a movement based on causal antecedents and by no means an accidental phenomenon. Indisputably, the combined impact of societal, economic and technological developments (Gehl, 2011; Hearn, 2008; Lair et al., 2005; Philbrick and Cleveland, 2015; Schau and Gilly, 2003) created the emergence of pervasive personal branding and the resulting personal brands. Celebrities, defined as "part of the social elite who engage in the public relations machine of television and movie roles, special event appearances and talk show and gossip magazine placements" (Lunardo et al., 2015, p. 687) evoke much of the academic effort on personal brands, also expressed in its publication platform of the Celebrity Studies journal. But celebrities on the one hand and the personal brand of the ordinary person on the other are not sufficient to capture the diversity of personal brands. Therefore, I advocate for a structure of three classes, i.e., the icon, the celebrity, and the personal brand, and two intermediate stages, i.e., the superstar and the micro-celebrity, assigned to 11 different categories (see Chapter 2). The demand for permanent refashioning in social media and the competition for public attention leads to a rapid turnover of celebrities in the media, only appearing interesting for a limited time through the symbolic meanings associated with their private and public selves. In contrast, the icon represents a legitimate cultural symbol of personal achievement and societal values and experiences convergence and change in meaning over time, reflecting broader cultural concerns, which transcends time. Celebrities can become icons when their fame lasts through changes in their cultural significance and values that reflect changes in society (Lindridge and Eagar, 2015). Along the way, the superstar represents an intermediate stage to stand out from the crowd of an increasing 
number of celebrities. Likewise, the personal brand of an ordinary person can transform into a celebrity. Rojek (2012) distinguishes between ascribed celebrity status based on bloodline or family relationships, achieved celebrity status that originates from talent or accomplishments, and attributed celebrity, imposed by the media. The latter seems most in line with the contemporary type of celebrity, manufactured and made famous by media publicity alone (Lindridge and Eagar, 2015; Milner, 2010; Rojek, 2014). The micro-celebrity appears as an intermediate stage in the transition from an ordinary people's personal brand to celebrity status (Khamis et al., 2017), enabled especially by social media and exemplified by the influencer.

As far as the personal brand category of business managers is concerned, and here specifically top managers as the target group of our research, I also advocate for personal branding as a managerial practice in itself (Chapter 3 ). This represents an unprecedented view of personal branding and an equally new facet of managerial work that is increasingly concerned with managerial practices, in areas such as leadership (Cho and Poister, 2014), technology (Dougherty, 2004), knowledge management (Inkinen, 2016), accounting (Ahrens and Chapman, 2007), and marketing (Allen, 2002). Given the fact that personal branding is an essential part of today's managerial work, it needs to be understood from a practice perspective, which calls for a radical shift in the current way of thinking about how personal brands are constructed in general and the path that personal branding takes in this process. The application of the integrative framework of strategy practice (Whittington, 2006) in this dissertation provided a coherent approach to the practice-oriented investigation of top managers' personal brand. Top managers as practitioners who do the work of making, shaping, and executing their personal brands, the various activities on the part of top managers as the praxis that is necessary for the development of personal brands and their application, and three key personal branding practices that top managers typically draw on in their activities as the domain of practices are in line with Whittington's (2006) three concepts of praxis, practices, and practitioners. On this basis, I demonstrated that what top managers do 'in practice' over the course of their careers from a personal branding perspective can be categorized into three key practices labelled as 'managing position,' 'managing individuals,' and 'managing visibility'. Thus, this study confirms that the top managers' social environment that drives and facilitates their actions requires close anthropological attention for a constant stream of tricks, stratagems, and manoeuvres (De Certeau, 1984).

Personal branding started its campaign through academia as another instance of "broadening the concept of marketing" (Kotler and Levy, 1969). Over the decades, personal branding has moved beyond the marketing discipline. Aaker (1997) brought in the human perspective into branding since she defined brand 
personality as "the set of human characteristics associated with a brand" (1997, p. 347), different authors in focused on labour market and career emphasizing that everyone is able to position himself uniquely and in this way differs from anybody else (Rein et al., 2006; Lair et al., 2005), and an the educational perspective arose as personal branding "appear to be largely absent from marketing curricula in higher education" (Shepherd, 2005, p. 589). Sociology (e.g., Furedi, 2010; Wee and Brooks, 2010), psychology (e.g., Li, 2007; Moulard et al., 2015), and information technology (e.g., Alghawi et al., 2014; Chen, 2013; Elwell, 2014) as well as management science, communication, organisational behavior, and accounting (Gorbatov et al., 2018) have also begun to approach personal branding. Personal branding as an interdisciplinary field offers a glimpse at the future of marketing. Traditionally, marketing looks far beyond its borders and involves numerous theories from different disciplines. Personal branding shows that this interdisciplinary direction should be utilized even more for the dissemination of marketing ideas, knowledge, and theories through collaboration with both practitioners and other academic disciplines. This will certainly result in mutual enrichment and an even greater interdisciplinary profile for marketing.

But personal branding is not only representative of the fundamental tendency towards an interdisciplinary orientation in research. It has also emancipated itself from traditional branding disciplines, such as product or corporate branding. The application of traditional branding practices in equal measure to the field of personal branding has few clear advocates (e.g., Close et al., 2011; Ternès et al., 2014) or critics (e.g., Russell and Schau, 2010; Preece and Kerrigan, 2015), but it promises constructive approaches (e.g., Parmentier and Fischer, 2012; Preece and Kerrigan, 2015) that very selectively adapt proven branding practices. This research revealed that attributes such as brand personality (Aaker, 1997), competition which implies points of differentiation as well as points of parity (Keller et al., 2002), brand visibility (Keller, 2013), brand relationships (Fournier, 1998), or brand meaning transfer (McCracken, 1989) as well as brand co-creation (Prahalad and Ramaswamy, 2000) are verifiable components of personal branding. In addition, the identified key practices (Chapter 3), the reflexive work of the branded practitioner (Chapter 5) and the fundamental absence of anthropomorphising are distinctive features of personal branding. Therefore, I advocate to consider personal branding as a brand discipline in its own right.

Taken together, answering the question of what personal branding respectively a personal brand is, results in a multi-faceted perspective. It is a process, an outcome of a process, a specific class or intermediate stage, a management practice in itself, an interdisciplinary field, and a brand discipline in its own right, which does not yet claim to be exhaustive. A deeper understanding of what personal branding is inevitably leads to the how questions. 


\subsubsection{In mutual cooperation: Emergence and way of working of top managers' personal brand}

For the first time, this research demonstrated for a clearly defined category of personal brands which concrete key practices and tangible activities develop a personal brand over different time phases and which reflexive activities the branded top managers conduct or ought to conduct for this purpose. The three key practices identified, i.e., 'managing position', 'managing individuals', and 'managing visibility', represent the content of the distinct managerial practice personal branding and answer the questions of how the personal brand of top managers emerges, how it works and what managers actually do (Kurke and Aldrich, 1983; Tsoukas, 1994; Chia and Holt, 2006) by providing a new perspective (Chapter 3).

On the one hand, the activities contained in these key practices confirm individual key factors of personal brands that have already been mentioned in the fragmented body of knowledge of personal branding. As such, in the key practice 'managing position', I continue the findings of Parmentier et al. (2013) who identified points of differentiation as well as points of parity for personal branding in the job category of fashion models. Accordingly, the application of 'standing out' and 'fitting in' is supposed to be a managerial practice. However, I extend this view by adding the factor of time, in that differentiation and conformity are implemented in different ways by the top manager depending on the respective career phase. Furthermore, this study points out how these two activities are balanced on a practical level in different career phases.

Similar to other scholars (e.g., Bendisch et al., 2013), I also identified various stakeholders within and outside the company with whom the top manager interacts from a personal brand perspective. Taking into account the fundamentally collective nature of brands, this study builds on the multi-stakeholder approach developed by Freeman (1984). However, for the sake of my interest in how these stakeholders act and how they affect personal branding, I identified supportive, i.e., facilitators, and hindering, i.e., obstructors, stakeholders instead of applying the traditional functional view of stakeholders (e.g., Bendisch et al., 2013; Preece and Kerrigan, 2015), subsequently creating the key practice 'managing individuals'. In addition, I demonstrate that over the time of the emergence of the personal brand of top managers, partly the same but partly also different stakeholders are relevant for personal branding. The indications on how to deal with the differently aligned stakeholders in order to facilitate the development of the personal brand also represent a decisive extension to the previous understanding of personal branding as a collective act. The third key practice identified for top managers' personal branding, i.e., 'managing visibility', confirms visibility as a key factor for personal brands. Justification can be found in the emergence of mass communication 
(Kotler and Levy, 1969), cable television (Lair et al., 2005) and the explosion of Web 2.0 and social media (Gehl, 2011; Fillis, 2015). Fame and attention have significant cultural value in today's society. Therefore, media coverage turns into a key currency that can enhance or destroy personal brands (Hearn, 2008; Bendisch et al., 2013). However, it is noticeable that the focus on the visibility of personal brands in social media, as well as the consideration of the category of content creators in the online environment, particularly journalists (e.g., Brems et al., 2017; Molyneux et al., 2019), bloggers (e.g., Archer, 2019; Delisle and Parmentier, 2016) and YouTubers (e.g., Harrington, 2019; Lovelock, 2017) increased significantly in recent years. Although this online visibility is included in the key practice 'managing visibility', I deliberately contrast it with offline visibility in order to counteract one-sidedness. This study also connects to the recognition of the distinction between on-field and off-field visibility in personal branding (Parmentier and Fischer, 2012). While onfield visibility refers to the original field of practice and profession of the branded manager aiming for instance at awards and honours conferred by those in the field, off-field visibility operates outside the professional field in the sense of building a mainstream media persona. This approach proved to be very valuable, especially over the course of the development of the personal brand of top managers, in order to be able to classify the necessary activities. It became clear how important on-field visibility is at the beginning of a career, how it is created and what changes in the content of activities it undergoes over time in subsequent career phases. This investigation also revealed that the on-field visibility is extended by activities in the field of management and leadership from the career phase 'manager' onwards. From a different interpretative perspective, on-field visibility is supplemented here by off-field visibility, i.e., with activities in the area of management, leadership and personality beyond original professional competences. The resulting practice 'personal branding' transfers already known, individual key factors of personal brands into a coherent overall construct with interdependent activities, which develops, works and has an effect over time.

On the other hand, my research presents aspects that are completely new for the understanding of how the personal brand of top managers is created and even provide transfer possibilities and inspiration for the understanding of the creation of other personal brands. As such, this study demonstrates that the activities themselves within a key practice of developing top managers' personal brand have aspects that are consistently dual in nature, both in their positioning as an activity and in their effects (Chapter 3 ). Dualism is often equated with opposition and potential conflict, as it is attributed to contain a clear and unambiguous contradiction as well as a well-defined boundary and to lack overlap (Farjoun, 2010). The activities, which have emerged as dualities in the course of the study, have completely different and also independent characteristics in comparison to 
each other during the course of a career. In other words, each of the five identified dualities possesses a unique character with regard to the interactions of the two imperatives, their weightings, dependencies and exclusions from each other as well as their constitution over time. Consequently, each duality requires targeted management by the top manager, both in its individual nature and in its interactions with the other four dualities. The duality between 'standing out' and 'fitting in' within the key practice of 'managing position', for instance, only appeared in the second career phase after the imperative of 'standing out' had been solely relevant before. While this initially represented a paradox in which the two activities proved to be opposites, these two activities must have been balanced against each other in the further course of personal branding in order to avoid turning the previous advantage of differentiation through 'standing out' into a disadvantage. Or, considered from a different perspective, this balance between consciously'standing out' and 'fitting in' resulted in a former imperative within the duality, i.e., 'standing out', mutating into an independent activity that corresponds to its original effect with a content expanded by the other imperative. The duality between internal and external visibility, however, showed an asymmetrical dependence on each other. As far as the personal brand was visible outside the company, this also generated internal visibility. Conversely, visibility within the company did not necessarily lead to visibility outside the company. Here, one activity supported the effect of another to which it seemed at first glance to be contrary in the sense of a dual relationship. Moreover, at an advanced career stage, the personal brand was developed mainly through one of the two imperatives of this duality, namely outside the company. In contrast to Farjoun (2010), the dualities in top managers' personal branding processes identified by this research confirm the approach of social theorists. They argue that conceptual distinctions can be maintained in dualities without being committed to rigid antagonism or separation (e.g., Elias, 1991; Giddens, 1984a). Rather, the two imperatives that make up a duality are no longer separate but interdependent, potentially compatible and even mutually enabling and constituting, while remaining conceptually distinct. The management of dualities thus extends both to overcoming the tensions arising from the dualities and to strategizing with these dualities and it concerns both the targeted application of a single activity as well as the conscious balance of dual activities in relation to each other. Evidently, developing the personal brand of top managers does not imply using all dual activities continuously during the personal branding process in order not to miss anything. Rather, a qualitative approach emphasises recognising these dualities, accepting them for oneself and one's personal branding, and dealing with them actively and selectively.

With an emphasis on temporal work, I acknowledge more than just the call for process research of organisational research at the individual level (Langley 
et al., 2013). The importance of temporal work highlighted by my analysis of top managers' personal branding processes also encourages a general consideration of the ways in which time and especially reflexivity is treated in personal branding research and thus in theory development (Chapter 5). Scholars emphasize the importance of reflexivity for the development of personal brands from different perspectives. Gorbatov et al. (2018) derive from their comprehensive review on the body of knowledge of personal branding that in addition to effective sense-making, seeking feedback and greater self-awareness, also the process of self-reflection contributes to a stronger and more coherent personal brand. As such, self-awareness is named as the first step of the personal branding process (Cederberg, 2017; Philbrick and Cleveland, 2015), a certain kind of reflexivity is required for posting a narrated selfie (Eagar and Dann, 2016), and the development of reflexivity is evoked by personal branding strategies as branded individuals undertake a careful and critical self-assessment of their relative strengths and weaknesses (Wee and Brooks, 2010). However, the results of my research not only confirm the importance of reflection in the personal branding process. It also demonstrates how reflection is indispensable in the development of a top manager's personal brand over time and how this is applied in practice. I found that top managers' personal brand viewed as a thing with fixed properties cannot be understood as the product of more or less intentional actions without considering the multiple interpretations of present concerns and historical trajectories as well as anticipations of prospective options that help to constitute those personal brands. Rather, it depends on the individual's temporal work processes generated by critical events and triggers experienced by her or him. This approach indicates that personal branding is not a deliberate, predictable and future-oriented process but requires frequent interpretive links across the past, present and future in the various career phases. Also, a personal brand is not fully determined by background or luck for it requires a thoughtful, reflexive process by the branded individual in practice. The use of this lens potentially reveals the temporal-reflexive dynamics of personal branding, which is also contained in Schön's (1983) notion of 'reflection in action' (Yanow and Tsoukas, 2009). In doing so, this study confirms scholars who use this view to explain that personal branding should be seen as a self-development tool that involves reflexivity (Khedher, 2015; Shepherd, 2005). However, I extend this view by adding concrete procedures of how temporal work guides activities and affects visibility and social relations when top managers are confronted with changing circumstances that challenge their current situation. Temporal work is a subjective process and highly dependent on opportunities and threats posed in the successive stages of a career. Considering reflexivity as an indispensable activity for the development of top managers' personal brands over time and understanding personal branding as a managerial practice in its own right as part 
of managerial work, confirms that both personal branding itself and the way we have identified for the emergence of top managers' personal brands are inevitably part of managerial development as Henry Mintzberg stated, "you can't create a manager in a classroom. Forget it. What we can do is take people who are managers and enhance their practice by giving them a chance to reflect on their experience, share it with each other, and learn from that experience to become more reflective and to understand their practice and enhance it" (Grand and Rüegg-Stürm, 2019).

My empirically based understanding of personal branding as a comprehensive process involving concrete practices that tangibly answer the how questions significantly expands the previous view. Gorbatov et al. (2018) pointed out that scholars who effectively discuss the process of personal branding only refer to models from the popular literature, such as Aruda's "extract, express, and exude" (Chen, 2013, p. 334), or the three-step model by McNally and Speak:"(1) identify the areas where your competencies matter; (2) examine your standards and values; (3) define your style" (Gander, 2014, p. 101). Further inspiration is given by, for instance, Brooks and Anumudu (2016) examining the 10-step model used by the consultancy PriceWaterhouseCoopers to teach personal branding, and the "4Ps" to design a self-branding model (Resnick et al., 2016). In contrast to this conceptual transfer of existing models to personal branding, I used a framework at the methodological level (Whittington, 2006) to identify the personal branding process in a practiceoriented approach (Chapter 3). Defining vision and targets, needs analysis and positioning, constructing brand architecture and brand story, self-reflection, and feedback-seeking are the mostly named processes in personal branding (Gorbatov et al., 2018). However, a large part of personal branding scholarship tends to exclude the temporal perspective to depict personal brands as static propositional statements.

My approach of examining personal branding from a process perspective significantly complements the very few empirical studies in the field of personal branding that look at personal brands' development over time (Preece and Kerrigan, 2015; Lindridge and Eagar, 2015). Preece and Kerrigan (2015) applied a longitudinal life-passage approach based on retrospective interviews with artists and their stakeholders to understand how the artistic brand is constructed. This results in the depiction of the artist's brand as an artistic career that maps a series of statuses with different identities of the artist and is primarily based on an individual brand narrative. Lindridge and Eagar (2015), in turn, applied process research strategies, such as alternative templates and temporal brackets, but limited their study of the personal brand of a single celebrity, namely the late musician David Bowie, to archival data. They point out that a celebrity's personal brand is a creation of the market, and that the enduring popularity of a celebrity's character reflects not only a particular point in time, but also the ability to adapt to different times. This 
study complements this already applied process perspective with tangible insights into how personal brands are created and, in particular, how people's actions are shaped and influenced by structural conditions within and beyond their immediate control. In doing so, I extended the methodology to investigate personal branding by applying a practice-based perspective on time and proven process research strategies in face-to-face reflection with a group of branded individuals, i.e., top managers.

Although temporality is a fundamental element of this dissertation, even without its explicit consideration in the area of endorsement (Chapter 4), a confirming but also expanding understanding emerged of how top managers' personal brands work within the context of corporate brands. Beyond demographic and functional associations, e.g., age, tenure and educational background, of successful celebrity CEOs, I took an anthropomorphised and thus differentiated view by identifying non-evaluative associations as underlying carriers of meaning between celebrity CEOs and corporate brands. I extended the already proven influence of an international CEO on companies (Black, 1997; Hsu et al., 2013; Kedia and Mukherji, 1999; Sambharya, 1996) by adding a meaning transfer form at the brand attribute level. This resulted in empirical evidence for the first time to support the assumption that CEO fame is inextricably linked to the company and that credibility is an essential element for celebrity CEOs in transferring meaning to a corporate brand (Bendisch et al., 2013). With a view to further personal brand attributes, I differentiated personal branding for the category of celebrity CEOs. While scholars cite the attributes 'likeable' (Braunstein and Zhang, 2005), 'trustworthy' (Arai et al., 2014; Braunstein and Zhang, 2005; Erdem and Swait, 2004; Ohanian, 1990) and 'successful' (Arai et al., 2014) as important characteristics for endorsers in general, this cannot be confirmed for celebrity CEOs. The brand attribute 'authentic' also does not work in meaning transfer from celebrity CEO to corporate brand, although it remains a key success factor for the branding of celebrities (Moulard et al., 2015; Speed et al., 2015). In addition to this 'celebrity-to-brand transfer', the underresearched area of 'brand-to-celebrity transfer' exists in the opposite direction (Bergkvist and Zhou, 2016), which entails that brand traits may also transfer to people who are associated with the brand (Arsena et al., 2014). The findings in this study eventually provide the first empirical evidence that a corporate brand can serve as a source for an endorsement to a CEO, in particular for the brand attributes 'successful', 'international' and 'professional'. In view of the increasing celebritization of CEOs in the media and especially in social media, a more expansive approach is proposed that takes into account the corporate brand and its transfer of meaning in the personal branding of top managers. The initial empirical evidence of mutual meaning transfer between celebrity CEO and corporate brand also suggests that the combination of celebrity CEO and corporate brand should be considered as a 
brand alliance, where meanings and values can be transferred from one partner to the other (Halonen-Knight and Hurmerinta, 2010).

Reflecting again on Webster and Watson (2002) referring to Parsons and Shils (1962) who established a hierarchy for classifying theories, this research provided classes and categories of personal brands and elaborated their taxonomies. However, many scholars who skipped this step, at least in thought, already produced conceptual frameworks based primarily on the application of theories from other fields of research. Therefore, and encouraged by my research findings, I propose to complement the classification model of Webster and Watson (2002) by a hierarchical level between conceptual frameworks and theoretical systems: practice-based models that incorporate empirical observations and predictions and are generalised for a defined category.

\subsection{THEORETICAL IMPLICATIONS}

With this interdisciplinary dissertation, I also aim to make some contributions to different literature streams.

First, it follows inevitably from the title of this dissertation and its field of research that this dissertation contributes to the personal branding literature. While the 'marketing of persons' was initially mentioned in the marketing literature more than five decades ago and was ascribed to represent a defining feature of the expansion of the traditional marketing concept (Kotler and Levy, 1969), this research field only experienced an increase in publications from the mid-2000s onwards, which stepped up very steeply (Scheidt et al., 2020). This significant increase in scholarly attention to personal branding has given this contemporary phenomenon a widespread, albeit fragmented, academic presence in which valid personal branding frameworks or even theories cannot be identified yet. Initial literature reviews attempted to address the need for an overview of personal branding, which however limit themselves to specific sub-fields, such as personal branding and social media (Alipour et al., 2015) and the sociological discussion of personal branding (Whitmer, 2019), and thus do not provide a comprehensive overview. I deliberately created an initial structured overview of the research field of personal branding at the beginning of this research project and thus before the further empirical investigations, in order to obtain the necessary guidance for these. In the further course of my empirical research, this first overview was continuously updated, which ultimately allowed me to contribute significantly to the structuring of the existing personal branding literature (Scheidt et al., 2020) and which resulted in Chapter 2 of this dissertation. The interdisciplinary framework covers six key research streams of personal branding, i.e., terminology 
and definition, underlying theories, classes and categories, benefits, antecedents, and key ingredients and applications. It is complemented by challenges in the domain of personal branding and may serve as a guidance for approaching personal branding as a holistic academic field and the interrelations between its different streams. This was paralleled by a first literature review on personal branding published by Gorbatov et al. (2018), which aggregates the trends, drivers, processes, and outcomes of personal branding from the literature and proposes a theoretical model for personal branding. In its genesis independent of this, my literature review in turn complements that of Gorbatov et al. (2018) with a number of additional points. It channels the diverse use of the term 'personal brand' and its numerous synonyms, as well as the recognition that personal branding is no longer limited to actors and musicians but is complemented by other professional and personal groups (Moulard et al., 2015), by offering for the first time a clear structure of classes and categories that is both based on previous literature and grounded in societal, technological and cultural developments. In addition, this study expands the understanding of personal brands, which is strongly oriented towards a static statement, to a processual view of personal branding over time. I respond empirically to academic calls (Keller, 2013; Gander, 2014; Lunardo et al., 2015) to emphasize time as an indispensable factor in the creation of personal brands, complementing the few existing examples of viewing personal brands as true narratives (Lindridge and Eagar, 2015; Preece and Kerrigan, 2015) with an application of process research strategies and the perspective of temporal work. In this regard, I also point out the necessary distinction between personal brand as a thing and personal branding as a process, which is insufficiently developed in this field of research, and therefore propose specific definitions. Many scholars already identified key factors of what constitutes a personal brand, such as a focus on target groups (Bendisch et al., 2013), endorsement effects (Halonen-Knight and Hurmerinta, 2010), differentiation (Parmentier et al., 2013) and visibility (Philbrick and Cleveland, 2015). My research extends the existing knowledge about these key factors by progressing them to clearly outlined and interrelated key practices that contain coherent activities, thus providing a differentiated understanding of how to build personal brands. I also propose an empirically derived model for the development of top manager personal brands that may be transferable to other personal brand categories.

Second, and equally inevitably from the research field of this dissertation, this study contributes to the literature that deals with top managers such as CEOs. From a configurational perspective the fragmented research results can be categorized into three interrelated domains: the position (i.e., the role and structure of the CEO job), the person (i.e., personal characteristics of the CEO and his or her selfperceptions), and the environment (i.e., how others perceive the CEO) (Busenbark 
et al., 2016). Even though the personal component is already focused on here, the consideration of top managers as publicly visible personal brands is largely missing, which also applies to the literature that already considers the traits of top managers manifold (Ahn, 2014; Fetscherin, 2015; Graham et al., 2010; Hsu et al., 2013; Rule and Ambady, 2008). Here I provide a first fundamental, empirically based understanding of the construction and development of the personal brand of top managers by not limiting myself to individual aspects but using their entire career as a time frame for the development of their personal brand and applying a practice-oriented perspective. I also deliver evidence on how CEO brand and corporate brand are related to each other through meaning transfer effects at brand attribute level. Existing evidence on the impact of CEOs on corporates tends to focus on the corporate performance aspect (Agarwal et al., 2011; Fombrun, 1996; Malmendier and Tate, 2009; Milbourn, 2003; Rajgopal et al., 2006; Wade et al., 2006), which my research extends by adding the branding perspective.

I also aim to contribute to celebrity endorsement research (Keller, 2013; Miller and Allen, 2012), which has predominantly considered endorsement from a celebrity-tobrand-perspective (Bergkvist et al., 2016; Eisend and Langner, 2010). This research extends initial findings demonstrating that brand traits may also transfer to people who are associated with the brand (Arsena et al., 2014). As such, the findings eventually provide the first empirical evidence that a corporate brand can serve as a source for an endorsement to a CEO, which contributes to the under-researched area of "brand-to-celebrity transfer" (Bergkvist and Zhou, 2016). While general agreement exists that celebrity CEOs serve as endorsers for their corporate (Bendisch et al., 2013; Fetscherin, 2015; Graffin et al., 2012), I add insights about how mutual endorsement effects between celebrity CEO and corporate brand may work at the level of specific brand attributes. In doing so, I provide new theoretical insights into what specific attributes possess the potential to turn CEOs into successful celebrity CEO endorsers. This research extends the predominantly considered demographic and functional associations in endorsements, such as age, tenure and educational background, by a more anthropomorphized and thus distinctive view resulting in brand attributes as non-evaluative associations. The mutual meaning transfer between celebrity CEO and corporate brand demonstrated in my research contributes especially to the literature on co-branding, which has generally traced a one-sided approach that produces outcomes for just one of the two partnering brands (Close et al., 2011; Fournier, 2010; Keller, 2003). The resulting extension of this limited view on co-branding implicates calls for an analysis and development of co-branding models that must not be restricted to one direction between the partner brands. Reciprocal effects in co-branding models are to be considered, as this has significant impact on theory building as well as on applicability. My proposed, expanded and specified definitions of endorsement and endorser consolidate the contributions to this field of research. 
Another contribution can be made to the stream of management literature and especially to some of its sub-streams. The literature on managerial work and practices efforts to answer the decades-old fundamental question 'What do managers do?' (Mintzberg, 1973) by identifying numerous managerial practices in various areas of management (Korica et al., 2017; Kurke and Aldrich, 1983; Tsoukas, 1994; Chia and Holt, 2006). This research enriches the given body of knowledge by providing answers to both the 'what' and 'how' questions with a view to managerial practices. This allowed me to identify personal branding as a distinct management practice in itself and an additional facet of managerial work, which, given the high visibility of top managers as individuals and as representatives of companies, should be one of the most important contemporary management practices of current and future top managers. Moreover, I suggest that any managerial work - like personal brand development - must be understood from a practice point of view and thus I contribute to practice-oriented literature (Bourdieu, 1990; Giddens, 1984, 1991; Reckwitz, 2002), which pays particular attention to strategy practice (Jarzabkowski, 2004; Whittington, 2006). On the one hand, I confirm here the applicability of the integrative framework of strategy practice, by applying its three concepts of praxis, practices, and practitioners (Whittington, 2006) to personal branding as a managerial practice. On the other hand, I indicate that personal branding is a practice that cannot only coexist with strategy-related issues such as strategic decision-making, corporate strategies and strategy implementation. Rather, I add that personal branding has a direct impact on strategy practice, both in terms of the activity within organisations that is central to managerial work, but also as a phenomenon that spreads beyond organisations with potential influence on entire societies, contributing to an expanded and innovative understanding of 'strategy-as-practice'.

In addition, this dissertation contributes to the literature stream that addresses dualism and duality (Abbott, 2001; Elias, 1991; Farjoun, 2010; Giddens, 1984; Orlikowski, 1992). These phenomena typically demonstrate a clear and definite contradiction, a well-defined boundary, and an absence of overlap. This often turns into a synonym for opposition and potential conflict (Farjoun, 2010). In contrast, the recognized dualities in the top managers' personal branding processes of this study confirmed the approach of social theorists who claim that conceptual distinctions can be maintained in dualities without being committed to a rigid antagonism or separation (Elias, 1991). Rather, the two imperatives a duality consists of are no longer separate but interdependent, potentially compatible, and even mutually enabling and a constituent of one another, while remaining conceptually distinct.

Time is a key dimension in the process research literature (Berends and Lammers, 2010; Bingham and Kahl, 2013; Jacques, 1982; Orlikowski and Yates, 2002; Van de Ven and Huber, 1990; Van de Ven and Poole, 2005). I appreciate the call for process 
research in organizational concerns at the individual level (Langley et al., 2013) by applying process research strategies, which extends significantly the very few empiric studies that consider how personal brands are built over time (Lindridge and Eagar, 2015; Preece and Kerrigan, 2015). In doing so, I contribute to scholars' general agreement that personal brands need to be managed in and over time (Gander, 2014; Lunardo et al., 2015), although they have been previously portrayed as static constructs rather than something that emerges over time. The literature stream on temporal work considers the dimension of time through a specific lens, implying a practice-based perspective on time that encompasses both the shaping of people's action and the being shaped by structural conditions within and outside of their immediate control (Emirbayer and Mische, 1998; Kaplan and Orlikowski, 2013). My research contributes to this concept of temporal work in grasping how managers make reflexive links to the past, present and future in the development of their personal brand.

Finally, this dissertation enriches the career literature and especially the scholarship interested in the role of time in career development. Scholars already understand careers as an "evolving sequence of a person's work experiences over time" (Arthur et al. 1989, p. 8) and as a pattern of positions and conditions of a career actor within a bounded social and geographical space over a lifetime (Gunz and Mayrhofer, 2018). I support and extend these perspectives by substantiating them through clear practices and activities over the duration of careers. In addition, I emphasize the importance of temporal work in career research when we want to understand why certain activities are taken and decisions made to develop a personal brand during career trajectories. Furthermore, this research enriches the knowledge of how different career stages can be characterized in terms of certain continuities in activities within each stage and certain discontinuities at their boundaries. This contributes to classic career studies in the form of models of the developmental and career stages through which actors pass during their lives (Bateson, 1989, 2011) and studies that focus on timetables as playing an important role in describing and understanding careers (Lawrence, 1984). By better integrating the temporal perspective into career studies, I decisively improve the understanding of the career phenomenon: instead of a static, momentary view of people's job-related positions and experiences, the concept of career now captures how these positions and experiences develop or, conversely, remain stable over time. On the whole, this research enriches the view of career with the important facet of the contemporary phenomenon of personal branding as a career catalyst over time, which has not yet played a role in the career literature. 


\subsection{IMPLICATIONS FOR PRACTICE}

One aspiration of this dissertation is to build the bridge from practice, exemplified by sample groups of top managers and their real-life narratives, to theory and its implicit methodological analysis and theory development, and back to practice with the aim of applying key practices and models. This application in practice subsequently provides the opportunity for reflection and new inspiration for further theory development.

In view of this close, mutual and iterative interlocking of theory and practice, not accidentally I have applied the practice-oriented perspective in Chapters 3 and 5 in order to prepare the ground for practice already in the process of building a theory. Practice theorists emphasize the importance not only of what is done, something that can be understood by counting, but also of how it is done, something that necessitates close anthropological attention (De Certeau, 1984; Whittington, 2006). The substance that leads to added value in practice results from this what and how in the theoretical examination - complemented, naturally, by the answer to the question of why. However, the reality in practice shows that the fundamental substance suffers to the advantage of rapid commercialization. Time to market and a strong predatory competition for the favour of the manager and top manager to be advised but also of the ordinary person who needs a personal brand as otherwise the inescapable consequence is "being marginalised or left behind" (Harris and Rae 2011, p. 14), let the number of countless guidebooks from railway station and airport bookshops increase steadily. Their qualitative level is not the aim of the implications for practice in this dissertation, just as this research does not aim to produce simple instruction manuals.

Practice theorists also focus on the actors who have the skills and initiative on which the activity depends. These actors are ascribed to be creative agents insofar as they are reflective enough to liberate their activity from the thoughtless reproduction of the initial conditions (Giddens 1984; 1991) and thus can both change and reproduce the set of practices they draw upon. "For practice theory, people count" (Whittington, 2006, p. 615), which is why I target people in three core target groups who may benefit in the practical application and use of my research findings. This is firstly intended for professionals and managers who are at different stages of their careers on the way to becoming top managers. Then, I am concerned with top managers themselves. And finally, my contributions also address those people who support the two aforementioned target groups in their personal branding and beyond.

The first target group of professional and managerial staff can benefit from building or expanding their basic knowledge and awareness of personal branding before they even start working on their personal brand by using the findings 
from Chapter 2 in the sense of an overview as well as from the further chapters to deepen their knowledge. Alongside the fact that personal branding is mainly marketed to this target group as a communication activity with primary visibility in social media, the ownership of one's own personal brand constitutes one of the greatest challenges in this field. Conventional notions of brand ownership are perceived as inadequate in a world facing a massive transition from an industrial to an information-based economy. Particularly the rise of social media, where personal brands are constructed for individuals through user-generated content, suggests that control over and ownership of the self needs to be challenged (Hearn, 2008). The personal brand and its values are co-constructed by a variety of actors, going beyond simple producer-consumer relationships (Preece and Kerrigan, 2015), which results, for instance, in ownership of a top manager's personal brand now resting in the hand of the media, agencies, customers, employees, analysts, investors, and advisory boards to name just a few (Bendisch et al., 2013). The statement "that [personal] brands need to accept the loss of control that arises from an empowered audience and technological changes" (Lindridge and Eagar, 2015 , p. 5 referring to Iglesias and Bonet, 2012) appears overly pessimistic to me. However, the fear of losing ownership of one's personal brand, as someone else will manage this personal brand if the individual does not do so him or herself, as well as the accompanying fear of losing one's own existence, has its justification. Consequently, I suggest that the responsibility for one's own personal brand must not be delegated to a coach, consultant or even a seminar or book, but that personal branding should be understood and implemented as part of the responsibility for oneself. In order to bring this notion of self-responsibility to life, professionals and managers can benefit in developing their personal brand by broadening their scope for purposeful activity through the key practices I identified in Chapter 3. Depending on the stage of their career as well as on how effectively one recognizes the dualities involved in these key practices and how one overcomes them, the transition to the next career stage is practicable and contributes to the development of the personal brand. Given the prevalent and biased view in practice that personal branding relies on strong personal differentiation, I particularly highlight the importance of finding the balance between 'standing out' and 'fitting in', which moreover changes as a requirement throughout one's career. However, the key practices and the dual activities inherent in them are not a simple manual that is applied in the particular career phase in which the leader finds himself or herself and the personal brand then emerges, more or less as a matter of course. Reflexivity is key and an indispensable part of self-responsibility. Therefore, young careerists are encouraged to deal deliberately with the challenges of creating their careers when confronted with a contemporary and prospective world of work that implies the need for continuous development including personal branding and constant 
change. I like to advise them to critically reflect on their own personal branding process and the associated actions and decisions at every stage of their career and to align them for the future by temporal work as described in Chapter 5.

Top managers are equally confronted with the same challenge as professionals and managers in terms of ownership of their own personal brand. For that reason, they also benefit from the insights and overviews of this dissertation in their awareness about personal branding. I also want to sensitise top managers to integrate personal branding as an indispensable practice in their managerial work and to actively take part in it themselves. On the one hand, the key practices of top managers presented in Chapter 3 can be used to determine self-critically which activities from previous career phases can still be meaningfully completed and how this can be realised. On the other hand, visibility and shining in the company and in public are key success factors in personal branding at top manager level. Therefore, they are particularly advised to actively manage off-field visibility in its duality with on-field visibility by consciously building skills and experience in management, strategy, leadership and communication. In addition, I suggest specifically to top managers to add a deliberate, targeted and selective visibility, which I have called 'controlled shining', in order to preserve privacy as described in Chapter 5. Even though top managers have reached the supposed pinnacle of their professional career and advancement, and despite the fact that these CEOs are unique as individuals and because of their unique position and context (Lange et al., 2015), this does not keep them from the necessary reflection to build up their personal brand respectively to stabilise and develop it further. Therefore, I also advise them not to understand their personal branding and the associated positioning and visibility as a conscious, predictable and unilaterally future-oriented process. I would also like to suggest top managers that a personal brand is not fully determined by background, luck or fate. Rather, it requires a thoughtful, reflexive process by the top manager that includes frequent interpretive connections between past, present and future. I propose to consider the multiple interpretations of present concerns and historical trajectories, as well as anticipations of future options, that help constitute these personal brands. In addition, I show this target group how they interact as a personal brand with the corporate brand of the company they work for. On the one hand, I would like to sensitise top managers to take the meaning transfer effect between their own personal brand and the corporate brand of their future employer into account when deciding on their next career move. On the other hand, I advise a self-reflexive (concerning one's own personal brand) and an analytical (regarding the corporate brand) approach to those brand attributes that have been identified in Chapter 4 as having a mutual meaning transfer effect between these two brands. This applies to both the planned step of moving to a new company and in the continuous work as a representative of the current company. 
The third target group, those who support professionals, managers and top managers in their development, their positioning or even consciously in their personal branding, benefit from the advice for professionals and managers as well as from that for top managers mentioned above. Brand managers, communication managers, human resource managers, and advisory boards within companies are encouraged to think outside the box of their traditional professions and perspectives to gain a more comprehensive understanding of brands, people, and management. Brand managers and communication managers are advised to combine activities for corporate branding and personal branding of company representatives. Nowadays, a marketing or branding unit often takes care of the corporate brand while a communication unit supplies the CEO and other board members with texts for the public and the media. As a consequence, board members tend to be limited to transmitting corporate messages that are intended to serve the reputation of the company and thus the corporate brand. The targeted development and conscious use of the personal brand of top managers in a joint, combined synergistic mechanism of effect with the corporate brand is advisable. In this regard, the key practices identified in this dissertation as well as the identified meaning transfer effects can be used. I recommend, for instance, that an ambassador programme be set up in which managers and top managers represent the company internally and externally based on their individually developed personal brands. Human resource managers are recommended to include the idea of personal branding already in recruitment processes and, for instance, to use it as a reflexive exercise during assessment centres for applicants in order to question their understanding of their own personality and its effect in the company context and to sensitise them to it. I also suggest that the development of personal brands constitutes a reflexive part of leadership development programs to induce an early sensitisation among young leaders and managers for personal branding as a conscious and reflexive process and as a managerial practice in itself, which may support career building inside the company. Similar to human resource managers, I also advise advisory board members to consider the importance of meaning transfer effects between the personal brand of C-level candidates and the corporate brand as part of the decision-making process when it comes to hiring for vacancies at this level. Coaches and consultants outside companies, in turn, will hopefully gain inspiration from the findings in this dissertation to broaden their approach of service delivery when it comes to developing and positioning personal brands or coaching managerial personalities.

Whenever the talk is of a 'core', there must be something else beyond this 'core'. Therefore, I naturally take a look beyond the three core target groups of the implications for practice and additionally focus on further groups that can benefit in their practice by transferring the findings to themselves. Lecturers in branding 
are advised to expand their curriculum by adding the field of personal branding, as I have been able to identify personal branding as a discipline in its own right. Business schools that offer executive programmes targeting managers and top managers, be it an executive MBA, a tailor-made one for the top management of a company or an open one, are well advised to include an elective that includes personal branding. Again, I point out that reflexivity is key and agree with Henry Mintzberg's call for what management development requires: "What managers need now, above all else, is to slow down, step back, and reflect thoughtfully on their natural experience" (Mintzberg, 2004, p. 28). Finally, I would like to encourage the academics to strengthen their own personal branding efforts. The findings in Chapter 2 reveal that there exists neither a publication nor an empirical study for celebrities and icons in the category of academics, and just four publications on the personal brand of the ordinary professor. However, I am convinced that academics can also benefit from my findings in the sense of a transfer for their personal brand, but also are obliged to do so, as an increasing number of faculty leaders are no longer just researchers or lecturers, but clearly placed in a managerial role.

On the whole, personal branding proves to be an indispensable component in the practice of leadership development, management work and coaching.

\subsection{A PERSPECTIVE ON FURTHER RESEARCH}

This dissertation provides confirming as well as new findings, theoretical contributions, and implications for practice, thus opening the black box of personal branding to a certain extent. From the findings around my research, however, the question arises to what extent personal branding represents a fundamentally recognised scientific discipline or predominantly an advisory service provided by consultants. The key question of whether "the discipline of marketing [can] reclaim self marketing and personal branding from the enthusiasts" (Shepherd, 2005, p. 12) can thus be answered on the one hand with the fact that this responsibility lies in the discipline of personal branding itself. On the other hand, conceptual considerations and empirical studies will also be necessary in the future to give personal branding the scientific weight it deserves. Despite a number of useful findings from this study that may act as initial empirical door-openers and irrespective of the care spent along the entire research process, this dissertation, like all research, encounters some limitations and areas for improvement. Such limitations, by their nature, also have value, as they inevitably lead to further directions for future research. While specific limitations are identified within each chapter, the following reflections are of a general nature and relate to this dissertation as a whole. 
"If a study is worth doing at all, it's worth doing twice" (Lindsay and Ehrenberg, 1993, p. 236), which imposes fundamental approaches for further research emerging from this study. In this way, the external validity of the quantitative study (Chapter 4) could be increased through replication, and I suggest that the identified dualities (Chapter 3 ) be deepened and enriched through further empirical studies in the field of top manager personal brands. The exploration of the partnership between the personal brand and the corporate brand at the level of top managers requires a more in-depth examination of the first time demonstrated 'brand-tocelebrity-CEO transfer'. Moreover, it should be extended to the concept of brand alliance (Simonin and Ruth, 1998), also considering a measurement of the resulting brand equity between partnering celebrity CEOs and corporate brands.

In addition to simply extending existing results through further research, the added value of future studies in the area of personal branding lies primarily in a stronger differentiation of the findings from our research. The sample group in this study in Chapters 3 and 5 provides heterogeneity in terms of gender, age, and exact job function. Future research is recommended to explore possible distinctions between these dimensions. Indeed, there are different chief officers, such as CFO, $\mathrm{COO}$ or CTO, as well as distinct types of CEOs. The distinction between 'agent or non-founder CEOs' and 'founder CEOs' may also show differences in the personal branding processes as well as the construction of the personal brands beyond their already studied contexts with the company (He, 2008; Randøy and Goel, 2003; Shulman, 2010; Nelson, 2010). Considering the gender-heterogeneous composition of our research group, I was not able to identify any gender-specific differences for the personal branding of top managers, which should be the subject of future research. Here, too, existing, gender-specific findings can be drawn upon and at least used as inspiration. Women, for instance, are less likely to self-promote than men (Dobbins et al., 1990; Oakley, 2000; Singh et al., 2002). This gender gap in selfpromotion mirrors the gender gap in self-evaluation, and furthermore, the gender gap in self-evaluation is specific to the evaluation of one's own performance (Exley and Kessler, 2019). Although many women are aware of the potential of impression management, self-promotion, and networking, they decide not to use it (Singh et al., 2002), which might affect their personal brand.

Further differentiating the findings of my research by examining them in additional fields also offers valuable opportunities for future research. The comparison between different industries, for instance, provides indications of the extent to which regulatory frameworks of industries such as the financial sector and the energy and telecommunications industry may have an impact on personal branding compared to non-regulated industries such as the event industry. Cultural differences in the development of personal brands are also conceivable. Certainly, the prevailing management theory developed in the United States and applied 
worldwide (House, 1998; Triandis, 2004) suggests that modern management practices are largely cross-cultural. However, this should also be explored for the management practice of 'personal branding'.

In addition to the 'what' and 'how' in personal branding, the 'why' should also become subject of future research. I propose to examine the antecedents of the individual personal brand and consider their impact on the individual personal branding process. This could include the family background and other imprinting factors that shape and mould the personal brand. Methodologically, the process data from the qualitative research in this dissertation is based on retrospectively collected live stories from interviews with current top managers. I suggest that even stronger patterns can be developed from temporal work through real longitudinal research, for example auto-ethnographic accounts from managers who potentially reach the position of top manager in the medium term. On the way to a comprehensive personal branding framework or even theory, all research efforts should take into account that even in a well-defined field such as commercial sports, a general model for personal branding is not effective, as, for instance, "wrestlers or boxers might be seen as rude athletes, while golfers might be seen as sophisticated ones" (Lunardo et al., 2015, p. 706). I therefore propose to develop more practice-based and empirical models for specific personal branding categories, as their aggregation may serve as an approximation towards an overarching theory of personal branding.

Beyond these rather obvious paths of expansion and differentiation for future research in the field of personal branding, it is important to courageously leave the familiar paths of discipline, methodology and content. The multidisciplinary approach of personal branding, career, and organisational behaviour, for instance, is already proving fruitful for all disciplines involved and also for personal branding from the perspective of these different disciplines - in theory and practice. The use of empirical and observational approaches to learning is part of the modern researcher's day-to-day work. Equally, it is challenging to translate the gained evidence into concrete, sustainable action to change policy or practice. The need to inspire learning and action is far from new. Centuries ago, Leonardo da Vinci is supposed to have remarked, "I have been impressed with the urgency of doing. Knowing is not enough; we must apply. Being willing is not enough; we must do" (Zelmer, 2014). But what happens when everyone knows, wants, applies and acts with their personal brand in mind? Can there be an infinite number of different personal brands, each with its own human complexity? Can all these personal brands work and have an effect as distinctive personal brands? Simply said, "even if it were possible that we could all be famous, if everyone were famous, then no one would be famous" (Holmes and Redmond 2006, p. 14). From my experience, the clear positioning of a person always includes his or her realistic demarcations. 
I suppose this also applies to people's personal brand and also to personal branding as such. Besides the urge to explore and prove further application areas and approaches of personal branding, research should therefore also focus on the limitation of personal branding. Possibly, this represents a way to give guidance to the fragmented body of knowledge of personal branding and to come closer to a theory of personal branding. 
APPENDIX 


\section{APPENDIX A}

Appendix 1: Overview of publications concerning three different classes of personal brand in eleven different categories

\begin{tabular}{|c|c|c|c|c|}
\hline \multirow[t]{2}{*}{ Categories } & \multirow{2}{*}{$\begin{array}{c}\text { Sub- } \\
\text { categories }\end{array}$} & \multicolumn{3}{|c|}{ Classes of Human Brands } \\
\hline & & Icon & Celebrity & Personal brand \\
\hline \multirow[t]{3}{*}{ Sports } & Athletes & --- & $\begin{array}{l}\text { Rascher et al., 2017; } \\
\text { Sassenberg et al., 2012; } \\
\text { Shuart, 2007; Summers \& } \\
\text { Morgan, 2008 }\end{array}$ & $\begin{array}{l}\text { Agyemang, 2011; Arai et } \\
\text { al., 2013; Arai et al., 2014; } \\
\text { Ballouli \& Hutchinson, 2012; } \\
\text { Carlson \& Donavan, 2013; } \\
\text { Carlson \& Donavan, 2017; } \\
\text { Chang, 2018; Chang et al.., } \\
\text { 2018; Constantinescu, 2017; } \\
\text { Desmarais, 2017; Emmons \& } \\
\text { Mocarski, 2014; Geurin, 2017; } \\
\text { Geurin-Eagleman \& Burch, } \\
\text { 2016; Green, 2016; Hasaan et } \\
\text { al., 2016; Hasaan et al., 2018; } \\
\text { Hasaan et al., 2019; Hodge } \\
\text { \& Walker, 2015; Kunkel et al., } \\
\text { 2019; Lebel \& Danylchuk, 2014; } \\
\text { Lobpries et al., 2017; Lobpries } \\
\text { et al., 2018; McGhee, 2012; } \\
\text { Parris et al., 2014; Schwartz \& } \\
\text { Vogan, 2017; Staskeviciute- } \\
\text { Butiene, 2014; Tsiotsou, 2016; } \\
\text { Williams et al., 2015; Wilson \& } \\
\text { Liu, 2012; Zhou \& Tainsky, 2017 }\end{array}$ \\
\hline & $\begin{array}{l}\text { Athletic } \\
\text { trainers }\end{array}$ & --- & -- & $\begin{array}{l}\text { Kahanov \& Andrews, 2001; } \\
\text { Walsh \& Williams, } 2017\end{array}$ \\
\hline & $\begin{array}{l}\text { Athletes } \\
\text { from specific } \\
\text { disciplines }\end{array}$ & $\begin{array}{l}\text { David Beckham } \\
\text { (Kelting \& } \\
\text { Rice, 2013; } \\
\text { Parmentier \& } \\
\text { Fischer, 2012) }\end{array}$ & $\begin{array}{l}\text { Ryan Giggs (Parmentier \& } \\
\text { Fischer, 2012) } \\
\text { LeBron James (Fresco, } \\
\text { 2017) } \\
\text { Andy Murray (Davies \& } \\
\text { Slater, 2015) } \\
\text { Suzann Pettersen } \\
\text { (Kristiansen \& Williams, } \\
\text { 2015) } \\
\text { Eugen Sandow (Morais, } \\
\text { 2013) } \\
\text { Annika Sörenstam } \\
\text { (Cortsen, 2013) } \\
\text { Tiger Woods (Tanner \& } \\
\text { Maenq, 2012) }\end{array}$ & $\begin{array}{l}\text { Bigsby et al., 2019; Chadwick } \\
\text { \& Burton, 2008; Kakitek, 2018; } \\
\text { Lebel \& Danylchuk, 2012; } \\
\text { O'Reilly \& Braedley, 2008; Price } \\
\text { et al., } 2013\end{array}$ \\
\hline
\end{tabular}




\begin{tabular}{|c|c|c|c|c|}
\hline \multirow[t]{3}{*}{ Academics } & General & \begin{tabular}{|l|}
--- \\
I
\end{tabular} & --- & $\begin{array}{l}\text { Banet-Weiser \& Juhasz, 2011; } \\
\text { Borman-Shoap et al., 2019; Close } \\
\text { et al., 2011; Cole-Turner, 2019; } \\
\text { Duffy \& Pooley, 2017; Hotez, 2018; } \\
\text { Radford et al., 2018; Reif-Lehrer, } \\
\text { 1992; Shafaei et al., } 2019\end{array}$ \\
\hline & Professors & --- & --- & $\begin{array}{l}\text { Jillapalli \& Jillapalli, 2014; Jillapalli } \\
\text { \& Wilcox, 2010; Zamudio et al., } \\
\text { 2013; Zamudio \& Meng, 2015 }\end{array}$ \\
\hline & Students & --- & --- & $\begin{array}{l}\text { Bergh et al., 2017; Bronstein, 2014; } \\
\text { Chakrabarti, 2014; Edmiston, 2014; } \\
\text { Flostrand et al., 2016; Holmberg } \\
\text { \& Strannegård, 2015; Hood et } \\
\text { al., 2014; Humphrey et al., 2019; } \\
\text { Ilies, 2018; Johnson, 2017; Jones \& } \\
\text { Leverenz, 2017; Lee \& Cavanaugh, } \\
\text { 2016; Levin et al., 2019; Manai \& } \\
\text { Holmlund, 2015; McCorkle et al., } \\
\text { 1992; McCorkle et al., 2003; Myers, } \\
\text { 2017; Robson, 2019; Shuker, 2014; } \\
\text { Stanton \& Stanton, 2013; Taylor, } \\
\text { 2003; Watson, 2019 }\end{array}$ \\
\hline \multirow[t]{5}{*}{ Politicians } & General & --- & $\begin{array}{l}\text { McKernan, 2011; Street, } \\
2004\end{array}$ & $\begin{array}{l}\text { Algara, 2019; Bors, 2019; } \\
\text { Coesemans \& De Cock, 2017; } \\
\text { Colliander et al., 2017; Jones, } \\
\text { 2010; Medveschi \& Frunzã, 2018; } \\
\text { Milewicz \& Milewicz, 2014; Speed } \\
\text { et al., } 2015\end{array}$ \\
\hline & \begin{tabular}{|l|} 
Prime \\
ministers
\end{tabular} & --- & \begin{tabular}{|l} 
Tony Blair (Scammell, \\
2007) \\
Benito Mussolini (Swan, \\
2016) \\
Kevin Rudd (Burgess et \\
al., 2020; Craig, 2014) \\
\end{tabular} & --- \\
\hline & Presidents & --- & $\begin{array}{l}\text { George W. Bush (Tanner } \\
\text { \& Maeng, 2012) } \\
\text { Wladimir Putin } \\
\text { (Campbell \& } \\
\text { Denezhkina, 2017) } \\
\text { Donald Trump (Hearn, } \\
\text { 2016; Pérez-Curiel \& } \\
\text { Naharro, 2019) } \\
\end{array}$ & --- \\
\hline & \begin{tabular}{|l|} 
Election \\
candidates
\end{tabular} & \begin{tabular}{|l|}
--- \\
\end{tabular} & $\begin{array}{l}\text { Charles Kennedy (Harris } \\
\text { \& Lock, 2001) }\end{array}$ & $\begin{array}{l}\text { Chai \& Kim, 2013; Kaneva \& } \\
\text { Klemmer, 2016; Parker, 2012; Van } \\
\text { Steenburg \& Guzmán, 2019 }\end{array}$ \\
\hline & $\begin{array}{l}\text { Ordinary } \\
\text { politicians }\end{array}$ & --- & --- & Rozanova, 2017 \\
\hline
\end{tabular}




\begin{tabular}{|c|c|c|c|c|}
\hline \multirow[t]{4}{*}{$\begin{array}{l}\text { Visual } \\
\text { artists }\end{array}$} & General & --- & --- & $\begin{array}{l}\text { Baumgarth \& O'Reilly, 2014; } \\
\text { Baumgarth et al., 2014; } \\
\text { Hernando \& Campo, 2017; } \\
\text { Kucharska \& Mikolajczak, 2018; } \\
\text { Moulard et al., 2014; Preece \& } \\
\text { Kerrigan, 2015; Schroeder, } 2005\end{array}$ \\
\hline & $\begin{array}{l}\text { Painters/ } \\
\text { Graphic } \\
\text { artists }\end{array}$ & --- & \begin{tabular}{|l|} 
Thomas Kinkade (Fillis, \\
2015) \\
Ernst Ludwig Kirchner \\
(Weikop, 2012) \\
Pablo Picasso (Muñiz Jr. \\
et al., 2014) \\
Andy Warhol (Kerrigan \\
et al., 2011)
\end{tabular} & --- \\
\hline & Sculptors & --- & $\begin{array}{l}\text { Ai Weiwei (Preece, } \\
\text { 2015) }\end{array}$ & --- \\
\hline & $\begin{array}{l}\text { Video/film } \\
\text { producers }\end{array}$ & --- & $\begin{array}{l}\text { Marina Abramovic } \\
\text { (Marcus, 2015) }\end{array}$ & --- \\
\hline \multirow[t]{5}{*}{$\begin{array}{l}\text { Performing } \\
\text { artists }\end{array}$} & Actors & --- & \begin{tabular}{|l|} 
Drew Barrymore (Choi \\
\& Rifon, 2012) \\
Russell Brand (Mills et \\
al., 2015) \\
Dustin Hoffmann (Tripp \\
et al., 1994) \\
Elizabeth Hurley \\
(Barron, 2007) \\
Jena Malone (Wohlfeil \\
\& Whelan, 2012) \\
Julia Roberts (Choi \& \\
Riffon, 2012) \\
\end{tabular} & Mathys et al., 2016 \\
\hline & Musicians & $\begin{array}{l}\text { David Bowie } \\
\text { (Lindridge \& Eagar, } \\
\text { 2015; Eagar \& } \\
\text { Lindridge, 2015) }\end{array}$ & $\begin{array}{l}\text { Cheryl Cole (Cocker et } \\
\text { al., 2015) } \\
\text { Ladi6 (Friend, 2015) } \\
\text { Lady Gaga (Click et al., } \\
\text { 2013) } \\
\text { Kylie Minogue } \\
\text { (Chapman et al., 2005) }\end{array}$ & $\begin{array}{l}\text { Huang \& Huang, 2016; } \\
\text { Matenge, 2013; Meiseberg, } \\
\text { 2014; Turri et al., 2013; Saboo et } \\
\text { al., 2016; Scharff, 2015 }\end{array}$ \\
\hline & Comedians & --- & $\begin{array}{l}\text { Matthew Broderick } \\
\text { (Tripp et al., 1994) }\end{array}$ & --- \\
\hline & Models & --- & \begin{tabular}{|l|} 
Tyra Banks (Keller, 2014; \\
Persis Murray, 2015) \\
Katie Price (Cocker et \\
al., 2015; Genz, 2015) \\
\end{tabular} & $\begin{array}{l}\text { Belk, 2019; Parmentier et al., } \\
2013\end{array}$ \\
\hline & TV Anchor & --- & \begin{tabular}{|l|} 
Bethenny Frankel \\
(Nayar, 2015) \\
Oprah Winfrey (Loroz \& \\
Braig, 2015) \\
\end{tabular} & Finneman et al., 2019 \\
\hline Aristocracy & Royals & \begin{tabular}{|l} 
British royals \\
(Otnes \& Maclaran, \\
2018) \\
\end{tabular} & --- & Dionise, 2018 \\
\hline $\begin{array}{l}\text { Producers } \\
\text { of hedonic } \\
\text { products }\end{array}$ & Chefs & --- & $\begin{array}{l}\text { Chen et al., 2017; Clark } \\
\text { et al., 2016; Ehrmann et } \\
\text { al., } 2009\end{array}$ & --- \\
\hline
\end{tabular}




\begin{tabular}{|c|c|c|c|c|}
\hline \multirow[t]{8}{*}{$\begin{array}{l}\text { Professional } \\
\text { services }\end{array}$} & General & --- & |-- & $\begin{array}{l}\text { Abrate \& Viglia, 2019; Henning \& } \\
\text { Padayachee, 2018; Maiksteniene, } \\
\text { 2009; Ogutu \& Ougo, 2016; Shek et } \\
\text { al., 2015; Tussvadiah \& Park, } 2018 \\
\end{array}$ \\
\hline & Medical staff & --- & --- & $\begin{array}{l}\text { Brigham, 2016; Cederberg, 2017; Chu } \\
\text { et al., 2018; Ioan et al., 2014; Kalia et } \\
\text { al., 2017; Luca et al., 2015; Marwitz } \\
\text { et al., 2018; Mishra, 2019; Munden, } \\
\text { 2015; Trepanier \& Gooch, } 2014 \\
\end{array}$ \\
\hline & Consultants & \begin{tabular}{|l|}
--- \\
\end{tabular} & --- & Pagis \& Ailon, 2017 \\
\hline & $\begin{array}{l}\text { IT } \\
\text { professionals }\end{array}$ & --- & --- & Johnson, 2015 \\
\hline & Engineers & --- & --- & $\begin{array}{l}\text { Brennan et al., 2015; Sheikh \& Lim, } \\
2011\end{array}$ \\
\hline & Salespeople & --- & |-- & $\begin{array}{l}\text { Amoako \& Okpattah, 2018; Little, } \\
2012\end{array}$ \\
\hline & Teachers & --- & \begin{tabular}{|l|}
--- \\
\end{tabular} & Ilina et al., 2017 \\
\hline & Librarians & --- & --- & $\begin{array}{l}\text { Ahmad et al., 2016; Eke, 2012; Gall, } \\
\text { 2010; Kalbande, 2019; Schneider, } \\
\text { 2012; Thomas, } 2011 \\
\end{array}$ \\
\hline \multirow{3}{*}{$\begin{array}{l}\text { Self- } \\
\text { employed }\end{array}$} & General & \begin{tabular}{|l|}
--- \\
\end{tabular} & --- & Gandini, 2016 \\
\hline & $\begin{array}{l}\text { Creative } \\
\text { industry }\end{array}$ & --- & --- & $\begin{array}{l}\text { Duffy \& Pruchniewska, 2017; Pick et } \\
\text { al., 2015; Pruchniewska, } 2018\end{array}$ \\
\hline & Spiritual & --- & --- & Gregory, 2019 \\
\hline \multirow[t]{5}{*}{$\begin{array}{l}\text { Business } \\
\text { managers }\end{array}$} & CEOs & --- & |-- & $\begin{array}{l}\text { Alghawi et al., 2014; Bendisch et } \\
\text { al., 2013; Catellani et al., 2016; Chen } \\
\text { \& Chung, 2016; Chen \& Chung, } \\
\text { 2017; Cottan-Nir, 2019; Cottan-Nir } \\
\text { \& Lehman-Wilzig, 2018; Erdoğmuş } \\
\text { \& Esen, 2018; Fetscherin, 2015; Friel } \\
\text { \& Duboff, 2009; Takács et al., 2018; } \\
\text { Mudambi et al., 2019; Scheidt et al., } \\
\text { 2018; Treadway et al., 2009; Wade et } \\
\text { al., 2006 } \\
\end{array}$ \\
\hline & Executives & --- & |-- & $\begin{array}{l}\text { Karaduman, 2013; Schlosser et al., } \\
2017\end{array}$ \\
\hline & Leaders & --- & --- & $\begin{array}{l}\text { Manurung, 2015; Nolan, 2015; } \\
\text { Uymaz, } 2016\end{array}$ \\
\hline & Entrepreneurs & --- & $\begin{array}{l}\text { Martha Stewart } \\
\text { (Fournier, 2010; } \\
\text { Murphy, 2010) }\end{array}$ & $\begin{array}{l}\text { Ekhlasi et al., 2015; Raftari \& Amiri, } \\
\text { 2014; Razeghi et al., 2016; Sweeney } \\
\text { et al., 2018; Thompson-Whiteside et } \\
\text { al., } 2018\end{array}$ \\
\hline & $\begin{array}{l}\text { Owner- } \\
\text { manager }\end{array}$ & --- & |-- & Resnick et al., 2016 \\
\hline
\end{tabular}




\begin{tabular}{|c|c|c|c|c|}
\hline \multirow[t]{6}{*}{$\begin{array}{l}\text { Content } \\
\text { creators }\end{array}$} & Journalists & --- & --- & $\begin{array}{l}\text { Bossio \& Sacco, 2017; Brems et al., 2017; } \\
\text { Bruns, 2012; Canter, 2015; Carpenter et al., } \\
\text { 2017; Hanusch, 2018; Hanusch \& Bruns, 2017; } \\
\text { Hedman, 2015; Hedman \& Djerf-Pierre, } \\
\text { 2013; Holton \& Molyneux, 2017; Jukes, 2019; } \\
\text { Molyneux, 2015; Molyneux, 2019; Molyneux \& } \\
\text { Holton, 2015; Molyneux et al., 2018; Molyneux } \\
\text { et al., 2019; Olausson, 2017; Olausson, 2018; } \\
\text { Ottovordemgentschenfelde, 2017; Schultz \& } \\
\text { Sheffer, 2012; Van Hove et al., 2018; Zeng \& } \\
\text { Song, } 2018\end{array}$ \\
\hline & Authors & --- & $\begin{array}{l}\text { Elizabeth Gilbert } \\
\text { (Johns \& English, } \\
\text { 2016) }\end{array}$ & $\begin{array}{l}\text { Bremner \& Phung, 2015; Corrigan, 2015; } \\
\text { Makkai, } 2016\end{array}$ \\
\hline & Influencers & --- & $\begin{array}{l}\text { Kim Kardashian } \\
\text { (Harvey, 2018) }\end{array}$ & Khamis et al., 2017 \\
\hline & Bloggers & --- & --- & $\begin{array}{l}\text { Ahmad et al., 2013; Archer, 2019; Bronstein, } \\
\text { 2013; Delisle \& Parmentier, 2016; Draper \& } \\
\text { McDonnell, 2018; Duffy, 2015; Duffy \& Hund, } \\
\text { 2015; Erz \& Christensen, 2018; Hendrawan } \\
\text { \&Nahdiah, 2019; Kretz \& De Valck, 2010; Liu \& } \\
\text { Suh, 2017; McFadden, 2018; Pihl, 2013; Safitri, } \\
\text { 2017; Van Nuenen, 2016; Wang et al., 2015 }\end{array}$ \\
\hline & YouTubers & --- & $\begin{array}{l}\text { Jenna Marbles } \\
\text { (Maguire, 2015) }\end{array}$ & $\begin{array}{l}\text { Chen, 2013; Harrington, 2019; Lovelock, 2017; } \\
\text { Smith, 2014; Tarnovskaya, } 2017\end{array}$ \\
\hline & Vloggers & --- & $\begin{array}{l}\text { Bubz (García-Rapp } \\
\text { \& Roca-Cuberes, } \\
\text { 2017) } \\
\text { Zoe Sugg } \\
\text { (Berryman \& } \\
\text { Kavka, 2017) } \\
\end{array}$ & Berryman \& Kavka, 2017; Pahwa, 2019 \\
\hline
\end{tabular}




\section{APPENDIX B}

Appendix 2: Protocol of the semi-structured interviews with top managers

\begin{tabular}{|c|c|}
\hline Stages & Questions \\
\hline Warm-up & $\begin{array}{l}\text { - First of all, we are interested in understanding you as a person. Can you please } \\
\text { give us some information about what characterizes you (societal background, } \\
\text { family, parents, special events in your childhood and youth, school etc.)? }\end{array}$ \\
\hline Pre-branding & $\begin{array}{l}\text { - When did personal branding become an issue for you in your career? } \\
\text { - Was this always the case or did it happen later in your career? } \\
\text { - How intentional were you in planning to build your personal brand? } \\
\text { - Why was this important to you? What did motivate you to do so? }\end{array}$ \\
\hline $\begin{array}{l}\text { Personal } \\
\text { branding }\end{array}$ & $\begin{array}{l}\text { - What events have been critical in the development of your personal brand? } \\
\text { - Why were these events critical? } \\
\text { - What were the effects of these events? } \\
\text { - When did you become aware that you are developing your personal brand for } \\
\text { specific target groups? } \\
\text { - How did you do this? }\end{array}$ \\
\hline Competition & $\begin{array}{l}\text { - At which moment was it obvious to you that you are competing with others with } \\
\text { - your personal brand? } \\
\text { - In which specific fields did you compete (industry, in the company, to other top } \\
\text { managers etc.)? } \\
\text { - How did you compete? } \\
\text { - Who were your competitors? } \\
\text { - Did this field change over time? If so, why did this happen? And how? } \\
\text { - How did this affect your personal brand? }\end{array}$ \\
\hline Visibility & $\begin{array}{l}\text { - When did you reach visibility in your career? } \\
\text { - What did you do to gain this visibility? } \\
\text { - What was the result of your visibility? } \\
\text { - Has there been a difference in the emergence of your visibility between your } \\
\text { - professional field and mainstream media? } \\
\text { - How did this happen? }\end{array}$ \\
\hline Relationship & $\begin{array}{l}\text { - Did you build any crucial relationships during your personal branding process? } \\
\text { - How did you do so? When? } \\
\text { - Why did you form these relationships? } \\
\text { - What was the impact of these relationships? }\end{array}$ \\
\hline Sponsor & $\begin{array}{l}\text { - When did you receive any sponsoring in building your personal brand? } \\
\text { - How did the sponsor act? } \\
\text { - What result emerged from his/her activities? } \\
\text { - Did any stakeholder damage you in your personal branding process? } \\
\text { - What did he/she do? } \\
\text { - How did this affect your personal brand? }\end{array}$ \\
\hline
\end{tabular}




\begin{tabular}{|l|l|}
\hline Stages & Questions \\
\hline Endorsement & $\begin{array}{l}\text { - Have you ever been endorsed by any other brand? } \\
\text { - What other brands have you been endorsed by? } \\
\text { - How did this happen? } \\
\text { - What was the result? } \\
\text { - When did you act as an endorser for other brands through your personal brand? } \\
\text { - What other brands did you endorse? } \\
\text { - How did this happen? } \\
\text { - What has been the result? }\end{array}$ \\
\hline $\begin{array}{l}\text { Brand } \\
\text { Personality }\end{array}$ & $\begin{array}{l}\text { - What are the key characteristics of your personal brand personality? How did } \\
\text { - When did you develop specific aspects of your brand personality? } \\
\text { - How did you do this? }\end{array}$ \\
\hline $\begin{array}{l}\text { Closing } \\
\text { reflections }\end{array}$ & $\begin{array}{l}\text { - What were the main enablers and obstacles in your personal branding } \\
\text { - Wourgence? }\end{array}$ \\
& $\begin{array}{l}\text { - If not, why not? } \\
\text { - If so, what would you keep and what would you do differently to improve it? } \\
- \text { Finally, if you had to provide a short definition of personal branding, what would } \\
\text { it be? }\end{array}$ \\
\hline
\end{tabular}


Appendix 3: Protocol of the semi-structured interviews with stakeholders

\begin{tabular}{|c|c|}
\hline Stages & Questions \\
\hline Warm-up & $\begin{array}{l}\text { - We want to start by getting to know more about you as a person and as a } \\
\text { professional in your role. Can you tell us more about your current function / } \\
\text { industry? }\end{array}$ \\
\hline Pre-branding & $\begin{array}{l}\text { - To what degree have you been involved with the question of "personal } \\
\text { branding"? } \\
\text { - When did the issue of personal branding become an important part of your } \\
\text { - Wrofessional life? } \\
\text { - Why is that? }\end{array}$ \\
\hline \begin{tabular}{|l|} 
Personal \\
branding
\end{tabular} & $\begin{array}{l}\text { - What is your role / function in relationship with the top manager? } \\
\text { - When did you first encounter the top manager? } \\
\text { - How long did you work with the top manager? } \\
\text { - What is or was your personal relationship with the top manager? } \\
\text { - How would you characterize your work with the top manager? }\end{array}$ \\
\hline $\begin{array}{l}\text { Brand } \\
\text { Personality }\end{array}$ & $\begin{array}{l}\text { - How would you describe the personal brand of the top manager? } \\
\text { - What would you associate with the top manager's personal brand? From your } \\
\text { - point of view, what does that brand stand for? } \\
\text { - What would be the brand core of the top manager's personal brand? } \\
\text { - What would you see as the core characteristics of the personal brand personality } \\
\text { - of the top manager? } \\
\text { - How has the personal brand personality of the top manager developed over } \\
\text { time? }\end{array}$ \\
\hline $\begin{array}{l}\text { Managing } \\
\text { position }\end{array}$ & $\begin{array}{l}\text { - In what sense does the top manager's personal brand differ from that of other } \\
\text { people? } \\
\text { - What did the top manager do to stand apart from others? } \\
\text { - To what extent did the top manager use his or her personal brand to engage in } \\
\text { - competition with others? } \\
\text { - To what degree has the top manager integrated with his or her professional } \\
\text { environment? }\end{array}$ \\
\hline $\begin{array}{l}\text { Managing } \\
\text { individuals }\end{array}$ & $\begin{array}{l}\text { - Which relationships has the top manager benefited from in the process of } \\
\text { - personal branding? } \\
\text { - How did the top manager proceed in this respect? } \\
\text { - What were the effects of these relationships for the top manager? } \\
\text { - Did the top manager receive support or sponsoring from others in the } \\
\text { - development of the personal brand? } \\
\text { - What did the supporter or sponsor do? } \\
\text { - What were the results of the efforts of the supporter or sponsor? } \\
\text { - personal brand? } \\
\text { - What did this antagonist do? } \\
\text { - How did this affect the top manager's personal brand? }\end{array}$ \\
\hline
\end{tabular}




\begin{tabular}{|c|c|}
\hline Stages & Questions \\
\hline $\begin{array}{l}\text { Managing } \\
\text { visibility }\end{array}$ & $\begin{array}{l}\text { - From your point of view, at what point did the top manager become truly visible } \\
\text { in his or her career? } \\
\text { - How did the top manager achieve this level of visibility? } \\
\text { - What did this visibility bring the top manager? } \\
\text { - How did you perceive the top manager's visibility over the course of his or her } \\
\text { - career: } \\
\text { - Internal vs external } \\
\text { - Limited to the industry vs going across industries } \\
\text { - Online media vs offline media } \\
\text { - Inside vs outside of the top manager's original field of expertise } \\
\text { - How did this happen? }\end{array}$ \\
\hline Events & $\begin{array}{l}\text { - Which incidents and events were important for the development of the top } \\
\text { manager's personal brand? } \\
\text { - What made these events important in this respect? } \\
\text { - What were the effects of these events? }\end{array}$ \\
\hline KSFs & $\begin{array}{l}\text { - From your point of view, what would be the main factors enabling or hindering } \\
\text { the development of a personal brand of the top manager? }\end{array}$ \\
\hline $\begin{array}{l}\text { Support by the } \\
\text { Stakeholder }\end{array}$ & $\begin{array}{l}\text { - Did you consciously and purposefully plan or support the development of the } \\
\text { top manager's personal brand? } \\
\text { - If so, why did you do this? What motivated you? } \\
\text { - How specifically did you support the top manager in the evolution of his or her } \\
\text { - personal brand? } \\
\text { - Would you offer the top manager support with establishing his or her personal } \\
\text { - If not, why not? } \\
\text { - If so, what would you do again and what would you improve? }\end{array}$ \\
\hline $\begin{array}{l}\text { Closing } \\
\text { reflections }\end{array}$ & $\begin{array}{l}\text { - What would you consider the main factors that enable or preclude the } \\
\text { - development of a personal brand in top management? } \\
\text { - What constitutes a personal brand? } \\
\text { - How important is visibility for you? What type of visibility? } \\
\text { - How important are stakeholders? Which stakeholders? } \\
\text { - When is conformity required? } \\
\text { - How important would you consider the issue of personal branding for today's } \\
\text { top managers? Why is that? } \\
\text { - To conclude: If you had a give a brief definition of "personal brands", what would } \\
\text { it be? }\end{array}$ \\
\hline
\end{tabular}




\section{BIBLIOGRAPHY}


Aaker, J. L. (1997). Dimensions of Brand Personality. Journal of Marketing Research, 34, 347-356.

Abbott, A. (2001). Chaos of disciplines. Chicago: University of Chicago Press.

Abetti, P. A. (2006). Case study: Jack Welch's creative revolutionary transformation of General Electric and the Thermidorean reaction (1981-2004). Creativity Innovation Management, 15(1), 74-84.

Abrate, G., \& Viglia, G. (2019). Personal or product reputation? Optimizing revenues in the sharing economy. Journal of Travel Research, 58, 136-148.

Adam, B. (1994). Perceptions of time. In: T. Ingold (ed.), Companion Encyclopedia of Anthropology Humanity Culture, and Social Life. London, U.K.: Routledge, 503526.

Agarwal, V., Taffler, R., \& Brown, M. (2011). Is management quality value relevant?. Journal of Business Finance \& Accounting, 38(9/10), 1184-1208.

Aggarwal, P., \& McGill, A. L. (2007). Is that car smiling at me? Schema congruity as a basis for evaluating anthropomorphized products. Journal of Consumer Research, 34, 468-479.

Aggarwal, P., \& McGill, A. L. (2012). When Brands Seem Human, Do Humans Act Like Brands? Automatic Behavioral Priming Effects of Brand Anthropomorphism. Journal of Consumer Research, 39(2), 307-323.

Agyemang, K. J. (2011). Athlete brand revitalisation after a transgression. Journal of Sponsorship, 4.

Ahmad, R., Hashim, L., \& Harun, N. (2016). Criteria for effective authentic personal branding for academic librarians in Universiti Sains Malaysia libraries. ProcediaSocial and Behavioral Sciences, 224, 452-458.

Ahmad, A. L., Bromley, M., \& Cokley, J. (2013). The social reality of blogging and empowerment among Malaysian bloggers. Journal of Asian Pacific Communication, 23, 210-221.

Ahn, J. M., Mortara, L., \& Minshall, T. (2014). Linkage between CEO characteristics and open innovation adoption in innovative manufacturing SMEs. Paper presented at the DRUID Academy conference, 15-17 January, Rebild, Aalborg, Denmark, available at: http://dx.doi.org/10.2139/ssrn.2328644 (accessed 15 November 2016).

Ahrens, T., \& Chapman, C. S. (2007). Management accounting as practice. Accounting, organizations and society, 32(1/2), 1-27.

Algara, C. (2019). The conditioning role of polarization in US senate election outcomes: A direct-election era \& voter-level analysis. Electoral Studies, 59, 1-16.

Alghawi, I. A., Yan, J., \& Wie, C. (2014). Professional or interactive: CEOs' image strategies in the microblogging context. Computers in Human Behavior, 41, 184-189. 
Alipour, H., Jahan, M. H., \& Jamaati-e-Somarin, S. (2015). A Review on Personal Branding and Social Media. Journal of Current Research in Science, 3(6), 9-21.

Allen, D. E. (2002). Toward a theory of consumer choice as sociohistorically shaped practical experience: The fits-like-a-glove (FLAG) framework. Journal of Consumer Research, 28(4), 515-532.

Amabile, T. (2012). Componential theory of creativity. Boston, MA: Harvard Business School.

Amoako, G. K., \& Okpattah, B. K. (2018). Unleashing salesforce performance: The impacts of personal branding and technology in an emerging market. Technology in society, 54, 20-26.

Andrusia, D., \& Haskins, R. (2000). Brand yourself: how to create an identity for a brilliant career. New York, NY: Ballantine Books.

Amos, C., Holmes, G., \& Strutton, D. (2008). Exploring the relationship between celebrity endorser effects and advertising effectiveness: A quantitative synthesis of effect size. International Journal of Advertising, 27(2), 209-234.

Anton, C. (2001). Selfhood and authenticity. Albany, NY: State University of New York Press.

Arai, A., Ko, Y. J., \& Kaplanidou, K. (2013). Athlete brand image: scale development and model test. European Sport Management Quarterly, 13, 383-403.

Arai, A., Ko, Y.J., \& Ross, S. (2014). Branding athletes: exploration and conceptualization of athlete brand image. Sport Management Review, 17(2), 97-106.

Archer, C. (2019). How influencer 'mumpreneur' bloggers and 'everyday' mums frame presenting their children online. Media International Australia, 170, 4756.

Arnould, E. J., \& Thompson, C. J. (2005). Consumer Culture Theory (CCT): Twenty Years of Research. Journal of Consumer Research, 31, 868-882.

Arsena, A., Silvera, D. H., \& Pandelaere, M. (2014). Brand trait transference: When celebrity endorsers acquire brand personality traits. Journal of Business Research, 67(7), 1537-1543.

Arthur, M. B., Hall, D. T., \& Lawrence, B. S. (1989): Generating new directions in career theory: The case for a transdisciplinary approach. In: M. B. Arthur, D. T. Hall and B. S. Lawrence (eds.): Handbook of Career Theory. Cambridge: Cambridge University Press, 7-25.

Atkinson, K. M., Koenka, A. C., Sanchez, C. E., Moshontz, H., \& Cooper, H. (2015). Reporting standards for literature searches and report inclusion criteria: making research syntheses more transparent and easy to replicate. Research Synthesis Methods, 6, 87-95.

Bakker, A., Westman, M., \& Schaufeli, W. (2007). Crossover of burnout: An experimental design. European Journal of Work and Organizational Psychology, $16(2), 220-239$. 
Ballouli, K., \& Hutchinson, M. (2012). Branding the elite professional athlete through use of new media and technology: an interview with Ash De Walt. International Journal of Entrepreneurial Venturing, 4, 58-64.

Balmer, J. M. (2001). Corporate identity, corporate branding and corporate marketing-seeing through the fog. European Journal of Marketing, 35(3/4), 248-291.

Banet-Weiser, S., \& Juhasz, A. (2011). Feminist labor in media studies/communication: Is self-branding feminist practice?. International Journal of Communication, 5, 1768-1775.

Banister, E. N., \& Cocker, H. L. (2014). A cultural exploration of consumers'interactions and relationships with celebrities. Journal of Marketing Management, 30(1/2), 1-29.

Baregheh, A., Rowley, J., \& Sambrook, S. (2009). Towards a multidisciplinary definition of innovation. Management decision, 47(8), 1323-1339.

Barnett, W. P., \& Burgelman, R. A. (1996). Evolutionary perspectives on strategy. Strategic Management Journal, 17, 5-20.

Barron, L. (2007). The habitus of Elizabeth Hurley: Celebrity, fashion, and identity branding. Fashion Theory, 11, 443-461.

Bartlett, A., \& Ghoshal, S. (2003). What Is a Global Manager?. Harvard Business Review, 81(8), 101-108.

Bateson, M. C. (1989). Composing a Life. New York: Penguin.

Bateson, M. C. (2011) Composing a Further Life: The Age of Active Wisdom. New York: Vintage.

Baumgarth, C. (2004). Evaluations of Co-Brands and Spill-Over Effects: Further Empirical Results. Journal of Marketing Communications, 10(2), 115-131.

Baumgarth, C., \& O'Reilly, D. (2014). Brands in the arts and culture sector. Arts Marketing: An International Journal, 4, 2-9.

Baumgarth, C., O'Reilly, D., Sjöholm, J., \& Pasquinelli, C. (2014). Artist brand building: towards a spatial perspective. Arts Marketing: An International Journal, 4, 10-24.

Baxter, P., \& Jack, S. (2008). Qualitative case study methodology: Study design and implementation for novice researchers. The Qualitative Report, 13(4), 544-559.

Belk, R. W. (2013). Extended self in a digital world. Journal of Consumer Research, 40(3), 477-500.

Belk, R. (2019). On standing out and fitting in. Journal of Global Fashion Marketing, 10, 219-227.

Bello, D., Leung, K., Radebaugh, L., Tung, R. L., \& van Witteloostuijn, A. (2009). From the editors: Student samples in international business research. Journal of International Business Studies, 40, 361-364. 
Bendisch, F., Larsen, G., \& Trueman, M. (2013). Fame and fortune: a conceptual model of CEO brands. European Journal of Marketing, 47(3/4), 596-614.

Berends, H., \& Lammers, I. (2010). Explaining Discontinuity in Organizational Learning: A Process Analysis. Organization Studies, 31(8), 1045-1068.

Bergh, L., Jordaan, J., Lombard, E., Naude, L., \& van Zyl, J. (2017). Social Media, Permanence, and Tattooed Students: The Case for Personal, Personal Branding. Critical Arts, 31, 1-17.

Bergkvist, L., \& Zhou K. Q. (2016). Celebrity endorsements: a literature review and research agenda. International Journal of Advertising, 35(4), 642-663.

Bergkvist, L., Hjalmarson, H., \& Mägi, A. W. (2016). A new model of how celebrity endorsements work: attitude toward the endorsement as a mediator of celebrity source and endorsement effects. International Journal of Advertising, 35(2), 171-184.

Berryman, R., \& Kavka, M. (2017). 'I Guess A Lot of People See Me as a Big Sister or a Friend': the role of intimacy in the celebrification of beauty vloggers. Journal of Gender Studies, 26, 307-320.

Bigsby, K. G., Ohlmann, J. W., \& Zhao, K. (2019). Keeping it 100: Social Media and Self-Presentation in College Football Recruiting. Big data, 7, 3-20.

Bingham, C. B., \& Kahl, S. J. (2013). The process of schema emergence: Assimilation, deconstruction, unitization, and the plurality of analogies. Academy of Management Journal, 56, 14-34.

Black, S. S. (1997). Top Management Team Characteristics: A Study of Their Impact on the Magnitude of International Operations and International Performance. Unpublished Doctoral Dissertation. Columbia University, New York.

Blyton P., Hassard, J., Hill, S., \& Starkey, K. (1989). Time, Work and Organization. London, U.K.: Routledge

Boorstin, D. (2012). The image: A guide to pseudo-events in America. New York: Vintage.

Borman-Shoap, E., Li, S. T. T., St Clair, N. E., Rosenbluth, G., Pitt, S., \& Pitt, M. B. (2019). Knowing Your Personal Brand: What Academics Can Learn From Marketing 101. Academic Medicine, 94, 1293-1298.

Bourdieu, P. (1990). The Logic of Practice. Cambridge, UK: Polity.

Bors, O. C. (2019). The Importance of Image when Developing a Powerful Political Brand. Postmodern Openings, 10, 72-85.

Bossio, D., \& Sacco, V. (2017). From "selfies" to breaking Tweets: How journalists negotiate personal and professional identity on social media. Journalism practice, $11,527-543$.

Bowlby, J. (1969). Attachment and loss: Vol. 1. Attachment. New York: Basic Books.

Boynton, A. C., \& Zmud, R. W. (1984). An Assessment of Critical Success Factors. Sloan Management Review, 25(4), 17-27. 
Braudy, L. (1997). The frenzy of renown: Fame and its history. New York: Vintage Books.

Braunstein, J., \& Zhang, J. (2005). Dimensions of athletic star power associated with generation $\mathrm{Y}$ sports consumption. International Journal of Sports Marketing \& Sponsorship, 6, 242-267.

Bremner, S., \& Phung, B. (2015). Learning From the Experts: An Analysis of Résumé Writers' Self-Presentation on LinkedIn. IEEE Transactions on Professional Communication, 58, 367-380.

Brems, C., Temmerman, M., Graham, T., \& Broersma, M. (2017). Personal Branding on Twitter: How employed and freelance journalists stage themselves on social media. Digital Journalism, 5, 443-459.

Brennan, R., Halliday, S., Sheikh, A., \& Lim, M. (2015). The making of brand attachment and brand meanings: the case of a UK engineering services firm. Marketing Intelligence \& Planning, 33, 887-907.

Brigham, T. J. (2016). Online professional profiles: Health care and library researchers show off their work. Medical reference services quarterly, 35, 440-448.

Brivio, E., \& Ibarra, C. F. (2009). Self presentation in blogs and social networks. Annual Review of CyberTherapy and Telemedicine, 7(1), 113-115.

Brodsky, S. L., Neal, T. M., Cramer, R. J., \& Ziemke, M. H. (2009). Credibility in the courtroom: How likeable should an expert witness be?. Journal of the American Academy of Psychiatry and the Law Online, 37(4), 525-532.

Bronstein, J. (2012). Being private in public: information disclosure behaviour of Israeli bloggers. Information Research: An International Electronic Journal, 18, n1.

Bronstein, J. (2014). Creating possible selves: information disclosure behaviour on social networks. Information Research: An International Electronic Journal, 19, $\mathrm{n} 1$.

Brooks, A. K., \& Anumudu, C. (2016). Identity development in personal branding instruction: Social narratives and online brand management in a global economy. Adult Learning, 27(1), 23-29.

Bruns, A. (2012). Journalists and Twitter: How Australian news organisations adapt to a new medium. Media International Australia, 144, 97-107.

Burgess, J., Spinks, W., \& Sharma, B. (2020). The Effect of a Brand Transgression on a Politician's Brand Resonance: The Case of Kevin Rudd. Journal of Political Marketing, 19(4), 362-385.

Burton, R., Farrelly, F. J., \& Quester, P. G. (2001). Exploring the curious demand for athletes with controversial images: A review of anti-hero product endorsement advertising. International Journal of Sports Marketing \& Sponsorship, 2, 44-59.

Busenbark, J. R., Krause, R., Boivie, S., \& Graffin, S. D. (2016). Toward a configurational perspective on the CEO: A review and synthesis of the management literature. Journal of Management, 42(1), 234-268. 
Buss, D. M. (1988). The evolution of human intrasexual competition: Tactics of mate attraction. Journal of Personality and Social Psychology, 54, 616-628.

Buss, D. M. (1989). Sex differences in human mate preferences: Evolutionary hypotheses tested in 37 cultures. Behavioral and Brain Sciences, 12, 1-14.

Butler, P., \& Harris, P. (2009). Considerations on the evolution of political marketing theory. Marketing Theory, 9, 149-164.

Campbell, A., \& Denezhkina, E. (2017). From project Putin to brand Putin. Celebrity Studies, 8, 318-323.

Canter, L. (2015). Personalised tweeting: The emerging practices of journalists on Twitter. Digital Journalism, 3(6), 888-907.

Carlson, B. D., Donavan, D. T., \& Cumiskey, K. J. (2009). Consumer-brand relationships in sport: Brand personality and identification. International Journal of Retail and Distribution Management, 37, 370-384.

Carlson, B. D., \& Donavan, D. T. (2013). Human brands in sport: athlete brand personality and identification. Journal of Sport Management, 27(3), 193-206.

Carlson, B. D., \& Donavan, D. T. (2017). Be Like Mike:The Role of Social Identification in Athlete Endorsements. Sport Marketing Quarterly, 26, 176-191.

Carpenter, M. A., Geletkanycz, M. A., \& Sanders, W. G. (2004). Upper echelons research revisited: Antecedents, elements, and consequences of top management team composition. Journal of Management, 30(6), 749-778.

Carr, E. H., Evans, R. J., \& Evans, R. J. (2001). What is history?. Houndmills: Palgrave.

Cashmore, E., \& Parker, A. (2003). One David Beckham? Celebrity, masculinity, and the soccerati. Sociology of Sport Journal, 20(3), 214-231.

Catellani, A., Zerfass, A., Verčič, D., \& Wiesenberg, M. (2016). Managing CEO communication and positioning. Journal of Communication Management, 20, 37-55.

Cederberg, C. D., (2017). Personal branding for psychologists: Ethically navigating an emerging vocational trend. Professional Psychology: Research and Practice, 48, 183-190.

Chadwick, S., \& Burton, N. (2008). From Beckham to Ronaldo--Assessing the nature of football player brands. Journal of Sponsorship, 1, 307-317.

Chai, Y. D., \& Kim, J. S. (2013). Mediator Effect of Presidential Candidate Brand Affiliated to Certain Party. Journal of the Korea Safety Management and Science, 15, 303-315.

Chakrabarti, D. (2014). Awareness and importance of 'personal branding'phenomenon among post-graduate management students: An empirical enquiry. International Journal of Research and Development in Technology and Management Science, 21, 88-101.

Chang, Y. (2018). When infamy becomes fame: The positive side of negative athlete publicity. Journal of Sport Management, 32, 401-411. 
Chang, Y., Ko, Y. J., \& Carlson, B. D. (2018). Implicit and explicit affective evaluations of athlete brands: The associative evaluation-emotional appraisal-intention model of athlete endorsements. Journal of Sport Management, 32, 497-510.

Chapman, S., Holding, S., McLeod, K., \& Wakefield, M. (2005). Impact of news of celebrity illness on breast cancer screening: Kylie Minogue's breast cancer diagnosis. Medical Journal of Australia, 183, 247-250.

Chen, C.-P. (2013). Exploring personal branding on YouTube. Journal of Internet Commerce, 12(4), 332-347.

Chen, H.-M., \& Chung, H.-M. (2017). A scale for CEO personal brand measurement. South African Journal of Business Management, 48(2), 23-32.

Chen, H. M., \& Chung, H. M. (2016). How to Measure Personal Brand of a Business CEO. Journal of Human Resource and Sustainability Studies, 4, 305-324.

Chen, Y. S., Raab, C., \& Chen, C. C. (2017). The influence of celebrity chefs on restaurant customers' behavior. Journal of Hospitality Marketing \& Management, 26, 489510.

Chia, R., \& Holt, R. (2006). Strategy as practical coping: A Heideggerian perspective. Organization Studies, 27(5), 635-655.

Cho, Y. J., \& Poister, T. H. (2014). Managerial practices, trust in leadership, and performance: Case of the Georgia department of transportation. Public Personnel Management, 43(2), 179-196.

Choi, J. P., \& Jeon, D. S. (2007). A leverage theory of reputation building with cobranding: Complementarities in reputation building. Working Paper, Michigan State University.

Choi, S. M., \& Rifon, N. J. (2007). Who is the celebrity in advertising? Understanding dimensions of celebrity images. Journal of Popular Culture, 40(2), 304-324.

Choi, S. M., \& Rifon, N. J. (2012). It is a match: The impact of congruence between celebrity image and consumer ideal self on endorsement effectiveness. Psychology \& Marketing, 29, 639-650.

Chu, F. Y., Dai, Y. X., Liu, J. Y., Chen, T. J., Chou, L. F., \& Hwang, S. J. (2018). A Doctor's Name as a Brand: A Nationwide Survey on Registered Clinic Names in Taiwan. International journal of environmental research and public health, 15, 1134

Clark, D. (2011). Reinventing your personal brand. Harvard Business Review, 89, 7881.

Clark P. (1985). A review of the theories of time and structure for organizational sociology. Research in the Sociology of Organizations, 4, 35-79.

Clarke, T. B., Murphy, J., \& Adler, J. (2016). Celebrity chef adoption and implementation of social media, particularly pinterest: A diffusion of innovations approach. International Journal of Hospitality Management, 57, 8492. 
Click, M. A., Lee, H., \& Holladay, H. W. (2013). Making monsters: Lady Gaga, fan identification, and social media. Popular Music and Society, 36, 360-379.

Close, A. G., Moulard, J. G., \& Monroe, K. B. (2011). Establishing human brands: determinants of placement success for first faculty positions in marketing. Journal of the Academy of Marketing Science, 39(6), 922-941.

Cocker, H. L., Banister, E. N., \& Piacentini, M. G. (2015). Producing and consuming celebrity identity myths: unpacking the classed identities of Cheryl Cole and Katie Price. Journal of Marketing Management, 31(5/6), 502-524.

Coelho, P. S., \& Esteves, S. P. (2006). The choice between a five-point and a ten-point scale in the framework of customer satisfaction measurement. International Journal of Market Research, 49(3), 313-339.

Coesemans, R., \& De Cock, B. (2017). Self-reference by politicians on Twitter: Strategies to adapt to 140 characters. Journal of Pragmatics, 116, 37-50.

Cohen, J. (2001). Defining identification: A theoretical look at the identification of audiences with media characters. Mass Communication \& Society, 4(3), 245-264.

Cohen, M. D., \& Sproull, L. S. (1991). Editors' introduction: Special issue on organizational learning: Papers in honor of James G. March. Organization Science, 2(1).

Cole-Turner, R. (2019). Commodification and transfiguration: Socially mediated identity in technology and theology. HTS Theological Studies, 75(1), 1-11.

Colliander, J., Marder, B., Falkman, L. L., Madestam, J., Modig, E., \& Sagfossen, S. (2017). The social media balancing act: Testing the use of a balanced selfpresentation strategy for politicians using twitter. Computers in Human Behavior, 74, 277-285.

Collins, H. (2004). Interactional expertise as a third kind of knowledge. Phenomenology and the Cognitive Sciences, 3, 125-143.

Collis, D. J. (1991). A resource-based analysis of global competition: The case of the bearings industry. Strategic Management Journal, 12(S1), 49-68.

Conboy, K., \& Fitzgerald, B. (2004). Toward a conceptual framework of agile methods: a study of agility in different disciplines. In: Proceedings of the 2004 ACM workshop on Interdisciplinary software engineering research. ACM, 37-44.

Constantinescu, M. (2016). The Brand of an Athlete-Reconsidering Its Dimensions. Journal of Emerging Trends in Marketing and Management, 1, 354-363.

Cooper, H. M. (1989). Integrating Research: A Guide for Literature Reviews, (2 ${ }^{\text {nd }}$ ed.). Newbury Park, CA: Sage Publications.

Cooper H. M. (2010). Research synthesis and meta-analysis: A step-by-step approach, ( $5^{\text {th }}$ ed.). Thousand Oaks, CA: Sage Publications, Inc.

Cornwell, T. B., \& Maignan, I. (1998). An International Review of Sponsorship Research. Journal of Advertising, 27, 2-21. 
Corrigan, T. (2015). Media and Cultural Industries Internships: A Thematic Review and Digital Labor Parallels. tripleC: Communication, Capitalism \& Critique. Open Access Journal for a Global Sustainable Information Society, 13, 336-350.

Cortsen, K. (2013). Annika Sörenstam-a hybrid personal sports brand. Sport, Business and Management: An International Journal, 3, 37-62.

Cottan-Nir, O. (2019). Toward a Conceptual Model for Determining CEO Brand Equity. Corporate Reputation Review, 22, 121-133.

Cottan-Nir, O., \& Lehman-Wilzig, S. (2018). CEO Branding: Between Theory and Practice-Case Studies of Israeli Corporate Founders. International Journal of Strategic Communication, 12(2), 87-106.

Couper, M. P. (2000). Review: Web surveys: A review of issues and approaches. The Public Opinion Quarterly, 64(4), 464-494.

Craig, G. (2014). Kevin's Predicaments: Power and Celebrity across the Political and Media Fields. The International Journal of Press/Politics, 19(1), 24-41.

Creswell, J.W. (2007). Qualitative inquiry and research design: Choosing among five approaches. 2nd ed., Thousand Oaks, CA: Sage.

Crossland, C., Zyung, J., Hiller, N., \& Hambrick, D. (2014). CEO career variety: Effects on firm-level strategic and social novelty. Academy of Management Journal, $57(3), 652-674$.

Davies, F., \& Slater, S. (2015). Unpacking celebrity brands through unpaid market communications. Journal of Marketing Management, 31, 665-684.

De Certeau, M. (1984). The practice of everyday life. Berkeley: University of California Press.

De Chernatony, L. (1999). Brand management through narrowing the gap between brand identity and brand reputation. Journal of Marketing Management, 15(13), 157-179.

De Chernatony, L. (2001). From brand vision to brand evaluation: Strategically building sustaining brand. Oxford: Butterworth-Heinemann.

Delisle, M. P., \& Parmentier, M. A. (2016). Navigating person-branding in the fashion blogosphere. Journal of Global Fashion Marketing, 7, 211-224.

Desmarais, F. (2017). Who is the Athlete Endorser? A Cross-Cultural Exploration of Advertising Practitioners' Views. Journal of Global Marketing, 30, 12-30.

Dickinson, S., \& Barker, A. (2007). Evaluations of Branding Alliances between Nonprofit and Commercial Brand Partners: The Transfer of Affect. International Journal of Nonprofit \& Voluntary Sector Marketing, 12(1), 75-89.

Dillon, F. R., Worthington, R. L., \& Moradi, B. (2011). Sexual identity as a universal process. In Handbook of identity theory and research (pp. 649-670). New York, NY: Springer.

Dionise, A. (2018). Communicating Royalty: A Study of Modern Monarchs' Online Branding. Elon Journal of Undergraduate Research in Communications, 9, 18-26. 
Dobbins, G., Long, W. S., Dedrick E. J., \& Clemons, T. C. (1990). The Role of SelfMonitoring and Gender on Leader Emergence: A Laboratory and Field Study. Journal of Management, 16, 609-618.

Donahue, E. M., Robins, R. W., Roberts, B. W., \& John, O. P. (1993). The divided self: Concurrent and longitudinal effects of psychological adjustment and social roles on self-concept differentiation. Journal of Personality and Social Psychology, 64, 834-846.

Dougherty, D. (2004). Organizing practices in services: Capturing practice based knowledge for innovation. Strategic Organization, 2(1), 35-64.

Draper, J., \& McDonnell, A. M. (2018). Fashioning multiplatform masculinities: Gay personal style bloggers' strategies of gendered self-representation across social media. Men and Masculinities, 21, 645-664.

Duffy, B. (2015). Amateur, autonomous, and collaborative: Myths of aspiring female cultural producers in Web 2.0. Critical Studies in Media Communication, 32, 4864.

Duffy, B. E., \& Hund, E. (2015). "Having it all" on social media: Entrepreneurial femininity and self-branding among fashion bloggers. Social Media+ Society, 1(2).

Duffy, B. E., \& Pooley, J. (2019). Idols of promotion: The triumph of self-branding in an age of precarity. Journal of Communication, 69, 26-48.

Duffy, B. E., \& Pruchniewska, U. (2017). Gender and self-enterprise in the social media age: A digital double bind. Information, Communication \& Society, 20, 843-859.

Dumont, G., \& Ots, M. (2020). Social dynamics and stakeholder relationships in personal branding. Journal of Business Research, 106, 118-128.

Dutta, S. K. (2010). What's your personal social media strategy?. Harvard Business Review, 88(11), 127-136.

Eagar, T., \& Dann, S. (2016). Classifying the narrated\# selfie: genre typing humanbranding activity. European Journal of Marketing, 50, 1835-1857.

Eagar, T., \& Lindridge, A. (2015). Resolving contradictions in human brand celebrity and iconicity. Consumer culture theory, 17, 311-330.

Edmiston, D. (2014). Creating a personal competitive advantage by developing a professional online presence. Marketing Education Review, 24(1), 21-24.

Eggert, A., \& Helm, S. (2003). Exploring the impact of relationship transparency on business relationships: A cross-sectional study among purchasing managers in Germany. Industrial Marketing Management, 32(2), 101-108.

Ehrmann, T., Meiseberg, B., \& Ritz, C. (2009). Superstar effects in deluxe gastronomyAn empirical analysis of value creation in German quality restaurants. Kyklos.62, 526-541. 
Eisend, M., \& Langner, T. (2010). Immediate and delayed advertising effects of celebrity endorsers' attractiveness and expertise. International Journal of Advertising, 29(4), 527-546.

Eisend, M., \& Stokburger-Sauer, N. E. (2013). Measurement Characteristics of Aaker's Brand Personality Dimensions: Lessons to be Learned from Human Personality Research. Psychology and Marketing, 30(11), 950-958.

Eisenhardt, K. M. (1989). Building theories from case study research. Academy of Management Review, 14(4), 532-550.

Eisenhardt, K. M., \& Graebner, M. E. (2007). Theory building from cases: Opportunities and challenges. Academy of Management Journal, 50(1), 25-32.

Eke, H. N. (2012). Creating a digital footprint as a means of optimizing the personal branding of librarians in the digital society. Webology, 9, 31-40.

Ekhlasi, A., Talebi, K., \& Alipour, S. (2015). Identifying the process of personal branding for entrepreneurs. Asian Journal of Research in Marketing, 4, 100-111.

Elberse, A., \& Verleun, J. (2012). The economic value of celebrity endorsements. Journal of Advertising Research, 52(6), 149-165.

Elias, N. (1991). The society of individuals. Oxford: Blackwell.

Elwell, J. S. (2014). The transmediated self: Life between the digital and the analog. Convergence: The International Journal of Research into New Media Technologies, 20(2), 233-249.

Elving, W. J. (2013). Scepticism and corporate social responsibility communications: The influence of fit and reputation. Journal of Marketing Communications, 19(4), 277-292.

Emirbayer, M., \& Mische, A. (1998). What is agency?. American Journal of Sociology, 103(4), 962-1023.

Emmons, B., \& Mocarski, R. (2014). She poses, he performs: A visual content analysis of male and female professional athlete Facebook profile photos. Visual Communication Quarterly, 21, 125-137.

Epstein, J. (2005). Celebrity Culture. Hedgehog Review, 7(1), 7-20.

Erdem, T., \& Swait, J. (2004). Brand credibility, brand consideration, and choice. Journal of Consumer Research, 31, 191-198.

Erdoğmuş, N., \& Esen, E. (2018). Constructing the CEO Personal Brand: The Case of Four Pioneering CEOs in Turkey. Corporate Reputation Review, 21, 37-49.

Erevelles, S., Horton, V., \& Fukawa, N. (2008). Understanding B2C brand alliances between manufacturers and suppliers. Marketing Management Journal, 18(2), $32-46$.

Erikson, E. (1980). Identity and the life-cycle: A re-issue. New York: Norton. 
Erz, A., \& Christensen, A. B. H. (2018). Transforming consumers into brands: Tracing transformation processes of the practice of blogging. Journal of Interactive Marketing, 43, 69-82.

Exley, C. L., \& Kessler, J. B. (2019). The Gender Gap in Self-Promotion. National Bureau of Economic Research Working Paper Series, 26345.

Farjoun, M. (2010). Beyond dualism: Stability and change as a duality. Academy of Management Review, 35(2), 202-225.

Ferreira, F. A. (2018). Mapping the field of arts-based management: Bibliographic coupling and co-citation analyses. Journal of Business Research, 85, 348-357.

Fetscherin, M. (2015). The CEO branding mix. Journal of Business Strategy, 36(6), 2228.

Ferns, B., Emelianova, O., \& Sethi, S. (2008). In his own words: The effectiveness of CEO as spokesperson on CSR-sustainability issues - analysis of data from the Sethi CSR monitor. Corporate Reputation Review, 11(2), 116-129.

Fillis, I. R. (2015). The production and consumption activities relating to the celebrity artist. Journal of Marketing Management, 31(5/6), 646-664.

Filo, K., Lock, D., \& Karg, A. (2015). Sport and social media research: A review. Sport Management Review, 18, 166-181.

Finneman, T., Thomas, R. J., \& Jenkins, J. (2019). "I Always Watched Eyewitness News Just to See Your Beautiful Smile": Ethical Implications of US Women TV Anchors' Personal Branding on Social Media. Journal of Media Ethics, 34(3), 146-159.

Fink, J. S., Parker, H. M., Brett, M., \& Higgins, J. (2009). Off-field behavior of athletes and team identification: Using social identity theory and balance theory to explain fan reactions. Journal of Sport Management, 23, 142-155.

Fletcher, J. K. (1999). Disappearing Acts: Gender, Power and Relational Practice at Work. Cambridge, MA: MIT Press.

Flostrand, A., Ho, J. Y., \& Krider, R. E. (2016). Implementing "Marketing Me" A Simulation Enhanced Variant for a Student Self-Marketing Exercise. Journal of Marketing Education, 38, 83-89.

Fombrun, C. J. (1996). Reputation: Realizing Value from the Corporate Image. Boston: Harvard Business School Press.

Fournier, S. (1998). Consumers and their brands: Developing relationship theory in consumer research. Journal of Consumer Research, 24(4), 343-373.

Fournier, S. (2010). Taking stock in Martha Stewart: A cultural critique of the marketing practice of building person-brands. In Campbell, M. C., Inman, J., and Pieters, R. (Eds.), Advances in consumer research, Association for Consumer Research. Duluth. 37.

Freeman, R. E. (1984). Strategic management: A stakeholder approach. Boston, MA: Pittman. 
Fresco, E. (2020). In LeBron James' promotional skin: Self-branded athletes and fans' immaterial labour. Journal of Consumer Culture, 20(4), 440-456.

Friedman, H. H., \& Friedman, L. (1979). Endorser effectiveness by product type. Journal of Advertising Research, 19(5), 63-71.

Friel, T. J., \& Duboff, R. S. (2009). The last act of a great CEO. Harvard Business Review, 87, 82-89.

Friend, A. (2016). The Edge of Ladyspace: Ladi6 and the Political Limits of SelfBranding. MEDIANZ: Media Studies Journal of Aotearoa New Zealand, 15, 1-24.

Furedi, F. (2010). Celebrity Culture. Society, 47(6), 493-497.

Gall, D. (2010). Librarian like a rock star: Using your personal brand to promote your services and reach distant users. Journal of Library Administration, 52(6/7), 549558.

Gammoh, B. S., \& Voss, K. E. (2011). Brand alliance research: In search of a new perspective and directions for future research. Journal of Marketing Development and Competitiveness, 5(3), 81-93.

Gander, M. (2014). Managing your personal brand. Perspectives: Policy and Practice in Higher Education, 18(3), 99-102.

Gandini, A. (2016). Digital work: Self-branding and social capital in the freelance knowledge economy. Marketing Theory, 16, 123-141.

García-Rapp, F., \& Roc-Cuberes, C. (2017). Being an online celebrity: Norms and expectations of YouTube's beauty community. First Monday, 22(7).

Garthwaite, C. L. (2014). Demand spillovers, combative advertising, and celebrity endorsements. American Economic Journal: Applied Economics, 6(4), 76-104.

Gehl, R. W. (2011). Ladders, samurai, and blue collars: Personal branding in Web 2.0. First Monday, 16(9).

Gehman, J., Trevino, L. K., \& Garud, R. (2013). Values work: A process study of the emergence and performance of organizational values practices. Academy of Management Journal, 56(1), 84-112.

Genz, S. (2015). My job is me: Postfeminist celebrity culture and the gendering of authenticity. Feminist media studies, 15(4), 545-561.

Gergen, K. J. (1991). The saturated self: Dilemmas of identity in contemporary life. New York: Basic Books.

Gershon, I. (2014). Selling Your Self in the United States. Political and Legal Anthropology Review, 37(2), 281-295.

Geurin, A. N. (2017). Elite female athletes' perceptions of new media use relating to their careers: A qualitative analysis. Journal of Sport Management, 31, 345-359.

Geurin-Eagleman, A. N., \& Burch, L. M. (2016). Communicating via photographs: A gendered analysis of Olympic athletes' visual self-presentation on Instagram. Sport management review, 19, 133-145. 
Giberson, T. R., Resick, C. J., Dickson, M. W., Mitchelson, J. K., Randall, K. R., \& Clark, M. A. (2009). Leadership and Organizational Culture: Linking CEO Characteristics to Cultural Values. Journal of Business Psychology, 24, 123-137.

Giddens, A. (1984). The constitution of society: Outline of the theory of structuration. Cambridge: Polity Press.

Giddens, A. (1984a). The constitution of society. Berkeley, CA: University of California Press.

Giddens, A. (1991). Modernity and self-identity. Cambridge: Polity.

Goebel, V. (2011). Studie: Markenattraktivität von Automarken", Markenartikel - das Magazin für Markenführung, 6 September, available at: http://www. markenartikel-magazin.de/unternehmen-marken/artikel/details/100925studie-markenattraktivitaet-von-automarken (accessed 17 December 2016).

Goffman, E. (1956). The presentation of self in everyday life. New York, NY: Anchor Books.

Golden-Biddle, K., \& Locke, K. (1993). Appealing work: An investigation of how ethnographic texts convince. Organization Science, 4, 595-616.

Gorbatov, S., Khapova, S., \& Lysova, E. (2018). Personal Branding: Interdisciplinary Systematic Review and Research Agenda. Frontiers in Psychology, 9, 2238.

Gorbatov, S., Khapova, S., \& Lysova, E. (2019). Get Noticed to Get Ahead: The Impact of Personal Branding on Career Success. Frontiers in Psychology, 10, 2662.

Goulding, C. (2005). Grounded theory, ethnography and phenomenology: A comparative analysis of three qualitative strategies for marketing research. European Journal of Marketing, 39(3/4), 294-308.

Goulding, C., Follett, J., Saren, M., \& MacLaren, P. (2004). Process and meaning in 'getting a tattoo'. Advances in Consumer Research, 31, 279-284.

Graffin, S., Pfarrer, M., \& Hill, M. (2012). Executive reputation: Reviewing and developing a nascent construct. The Oxford Handbook of Corporate Reputation. Oxford: Oxford University Press.

Graham, J. R., Harvey, C. R., \& Puri, M. (2010). A Corporate Beauty Contest. Working paper. National Bureau of Economic Research, Cambridge, MA, April 2010.

Grand, S., \& Rüegg-Stürm, J. (2019). Interview mit Henry Mintzberg, December 2019, available at: https://www.sgmm.ch/wp-content/uploads/2019/12/ sgmm_interview-henry-mintzberg.pdf (accessed 1 January 2021).

Green, M. R. (2016). The impact of social networks in the development of a personal sports brand. Sports, Business and Management: An International Journal, 6, 274-294.

Gregory, K. (2019). Pushed and Pulled to the Internet: Self Employment in the Spiritual Marketplace. American Behavioral Scientist, 63, 208-224.

Guiso, L., Sapienza, P., \& Zingales, L. (2015). The value of corporate culture. Journal of Financial Economics, 117(1), 60-76. 
Gunz, H., \& Mayrhofer, W. (2018). Rethinking Career Studies. Facilitating Conversation Across Boundaries with the Social Chronology Framework. Cambridge: Cambridge University Press.

Gupta, A., Briscoe, F., \& Hambrick, D. C. (2018). Evenhandedness in resource allocation: Its relationship with CEO ideology, organizational discretion, and firm performance. Academy of Management Journal, 61(5), 1848-1868.

Gurrieri, L. (2012). The Don Draper complex: Consuming work, productive leisure and marketer boundary work. Journal of Marketing Management, 28(7/8), 784808.

Halonen-Knight, E., \& Hurmerinta, L. (2010). Who endorses whom? Meanings transfer in celebrity endorsement. Journal of Product and Brand Management, 19(6), 452-460.

Hammer, D. P. (2000). Professional attitudes and behaviors: the" A's and B's" of professionalism. American Journal of Pharmaceutical Education, 64(4), 455-464.

Hanusch, F. (2018). Political journalists' corporate and personal identities on Twitter profile pages: A comparative analysis in four Westminster democracies. New Media \& Society, 20, 1488-1505.

Hanusch, F., \& Bruns, A. (2017). Journalistic branding on Twitter: A representative study of Australian journalists' profile descriptions. Digital journalism, 5(1), 2643.

Harrington, C. (2019). Neo-liberal subjectivity, self-branding and 'my rape story' YouTube videos. Critical Sociology, 45, 1181-1194.

Harris, L., \& Rae, A. (2011). Building a personal brand through social networking. Journal of Business Strategy, 32(5), 14-21.

Harris, P., \& Lock, A. (2001). Establishing the Charles Kennedy brand: a strategy for an election the result of which is a foregone conclusion. Journal of Marketing Management, 17, 943-956.

Hartmann, P., \& Apaolaza-lbàñez, V. (2012). Consumer attitude and purchase intention toward green energy brands: The roles of psychological benefits and environmental concern. Journal of Business Research, 65, 1254-1263.

Harvey, A. (2018). The fame game: Working your way up the celebrity ladder in Kim Kardashian: Hollywood. Games and Culture, 13, 652-670.

Hasaan, A., Kerem, K., Biscaia, R., \& Agyemang, K. J. (2016). Understanding the implications of athlete brand among fans. Technics Technologies Education Management, 11, 68-81.

Hasaan, S. A., Nawaz, S., Iqbal, S. J., \& Khalid, J. (2018). Challenges That Make/Break the Athlete's Quest to Become an Entrepreneur: A Qualitative Study About Fans' Perceptions. Physical Culture and Sport. Studies and Research, 79, 53-61.

Hasaan, A., Biscaia, R., \& Ross, S. (2019). Understanding athlete brand life cycle. Sport in Society. 1-42. 
Hayward, M. L. A., \& Hambrick, D. C. (1997). Explaining the premiums paid for large acquisitions: Evidence of CEO hubris. Administrative Science Quarterly, 42, 103127.

Hayward, M. L. A., Rindova, V. P., \& Pollock, T. G. (2004). Believing one's own press: the causes and consequences of CEO celebrity. Strategic Management Journal, 25(7), 637-653.

He, L. (2008). Do founders matter? A study of executive compensation, governance structure and firm performance. Journal of Business Venturing, 23(3), 257-279.

Hearn, A. (2008). Meat, mask, burden: Probing the contours of the branded 'self'. Journal of Consumer Culture, 8(2), 197-217.

Hearn, A. (2016). Trump's "reality" hustle. Television \& New Media, 17, 656-659.

Hedman, U. (2015). J-Tweeters: Pointing towards a new set of professional practices and norms in journalism. Digital Journalism, 3, 279-297.

Hedman, U., \& Djerf-Pierre, M. (2013). The social journalist: Embracing the social media life or creating a new digital divide?. Digital Journalism, 1(3), 368-385.

Helmig, B., Huber, J., \& Leeflang, P. (2008). Co-branding: the state of the art. Schmalenbach Business Review, 60, 359-377.

Hendrawan, A., \& Nahdiah, S. (2019). Personal branding analysis of food blogger cindy lulaby through instagram social media. International Journal of Scientific and Technology Research, 8, 164-168.

Henning, S., \& Padayachee, S. (2018). A Conceptual Framework for the Management of a Personal Leadership Brand within the Tourism and Hospitality Industry. African Journal of Hospitality, Tourism and Leisure, 7, 1-26.

Henseler, J., Wilson, B., \& de Vreede, D. (2009). Can sponsorships be harmful for events? Investigating the transfer of associations from sponsors to events. International Journal of Sports Marketing \& Sponsorship, 10(3), 244-251.

Hernando, E., \& Campo, S. (2017). Does the artist's name influence the perceived value of an art work?. International Journal of Arts Management, 19, 46.

Herrmann, P., \& Datta, D. K. (2006). CEO Experiences: Effects on the Choice of FDI Entry Mode. Journal of Management Studies, 43, 755-778.

Hodge, C., \& Walker, M. (2015). Personal branding: a perspective from the professional athlete-level-of-analysis. International Journal of Sport Management and Marketing, 16, 112-131

Hoeymans, N., Feskens, E. J. M., Van Den Bos, G. A. M., \& Kromhout, D. (1997). Age, time, and cohort effects on functional status and self-rated health in elderly men. The American Journal of Public Health, 87, 1620-1625.

Hofmann, J., Schnittka, O., Johnen, M., \& Kottemann, P. (2019). Talent or popularity: What drives market value and brand image for human brands?. Journal of Business Research. 
Hogg, M. A., Terry, D. J., \& White, K. M. (1995). A tale of two theories: A critical comparison of identity theory and social identity theory. Social Psychology Quarterly, 58, 255-269.

Holmberg, I., \& Strannegård, L. (2015). Students' self-branding in a Swedish business school. International Studies of Management \& Organization, 45, 180-192.

Holmes, B. (2002). The Flexible Personality: For A New Cultural Critique. Available at: http://transform.eipcp.net/transversal/1106/holmes/en (accessed 7 September 2016).

Holmes, S., \& Redmond, S. (2006). Introduction: Understanding Celebrity Culture. In: Holmes, S., and Redmond, S. (Eds.), Framing celebrity: New directions in celebrity culture (pp. 1-16). New York: Routledge.

Holton, A. E., \& Molyneux, L. (2017). Identity lost? The personal impact of brand journalism. Journalism, 18, 195-210.

Hood, K. M., Robles, M., \& Hopkins, C. D. (2014). Personal branding and social media for students in today's competitive job market. The journal of research in business education, 56,33 .

Hotez, P. J. (2018). Crafting your scientist brand. PLoS biology. 16(10), e3000024.

House, R. J. (1998). A brief history of GLOBE. Journal of Managerial Psychology, 13(3/4), 230-237.

Hsu, W.-T., Chen, H.-L., \& Cheng, C.-Y. (2013). Internationalization and firm performance of SMEs: The moderating effects of CEO attributes. Journal of World Business, 48, 1-12.

Huang, S. C. T., \& Huang, T. J. (2016). The evolution of fan kingdom: the rising, expansion, and challenges of human brands. Asia Pacific Journal of Marketing and Logistics, 28, 683-708.

Huang, Y., Lin, C., \& Phau, I. (2015). Idol attachment and human brand loyalty. European Journal of Marketing, 49(7), 1234-1255.

Hughes, A., \& Dann, S. (2009). Political marketing and stakeholder engagement. Marketing Theory, 9, 243-256.

Humphrey Jr, W., Laverie, D., \& Shields, A. (2021). Exploring the effects of encouraging student performance with text assignment reminders. Journal of Marketing Education, 43(1), 91-102.

Iglesias, O., \& Bonet, E. (2012). Persuasive brand management: How managers can influence brand meaning when they are losing control over it. Journal of Organizational Change Management, 25(2), 251-264.

Ilieş, V. I. (2018). Strategic Personal Branding for Students and Young Professionals. Cross-Cultural Management Journal, 20, 43-51.

Ilina, I., Kryukova, E., Potekhina, E., Abyzova, E., \& Shadskaja, I. (2017). Russian lectures at the crossroads of reforms: strategies of survival and adaptation. European Research Studies Journal, 20, 86-97. 
Ilinitch, A. Y., D'Aveni, R. A., \& Lewin, A. Y. (1996). New organizational forms and strategies for managing in hypercompetitive markets. Organization Science, 7(3), 211-220.

Inkinen, H. (2016). Review of empirical research on knowledge management practices and firm performance. Journal of knowledge management, 20(2), 230257.

Ioan, C. A., Luca, F., \& Sasu, C. (2014). Personal Marketing of Doctors in Context of Social Networks. Cross-Cultural Management Journal, 6, 369-376.

Isabella, L. A. (1990). Evolving interpretations as change unfolds: How managers construe key organizational events. Academy of Management Journal, 33(1), 7-41.

Jacques, E. (1982). The Form of Time. Heinemann, London, U.K.

Jarzabkowski, P. (2004). Strategy as practice: Recursiveness, adaptation, and practices-in-use. Organization Studies, 25(4), 529-560.

Jay, J. (2013). Navigating paradox as a mechanism of change and innovation in hybrid organizations. Academy of Management Journal, 56(1), 137-159.

Jervell, E. E. (2016). Outsider Kasper Rorsted Is Tapped to Lead Adidas. The Wall Street Journal, 18 January, available at: http://www.wsj.com/articles/adidasappoints-kasper-rorsted-as-new-chief-executive-1453116582 (accessed 8 March 2016).

Jillapalli, R. K., \& Jillapalli, R. (2014). Do professors have customer-based brand equity?. Journal of Marketing for Higher Education, 24, 22-40.

Jillapalli, R. K., \&Wilcox, J. B. (2010). Professor brand advocacy: do brand relationships matter?. Journal of Marketing Education, 32, 328-340.

Jin, C., \& Yeo, H. (2011). Satisfaction, corporate credibility, CEO reputation and leadership effects on public relationships. Journal of Targeting, Measurement and Analysis for Marketing, 19(2), 127-140.

Johns, R., \& English, R. (2016). Transition of self: Repositioning the celebrity brand through social media-The case of Elizabeth Gilbert. Journal of Business Research, 69, 65-72.

Johnson, C. E. (2008). The Rise and Fall of Carly Fiorina: An Ethical Case Study. Journal of Leadership \& Organizational Studies, 15(2), 188-196.

Johnson, K. M. (2015). Non-technical skills for IT professionals in the landscape of Social Media. American Journal of Business and Management, 4, 102-122.

Johnson, K. (2017). The importance of personal branding in social media: educating students to create and manage their personal brand. International Journal of Education and Social Science, 4, 21-27.

Jones, B. (2010). Climbing the greasy pole: Promotion in British politics. The Political Quarterly, 81, 616-626. 
Jones, B., \& Leverenz, C. (2017). Building Personal Brands with Digital Storytelling ePortfolios. International Journal of ePortfolio, 7, 67-91.

Jukes, S. (2019). Crossing the line between news and the business of news: Exploring journalists' use of Twitter. Media and Communication, 7, 248-258.

Kahanov, L., \& Andrews, L. (2001). A survey of athletic training employers' hiring criteria. Journal of athletic training, 36, 408-412.

Kakitek, A. (2018). Application of Aaker's Brand Personality Scale on Human Brands in Surf Sports. Journal of Management and Business Administration. Central Europe, 26, 11-31.

Kalbande, D. T. (2019). Digital footprint for the personal branding of librarians in the digital society. Library Philosophy and Practice, 1-11.

Kalia, V., Patel, A. K., Moriarity, A. K., \& Canon, C. L. (2017). Personal branding: a primer for radiology trainees and radiologists. Journal of the American College of Radiology, 14, 971-975.

Kaneva, N., \& Klemmer, A. (2016). The rise of brandidates? A cultural perspective on political candidate brands in postmodern consumer democracies. Journal of Customer Behaviour, 15, 299-313.

Kapferer, J. N. (2012). The New Strategic Brand Management: Advanced Insights and Strategic Thinking. Kogan Page Publishers.

Kaplan, S., \& Orlikowski, W. J. (2013). Temporal Work in Strategy Making. Organization Science, 24(4), 965-995.

Kaputa, C. (2016). The Personal Branding Advocate. Available at: http://selfbrand. com/ArtBrandingYourself.html (accessed 16 November 2016).

Karaduman, I. (2013). The effect of social media on personal branding efforts of top level executives. Procedia-social and behavioral sciences, 99, 465-473.

Kedia, B. L., \& Mukherji, A. (1999). Global Managers: Developing A Mindset For Global Competitiveness. Journal of World Business, 34, 230-251.

Keller, J. M. (2014). Fiercely Real?: Tyra Banks and the making of new media celebrity. Feminist Media Studies, 14, 147-164.

Keller, K. L. (1993). Conceptualizing, measuring, and managing customer-based brand equity. Journal of Marketing, 57, 1-22.

Keller, K. L. (2003). Brand Synthesis: The Multidimensionality of Brand Knowledge. Journal of Consumer Research, 29(4), 595-600.

Keller, K. L. (2013). Strategic Brand Management, Building, Measuring, and Managing Brand Equity. (4th ed.). New Jersey: Pearson Education Inc.

Keller, K. L., Calder, B., \& Tybout, A. (2002). Three questions you need to ask about your brand. Harvard Business Review, 80(9), 80-86. 
Kelting, K., \& Rice, D. H. (2013). Should we hire David Beckham to endorse our brand? Contextual interference and consumer memory for brands in a celebrity's endorsement portfolio. Psychology \& Marketing, 30, 602-613.

Kerrigan, F., Brownlie, D., Hewer, P., \& Daza-LeTouze, C. (2011). 'Spinning' Warhol: Celebrity brand theoretics and the logic of the celebrity brand. Journal of Marketing Management, 27(13/14), 1504-1524.

Khamis, S., Ang, L., \& Welling, R. (2017). Self-branding, 'micro-celebrity' and the rise of Social Media Influencers. Celebrity Studies, 8, 191-208.

Khedher, M. (2014). Personal branding phenomenon. International Journal of Information, Business and Management, 6(2), 29-40.

Khedher, M. (2015). A Brand for Everyone: Guidelines for Personal Brand Managing. Journal of Global Business Issues, 9(1), 19-27.

Khedher, M. (2019). Conceptualizing and researching personal branding effects on the employability. Journal of Brand Management, 26, 99-109.

Kippenberger, T. (2000). Co-branding as a New Competitive Weapon. The Antidote, $5(6), 12-15$.

Kitchen, P. J., Brignell, J., Li, T., \& Jones, S. G. (2004). The Emergence of IMC: A Theoretical Perspective. Journal of Advertising Research, 44(3), 19-30.

Koch, M., Forgues, B., \& Monties, V. (2017). The way to the top: Career patterns of Fortune 100 CEOs. Human Resource Management, 56(2), 267-285.

Koh, K. (2011). Value or Glamour? An empirical investigation of the effect of celebrity CEOs on financial reporting practices and firm performance. Accounting and Finance, 51, 517-547.

Korica, M., Nicolini, D., \& Johnson, B. (2017). In search of 'managerial work': Past, present and future of an analytical category. International Journal of Management Reviews, 19(2), 151-174.

Kotler, P., \& Levy, S. (1969). Broadening the concept of marketing. Journal of Marketing, 33(1), 10-15.

Kowalczyk, C. M., \& Pounders, K. R. (2016). Transforming celebrities through social media: the role of authenticity and emotional attachment. Journal of Product \& Brand Management, 25, 345-35.

Kretz, G., \& de Valck, K. (2010). 'Pixelize me!': digital storytelling and the creation of archetypal myths through explicit and implicit self-brand association in fashion and luxury blogs. Research in consumer behavior, 12, 313-329.

Kristiansen, E., \& Williams, A. S. (2015). Communicating the athlete as a brand: An examination of LPGA star Suzann Pettersen. International Journal of Sport Communication, 8, 371-388.

Kucharska, W., \& Mikołajczak, P. (2018). Personal branding of artists and artdesigners: necessity or desire?. Journal of Product \& Brand Management, 27, 249-261. 
Kunkel, T., Walker, M., \& Hodge, C. M. (2019). The influence of advertising appeals on consumer perceptions of athlete endorser brand image. European Sport Management Quarterly, 19, 373-395.

Kuo, H.-C., Wang, L.-H., \& Lin, D. (2015). CEO Traits, Corporate Performance, and Financial Leverage. International Journal of Economics and Finance, $7(1), 68-86$.

Kurke, L. B., \& Aldrich, H. E. (1983). Note-Mintzberg was right!: A replication and extension of the nature of managerial work. Management Science, 29(8), 975984.

Kurzman, C., Anderson, C., Key, C., Lee, Y., Moloney, M., Silver, A., \& Van Ryn, M. (2007). Celebrity Status. Sociological Theory, 25(4), 347-367.

Labrecque, L. I., Markos, E., \& Milne, G. R. (2011). Online Personal Branding: Processes, Challenges, and Implications. Journal of Interactive Marketing, 25(1), 37-50.

Lafferty, B. A. (2009). Selecting the right cause partners for the right reasons: The role of importance and fit in cause-brand alliances. Psychology \& Marketing, 26(4), 359-382.

Lair, D. J., Sullivan, K., \& Cheney, G. (2005). Marketization and the Recasting of the Professional Self: The Rhetoric and Ethics of Personal Branding. Management Communication Quarterly, 18(3), 307-343.

Lange, D., Boivie, S., \& Westphal, J. (2015). Predicting organizational identification at the CEO level. Strategic Management Journal, 36(8), 1224-1244.

Langley, A. (1999). Strategies for theorizing from process data. Academy of Management Review, 24(4), 691-710.

Langley, A., \& Truax, J. (1994). A process study of new technology adoption in smaller manufacturing firms. Journal of Management Studies, 31(5), 619-652.

Langley, A., Smallman, C., Tsoukas, H., \& Van de Ven, A. H. (2013). Process studies of change in organization and management: Unveiling temporality, activity, and flow. Academy of Management Journal, 56(1), 1-13.

Lawrence, B. S. (1984). Age Grading: The Implicit Organizational Timetable. Journal of Occupational Behaviour, 5(1), 23-35.

Leary, M. R., \& Tangney, J. P. (2012). Handbook of self and identity. $2^{\text {nd }}$ edn, New York: Guildford.

Lebel, K., \& Danylchuk, K. (2014). An Audience Interpretation of Professional Athlete Self-Presentation on Twitter. Journal of Applied Sport Management, 6.

Lee, C.-L. (2014). Is Co-Branding a Double-Edged Sword for Brand Partners?. European Research Studies, 17(4), 19-34.

Lee, J.W., \& Cavanaugh, T. (2016). Building your brand: The integration of infographic resume as student self-analysis tools and self-branding resources. Journal of Hospitality, Leisure, Sport \& Tourism Education, 18, 61-68. 
Levin, E., Rixon, A., \& Keating, M. (2019). How can a 'Sense of Belonging' inform your teaching strategy? Reflections from a core Business unit. A Practice Report. Student Success, 10, 71-79.

Li, C. (2007). Online Chatters' Self-Marketing in Cyberspace. Cyberpsychology and Behaviour, 10(1), 131-132.

Lindridge, A., \& Eagar, T. (2015). 'And Ziggy played guitar': Bowie, the market, and the emancipation and resurrection of Ziggy Stardust. Journal of Marketing Management, 31(5/6), 546-576.

Lindsay, R. M., \& Ehrenberg, A. S. C. (1993). The design of replicated studies. American Statistician, 47, 217-228.

Linville, P. W. (1987). Self-complexity as a cognitive buffer against stress-related depression and illness. Journal of Personality and Social Psychology, 52, 663-676.

Little, B. (2012). Identifying key trends in sales-from a training perspective. Industrial and Commercial Training, 44, 103-108.

Liu, R., \& Suh, A. (2017). Self-branding on social media: An analysis of style bloggers on Instagram. Procedia Computer Science, 124, 12-20.

Lobpries, J., Bennett, G., \& Brison, N. (2017). Mary Ann to her Ginger: comparing the extended brand identity of two elite female athletes. International Journal of Sports Marketing and Sponsorship, 18, 347-362.

Lobpries, J., Bennett, G., \& Brison, N. (2018). How I Perform is Not Enough: Exploring Branding Barriers Faced by Elite Female Athletes. Sport Marketing Quarterly, 27, 5-17.

Loohuis, R. P. A., \& Ehrenhard, M. L. (2016, July). A temporal perspective on phronetic strategizing: exploring strategy making in unsettled times. In 32nd EGOS Colloquium 2016: Organizing in the shadow of power.

Loroz, P. S., \& Braig, B. M. (2015). Consumer attachments to human brands: The "Oprah Effect". Psychology \& Marketing, 32(7), 751-763.

Lovelace, J. B., Bundy, J., Hambrick, D. C., \& Pollock, T. G. (2018). The shackles of CEO celebrity: Sociocognitive and behavioral role constraints on "star" leaders. Academy of Management Review, 43(3), 419-444.

Lovelock, M. (2017). 'Is every YouTuber going to make a coming out video eventually?': YouTube celebrity video bloggers and lesbian and gay identity. Celebrity Studies, 8, 87-103.

Luca, F.-A., loan, C. A., \& Sasu, C. (2015). The Importance of the Professional Personal Brand. The Doctors' Personal Brand. Procedia Economics and Finance, 20, 350357.

Lunardo, R., Gergaud, O., \& Livat, F. (2015). Celebrities as human brands: an investigation of the effects of personality and time on celebrities' appeal. Journal of Marketing Management, 31(5/6), 685-712. 
Luo, L., Chen, X., Han, J., \& Whan Park, C. (2010). Dilution and Enhancement of Celebrity Brands Through Sequential Movie Releases. Journal of Marketing Research, 47(6), 1114-1128.

Lyles, M. A., \& Reger, R. K. (1993). Managing for autonomy in joint ventures: A longitudinal study of upward influence. Journal of Management Studies, 30(3), 383-404.

Madrigal, R., \& Chen, J. (2008). Moderating and mediating effects of team identification in regard to causal attributions and summary judgments following a game outcome. Journal of Sport Management, 22, 717-733.

Maguire, E. (2015). Self-branding, hotness, and girlhood in the video blogs of Jenna Marbles. Biography - An Interdisciplinary Quarterly, 38, 72-86.

Maguire, S., \& Hardy, C. (2013). Organizing processes and the construction of risk: A discursive approach. Academy of Management Journal, 56, 231-255.

Maiksteniene, K. (2009). Modeling Brand Alliance Effects in Professional Services. World Academy of Science, Engineering and Technology, 3, 1378-1386.

Makkai, J. A. (2016). Personal branding of contemporary novelists in the digital age. Journal of Media Research-Revista de Studii Media, 9, 100-105.

Malhotra, N. K., \& Birks, D. F. (2007). Marketing research: An applied approach. Pearson Education.

Malmendier, U., \& Tate, G. (2009). Superstar CEOs. Quarterly Journal of Economics, 124(4), 1593-1638.

Maltby, J., Houran, J., Lange, R., Ashe, D., \& McCutcheon, L. E. (2002). Thou shalt worship no other gods - unless they are celebrities: the relationship between celebrity worship and religious orientation. Personality and Individual Differences, 32(7), 1157-1172.

Manai, A., \& Holmlund, M. (2015). Self-marketing brand skills for business students. Marketing Intelligence and Planning, 33, 749-762.

Manurung, A. D. R. (2015). The Influence of Heroic Leadership and Learning Organization to Work Achievement with Authentic Personal Branding as Mediator. Mediterranean Journal of Social Sciences, 6, 18-25.

Marcus, S. (2015). Celebrity 2.0: the case of Marina Abramović. Public culture. 27, 21-52.

Matenge, T. M. (2013). Botswana music: Is personal branding the missing factor for growth?. Global Advanced Research Journal of Arts and Humanities, 2, 48-53.

Mathys, J., Burmester, A. B., \& Clement, M. (2016). What drives the market popularity of celebrities? A longitudinal analysis of consumer interest in film stars. International Journal of Research in Marketing, 33, 428-448.

Marwitz, K. K., Hertig, J. B., \& Weber, R. J. (2018). One Chance for Your Best First Impression: Tips for New Pharmacists. Hospital pharmacy, 53, 148-151. 
McAdams, D. P. (2011). Narrative identity, in Handbook of Identity Theory and Research, S. J. Schwartz, K. Luyckx, and V. L. Vignoles (eds), New York, NY: Springer, 99-115.

McAdams, D. P., \& Pals, J. L. (2006). A new Big Five: Fundamental principles for an integrative science of personality. American Psychologist, 61, 204-217.

McCarthy, M. S., \& Norris, D. G. (1999). Improving competitive position using branded ingredients. Journal of Product and Brand Management, 8(4), 267-285.

McCorkle, D. E., Alexander, J. F., \& Diriker, M. F. (1992). Developing self-marketing skills for student career success. Journal of Marketing Education, 14, 57-67.

McCorkle, D. E., Alexander, J. F., Reardon, J., \& Kling, N. D. (2003). Developing selfmarketing skills: Are marketing students prepared for the job search?. Journal of Marketing Education, 25, 196-207.

McCracken, G. (1989). Who is the celebrity endorser? Cultural foundations of the endorsement process. Journal of Consumer Research, 16(3), 310-321.

McCrae, R. R., \& Costa, P. T. (1997). Personality trait structure as a human universal. American Psychologist, 52(5), 509-516.

McCutcheon, L. E., \& Maltby, J. (2002). Personality Attributions about individuals high and low in the tendency to worship celebrities. Current Research in Social Psychology, 7(19), 325-338.

McFadden, S. E. (2018). They're good blogs, Brent:(Mostly) painless branding for information professionals. Public Library Quarterly, 37, 306-317.

McGhee, T. (2012). The rise and rise of athlete brand endorsements. Journal of Brand Strategy, 1, 79-84.

McKernan, B. (2011). Politics and celebrity: A sociological understanding. Sociology Compass, 5, 190-202.

McKnight, D. H., \& Chervany, N. L. (2001). Trust and distrust definitions: One bite at a time. In: Trust in Cyber-societies. Berlin Heidelberg: Springer, 27-54.

McNally, D., \& Speak, K. (2002). Be your own brand: A breakthrough formula for standing out from the crowd. San Francisco, CA: Berrett-Koehler Publishers.

McQuarrie, E. F., Miller, J., \& Phillips, B. J. (2013). The megaphone effect: Taste and audience in fashion blogging. Journal of Consumer Research, 40, 136-158.

Medveschi, I., \& Frunza, S. (2018). Political brand, symbolic construction and public image communication. Journal for the Study of Religions and Ideologies, 17, 137152.

Megehee, C. M. (2009). Advertising time expansion, compression, and cognitive processing influences on consumer acceptance of message and brand. Journal of Business Research, 62(4), 420-431.

Meiseberg, B. (2014). Trust the artist versus trust the tale: performance implications of talent and self-marketing in folk music. Journal of Cultural Economics, 38, $9-42$. 
Mesle, C. R. (2008). Process-relational philosophy: an introduction to Alfred North Whitehead. Templeton Foundation Press.

Michaels, W. B. (1989). An American Tragedy, Or the Promise of American Life. Representations, 25, 71-98.

Milbourn, T. T. (2003). CEO reputation and stock-based compensation. Journal of Financial Economics, 68(2), 233-262.

Milewicz, C. M., \& Milewicz, M. C. (2014). The branding of candidates and parties: The US news media and the legitimization of a new political term. Journal of Political Marketing, 13, 233-263.

Miller, D. (1983). The correlates of entrepreneurship in three types of firms. Management Science, 29(7), 770-791.

Miller, F. M., \& Allen, C. T. (2012). How does celebrity meaning transfer? Investigating the process of meaning transfer with celebrity affiliates and mature brands. Journal of Consumer Psychology, 22, 443-452.

Mills, S., Patterson, A., \& Quinn, L. (2015). Fabricating celebrity brands via scandalous narrative: crafting, capering and commodifying the comedian, Russell Brand. Journal of Marketing Management, 31(5/6), 599-615.

Milner Jr, M. (2010). Is Celebrity a New Kind of Status System?. Sociology, 47(5), 379387.

Mintzberg, H. (1973). The nature of managerial work. Harper \& Row: New York, USA.

Mintzberg, H. (1978). Patterns in strategy formation. Management Science, 24(9), 934-948.

Mintzberg, H. (2004). Third-generation management development. TAND D, 58(3), 28-38.

Mintzberg, H., \&Waters, J. A. (1985). Of strategies, deliberate and emergent. Strategic Management Journal, 6(3), 257-272.

Mishra, S. (2019). When patients connect with physicians on facebook: physician perspectives on benefits, challenges, and strategies for managing interaction. Health and Technology, 9, 505-515.

Mittelstaedt, J. D., Riesz, P. C., \& Burns, W. J. (2000). Why are endorsements effective? Sorting among theories of product and endorser effects. Journal of Current Issues \& Research in Advertising, 22(1), 55-65.

Molyneux, L. (2015). What journalists retweet: Opinion, humor, and brand development on Twitter. Journalism, 16, 920-935.

Molyneux, L. (2019). A Personalized Self-image: Gender and Branding Practices Among Journalists. Social Media+ Society, 5(3), 2056305119872950.

Molyneux, L., \& Holton, A. (2015). Branding (health) journalism: Perceptions, practices, and emerging norms. Digital journalism, 3, 225-242. 
Molyneux, L., Holton, A., \& Lewis, S. C. (2018). How journalists engage in branding on Twitter: Individual, organizational, and institutional levels. Information, Communication \& Society, 21, 1386-1401.

Molyneux, L., Lewis, S. C., \& Holton, A. E. (2019). Media work, identity, and the motivations that shape branding practices among journalists: An explanatory framework. New media \& society, 21, 836-855.

Montoya, P. (2004). Stand Up to Stand Out. Advisor Today, 99(12), 52-54.

Morais, D. G. (2013). Branding Iron: Eugen Sandow's “Modern" Marketing Strategies, 1887-1925. Journal of Sport History, 40, 193-214.

Morton, R. L. (2012). Bringing your personal brand to life: an effective brand communicates your distinct value. Healthcare executive, 27, 70-73.

Morwitz, V., \& Fitzsimons, G. (2004). The Mere-Measurement Effect: Why does measuring intentions change actual behaviour?. Journal of Consumer Psychology, 14(1/2), 64-73.

Moulard, J. G., Garrity, C. P., \& Rice, D. H. (2015). What makes a human brand authentic? Identifying the antecedents of celebrity authenticity. Psychology \& Marketing, 32(2), 173-186.

Moulard, J. G., Rice, D. H., Garrity, C. P., \& Mangus, S. M. (2014). Artist Authenticity: How Artists' Passion and Commitment Shape Consumers' Perceptions and Behavioral Intentions across Genders. Psychology and Marketing, 31, 576-590.

Mudambi, S. M., Sinha, J. I., \& Taylor, D. S. (2019). Why B-to-B CEOs should be more social on social media. Journal of Business-to-Business Marketing, 26, 103-105.

Munden, R. F. (2015). Marketing and branding for a radiologist. Journal of the American College of Radiology, 12, 130-131.

Muñiz Jr, A. M., Norris, T., \& Fine, G. A. (2014). Marketing artistic careers: Pablo Picasso as brand manager. European Journal of Marketing, 48, 68-88.

Murphy, G. L. (1988). Comprehending Complex Concepts. Cognitive Science, 12(4), 529-562.

Murphy, P. (2010). The intractability of reputation: Media coverage as a complex system in the case of Martha Stewart. Journal of Public Relations Research, 22(2), 209-237.

Myers, J. (2017). Brand yourself on youtube: The design, execution, and reflection of a three-fold experiential exercise. Journal of Marketing Development and Competitiveness, 11.

Naresh, M., \& Birks, D. (2007). Marketing Research: An Applied Approach. $3^{\text {rd }}$ ed., Harlow: Prentice Hall.

Nayar, P. (2009). Seeing stars: spectacle, society and celebrity culture. London: Sage.

Nayar, K. I. (2015). You Did (n't) Build That: Audience Reception of a Reality Television Star's Transformation from a Real Housewife to a Real Brand. The Journal of Popular Culture, 48, 3-16. 
Nelson, T. (2010). The role and influence of firm founders. In: Handbook of Top Management Teams, 263-269, Palgrave Macmillan, UK.

Nicolau, J. L., \& Santa-María, M. J. (2013). Celebrity endorsers' performance on the "ground" and on the "floor". Marketing Letters, 24(6), 143-149.

Nolan, L. (2015). The impact of executive personal branding on non-profit perception and communications. Public Relations Review, 41, 288-292.

Noor, K. B. M. (2008). Case study: A strategic research methodology. American Journal of Applied Sciences, 5(11), 1602-1604.

Oakley, J. G. (2000). Gender-based Barriers to Senior Management Positions: Understanding the Scarcity of Female CEOs. Journal of Business Ethics, 27, 321334.

Ogutu, R. P. \& Ougo, R. T. (2016). The relationship between personal branding and career success: a case of employees at geothermal development company in kenya. International Journal of Economics, Commerce and Management, 4, 282306.

Ohanian, R. (1990). Construction and validation of a scale to measure celebrity endorsers' perceived expertise, trustworthiness, and attractiveness. Journal of Advertising, 19(3), 39-52.

Olausson, U. (2017). The reinvented journalist: The discursive construction of professional identity on Twitter. Digital Journalism, 5, 61-81.

Olausson, U. (2018). The celebrified journalist: Journalistic self-promotion and branding in celebrity constructions on Twitter. Journalism Studies, 19, 23792399.

Olson, J. C. (1977). Price as an informational cue: Effects on product evaluations. In: A. G. Woodside, J. N. Sheth, \& P. D. Bennett (Eds.), Consumer and industrial buying behavior (pp. 267-286). New York: Elsevier North Holland, Inc.

O'Reilly, D. (2005). Cultural brands/branding cultures. Journal of Marketing Management, 21, 573-588.

O'Reilly, N. J., \& Braedley, L. A. (2008). Celebrity athletes and athletic clothing design: branding female tennis players. International Journal of Sport Management and Marketing, 3, 119-139.

Orlikowski, W. (1992). The duality of technology: Rethinking the concept of technology in organizations. Organization Science, 3, 398-427.

Orlikowski, W. J., \& Yates, J. (2002). It's about time: temporal structuring in organizations. Organization Science, 13(6), 684-700.

Otnes, C. C., \& Maclaran, P. (2018). Royalty: marketplace icons. Consumption Markets \& Culture, 21, 65-75.

Ottovordemgentschenfelde, S. (2017). 'Organizational, professional, personal': An exploratory study of political journalists and their hybrid brand on Twitter. Journalism, 18, 64-80. 
Pagis, M., \& Ailon, G. (2017). The paradoxes of self-branding: An analysis of consultants' professional web pages. Work and Occupations, 44, 243-267.

Pahwa, S. (2019). Mediating modesty on Saudi YouTube: from postfeminist to posthuman performance. Women \& Performance: a journal offeminist theory, 29, 162-178.

Palmatier, R. W., Houston, M. B., \& Hulland, J. (2018). Review articles: purpose, process, and structure. Journal of Academy of Marketing Science, 46, 1-5.

Park, C. W., Jun, S. Y., \& Shocker, A. D. (1996). Composite branding alliances: An investigation of extension and feedback effects. Journal of Marketing Research, 33(4), 453-466.

Parker, B. T. (2012). Candidate brand equity valuation: A comparison of US presidential candidates during the 2008 primary election campaign. Journal of Political Marketing, 11, 208-230.

Parmentier, M. A. (2010). The pitfalls of fame: Insights from human brands. $A C R$ North American Advances.

Parmentier, M. A., \& Fischer, E. (2012). How athletes build their brands. International Journal of Sport Management and Marketing, 11(1/2), 106-124.

Parmentier, M. A., Fischer, E., \& Reuber, A. R. (2013). Positioning person brands in established organizational fields. Journal of the Academy of Marketing Science, $41(3), 373-387$.

Parmentier, M. A., \& Fischer, E. (2021). Working It: Managing Professional Brands in Prestigious Posts. Journal of Marketing, 85(2), 110-128.

Parris, D. L., Troilo, M. L., Bouchet, A., \& Peachey, J. W. (2014). Action sports athletes as entrepreneurs: Female professional wakeboarders, sponsorship, and branding. Sport Management Review, 17, 530-545.

Parsons, T., \& Shils, E. A. (1962). Toward a General Theory of Action. New York: Harper \& Row.

Paul, J., \& Singh, G. (2017). The 45 years of foreign direct investment research: Approaches, advances and analytical areas. The World Economy, 40, 2512-2527.

Payne, A. F., Storbacka, K., \& Frow P. (2008). Managing the co-creation of value. Journal of the Academy of Marketing Science, 36, 83-96.

Payne, A., Storbacka, K., Frow, P., \& Knox, S. (2009). Co-creating brands: Diagnosing and designing the relationship experience. Journal of Business Research, 62, 379-389.

Pepper, S. (2006). Senior executive reward: key models and practices. Gower.

Pepper, A., \& Gore, J. (2015). Behavioral agency theory: New foundations for theorizing about executive compensation. Journal of Management, 41(4), 1045-1068. 
Pérez-Curiel, C., \& Limón-Naharro, P. (2019). Political influencers. A study of Donald Trump's personal brand on Twitter and its impact on the media and users. Communication \& Society, 32(1), 57-75.

Persis Murray, D. (2015). "This Is What Was Birthed" Motherhood and Postfeminist Self-Branding in Tyra Banks' Brand. Journal of Communication Inquiry, 39, 232248.

Peters, T. (1997). The brand called you. Fast company, 10(10), 83-90.

Peters, T. (1999). The brand you 50: Or fifty ways to transform yourself from an 'employee' into a brand that shows distinction, commitment, and passion!. New York: Knopf.

Peterson, M. F. (1998). Embedded organizational events: The units of process in organizational science. Organization Science, 9(1), 16-33.

Peterson, R. A., \& Merunka, D. R. (2014). Convenience samples of college students and research reproducibility. Journal of Business Research, 67, 1035-1041.

Perdue, B. C., \& Summers, J. O. (1986). Checking the success of manipulations in marketing experiments. Journal of Marketing Research, 317-326.

Pernice, R. E., \& der Veer, K., Ommundsen, R., and Larsen, K. (2008). On use of student samples for scale construction. Psychological Reports, 102, 459-464.

Pettigrew, A. (1990). Longitudinal field research on change: Theory and practice. Organization Science, 1(3), 267-292.

Philbrick, J. L., \& Cleveland, A. D. (2015). Personal Branding: Building Your Pathway to Professional Success. Medical Reference Services Quarterly, 34(2), 181-189.

Pick, D., Weber, P., Connell, J., Geneste, L. A., \& de Klerk, S. (2015). The creative industries: an entrepreneurial bricolage perspective. Management Decision, $53,828-842$.

Pihl, C. (2013). In the borderland between personal and corporate brands - the case of professional bloggers. Journal of Global Fashion Marketing, 4, 112-127.

Poole, M. S., \& Van de Ven, A. H. (2004). Theories of organizational change and innovation processes. In: M. S. Poole \& A. H. Van de Ven (eds), Handbook of organizational change and innovation. New York: Oxford University Press, 374397.

Prahalad, C. K., \& Ramaswamy, V. (2000). Co-opting customer competence. Harvard Business Review, 78(1), 79-90.

Preece, C. (2015). The authentic celebrity brand: unpacking Ai Weiwei's celebritised selves. Journal of Marketing Management, 31, 616-645.

Preece, C., \& Kerrigan, F. (2015). Multi-stakeholder brand narratives: an analysis of the construction of artistic brands. Journal of Marketing Management, 31(11), 1207-1230. 
Price, J., Farrington, N., \& Hall, L. (2013). Changing the game? The impact of Twitter on relationships between football clubs, supporters and the sports media. Soccer \& Society, 14, 446-461.

Pruchniewska, U. M. (2018). Branding the self as an "authentic feminist": negotiating feminist values in post-feminist digital cultural production. Feminist Media Studies, 18, 810-824.

Quinn, J. B. (1980). Strategies for change: Logical incrementalism. Homewood, IL: Irwin.

Radford, M. L., Kitzie, V., Mikitish, S., Floegel, D., Radford, G. P., \& Connaway, L. S. (2018). Investigating practices for building an ethical and sustainable scholarly identity with online platforms and social networking sites. Proceedings of the Association for Information Science and Technology, 55, 404-413.

Radighieri, J. P., Mariadoss, B. J., Grégoire, Y., \& Johnson, J. L. (2014). Ingredient Branding and Feedback Effects: The Impact of Product Outcomes, Initial Parent Brand Strength Asymmetry, and Parent Brand Role. Marketing Letters, 25(2), 1-16.

Raftari, M., \& Amiri, B. (2014). An entrepreneurial business model for personal branding: proposing a framework. Journal of Entrepreneurship, Business and Economics, 2, 121-139.

Rajgopal, S., Shevlin, T., \&Zamora, V. (2006).CEOs'outside employment opportunities and the lack of relative performance evaluation in compensation contracts. The Journal of Finance, 61, 1813-1844.

Ramírez, S. A. O., Veloutsou, C., \& Morgan-Thomas, A. (2017). A Systematic Literature Review of Brand Commitment: Definitions, Perspectives and Dimensions. Athens Journal of Business and Economics, 3, 305-332.

Rampersad, H. K. (2008). A new blueprint for powerful and authentic personal branding. Performance Improvement, 47(6), 34-37

Rampersad, H. K. (2009). Authentic Personal Branding: a new blueprint for building and aligning a powerful leadership brand. Charlotte, NC: Information Age Pub.

Randøy, T., \& Goel, S. (2003). Ownership structure, founder leadership, and performance in Norwegian SMEs: implications for financing entrepreneurial opportunities. Journal of business venturing, 18(5), 619-637.

Rao, A. R., \& Ruekert, R. W. (1994). Brand Alliances as Signals of Product Quality. Sloan Management Review, 36(1), 87-97.

Rascher, D., Eddy, T., \& Hyun, G. (2017). What Drives Endorsement Earnings for Superstar Athletes? Journal of Applied Sport Management, 9.

Raska, D. (2011). Exploring the Effect of a Brand's Pro-Environmental Behaviour on Consumers' Attitudes Toward Similar Behaviours. In: Proceedings of ASBBS Annual Conference, Las Vegas. 18, 703-714. 
Razeghi, Y., Roosta, A., Gharache, M., \& Alemtabriz, A. (2016). Understanding the role of entrepreneur's personal brand in SMEs total brand. International Business and Management, 12, 47-57.

Reckwitz, A. (2002). Toward a theory of social practices: A development in culturalist theorizing. European Journal of Social Theory, 5(2), 243-263.

Reif-Lehrer, L. (1992). Self-marketing ensures that good scientists get credit they deserve. Scientist, 6 .

Rein, I., Kotler, P., Hamlin, M., \& Stoller, M. (2006). High Visibility: Transforming your Personal and Professional Brand. New York, NY: McGraw-Hill.

Rescher, N. (1996). Process metaphysics: An introduction to process philosophy. Albany, NY: SUNY Press.

Resnick, S. M., Cheng, R., Simpson, M., \& Lourenço, F. (2016). Marketing in SMEs: a "4Ps" self-branding model. International Journal of Entrepreneurial Behavior \& Research, 22, 155-174.

Richardson, P. S., Dick, A. S., \& Jain, A. K. (1994). Extrinsic and intrinsic cue effects on perceptions of store brand quality. Journal of Marketing, 58, 28-36.

Rigby, E., \& Parker, G. (2015). Johnson battles to turn brand Boris from 'comedy act' to leading man. Financial Times Weekend, 29/30 August, p. 3.

Ritson, M., \& Elliott, R. (1999). The Social Uses of Advertising: An Ethnographic Study of Adolescent Advertising Audiences. Journal of Consumer Research, 26(12), 260-277.

Robson, K. (2019). Motivating professional student behavior through a gamified personal branding assignment. Journal of Marketing Education, 41, 154-164.

Rodrigue, C. S., \& Biswas, A. (2004). Brand alliance dependency and exclusivity: an empirical investigation. Journal of Product and Brand Management, 13(7), 477487.

Rojek, C. (2012). Fame attack: The inflation of celebrity and its consequences. London: Bloomsbury.

Rojek, C. (2014). Niccolo Machiavelli, cultural intermediaries and the category of achieved Celebrity. Celebrity Studies, 5, 455-468.

Roper, S., \& Davies, G. (2007). The Corporate Brand: Dealing with Multiple Stakeholders. Journal of Marketing Management, 23(1/2), 75-90.

Rotaru, I., Nitulescu, L., \& Rudolf, C. (2010). The post-modern paradigm - a framework of today's media impact in cultural space. Procedia Social and Behavioral Sciences, 5, 301-305.

Rother, F. W. (2005). Comment: Unpaid bills and uncovered bills of exchange. Automotive News, 29 March, available at: http://www.autonews.com/ article/20050329/GERMANNEWSLETTER/503290716/comment\%3A-unpaidbills-and-uncovered-bills-of-exchange (accessed 17 December 2016) 
Roy, S. (2012). To Use the Obvious Choice: Investigating the Relative Effectiveness of an Overexposed Celebrity. Journal of Research for Consumers, 22, 41-69.

Rozanova, N. N. (2017). Priority value characteristics of the governor's personal brand (on the example of the Smolensk Region). RUDN Journal of Sociology, 17, 542-554.

Rule, N. O., \& Ambady, N. (2008). The face of success: Inferences from chief executive officers' appearance predict company profits. Psychological Science, 19(2), 109111.

Rushton, J. P. (2012). The general factor of personality: A reply to Muncer. Personality and Individual Differences, 52, 236-239.

Russell, C., \& Schau, H. J. (2010). The Ties That Bind: Consumer Engagement and Transference with a Human Brand. In Campbell, M. C., Inman, J., \& Pieters, R. (Eds). NA - Advances in Consumer Research, 37, (pp. 37-40). Duluth, MN: Association for Consumer Research.

Ryan, R. M., La Guardia, J. G., \& Rawsthorne, L. J. (2005). Self-complexity and the authenticity of self-aspects: Effects on well being and resilience to stressful events. North American Journal of Psychology, 3, 431-447.

Ryan, R. M., \& Deci, E. L. (2000). Self-determination theory and the facilitation of intrinsic motivation, social development, and well-being. American Psychologist, 55, 68-78.

Saboo, A. R., Kumar, V., \& Ramani, G. (2016). Evaluating the impact of social media activities on human brand sales. International Journal of Research in Marketing, 33, 524-541.

Safitri, Y. (2017). Personal branding through fashion blogging. Humaniora, 8, 69-78.

Saleem, F. Z., \& Iglesias, O. (2015) Online Personal Branding in the Middle East and North America: A Comparison of Social Capital Accumulation and Community Response. In: K. Kubacki (eds), Ideas in Marketing: Finding the New and Polishing the Old. Developments in Marketing Science: Proceedings of the Academy of Marketing Science. Springer, Cham.

Sambharya, R. B. (1996). Foreign experience of top management teams and international diversification strategies of U.S. multinational corporations. Strategic Management Journal, 17(5), 739-746.

Samra-Fredericks, D. (2003). Strategizing as lived experience and strategists' everyday efforts to shape strategic direction. Journal of Management Studies, 40(1), 141-174.

Sassenberg, A. M., Verreynne, M. L., \& Johnson Morgan, M. (2012). A sport celebrity brand image: a conceptual model. International Journal of Organisational Behaviour, 17, 108-121.

Scabini, E., \& Manzi, C. (2011). Family processes and identity. In Handbook of identity theory and research (pp. 565-584). New York, NY: Springer. 
Scammell, M. (2007). Political brands and consumer citizens: The rebranding of Tony Blair. The Annals of the American Academy of Political and Social Science, 611, 176-192.

Scharff, C. (2015). Blowing your own trumpet: Exploring the gendered dynamics of self-promotion in the classical music profession. The Sociological Review, 63, 97-112.

Schatzki, T. R. (2005). Peripheral vision: The sites of organizations. Organization Studies, 26(3), 465-484.

Schau, H. J., \& Gilly, M. C. (2003), We Are What We Post? Self-Presentation in Personal Web Space. Journal of Consumer Research, 30(3), 385-404.

Scheidt, S., Gelhard, C., \& Henseler, J. (2020). Old practice, but young research field: A systematic bibliographic review of personal branding. Frontiers in Psychology, $11,1809$.

Scheidt, S., Gelhard, C., Strotzer, J., \& Henseler, J. (2018). In for a penny, in for a pound? Exploring mutual endorsement effects between celebrity CEOs and corporate brands. Journal of Product \& Brand Management, 27(2), 203-220.

Schlosser, F., McPhee, D. M., \& Forsyth, J. (2017). Chance events and executive career rebranding: implications for career coaches and nonprofit HRM. Human Resources Management, 56, 571-591.

Schmitt, D. P., \& Buss, D. M. (1996). Strategic self-promotion and competitor derogation: Sex and context effects on the perceived effectiveness of mate attraction tactics. Journal of Personality and Social Psychology, 70, 1185-1204.

Schneider, K. G. (2012). Personal Branding for Librarians: Distinguishing yourself from the professional herd. American Libraries, 43, 34-37.

Schön, D. (1983). The Reflective Practitioner: How Professionals Think in Action. New York: Basic Books.

Schroeder, J. E. (2005). The artist and the brand. European Journal of Marketing, 39, 1291-1305.

Schultz, B., \& Sheffer, M. L. (2012). Personal branding still in future for most newspaper reporters. Newspaper Research Journal, 33, 63-77.

Schwartz, D., \& Vogan, T. (2017). The Players' Tribune: Self-Branding and Boundary Work in Digital Sports Media. Journal of Sports Media, 12, 45-63.

Shafaei, A., Nejati, M., \& Maadad, N. (2019). Brand equity of academics: demystifying the process. Journal of Marketing for Higher Education, 29, 121-133.

Sheikh, A., \& Lim, M. (2011). Engineering consultants' perceptions of corporate branding: A case study of an international engineering consultancy. Industrial Marketing Management, 40, 1123-1132.

Shek, D. T., Chung, P. P., \& Leung, H. (2015). Manufacturing economy vs. service economy: implications for service leadership. International Journal on Disability and Human Development, 14, 205-215. 
Sheldon, K. M., Ryan, R. M., Rawsthorne, L., \& Illardi, B. (1997). Trait self and true self: Cross-role variation in the Big Five traits and its relations with authenticity and subjective well-being. Journal of Personality and Social Psychology, 73, 13801393.

Shepherd, I. D. H. (2005). From cattle and coke to Charlie: meeting the challenge of self marketing and personal branding. Journal of Marketing Management, 21(5/6), 589-606.

Sheppard, D. L. (1989). Organizations, Power and Sexuality: The Image and SelfImage of Women Managers. In J. Hearn, D. Sheppard, P. Tancred-Sheriff and G. Burrell (eds.), The Sexuality of Organization. pp. 139-157, London: Sage.

Shuart, J. (2007). Heroes in sport: assessing celebrity endorser effectiveness. International Journal of Sports Marketing and Sponsorship, 8, 11-25.

Shuker, L. E. (2014). 'It'll look good on your personal statement': Self-marketing amongst university applicants in the United Kingdom. British Journal of Sociology of Education, 35, 224-243.

Shulman, J. M. (2010). Are Entrepreneur-Led Companies Better? Evidence from Publicly Traded US Companies: 1998-2010. Journal of Risk and Financial Management, 3(1), 118-138.

Silvera, D. H., \& Austad, B. (2004). Factors predicting the effectiveness of celebrity endorsement advertisements. European Journal of Marketing, 38(11/12), 15091526.

Simonin, B. L., \& Ruth, J. A. (1998). Is a company known by the company it keeps? Assessing the spillover effects of brand alliances on consumer brand attitudes. Journal of Marketing Research, 35(1), 30-42.

Singh, V., Kumra, S., \& Vinnicombe, S. (2002). Gender and Impression Management: Playing the Promotion Game. Journal of Business Ethics, 37, 77-89.

Smith, D. (2014). Charlie is so 'English'-like: Nationality and the branded celebrity person in the age of YouTube. Celebrity studies, 5, 256-274.

Smith, W. K., \& Lewis, M.W. (2011). Toward a theory of paradox: A dynamic equilibrium model of organizing. Academy of Management Review, 36(2), 381-403.

Smith, A. N., \& Fischer, E. (2021). Pay attention, please! Person brand building in organized online attention economies. Journal of the Academy of Marketing Science, 49(2), 258-279.

Speed, R., Butler, P., \& Collins, N. (2015). Human Branding in Political Marketing: Applying Contemporary Branding Thought to Political Parties and Their Leaders. Journal of Political Marketing, 14(1/2), 129-151.

Stake, R. E. (1995). The art of case study research. Thousand Oaks, CA: Sage.

Stallen, M., Smidts, A., Rijpkema, M., Smit, G., Klucharev, V., \& Fernández, G. (2010). Celebrities and shoes on the female brain: The neural correlates of product evaluation in the context of fame. Journal of Economic Psychology, 31(5), 802811. 
Stanton, A. D. A., \& Stanton, W. W. (2013). Building" Brand Me": Creating a personal brand statement. Marketing Education Review, 23, 81-86.

Staskeviciute-Butiene, I., Bradauskiene, K., \& Crespo-Hervas, J. (2014). Athletes' personal brand as a success factor for start-up. Transformations in Business \& Economics, 13, 525-540.

Strauss, A., \& Corbin, J. (1998). Basics of qualitative research: Grounded theory procedures and techniques. Newbury Park, CA: Sage.

Street, J.(2004). Celebrity politicians: Popularculture and political representation. The British journal of politics and international relations, 6, 435-452.

Summers, J., \& Morgan, M. J. (2008). More than just the media: Considering the role of public relations in the creation of sporting celebrity and the management of fan expectations. Public Relations Review, 34, 176-182.

Swain, W. N. (2004). Perceptions of IMC After a Decade of Development: Who's at the Wheel, and How Can We Measure Success?. Journal of Advertising Research, 44(3), 46-65.

Swan, A. A. (2016). The iconic body: Mussolini unclothed. Modern Italy, 21, 361-381.

Swaminathan, V., Reddy, S. K., \& Dommer, S. L. (2012). Spillover effects of ingredient branded strategies on brand choice: a field study. Marketing Letters, 23(1), 237251.

Sweeney, M., Docherty-Hughes, J., \& Lynch, P. (2018). Lifestyling entrepreneurs' sociological expressionism. Annals of Tourism Research, 69, 90-100.

Tajfel, H., \& Turner, J. C. (1985). The social identity theory of intergroup behavior. In: S. Worchel \& W. G. Austin (eds), Psychology of Intergroup Relations (pp. 7-24). Chicago, IL: Nelson-Hall.

Takács, I., Takács, V., \& Kondor, A. (2018). Empirical Investigation of Chief Executive Officers' Personal Brand. Periodica Polytechnica Social and Management Sciences, 26, 112-120.

Tanner, R. J., \& Maeng, A. (2012). A tiger and a president: Imperceptible celebrity facial cues influence trust and preference. Journal of Consumer Research, 39, 769-783.

Tarnovskaya, V. (2017). Reinventing personal branding building a personal brand through content on YouTube. Journal of International Business Research and Marketing, 3, 29-35.

Taylor, K. A. (2003). Marketing yourself in the competitive job market: An innovative course preparing undergraduates for marketing careers. Journal of Marketing Education, 25, 97-107.

Ternès, A., Rostomyan, A., Gursch, F., \& Gursch, G. (2014). Levers of personal branding to optimize success. Journal of Business and Economics, 5(1), 86-93.

Thomas, L. C. (2011). Building blocks for personal brands. Journal of Web Librarianship, 5(2), 142-145. 
Thompson-Whiteside, H., Turnbull, S., \& Howe-Walsh, L. (2018). Developing an authentic personal brand using impression management behaviours. Qualitative Market Research: An International Journal, 21, 166-181.

Thomson, M. (2006). Human brands: investigating antecedents to consumers' strong attachments to celebrities. Journal of Marketing, 70, 104-119.

Thurmond, A. V. (2001). The point of triangulation. Journal of Nursing Scholarship, 33(3), 253-258.

Treadway, D. C., Adams, G. L., Ranft, A. L., \& Ferris, G. R. (2009). A meso-level conceptualization of CEO celebrity effectiveness. The Leadership Quarterly, 20, 554-570.

Trepanier, S., \& Gooch, P. (2014). Personal branding and nurse leader professional image. Nurse Leader, 12(3), 51-53.

Triandis, H. C. (2004). The many dimensions of culture. Academy of Management Perspectives, 18(1), 88-93.

Tripp, C., Jensen, T. D., \& Carlson, L. (1994). The effects of multiple product endorsements by celebrities on consumers' attitudes and intentions. Journal of consumer research, 20, 535-547.

Tsiotsou, R. H., Wirtz, J., Mitsis, A., \& Leckie, C. (2016). Validating and extending the sport brand personality scale. Journal of Service Theory and Practice, 26, 203221.

Tsoukas, H. (1989). The validity of idiographic research explanations. Academy of Management Review, 14(4), 551-561.

Tsoukas, H. (1994). What is management? An outline of a metatheory. British Journal of Management, 5(4), 289-301.

Tsoukas, H. (2005). Complex knowledge: Studies in organizational epistemology. Oxford: Oxford University Press.

Tsoukas, H., \&Chia, R. (2002). On organizational becoming: Rethinking organizational change. Organization Science, 13(5), 567-582.

Turner, G. (2004). Understanding celebrity. London: Sage.

Turri, A. M., Smith, K. H., \& Kemp, E. (2013). Developing affective brand commitment through social media. Journal of Electronic Commerce Research, 14, 201-214.

Tussyadiah, I. P., \& Park, S. (2018). When guests trust hosts for their words: Host description and trust in sharing economy. Tourism Management, 67, 261-272.

Tyler, I. (2008). Chav mum, chav scum: Class disgust in contemporary Britain. Feminist Media Studies, 8, 17-34.

Uymaz, A. O. (2016). The Influence of Transformational Leadership on Personal Branding through the Learning Organization and Consideration of Future Consequences. International Journal of Academic Research in Business and Social Sciences, 6(3), 2222-6990. 
Vallas, S. P., \& Cummins, E. R. (2015). Personal Branding and Identity Norms in the Popular Business Press: Enterprise Culture in an Age of Precarity. Organization Studies, 36, 293-319.

Vannini, P., \& Franzese, A. (2008). The authenticity of self: Conceptualization, personal experience and practice. Sociology Compass, 2, 1621-1637.

Van de Ven, A. H., \& Huber, G. P. (1990). Longitudinal field research methods for studying processes of organizational change. Organization Science, 1(3), 213219.

Van de Ven, A. H., \& Grazman, D. N. (1999). Evolution in a nested hierarchy: A genealogy of twin cities health care organizations. 1853-1995. Campbell DT, Baum JAC, McKelvey B, eds. Variations in organizational science, Thousand Oaks, CA: Sage, 185-212.

Van de Ven, A. H., \& Poole, M. S. (2005). Alternative approaches for studying organizational change. Organization Studies, 26(9), 1377-1404.

Van Hove, F., Asdourian, B., \& Bourgeois, D. (2018). My tweets are (not) my own! "Normalizing" journalists' branding and digital identity on Twitter. Popular Communication, 16, 263-275.

Van Nuenen, T. (2016). Here I am: Authenticity and self-branding on travel blogs. Tourist Studies, 16, 192-212.

Van Oorschot, K. E., Akkermans, H., Sengupta, K., \& van Wassenhove, L. N. (2013). Anatomy of a decision trap in complex new product development projects. Academy of Management Journal, 56, 285-307.

Van Oort, M. (2015). Making the neoliberal precariat: Two faces of job searching in Minneapolis. Ethnography, 16(1), 74-94.

Van Steenburg, E., \& Guzmán, F. (2019). The influence of political candidate brands during the 2012 and 2016 US presidential elections. European Journal of Marketing, 53, 2629-2656.

Vincent, J., Hill, J. S., \& Lee, J. W. (2009). The multiple brand personalities of David Beckham: A case study of the Beckham brand. Sport Marketing Quarterly, 18(3), 173-180.

Wade, J. B., Porac, J. F., Pollock, T. G., \& Graffin, S. D. (2006). The burden of celebrity: The impact of CEO certification contests on CEO pay and performance. Academy of Management Journal, 49(4), 643-660.

Wainryb, C. (2006). Moral development in culture: Diversity, tolerance, and justice. Handbook of moral development, pp. 211-240.

Walsh, P., \& Williams, A. (2017). To extend or not extend a human brand: An analysis of perceived fit and attitudes toward athlete brand extensions. Journal of Sport Management, 31, 44-60.

Wang, S. J., Hsu, C. P., Huang, H. C., \& Chen, C. L. (2015). How readers' perceived self-congruity and functional congruity affect bloggers' informational influence. Online Information Review, 39, 537-555. 
Watson, M. (2019). Using Professional Online Portfolios to Enhance Student Transition Into the Poststudent World. Business and Professional Communication Quarterly, 82, 153-168.

Weaver, A. (2011). The fragmentation of markets, neo-tribes, nostalgia, and the culture of celebrity: The rise of themed cruises. Journal of Hospitality and Tourism Management, 18, 54-60.

Webster, J., \& Watson, R. T. (2002). Analyzing the past to prepare for the future: Writing a literature review. MIS quarterly, xiii-xxiii.

Wee, L., \& Brooks, A. (2010). Personal branding and the commodification of reflexivity. Cultural sociology, 4(1), 45-62.

Weick, K. (1979). The social psychology of organizing. Reading, MA: Addison-Wesley.

Weikop, C. (2012). Ernst Ludwig Kirchner as his Own Critic: The Artist's Statements as Stratagems of Self-Promotion. Forum for Modern Language Studies, 48, 406420.

Wetsch, L. R. (2012). A Personal Branding Assignment Using Social Media. Journal of Advertising Education, 16(1), 30.

Whitmer, J. M. (2019). You are your brand: Self-branding and the marketization of self. Sociology Compass, 13(3), e12662.

Whittington, R. (1996). Strategy as practice. Long range planning, 29(5), 731-735.

Whittington, R. (2003). The work of strategizing and organizing: For a practice perspective. Strategic Organization, 1(1), 117-125.

Whittington, R. (2006). Completing the practice turn in strategy research. Organization Studies, 27(5), 613-634.

Williams, A. S., Kim, D. Y., Choi, W., \& Walsh, P. (2015). What Children Love About Athletes: An Exploratory Assessment of Athlete Brand Associations Among Youth Consumers. Global Sport Business Journal, 3, 63-77.

Willmott, H. C. (1984). Images and ideals of managerial work: A critical examination of conceptual and empirical accounts. Journal of Management Studies, 21(3), 349-368.

Wilson, J. A., \& Liu, J. (2012). From laconophilia to 'The Sportan': balancing athletic excellence, sponsorship, branding and career prospects. International Journal of Sport Management and Marketing, 11, 125-142.

Windsor, D. (2001). The future of corporate social responsibility. The international journal of organizational analysis, 9(3), 225-256.

Wohlfeil, M., \& Whelan, S. (2012). "Saved!" by Jena Malone: An introspective study of a consumer's fan relationship with a film actress. Journal of Business Research, 65, 511-519.

Wolfe, R. A., \& Putler, D. S. (2002). How tight are the ties that bind stakeholder groups? Organization Science, 13(1), 64-80. 
Xyrichis, A., \& Lowton, K. (2008). What fosters or prevents interprofessional teamworking in primary and community care? A literature review. International Journal of Nursing Studies, 45, 140-153.

Yanow, D., \& Tsoukas, H. (2009). What is Reflection-In-Action? A Phenomenological Account. Journal of management studies, 46(8), 1339-1364.

Yin, R. K. (2003). Case study research design and methods third edition. Applied social research methods series. $3^{\text {rd }}$ ed., 5, Thousand Oaks: Sage.

Zamudio, C., Wang, Y., \& Haruvy, E. E. (2013). Human brands and mutual choices: an investigation of the marketing assistant professor job market. Journal of the Academy of Marketing Science, 41(6), 722-736.

Zamudio, C., \& Meng, M. (2015). Which Modeling Scholars Get Promoted, and How Fast?. Customer Needs and Solutions, 2, 91-104.

Zarkada, A. (2012). Concepts and constructs for personal branding: An exploratory literature review approach. Available at: SSRN 1994522.

Zelmer, J. (2014). da Vinci Revisited: Building Momentum for Action. Healthcare Policy, 9(3), 8.

Zeng, Y., \&Song, Y. (2018). The social foreign correspondent: reconfiguring journalistic branding research in the age of social media. Popular Communication, 16, 293308.

Zhou, Y., \& Tainsky, S. (2017). Enhanced Brand Credibility of American Athletes with International Teammates. Sport Marketing Quarterly, 26, 63-74.

Zinko, R., \& Rubin, M. (2015). Personal reputation and the organization. Journal of Management and Organization, 21, 217-236. 


\section{Personal branding is a journey - not a destination}

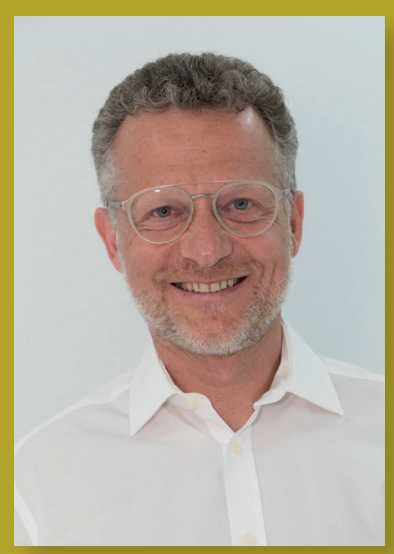

\section{Stefan Scheidt}

Lifelong learning and the continuous development of one's personality are a matter of course for Stefan Scheidt. After studying sports science at the German Sport University in Cologne, he graduated with a Master of Arts in Human Resources and Organisational Development (Technical University of Kaiserslautern) and an Executive MBA at Manchester Business School. He draws his practical experience from international motorsport as well as from management positions in corporate groups and medium-sized companies. His interdisciplinary research on the "Personal Branding of Top Managers" as part of a doctoral programme at the University of Twente contributes specifically to his many years of work as a business coach for executives and top managers. In addition to publications in renowned journals and presentations at international conferences, he also bridges the gap between science and practice as well as research and application.

Personal branding is more than just being personally visible in social media or presenting oneself appropriately in public or professional appearances. It is about positioning oneself as a top manager in a targeted way in the company, in the corporate environment and in public, establishing oneself as an opinion leader with individual strengths in one's own competitive environment. It is also about building a brand from one's own name, giving it a profile, positioning the appropriate topics in the respective media and further developing the individual personality in the relevant field. However, personal branding encompasses more than merely focusing on the person. Equally crucial is how the personal brand interacts and has an impact with the corporate brand and how it is integrated into its environment.

The individual personality with all its strengths, abilities, values, motives, interests, experiences and goals is unique and distinctive. This personality is the germ cell, the core and the highest asset of one's own personal brand. The strengths must be sharpened in a personal profile and staged individually through the appropriate storytelling in different media and in public. Personal branding is a constant, long-term process to present authenticity in a credible way and to make the personal brand equity tangible and visible.

The development of a personal brand is the crucial element on the path to top management and to be successful in top management. This dissertation and its findings from various research studies contribute to a deeper understanding of personal branding, especially for top managers, and provide profound options for applied practice. 